\title{
Triggers for food intake regulation : sensory and metabolic effects of specific food components
}

Citation for published version (APA):

Smeets, A. J. P. G. (2008). Triggers for food intake regulation : sensory and metabolic effects of specific food components. [Doctoral Thesis, Maastricht University]. Universitaire Pers Maastricht. https://doi.org/10.26481/dis.20080619as

Document status and date:

Published: 01/01/2008

DOI:

10.26481/dis.20080619as

Document Version:

Publisher's PDF, also known as Version of record

\section{Please check the document version of this publication:}

- A submitted manuscript is the version of the article upon submission and before peer-review. There can be important differences between the submitted version and the official published version of record.

People interested in the research are advised to contact the author for the final version of the publication, or visit the DOI to the publisher's website.

- The final author version and the galley proof are versions of the publication after peer review.

- The final published version features the final layout of the paper including the volume, issue and page numbers.

Link to publication

\footnotetext{
General rights rights.

- You may freely distribute the URL identifying the publication in the public portal. please follow below link for the End User Agreement:

www.umlib.nl/taverne-license

Take down policy

If you believe that this document breaches copyright please contact us at:

repository@maastrichtuniversity.nl

providing details and we will investigate your claim.
}

Copyright and moral rights for the publications made accessible in the public portal are retained by the authors and/or other copyright owners and it is a condition of accessing publications that users recognise and abide by the legal requirements associated with these

- Users may download and print one copy of any publication from the public portal for the purpose of private study or research.

- You may not further distribute the material or use it for any profit-making activity or commercial gain

If the publication is distributed under the terms of Article $25 \mathrm{fa}$ of the Dutch Copyright Act, indicated by the "Taverne" license above, 


\section{TRIGGERS FOR FOOD INTAKE REGULATION}

Sensory and metabolic effects of specific food components 

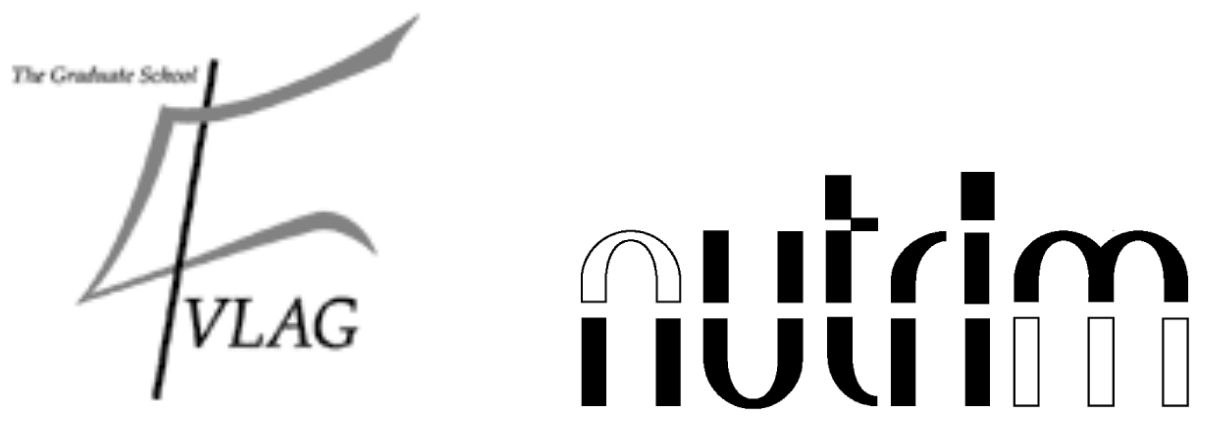

The studies presented in this thesis were performer at the Nutrition and Toxicology Research Institute Maastricht (NUTRIM), which participaties in the Graduate School VLAG (Food Technology, Agrobiotechnology, Nutrition and Health Sciences) accredited by the Royal Netherlands Academy of Arts and Sciences.

Cover design: Astrid Smeets and Datawyse

Layout: Astrid Smeets

Printed by: Datawyse, Universitaire Pers Maastricht

(C) Astrid Smeets, 2008

ISBN 978-90-5278-726-8 


\section{TRIGGERS FOR FOOD INTAKE REGULATION}

\section{Sensory and metabolic effects of specific food components}

\section{PROEFSCHRIFT}

ter verkrijging van de graad van doctor

aan de Universiteit Maastricht, op gezag van de Rector Magnificus,

Prof mr. G.P.M.F. Mols

volgens het besluit van het College van Decanen,

in het openbaar te verdedigen

op donderdag 19 juni 2008 om 16.00 uur

door

Astrid Jose Pierre Gertrude Smeets

Geboren te Geleen op 8 april 1981 


\section{Promotor:}

Prof. dr. M.S Westerterp-Plantenga

\section{Beoordelingscommissie:}

Prof. dr. K.R Westerterp (voorzitter)

Prof. dr. R-J.M. Brummer

Dr. C. Feinle-Bisset (University of Adelaide, Australia)

Prof. dr. R.J. Hamer (Top Institute Food and Nutrition, Wageningen Universiteit)

Prof. dr. A.A. Masclee

The research described in this thesis was supported by Top Institute Food and Nutrition, and the pan-European Programme DiOGenes. DiOGenes is the acronym of the project 'Diet, Obesity and Genes' supported by the European Community (Contract no. FOOD-CT-2005-513946), http:/www.diogeneseu.org/.

Financial support by the Netherlands Association for the Study of Obesity (NASO) for the publication of this thesis is gratefully acknowledged. 


\section{Contents}

$\begin{array}{ll}\text { 1. General introduction } & \text { Page } 7\end{array}$

2. Satiety and substrate mobilization after oral fat stimulation

Page 21

3. Oral exposure and sensory-specific satiety

Page 39

4. The second meal effect of oral fat perception compared to fat ingestion on energy expenditure, hormones and appetite profile

Page 55

5. Taste sensitivity for monosodium glutamate and an increased liking of dietary protein

Page 75

6. Effects of a high-protein diet with MSG and IMP'5 on metabolism and appetite

Page 89

7. Energy expenditure, plasma ghrelin, glucagon-like peptide 1, PYY concentrations, and satiety following a single high protein lunch

Page 103

8. The acute effects of a lunch containing resistant starch on energy and substrate utilization, ghrelin, glucagonlike peptide-1, PYY concentrations, and satiety

Page 119

9. The acute effects of a lunch containing capsaicin on energy and substrate utilization, hormones, and satiety Page 135

10. General discussion

Page 149

Summary

Page 169

Samenvatting

Page 173

Dankwoord

Page 179

Publications

Page 183

Curriculum Vitae

Page 187 

1 
Human food intake behaviour is determined by an interaction of environment and the physiological status of the individual. The environment includes cultural, social, emotional, psychological, cognitive, sensory, economical, and other factors. The ideal physiological status of the individual is homeostasis, or physiological balance. The physiological status is reflected in physiological variables such as gastric sensations, gut peptides, neuropeptides, hormones, substrates, and metabolic factors.

In terms of energy, homeostasis is reached when energy intake meets energy expenditure. Energy expenditure is continuous and determined by sex, age and body-composition, while energy intake is discontinuous and serves as the fine-tuning mechanism to reach energy balance. The tools for this finetuning mechanism of energy intake are appetite related sensations, such as hunger, appetite, satiation, satiety, and sensory-specific satiety, which are caused by physiological variables. Hunger reflects a physiological need for energy or macronutrients and leads to meal initiation. Appetite reflects one's desire to eat at a given point in time, but is not necessarily related to hunger. Apart from physiological hunger, appetite may be influenced by other factors such as palatability of available food or emotional state. Both hunger and appetite modulate meal size and food choice to some extent. Satiation reflects the satisfying feeling due to feeding within meals (intra-meal satiety) and is thus related to meal termination. Satiety refers to the satisfying feeling following food consumption, so it affects inter-meal interval and meal frequency. Sensory-specific satiety refers to a decline in pleasantness of taste of a specific food or food type after exposure to that food, while the taste of other uneaten foods is still perceived as pleasant. Sensory-specific satiety plays a role in meal size, composition, and meal termination.

Because of the worldwide increasing prevalence of obesity, which is the ultimate result of a positive balance between energy intake and energy expenditure, it is necessary to study the plasticity of the fine-tuning mechanism of energy intake. Obesity develops over a long period of time and is a condition, which can be reversed by weight-loss. Weight-loss results from a negative balance between energy intake and energy expenditure. As mentioned before, the tools for the fine-tuning mechanism of energy intake are appetite related sensations. A negative energy balance will therefore, even in the state of obesity, acutely result in physiologically mediated feelings of hunger. Feelings of hunger and little or no feelings of satiety make adherence to weight-loss and weight maintenance diets difficult. By studying the plasticity of the fine-tuning mechanism of energy intake to energy expenditure, the aim is to find modulators that affect physiological variables mediating appetite related sensations. An effective modulator must sustain satiety through physiological variables and at the same time, preferably have stimulating effects on energy expenditure, in order to 
prevent a decline in energy expenditure during a negative energy balance.

Where to look for eligible modulators?

Ingestive studies, mostly performed in animals, have shown that the effects of energy intake on physiological variables and appetite related sensations are larger when food is given orally compared to when food is given in the stomach or intestine. This implies a significant informative role of oral exposure to food in the monitoring of energy intake. Candidate modulators for appetite related sensations may therefore need specific sensory characteristics and may be found among food components with a distinctive sensory quality.

Secondly, features that may enable a food component to be a candidate modulator for appetite related sensations are postingestive effects. Sustained feelings of satiety and slow absorption of nutrients are examples of postingestive effects, which may affect physiological variables mediating appetite related sensations.

\section{$\underline{\text { Candidate modulators for appetite related sensations }}$}

\section{Sensory-specific satiety}

As a food is consumed to satiety, its perceived pleasantness of taste declines compared to that of foods that have not been consumed. This phenomenon is referred to as sensory-specific satiety ${ }^{1}$. These declines in pleasantness of taste are greatest within the first 20 min following consumption, suggesting that these effects are primarily based on sensory cues, and less on postingestive or post absorptive cues. The magnitude of sensory-specific satiety of a specific food is dependent on its texture, flavour and colour ${ }^{2,3}$. Although it has been reported that the macronutrient composition of a food also appears to influence its sensory-specific satiety ${ }^{4-9}$, the time framing of sensory-specific satiety and the finding that one does not need ingestion suggest that sensory-specific satiety is a sensory-based phenomenon ${ }^{3}$, i.e. foods high in protein, sweet carbohydrates and fatty acids have been suggested to have a relatively greater sensory-specific satiety ${ }^{5,6,10-13}$.

\section{Oral fat exposure}

High-fat foods are not simply rich in energy, but are also perceived as more palatable in general ${ }^{14,15}$. Important indicators of whether fat is present in a food are texture and odour ${ }^{16}$. Schemmel and co-workers observed a 'taste for fat' in specific rat strains by discovering an inverse relationship between the perception of non-esterified fatty acids (NEFA) and dietary preferences for fat. When placed on a high-fat diet, fat-preferring rats became obese whereas fat-avoiding rats stayed lean ${ }^{17}$. 
Further investigations by Gilbertson and co-workers revealed a dosedependent detection of low concentrations of NEFA (linoleic acid) by an inhibition of delayed rectifying $\mathrm{K}^{+}$channels in the taste receptor cells of rats, causing an increase in activity of these cells ${ }^{18}$. Human subjects are able to detect linoleic acid in these low concentrations as well ${ }^{19}$. Experiments using oral stimulation may shed some light on the consequences of vagal stimulation with fat. Previous oral stimulation experiments using the modified sham feeding (MSF) technique have revealed effects on metabolites, hormones and satiety. Mattes and co-workers found that oral stimulation after a gastric fat load resulted in higher plasma triacylglycerol concentrations 20-25. Robertson's group performed oral stimulation experiments in the postprandial phase in which they observed a sustained suppression of plasma NEFA ${ }^{26-30}$. In the experiments of Heath et al., oral stimulation $1 \mathrm{~h}$ before a fat load resulted in a further decline of ghrelin levels, which was interpreted as a decrease in hunger ${ }^{31}$.

\section{Monosodium glutamate and inosine-monophosphate-5}

Two specific food components that have received some attention as oral stimulators of appetite and metabolism are monosodium glutamate (MSG) and inosine-monophosphate-5 (IMP'5). Because of its natural association with protein-containing foods, glutamate is often described as the taste of protein; to Western palates its taste may best be described as savoury, meaty or broth-like, and to Asian palates it is described as UMAMI (Japanese word for deliciousness) ${ }^{32}$. IMP'5 is a nucleotide mono-phosphate that is found primarily in meats and some fish (e.g. tuna) and also exudes the UMAMI taste. It interacts synergistically with MSG to accentuate the intensity of the UMAMI taste ${ }^{33}$.

It is established that the addition of low concentrations of MSG to a variety of foods increases their pleasantness. This causes an increase in the spontaneous intake and also seems to emphasize sensory satiety of those foods. The accelerated satiety may reduce overall energy intake. In rat studies, the addition of MSG to food increases the thermic effect of feeding and causes a rapid switch in substrate utilization ${ }^{34,35}$. Furthermore, Niijima et al. showed that MSG administration stimulates vagal nerve activity and thereby can increase energy expenditure ${ }^{36}$.

\section{Dietary protein}

High-protein foods are more satiating and have a higher thermogenic effect than iso-energetic normal protein foods, over the short as well as over the long-term ${ }^{37-49}$. The relatively strong thermic effect of protein may be mediated by the high ATP costs of post-prandial protein synthesis ${ }^{50,51}$. The theoretical basis of the relationship between satiety and diet induced 
thermogenesis (DIT) may be that increased energy expenditure at rest implies increased oxygen consumption and an increase in body temperature that may be lead to feeling deprived of oxygen and translated into satiety feelings ${ }^{49}$. Another mechanism by which dietary protein exerts its satiating effect is through satiety related hormones. In a recent study Lejeune et al. showed that a high-protein diet, compared with an adequate-protein diet, when consumed in energy balance over 4 days, increased $24 \mathrm{~h}$ satiety, thermogenesis, sleeping metabolic rate, protein balance, and fat oxidation. In the high-protein condition, satiety was related to protein intake and incidentally to plasma ghrelin and glucagon-like peptide 1 (GLP-1) concentrations ${ }^{42}$. In a recent study, Batterham et al. observed significantly higher plasma peptide YY (PYY) responses to a high protein meal in both lean and obese subjects ${ }^{52}$. Apart from these hormones, other hormones have shown to be induced by protein ingestion, such as for instance cholecystokinin (CCK), insulin and gastric inhibitory polypeptide (GIP) ${ }^{53-55}$. Other factors, which may explain the high-protein effect on satiety, may be metabolites or amino acids. In a recent study, Veldhorst et al. showed that the satiating effect of a high protein breakfast was positively related to specific amino acids plasma concentrations up to $4 \mathrm{~h}^{56}$.

\section{Capsaicin}

Capsaicin is the pungent principle of hot red pepper. Capsaicin has been reported to have favourable effects on energy expenditure, fat oxidation, and appetite control ${ }^{57-61}$. The stimulating effects of capsaicin on energy and lipid metabolism are associated with an increase in sympathetic nervous system activity ${ }^{58,60-62}$. In a recent study, the satiating effect of capsaicin was present after gastrointestinal exposure, but was even more profound after the combination of sensory and gastrointestinal exposure ${ }^{59}$. Capsaicin sensitive primary afferent sensory nerves are found in the nerves innervating the whole gastrointestinal tract ${ }^{63-65}$. From predominantly animal studies we know that capsaicin may affect gastrointestinal physiology. Interestingly, capsaicin was found to increase blood flow and secretion in the gastrointestinal tract ${ }^{66-69}$. Furthermore, have capsaicin sensitive primary afferent sensory nerves been suggested to be involved in the effects of nutrients on gut-derived hormones, such as CCK, ghrelin, PYY, GLP-1, and gastric motility and emptying in rats ${ }^{70-73}$. Few studies have looked at the effects of capsaicin on gastrointestinal physiology, i.e. gastric emptying and isolated intestinal muscle strip relaxation, in humans ${ }^{74,75}$. Whether capsaicin affects the secretion of gut-derived hormones, and whether this is associated with the satiating effects of capsaicin is unknown. Capsaicin is perceived as a hot substance ${ }^{76}$. Because the ingestion of hot substances can lead to an increase in body temperature, feedback mechanisms are activated to lower body temperature, such as blood vessel dilatation and sweating. 
The greater heat loss, due to blood vessel dilatation and sweating, after capsaicin ingestion may contribute to a higher DIT. Capsaicin has been reported to increase carbohydrate oxidation over the short term (after 1 breakfast exposure) and to increase fat oxidation over the long term (in fasted state after 3 months exposure) ${ }^{61,77}$.

\section{Resistant starch}

Observations of epidemiological and intervention studies indicate that dietary fibre intake is involved in body weight control. A dietary fibre component that may be of specific importance is resistant starch (RS). Resistant starch (RS) is starch that is not digested in the small intestine but passes to the large intestine ${ }^{78}$. In the large intestine, RS is a potential substrate for fermentation, a process that results in the formation of shortchain fatty acids (SCFA), which can be absorbed and utilised as an energy source. Three types of RS can be identified: RS1 is RS present in foods having a dense or rigid structure, e.g. whole-grain cereals and legumes; RS2 is RS present in granules in raw foods, e.g. bananas; RS3 is RS in foods that have been cooked and subsequently cooled, e.g. bread and breakfast cereals. It is known that the replacement of digestible starch with RS may reduce post-prandial glycaemia and insulinemia, and may increase post-prandial satiety ${ }^{79}$. Recent rat studies have shown, that prolonged ingestion of RS resulted in increased plasma levels of the satiety related hormones GLP-1 and PYY, and a decrease in plasma levels of the hunger related hormone ghrelin, in addition to the effects of fermentation in the colon ${ }^{80,81}$. Because of its lower energy density, compared to a high-fat diet, a starch-rich and fibre-rich diet comprises large volumes of foods. To achieve the required energy intake a larger volume must be consumed, which may be difficult to sustain, and may therefore lead to a decrease in energy intake and consequently in bodyweight. A fibre-rich diet may also decrease energy intake by slowing down gastric emptying, which results in prolonged feelings of fullness and satiety.

\section{Outline of the thesis}

This thesis describes studies on the plasticity of the fine-tuning mechanism of energy intake. Several food-related triggers for food intake regulation were investigated for their ability to affect physiological variables mediating appetite related sensations.

To gain insight to what extent mere sensory perception can influence appetite related sensations, we studied the effect of mere sensory perception, thus without ingestion of nutrients, in order to separate sensory from metabolic triggers, on appetite sensations and taste perception during the development of sensory-specific satiety (chapter2). Subsequently, we studied to what extent mere sensory perception can actually influence 
physiological and metabolic mechanisms underlying appetite related sensations. Here also the duration of metabolic effects due to mere sensory stimulation was assessed (chapter 3 and 4).

Four triggers were studied for their effect on physiological variables mediating appetite related sensations. Characteristics of specific triggers imply hypothesized effects without contributing to energy intake.

Such energy neutral triggers may be certain spices that enhance sympathetic nervous system activity and have shown to affect the gastrointestinal tract, e.g. capsaicin. Stimulation of the sympathetic nervous system and sensory nerves in the gastrointestinal tract by this energy neutral trigger may affect appetite related sensations, which may be mediated by enhancing metabolism or the release of appetite related hormones (chapter 9).

An additional type of energy neutral triggers may be taste enhancers that increase palatability and vagal nerve activity, e.g. MSG and IMP'5. The increased palatability of a food after addition of an energy neutral trigger may be related to the taste sensitivity for the trigger. If this is the case, than taste sensitivity for that specific trigger may also predict food choice and consumption (chapter 5). Furthermore, this energy neutral trigger may enhance metabolism due to sensory or gastrointestinal stimulation of vagal nerve activity (chapter 6).

Another example is exchanging digestible starch for indigestible starch. Spreading the amount of available energy after energy intake over a longer period of time, by using an energy neutral trigger e.g. resistant starch, may affect appetite related sensations through changes in metabolism and nutrient stimulated hormone release (chapter 8).

Also one macronutrient can be exchanged iso-energetically for another macronutrient, e.g. protein. The acute effects on appetite related sensations of this energy neutral trigger may not only be mediated by acute effects on thermogenesis, but may also be mediated by the release of appetite related hormones (chapter 7).

Finally, in chapter 10, the plasticity of the fine-tuning mechanism of energy intake is described on the basis of the studied food-related triggers for food intake regulation and their ability to affect physiological variables mediating appetite related sensations over the short term. 


\section{References}

1. Rolls BJ, Rolls ET, Rowe EA, Sweeney K. Sensory specific satiety in man. Physiol Behav 1981;27(1):137-42.

2. Rolls BJ, Rowe EA, Rolls ET, Kingston B, Megson A, Gunary R. Variety in a meal enhances food intake in man. Physiol Behav 1981;26(2):215-21.

3. Rolls ET, Rolls JH. Olfactory sensory-specific satiety in humans. Physiol Behav 1997;61(3):461-73.

4. Hetherington MM. Sensory-specific satiety and its importance in meal termination. Neurosci Biobehav Rev 1996;20(1):113-7.

5. Johnson J, Vickers Z. Factors influencing sensory-specific satiety. Appetite 1992;19(1):15-31.

6. Johnson J, Vickers Z. Effects of flavor and macronutrient composition of food servings on liking, hunger and subsequent intake. Appetite 1993;21(1):25-39.

7. Miller DL, Bell EA, Pelkman CL, Peters JC, Rolls BJ. Effects of dietary fat, nutrition labels, and repeated consumption on sensory-specific satiety. Physiol Behav 2000;71(1-2):153-8.

8. Rolls BJ, Fedoroff IC, Guthrie JF, Laster LJ. Foods with different satiating effects in humans. Appetite 1990;15(2):115-26.

9. Westerterp-Plantenga MS, MJ IJ, Wijckmans-Duijsens NE. The role of macronutrient selection in determining patterns of food intake in obese and non-obese women. Eur J Clin Nutr 1996;50(9):580-91.

10. de Graaf C, Schreurs A, Blauw YH. Short-term effects of different amounts of sweet and nonsweet carbohydrates on satiety and energy intake. Physiol Behav 1993;54(5):833-43.

11. Kamphuis MM, Westerterp-Plantenga MS, Saris WH. Fat-specific satiety in humans for fat high in linoleic acid vs fat high in oleic acid. Eur J Clin Nutr 2001;55(6):499-508.

12. Vandewater K, Vickers Z. Higher-protein foods produce greater sensoryspecific satiety. Physiol Behav 1996;59(3):579-83.

13. Vickers Z, Holton E, Wang J. Effect of yoghurt sweetness on sensoryspecific satiety. J Sensory Stud 1998;13:377-88.

14. Drewnowski A. Energy intake and sensory properties of food. Am J Clin Nutr 1995;62(5 Suppl):1081S-1085S.

15. Drewnowski A. Taste preference and food intake. Ann Rev Nutr 1997;17:237-53.

16. Rolls ET, Critchley HD, Browning AS, Hernadi I, Lenard L. Responses tot the sensory properties of fat of neurons in the primate orbitofrontal cortex. $\mathrm{J}$ Neuroscience 1999;19(4):1532-40.

17. Schemmel R, Mickelsen O, Gill JL. Dietary obesity in rats: Body weight and body fat accretion in seven strains of rats. J Nutr 1970;100(9):1041-48.

18. Gilbertson TA, Fontenot DT, Liu L, Zhang H, Monroe WT. Fatty acid modulation of $\mathrm{K}+$ channels in taste receptor cells: gustatory cues for dietary fat. Am J Physiol 1997;272(4 Pt 1):C1203-10. 
19. Kamphuis MM, Saris WH, Westerterp-Plantenga MS. The effect of addition of linoleic acid on food intake regulation in linoleic acid tasters and linoleic acid non-tasters. Br J Nutr 2003;90(1):199-206.

20. Mattes RD. Oral fat exposure alters postprandial lipid metabolism in humans. Am J Clin Nutr 1996;63(6):911-17.

21. Mattes RD. Oral exposure to butter, but not fat replacers elevates postprandial triacylglycerol concentration in humans. J Nutr 2001;131(5):1491-96.

22. Mattes RD. The taste of fat elevates postprandial triacylglycerol. Physiol Behav 2001;74(3):343-48.

23. Mattes RD. Oral fat exposure increases the first phase triacylglycerol concentration due to release of stored lipid in humans. J Nutr 2002;132(12):3656-62.

24. Tittelbach TJ, Mattes RD. Oral stimulation influences postprandial triacylglycerol concentrations in humans: nutrient specificity. J Am Coll Nutr 2001;20(5):485-93.

25. Tittlebach TJ, Mattes RD. Effect of orosensory stimulation on postprandial thermogenesis in humans. Physiol Behav. 2002;75(1-2):71-81.

26. Jackson KG, Robertson MD, Deane LO, Fielding BA, Frayn KN, Williams $\mathrm{CM}$. The effect of modified sham-feeding meals of varying fat content on postprandial triacylglycerol, insulin and glucose response. Proc Nutr Soc 2000;59:14A.

27. Jackson KG, Robertson MD, Fielding BA, Frayn KN, Williams CM. Second meal effects: modified sham feeding does not provoke the release of stored triacylglycerol from a previous high-fat meal. Br J Nutr 2001;85(2):149-56.

28. Robertson MD, Jackson KG, Fielding BA, Williams CM, Frayn KN. Modified sham feeding of a modest-fat meal suppresses plasma nonesterified fatty acids. Proc Nutr Soc 1999;59:123A.

29. Robertson MD, Mason AO, Frayn KN. Oro-sensory stimulation prior to fat ingestion impairs postprandial fat tolerance. Int J Obesity 2000;24:S55.

30. Robertson MD, Mason AO, Frayn KN. Timing of vagal stimulation affects postprandial lipid metabolism in humans. Am J Clin Nutr 2002;76(1):71-7.

31. Heath RB, Jones R, Frayn KN, Robertson MD. Vagal stimulation exaggerates the inhibitory ghrelin response to oral fat in humans. J Endocrinol 2004;180(2):273-81.

32. Yamaguchi S, Ninomiya K. Umami and food palatability. J Nutr 2000;130(4S Suppl):921S-6S.

33. Kurihara K, Kashiwayanagi M. Physiological studies on umami taste. J Nutr 2000;130(4S Suppl):931S-4S.

34. Viarouge C, Caulliez R, Nicolaidis S. Umami taste of monosodium glutamate enhances the thermic effect of food and affects the respiratory quotient in the rat. Physiol Behav 1992;52(5):879-84. 
35. Viarouge C, Even P, Rougeot C, Nicolaidis S. Effects on metabolic and hormonal parameters of monosodium glutamate (umami taste) ingestion in the rat. Physiol Behav 1991;49(5):1013-8.

36. Niijima A. Effects of oral and intestinal stimulation with umami substance on gastric vagus activity. Physiol Behav 1991;49(5):1025-8.

37. Bensaid A, Tome D, Gietzen D, Even P, Morens C, Gausseres N, Fromentin G. Protein is more potent than carbohydrate for reducing appetite in rats. Physiol Behav 2002;75(4):577-82.

38. Crovetti R, Porrini M, Santangelo A, Testolin G. The influence of thermic effect of food on satiety. Eur J Clin Nutr 1998;52(7):482-8.

39. Johnstone AM, Stubbs RJ, Harbron CG. Effect of overfeeding macronutrients on day-to-day food intake in man. Eur J Clin Nutr 1996;50(7):418-30.

40. Karst H, Steiniger J, Noack R, Steglich HD. Diet-induced thermogenesis in man: thermic effects of single proteins, carbohydrates and fats depending on their energy amount. Ann Nutr Metab 1984;28(4):245-52.

41. LeBlanc J, Diamond P, Nadeau A. Thermogenic and hormonal responses to palatable protein and carbohydrate rich food. Horm Metab Res 1991;23(7):336-40.

42. Lejeune MP, Westerterp KR, Adam TC, Luscombe-Marsh ND, WesterterpPlantenga MS. Ghrelin and glucagon-like peptide 1 concentrations, 24-h satiety, and energy and substrate metabolism during a high-protein diet and measured in a respiration chamber. Am J Clin Nutr 2006;83(1):89-94.

43. Luscombe ND, Clifton PM, Noakes M, Farnsworth E, Wittert G. Effect of a high-protein, energy-restricted diet on weight loss and energy expenditure after weight stabilization in hyperinsulinemic subjects. Int J Obes Relat Metab Disord 2003;27(5):582-90.

44. Mikkelsen PB, Toubro S, Astrup A. Effect of fat-reduced diets on 24-h energy expenditure: comparisons between animal protein, vegetable protein, and carbohydrate. Am J Clin Nutr 2000;72(5):1135-41.

45. Poppitt SD, McCormack D, Buffenstein R. Short-term effects of macronutrient preloads on appetite and energy intake in lean women. Physiol Behav 1998;64(3):279-85.

46. Porrini M, Crovetti R, Testolin G, Silva S. Evaluation of satiety sensations and food intake after different preloads. Appetite 1995;25(1):17-30.

47. Stubbs RJ, van Wyk MC, Johnstone AM, Harbron CG. Breakfasts high in protein, fat or carbohydrate: effect on within-day appetite and energy balance. Eur J Clin Nutr 1996;50(7):409-17.

48. Weigle DS, Breen PA, Matthys CC, Callahan HS, Meeuws KE, Burden VR, Purnell JQ. A high-protein diet induces sustained reductions in appetite, ad libitum caloric intake, and body weight despite compensatory changes in diurnal plasma leptin and ghrelin concentrations. Am J Clin Nutr 
2005;82(1):41-8.

49. Westerterp-Plantenga MS, Rolland V, Wilson SA, Westerterp KR. Satiety related to $24 \mathrm{~h}$ diet-induced thermogenesis during high protein/carbohydrate vs high fat diets measured in a respiration chamber. Eur J Clin Nutr 1999;53(6):495-502.

50. Tessari P, Kiwanuka E, Zanetti M, Barazzoni R. Postprandial body protein synthesis and amino acid catabolism measured with leucine and phenylalanine-tyrosine tracers. Am J Physiol Endocrinol Metab 2003;284(5):E1037-42.

51. van Milgen J. Modeling biochemical aspects of energy metabolism in mammals. J Nutr 2002;132(10):3195-202.

52. Batterham RL, Heffron H, Kapoor S, Chivers JE, Chandarana K, Herzog H, Le Roux CW, Thomas EL, Bell JD, Withers DJ. Critical role for peptide YY in protein-mediated satiation and body-weight regulation. Cell Metab 2006;4(3):223-33.

53. Calbet JA, MacLean DA. Plasma glucagon and insulin responses depend on the rate of appearance of amino acids after ingestion of different protein solutions in humans. J Nutr 2002;132(8):2174-82.

54. Liddle RA, Goldfine ID, Rosen MS, Taplitz RA, Williams JA. Cholecystokinin bioactivity in human plasma. Molecular forms, responses to feeding, and relationship to gallbladder contraction. J Clin Invest 1985;75(4):1144-52.

55. Wolfe MM, Zhao KB, Glazier KD, Jarboe LA, Tseng CC. Regulation of glucose-dependent insulinotropic polypeptide release by protein in the rat. Am J Physiol Gastrointest Liver Physiol 2000;279(3):G561-6.

56. Veldhorst MAB, Nieuwenhuizen AG, Hochstenbach-Waelen A, Westerterp KR, Engelen MPKJ, Brummer RJ, Deutz NEP, Westerterp-Plantenga MS. Effects of high or normal casein-, soy-, or whey with or without GMPprotein breakfasts on satiety, 'satiety' hormones, and plasma amino acid responses. Appetite 2007;49(1):336.

57. Kawabata F, Inoue N, Yazawa S, Kawada T, Inoue K, Fushiki T. Effects of $\mathrm{CH}-19$ sweet, a non-pungent cultivar of red pepper, in decreasing the body weight and suppressing body fat accumulation by sympathetic nerve activation in humans. Biosci Biotechnol Biochem 2006;70(12):2824-35.

58. Kawada T, Watanabe T, Takaishi T, Tanaka T, Iwai K. Capsaicin-induced beta-adrenergic action on energy metabolism in rats: influence of capsaicin on oxygen consumption, the respiratory quotient, and substrate utilization. Proc Soc Exp Biol Med 1986;183(2):250-6.

59. Westerterp-Plantenga MS, Smeets A, Lejeune MP. Sensory and gastrointestinal satiety effects of capsaicin on food intake. Int J Obes (Lond) 2005;29(6):682-8.

60. Yoshioka M, St-Pierre S, Drapeau V, Dionne I, Doucet E, Suzuki M, Tremblay A. Effects of red pepper on appetite and energy intake. Br J Nutr 1999;82(2):115-23. 
61. Yoshioka M, St-Pierre S, Suzuki M, Tremblay A. Effects of red pepper added to high-fat and high-carbohydrate meals on energy metabolism and substrate utilization in Japanese women. Br J Nutr 1998;80(6):503-10.

62. Kawada T, Sakabe S, Watanabe T, Yamamoto M, Iwai K. Some pungent principles of spices cause the adrenal medulla to secrete catecholamine in anesthetized rats. Proc Soc Exp Biol Med 1988;188(2):229-33.

63. Holzer-Petsche U, Seitz H, Lembeck F. Effect of capsaicin on gastric corpus smooth muscle of the rat in vitro. Eur J Pharmacol 1989;162(1):29-36.

64. Maggi CA, Manzini S, Giuliani S, Santicioli P, Meli A. Extrinsic origin of the capsaicin-sensitive innervation of rat duodenum: possible involvement of calcitonin gene-related peptide (CGRP) in the capsaicin-induced activation of intramural non-adrenergic non-cholinergic neurons. Naunyn Schmiedebergs Arch Pharmacol 1986;334(2):172-80.

65. Maggi CA, Meli A, Santicioli P. Four motor effects of capsaicin on guineapig distal colon. Br J Pharmacol 1987;90(4):651-60.

66. Chen RY, Li DS, Guth PH. Role of calcitonin gene-related peptide in capsaicin-induced gastric submucosal arteriolar dilation. Am J Physiol 1992;262(5 Pt 2):H1350-5.

67. Manzini S, Perretti F. Vascular effects of capsaicin in isolated perfused rat mesenteric bed. Eur J Pharmacol 1988;148(2):153-9.

68. Myers BM, Smith JL, Graham DY. Effect of red pepper and black pepper on the stomach. Am J Gastroenterol 1987;82(3):211-4.

69. Solanke TF. The effect of red pepper (Capsicum frutescens) on gastric acid secretion. J Surg Res 1973;15(6):385-90.

70. Ahren B. Sensory nerves contribute to insulin secretion by glucagon-like peptide-1 in mice. Am J Physiol Regul Integr Comp Physiol 2004;286(2):R269-72.

71. Fu-Cheng X, Anini Y, Chariot J, Castex N, Galmiche JP, Roze C. Mechanisms of peptide YY release induced by an intraduodenal meal in rats: neural regulation by proximal gut. Pflugers Arch 1997;433(5):571-9.

72. Fukuda H, Mizuta Y, Isomoto H, Takeshima F, Ohnita K, Ohba K, Omagari K, Taniyama K, Kohno S. Ghrelin enhances gastric motility through direct stimulation of intrinsic neural pathways and capsaicin-sensitive afferent neurones in rats. Scand J Gastroenterol 2004;39(12):1209-14.

73. Raybould HE, Tache Y. Cholecystokinin inhibits gastric motility and emptying via a capsaicin-sensitive vagal pathway in rats. Am J Physiol 1988;255(2 Pt 1):G242-6.

74. Giuliani S, Turini D, Barbanti G, Maggi CA. Ruthenium red as a selective capsaicin antagonist of the motor response to capsaicin in the human isolated ileum. Eur J Pharmacol 1991;196(3):331-3.

75. Maggi CA, Theodorsson E, Santicioli P, Patacchini R, Barbanti G, Turini D, Renzi D, Giachetti A. Motor response of the human isolated colon to capsaicin and its relationship to release of vasoactive intestinal polypeptide. Neuroscience 1990;39(3):833-41. 
76. Rolls ET, Verhagen JV, Kadohisa M. Representations of the texture of food in the primate orbitofrontal cortex: neurons responding to viscosity, grittiness, and capsaicin. J Neurophysiol 2003;90(6):3711-24.

77. Lejeune MP, Kovacs EM, Westerterp-Plantenga MS. Effect of capsaicin on substrate oxidation and weight maintenance after modest body-weight loss in human subjects. Br J Nutr 2003;90(3):651-59.

78. Andoh A, Tsujikawa T, Fujiyama Y. Role of dietary fiber and short-chain fatty acids in the colon. Curr Pharm Des 2003;9(4):347-58.

79. Higgins JA. Resistant starch: metabolic effects and potential health benefits. J AOAC Int 2004;87(3):761-8.

80. Cani PD, Dewever C, Delzenne NM. Inulin-type fructans modulate gastrointestinal peptides involved in appetite regulation (glucagon-like peptide-1 and ghrelin) in rats. Br J Nutr 2004;92(3):521-6.

81. Keenan MJ, Zhou J, McCutcheon KL, Raggio AM, Bateman HG, Todd E, Jones CK, Tulley RT, Melton S, Martin RJ and others. Effects of resistant starch, a non-digestible fermentable fiber, on reducing body fat. Obesity (Silver Spring) 2006;14(9):1523-34. 
2

\section{Satiety and substrate mobilization after oral fat stimulation}

Astrid J.P.G. Smeets and Margriet S. Westerterp-Plantenga

Based on: Satiety and substrate mobilization after oral fat stimulation, British Journal of Nutrition (2006), 95, 795-801. 


\begin{abstract}
The aim of the study was to provoke cephalic and metabolic responses due to oral fat stimulation with different high-fat meals in the postprandial state.

A randomized parallel design was executed with 3 groups (26 females and 10 males, 12 subjects in each group). Oral fat stimulation was achieved by the modified sham feeding (MSF) technique. Five hours after a high-fat breakfast, the subjects were given 1 of 3 test meals in random order: a highfat lunch, water or the same lunch as MSF. The main fat sources in the highfat lunch and MSF were olive oil, linoleic oil and oleic oil. During $3 \mathrm{~h}$ after the test meal blood samples were taken for metabolite analysis, and Visual Analog Scales on the appetite profile were completed. A cephalic response appeared to be achieved by MSF in that we observed a relative increase in insulin and glucose; this response lasted up till 90 minutes indicating possible vagal stimulation.

Non-esterified fatty acids increased significantly after MSF compared to water ingestion, in the case of olive oil $(p<0.0001)$ and linoleic oil $(p<0.05)$, yet not with oleic oil. MSF provoked a significantly higher increase in triacylglycerol and glycerol compared to water ingestion in the case of linoleic oil $(p<0.05)$. Satiety was significantly increased in the eating condition and in the MSF condition ( $p<0.0002$, all oils) compared to water ingestion. We conclude that cephalic and perhaps vagal stimulation by different fats increased concentrations of metabolites and stimulated satiety, with linoleic oil showing the strongest response.
\end{abstract}




\section{Introduction}

Obesity and related disorders such as the metabolic syndrome are rapidly growing nutrition related diseases worldwide ${ }^{1}$. Metabolic targets for improving body-weight management are amongst others satiety and substrate-metabolism. With respect to satiety it is interesting to see that cephalic, enteric and intestinal phase responses follow nutrient intake. Some of these reactions may start even before the actual ingestion of food, while other reactions may last for hours in the postprandial period ${ }^{2-4}$. The thought, sight, smell and taste of food may initiate cephalic responses, which influence the absorption and utilization of nutrients through vagal cholinergic activity ${ }^{5,6}$. Vagal responses may have long-lasting effects on metabolism as they have been suggested to be involved in the improvement of postprandial glucose tolerance and satiety and the elevation of postprandial lipemia after a gastric fat load ${ }^{7}$. Until now few studies have examined the effects of the oral stimuli that occur before and during food ingestion, especially fat ingestion, on postprandial or postabsorptive metabolism. High fat foods are not simply rich in energy, they are perceived as more palatable in general as well ${ }^{8,9}$. Important indicators of whether fat is present in a food are texture and odour ${ }^{10}$. Schemmel et al. observed a 'taste for fat' in specific rat strains, by discovering an inverse relationship between perception of free fatty acids and dietary preferences for fat. When placed on a high fat diet, fat-preferring rats became obese whereas fat-avoiding rats stayed lean ${ }^{11}$. Further investigations by Gilbertson et al revealed a dose dependent detection of low concentrations of free fatty acids (linoleic acid) by inhibition of delayed rectifying $\mathrm{K}^{+}$channels in taste receptor cells of rats, causing an increase in activity of these cells ${ }^{12}$. Humans are able to detect linoleic acid in these low concentrations as well ${ }^{13}$. Experiments using oral stimulation may shed some light on the consequences of vagal stimulation with fat. Previous oral stimulation experiments using the Modified Sham Feeding (MSF) technique have revealed effects on metabolites, hormones and satiety. Mattes ${ }^{14-19}$ found that oral stimulation after a gastric fat load resulted in higher plasma triacylglycerol. Robertson et al. ${ }^{20-24}$ performed oral stimulation experiments in the postprandial phase in which they observed a sustained suppression of plasma non-esterified fatty acids (NEFA). In the experiments of Heath et al. ${ }^{25}$, oral stimulation $1 \mathrm{~h}$ before a fat load resulted in a further decline of ghrelin levels, which was interpreted as a decrease in hunger.

The aim of the present study was to further assess cephalic and metabolic responses using vagal stimulation in the postprandial state. We investigated cephalic and metabolic responses (i.e. metabolites and satiety) to oral stimulation using three different high-fat meals, being rich in one of the three oils: (i) olive oil or an (ii) oil rich in linoleic acid or an (iii) oil rich in oleic acid, in the postprandial phase. 
The design consisted of a high-fat meal following a high-fat breakfast. Previous oral stimulation experiments have shown effects of MSF using high-fat meals in the postprandial period ${ }^{7,24}$. In contrast to the MSF meals in previous studies the present MSF meals did contain very little carbohydrate and protein, which allows us to look at the effects of fat in particular. The three different (olive, linoleic acid or oleic acid) oils were used to assess the effects of MUFA and PUFA. Olive oil was chosen because of its possible effects on triaglycerol-rich chylomicron particles ${ }^{26}$. Linoleic acid was chosen because of its believed specific perception, with oleic acid as its control ${ }^{11,12}$.

\section{Subjects and Methods}

\section{Subjects}

Thirty-six subjects (26 females, BMI: $22.4 \pm 1.8$, age: $29.9 \pm 13.6$ yrs, and 10 males, BMI: $23.1 \pm 2.0$, age: $30.6 \pm 12.6$ yrs; 12 subjects in each group) were studied on three occasions, in a series of experiments with 1 type of fat. The subjects were divided into three treatment groups (Table 1). The subjects were selected based on age, height, weight, BMI and restrained eating score on the Three Factor Eating Questionnaire ${ }^{27}$. All subjects were healthy, not taking medication, non-smoking and not dieting. All subjects gave written informed consent and the study was approved by the Maastricht University Ethics Committee.

Table 1. Characteristics of the subjects (mean \pm SD)

\begin{tabular}{|llll|}
\hline & Olive oil & Oleic & Linoleic \\
\hline $\mathbf{N}$ & 12 & 12 & 12 \\
$\mathbf{F} / \mathbf{M}$ & $8 / 4$ & $9 / 3$ & $9 / 3$ \\
& 44.3 & $23.1 \pm 7.1$ & $22.8 \pm 6.8$ \\
Age & \pm 10.8 & $22.6 \pm 1.3$ & $21.7 \pm 1.1$ \\
\hline
\end{tabular}

\section{Study protocol}

A randomized parallel design was executed with 3 groups. On the day before each study day subjects consumed a low-fat evening meal (15 E\% from fat) at home, which was provided by us. Before breakfast on the test day the subjects were asked whether they had consumed the low-fat evening meal the previous evening. On each test day subjects consumed breakfast at 8:00 am, which consisted of 2 croissants with butter and Brie and a cup of chocolate milk. Five hours after a high-fat breakfast, the subjects were given 1 of 3 test meals in randomized order: a high-fat lunch, water or the same lunch as MSF. The macronutrient composition of the meals is specified in 
Table 2. The main fat sources of the lunch in the three different treatments were respectively olive oil, an oil rich in linoleic acid (Becel, Unilever, Vlaardingen, NL), and an oil rich in oleic acid "Hozol oil" (Contined B.V., Bennekom, NL). In the olive oil treatment the lunch consisted of a salad and whipped cream with orange flavoured energy-free lemonade syrup (Diaran). In the olive oil treatment group we used whipped cream because we expected the cream would give an optimal oral fat exposure. In the linoleic acid and oleic acid treatment group the lunch consisted of a soup and a salad, in order to simplify the manipulation with the type of fat. Blood samples were taken from the antecubital vein just before the lunch condition, 15, 30, 60, 90 and $120 \mathrm{~min}$ after the lunch condition. At the start of the lunch meal subjects were asked to fill in $100 \mathrm{~mm}$ Visual Analogue Scales (VAS) on their feelings of hunger, fullness, appetite, satiety, thirst, prospective food consumption, desire to eat and palatability of each course. Additionally, subjects were asked to fill in $100 \mathrm{~mm}$ Visual Analogue Scales (VAS) at six different time points after the lunch condition on their feelings of hunger, fullness, appetite, satiety, thirst, prospective food consumption, and desire to eat. The scale was anchored from "not at all" on the left to "extremely" on the right.

Table 2. Composition of the meals

\begin{tabular}{|llllll|}
\hline & Weight $(\mathbf{g})$ & Energy $(\mathrm{kJ})$ & Protein $(\mathrm{g})$ & Fat $(\mathrm{g})$ & Carbohydrates $(\mathrm{g})$ \\
\hline Evening meal & 475 & 2290 & 19 & 9.5 & 95 \\
Breakfast & 355 & 3656 & 23.3 & 59.4 & 61.35 \\
Lunch olive oil & 285 & 1446.3 & 2.9 & 35.7 & 4.3 \\
Lunch oleic & 443 & 1461.3 & 3.7 & 33.0 & 9.8 \\
Lunch linoleic & 443 & 1461.3 & 3.7 & 33.0 & 9.8 \\
\hline
\end{tabular}

\section{$M S F$}

In the MSF condition the subjects were presented with the test meal and were instructed to chew the food until the point at which they would normally swallow and then to expectorate the food into a plastic cup. They were continually instructed not to swallow any food. The subjects repeated the procedure until the meal had been fed completely (15-20 min). Weights of each meal were measured before and after MSF.

\section{Blood collection and analytical methods}

Blood samples were collected in tubes containing EDTA to prevent clotting. Plasma was obtained by centrifugation $\left(4^{\circ} \mathrm{C}, 3000 \mathrm{rpm}, 10 \mathrm{~min}\right)$ and stored at $-20^{\circ} \mathrm{C}$ until analysis of glucose by a hexokinase method (ABX Diagnostics), insulin (RIA kit, Linco Research) non-esterified fatty acids (NEFA C-kit Wako 994-75409, Sopar Biochemicals), triacylglycerol (GPO-trinder 337, Sigma) and glycerol by a glycerolkinase-lipase method (Boehringer, 
Mannheim, Germany) using a semi-automated centrifugal spectrophometer (Cobas Fara, Roche Diagnostics).

Statistical analysis

All data are presented as means \pm standard deviations (SD) or standard error of the mean (SEM). Areas under the curve (AUC) of the percentage of change in concentrations over 120 minutes were calculated by using the trapezoid method. The three conditions (water, MSF and eating) were compared within each treatment group (olive oil, oil rich in linoleic acid and oil rich in oleic acid) in terms of the postprandial metabolite responses, hormone responses and VAS scores by using repeated-measures analyses of variance (ANOVA). Differences between the oleic acid treatment group and the linoleic acid treatment group in terms of the postprandial metabolite responses, hormone responses and VAS scores were analyzed by using factorial analyses of variance (ANOVA). Post hoc analysis was done with a Scheffe F-test or a Fisher PLSD test. All of the statistical analyses were done with Statview SE Graphics ${ }^{\mathrm{TM}}$ software (version 4.5, Abacus Concepts Inc, Berkeley, CA, USA), and the criterion for significance was set at $p<0.05$.

\section{Results}

Subjects

The subjects in the three groups were all selected based on the same criteria. The subjects in the olive oil group were however significantly $(\mathrm{p}<0.0001)$ older compared to the two other groups.

\section{Palatability of the lunches}

The subjects rated their lunch, which was completely novel to them, as sufficiently and similarly palatable (olive oil treatment group: $5.9 \pm 1.6 \mathrm{~cm}$, linoleic acid treatment group: $6.2 \pm 1.7 \mathrm{~cm}$, oleic acid treatment group: $6.3 \pm 1.7 \mathrm{~cm})$.

\section{Expectorated meals}

The weights of the MSF meal before and after chewing were compared; this yielded a mean $( \pm \mathrm{SEM})$ recovery rate of $99.8 \pm 2.58 \%$. The recovery rates from the MSF meal in the olive oil group, the linoleic acid oil group and oleic acid oil group were not significantly different.

\section{Blood samples}

An overview of the results of the blood analyses calculated as AUC delta \% is given in Table 3. 
Table 3. Area under the curve of the percentage of change in concentrations \pm standard deviation

\begin{tabular}{|llllllllll|}
\hline & \multicolumn{3}{l}{ Linoleic acid } & \multicolumn{3}{l}{ Oleic acid } & \multicolumn{3}{l|}{ Olive oil } \\
& MSF & Water & Eating & MSF & Water & Eating & MSF & Water & Eating \\
\hline Glucose & $-823.4 \mathrm{~b}$ & $-804.2 \mathrm{a}$ & $512.2 \mathrm{ab}$ & $-118.0 \mathrm{bc}$ & $-587.1 \mathrm{ac}$ & $580.7 \mathrm{ab}$ & $426.8 \mathrm{~b}$ & $21.4 \mathrm{a}$ & $1401.2 \mathrm{ab}$ \\
& \pm 1061.5 & \pm 455.2 & \pm 809.2 & \pm 735.4 & \pm 612.9 & \pm 525.1 & \pm 940.4 & \pm 794.5 & \pm 1420.8 \\
\multirow{4}{*}{ Insulin } & & & & & & & & & \\
& & & & & & & & & \\
& \pm 3157.6 & \pm 2971.1 & \pm 2810.6 & \pm 6013.8 & \pm 2049.2 & \pm 5596.8 & \pm 1904.7 & \pm 2892.6 & \pm 3966.2 \\
NEFA & $1819.5 \mathrm{c}$ & $-2774.8 \mathrm{c}$ & -484.6 & 541.2 & -1095.7 & -1843.9 & $2909.8 \mathrm{bc}$ & $422.3 \mathrm{ac}$ & $6758.9 \mathrm{ab}$ \\
& \pm 4113.8 & \pm 2288.9 & \pm 3284.1 & \pm 2597.2 & \pm 1726.0 & \pm 5208.6 & \pm 1909.4 & \pm 2132.5 & \pm 3818.4 \\
Trig & & & & & & & & & \\
& $-695.5 \mathrm{c}$ & $675.6 \mathrm{c}$ & 2775.4 & -1525.6 & -1181.6 & 897.4 & $5267.7 \mathrm{~b}$ & $1271.6 \mathrm{a}$ & $11729.8 \mathrm{ab}$ \\
& \pm 4636.0 & \pm 3067.6 & \pm 1879.7 & \pm 3272.0 & \pm 3864.4 & \pm 2500.7 & \pm 9394.9 & \pm 5805.9 & \pm 16874.3 \\
& & & & & & & & & \\
Glycerol & $-2734.8 \mathrm{c}$ & $-4369.4 \mathrm{ac}$ & $-1715.9 \mathrm{a}$ & -2814.4 & -2141.3 & -2093.6 & $-4897.3 \mathrm{~b}$ & $-2049.5 \mathrm{a}$ & $1617.5 \mathrm{ab}$ \\
& \pm 2702.5 & \pm 1284.9 & \pm 2662.9 & \pm 1939.3 & \pm 3146.4 & \pm 2046.5 & \pm 2494.0 & \pm 3440.5 & \pm 7140.3 \\
\hline
\end{tabular}

a) after eating significantly different from after water, $\mathrm{P}<0.05$ by repeated measures ANOVA, b) after MSF significantly different from after eating, $\mathrm{P}<0.05$ by repeated measures ANOVA, c) after MSF significantly different from after water, $\mathrm{P}<0.05$ by repeated measures ANOVA

\section{Glucose}

We observed an increase in glucose concentrations with oleic acid during 15-90 minutes (calculated as AUC delta \%) after MSF and after eating compared to the water condition $(\mathrm{p}<0.0001$, Figure 1$)$. In the olive oil and linoleic acid treatment group we observed a significant increase in glucose concentrations after eating compared to the MSF and water condition, but no significant difference between the MSF and water condition $(p<0.001$, data not shown).

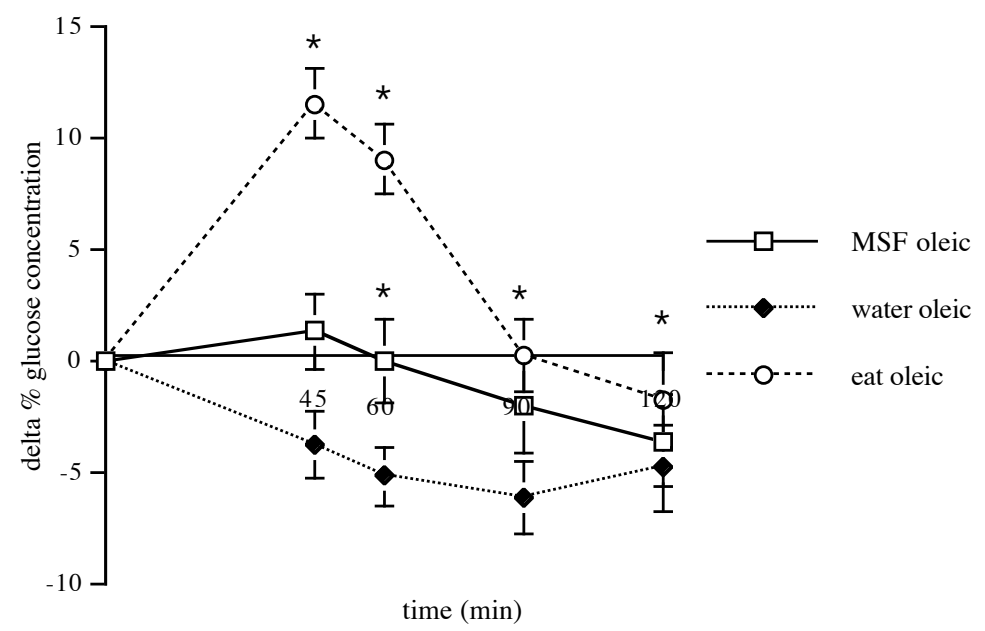

Figure 1. Mean \pm SEM percentage of change in plasma glucose concentrations with the oleic acid treatment. * after eating or MSF significantly different from after water, $\mathrm{P}<0.05$ by repeated measures ANOVA 


\section{Insulin}

Insulin concentrations (calculated as AUC delta \%) increased significantly more after MSF compared to the water condition and after eating compared to the water condition in the case of linoleic acid $(p<0.0001$, Figure 2$)$. In the oleic acid treatment group insulin concentrations increased significantly more after eating compared to the MSF and water condition ( $p<0.0004)$. We observed no significant differences in insulin concentrations after the MSF condition compared to the water condition in the oleic acid treatment group. Insulin concentrations after all conditions (MSF, eating and water) were not significantly different in the olive oil treatment group (data not shown).

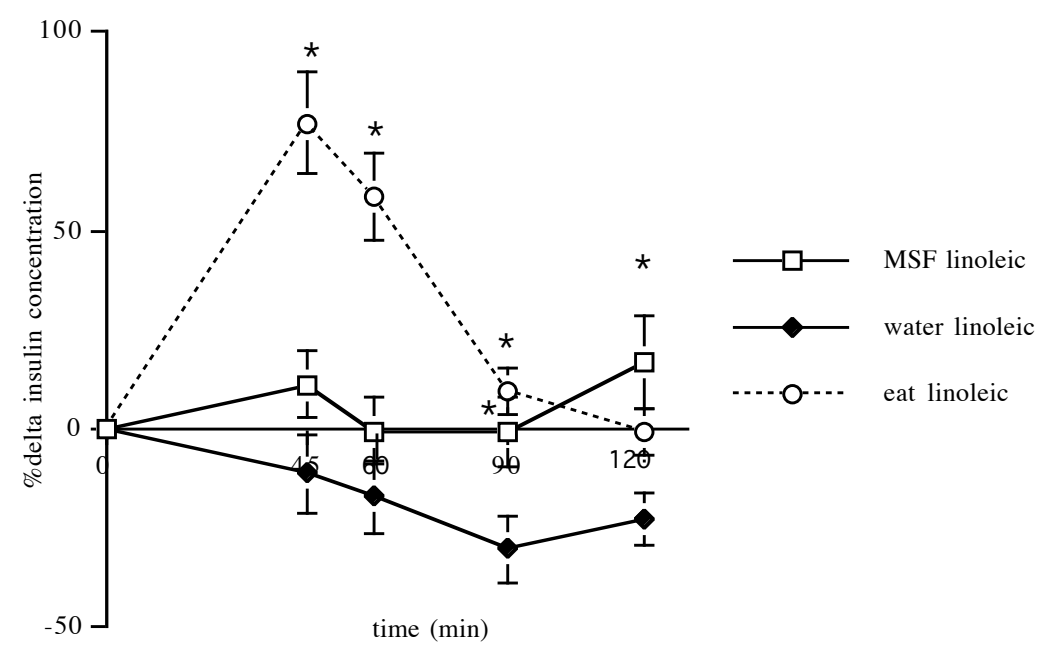

Figure 2. Mean \pm SEM percentage of change in plasma insulin concentrations with the linoleic acid treatment. * after eating or MSF significantly different from after water, $\mathrm{P}<0.05$ by repeated measures ANOVA

Non-esterified fatty acids

NEFA increased significantly (calculated as AUC delta \%) after MSF compared to the water condition and after eating compared to the water condition, in the case of olive oil ( $<<0.0001$, Figure 3). NEFA increased significantly after MSF compared to the water condition, in the case of linoleic acid $(\mathrm{p}<0.05$, Figure 4$)$. NEFA concentrations after all conditions (MSF, eating and water) were not significantly different in the oleic acid treatment group (data not shown). 


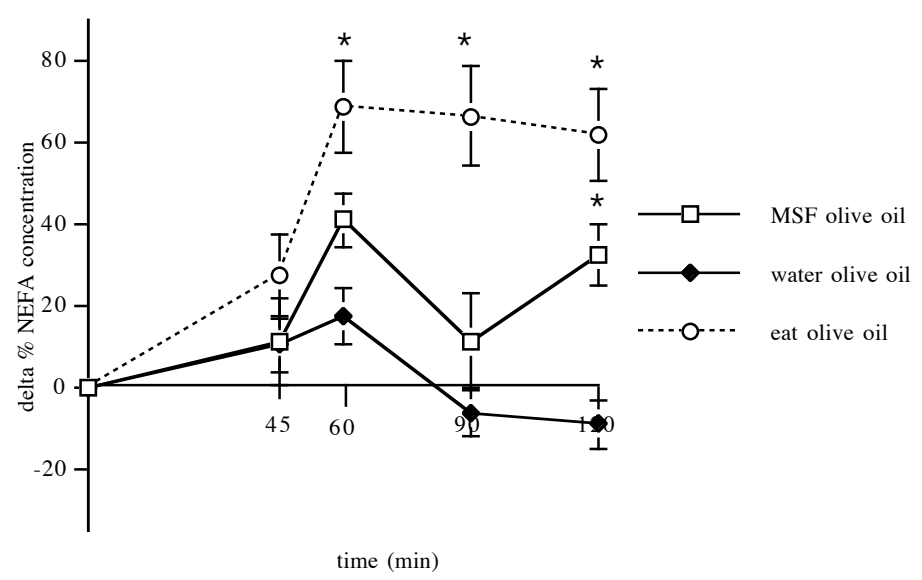

Figure 3. Mean \pm SEM percentage of change in plasma NEFA concentrations with the olive oil treatment. * after eating or MSF significantly different from after water, $\mathrm{P}<0.05$ by repeated measures ANOVA

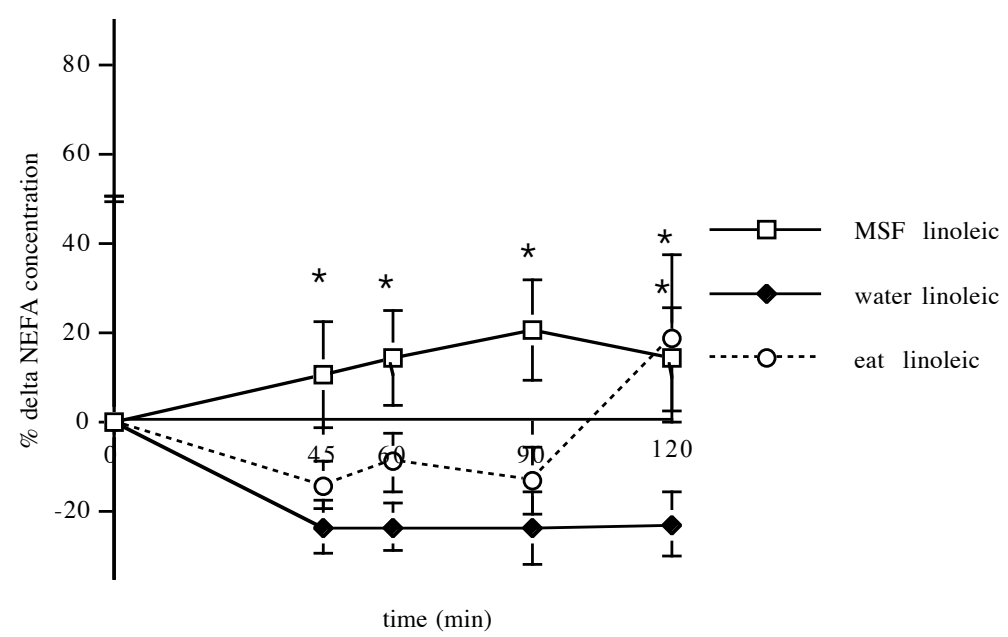

Figure 4. Mean \pm SEM percentage of change in plasma NEFA concentrations with the linoleic acid treatment. * after eating or MSF significantly different from after water, $\mathrm{P}<0.05$ by repeated measures ANOVA

\section{Triacylglycerol and glycerol}

MSF and eating provoked a significantly higher increase in triacylglycerol concentrations (calculated as AUC delta \%) compared to the water condition in the case of linoleic acid ( $<<0.05$, Figure 5).

The triacylglycerol concentrations following the eating condition were significantly higher compared to the triacylglycerol concentrations following the MSF and water condition in the olive oil treatment group. In the oleic acid treatment group we observed no significant differences in triacylglycerol concentrations after all conditions (data not shown). 
Additionally, the increase in triacylglycerol concentrations following MSF in the linoleic acid treatment group was significantly different compared to the decline in triacylglycerol concentrations following MSF in the oleic acid treatment group $(\mathrm{p}<0.01)$.

Glycerol concentrations (calculated as AUC delta \%) increased significantly after MSF compared to the water condition, in the case of linoleic acid $(p<0.05$, Figure 6). The glycerol concentrations following the eating condition were significantly higher compared to the glycerol concentrations following the MSF condition in the olive oil treatment group. In the oleic acid treatment group we observed no significant differences in glycerol concentrations after all conditions (data not shown).

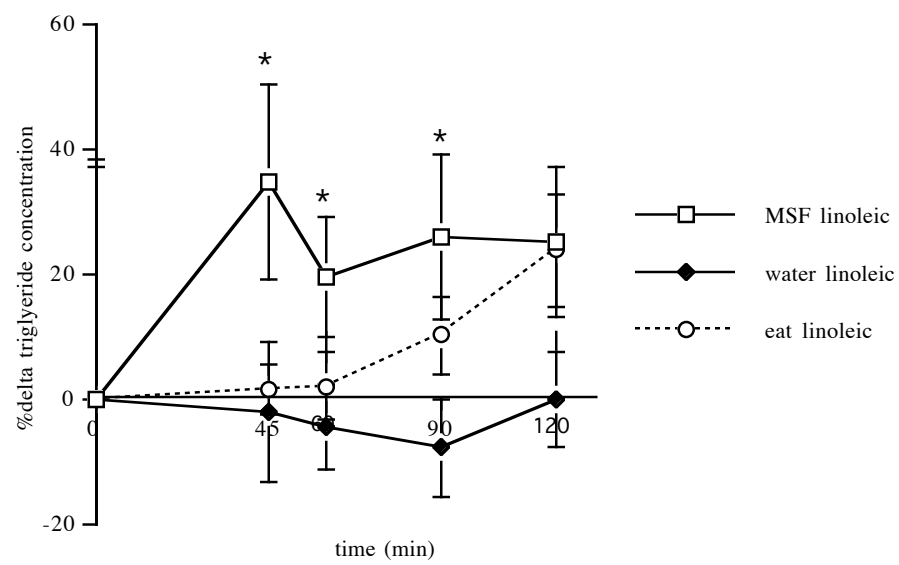

Figure 5. Mean \pm SEM percentage of change in plasma triacylglycerol concentrations with the linoleic acid treatment. * after eating or MSF significantly different from after water, $\mathrm{P}<0.05$ by repeated measures ANOVA

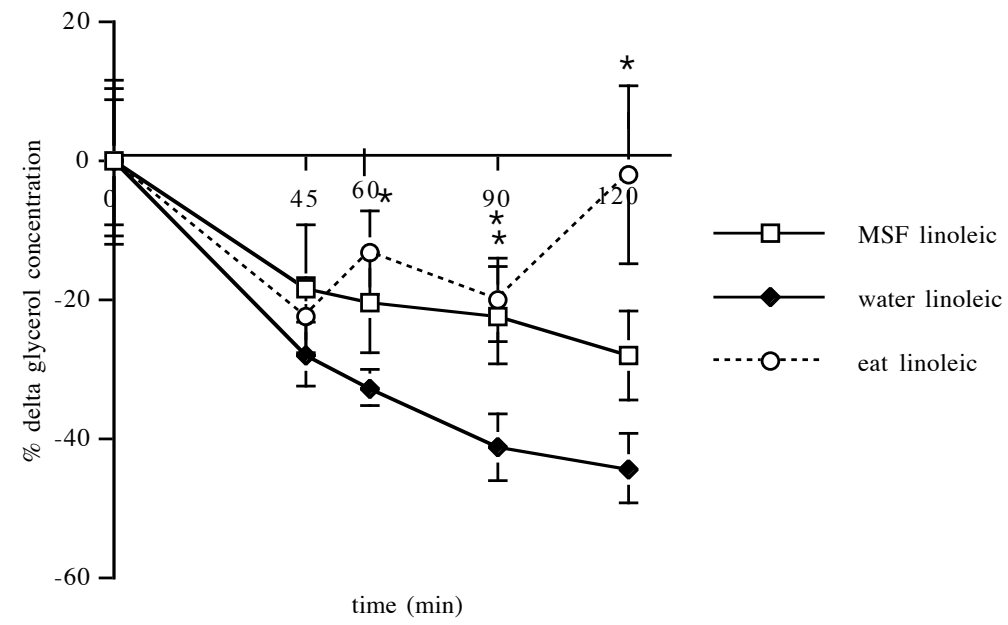

Figure 6. Mean \pm SEM percentage of change in plasma glycerol concentrations with the linoleic acid treatment. * after eating or MSF significantly different from after water, $\mathrm{P}<0.05$ by repeated measures ANOVA 


\section{Appetite profile}

Satiety (calculated as AUC delta) was not only significantly increased in the eating condition ( $\mathrm{p}<0.0002$, for all oils), but also, though to a smaller extent, in the MSF condition $(\mathrm{p}<0.0002$, for all oils) compared to the water condition (Figure 7a,b,c).

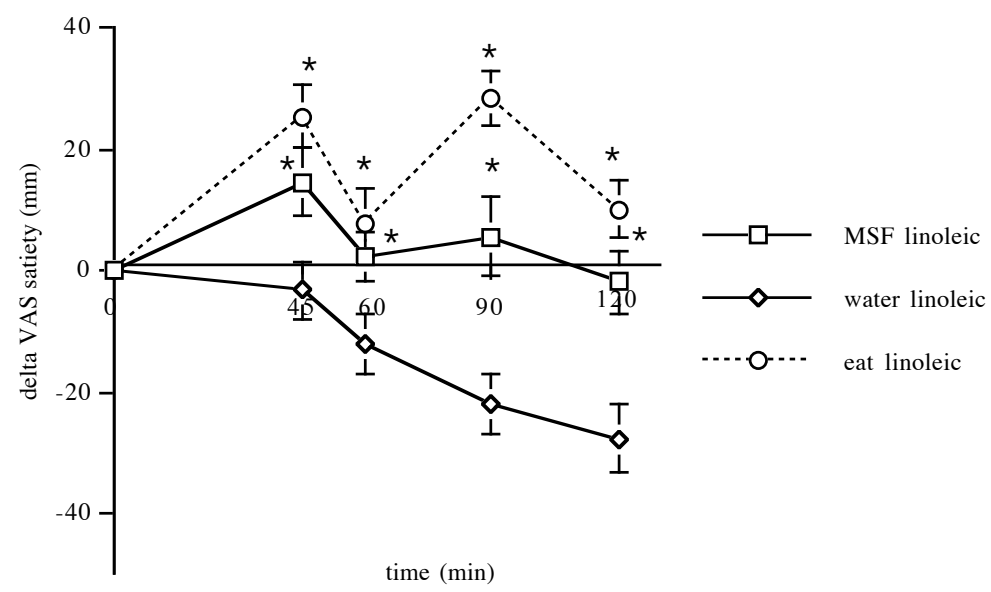

Figure 7a. Mean \pm SEM change in feelings of satiety $(\mathrm{mm})$ with the linoleic acid treatment. * after eating or MSF significantly different from after water, $\mathrm{P}<0.0002$ by repeated measures ANOVA

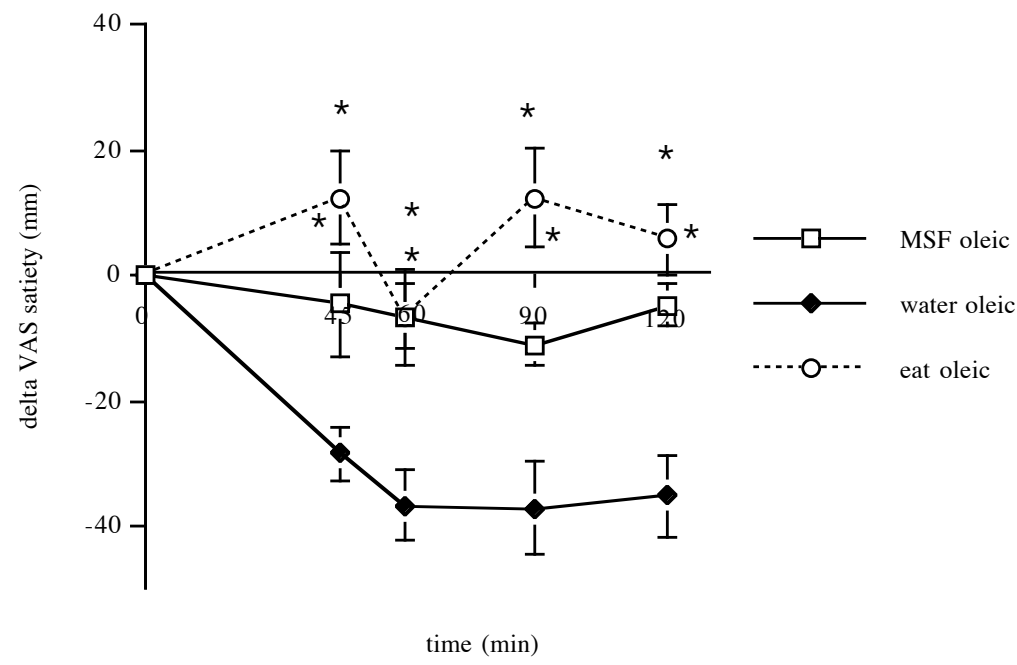

Figure 7b. Mean \pm SEM change in feelings of satiety $(\mathrm{mm})$ with the oleic acid treatment. * after eating or MSF significantly different from after water, $\mathrm{P}<0.0002$ by repeated measures ANOVA 


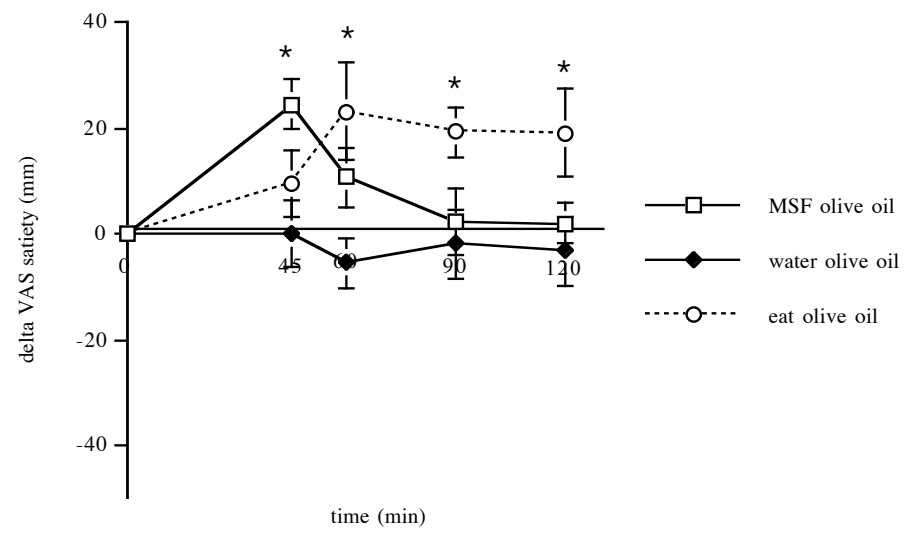

Figure 7c. Mean \pm SEM change in feelings of satiety $(\mathrm{mm})$ with the olive oil treatment. * after eating or MSF significantly different from after water, $\mathrm{P}<0.0002$ by repeated measures ANOVA

Feelings of fullness (calculated as AUC delta) were significantly increased in the eating condition ( $\mathrm{p}<0.0001$, for all oils) and in the MSF condition compared to the water condition in the linoleic acid $(\mathrm{p}<0.0001)$ and oleic acid treatment group $(\mathrm{p}<0.0001)$. Hunger, appetite and desire to eat (calculated as AUC delta) were significantly increased in the eating condition ( $\mathrm{p}<0.001$, for all oils) and in the MSF condition compared to the water condition in the linoleic acid $(\mathrm{p}<0.001)$ and oleic acid $(\mathrm{p}<0.001)$ treatment group (data not shown).

\section{Discussion}

Oral fat stimulation by MSF of different fats, i.e. olive oil and linoleic oil, appeared to increase a release of triacylglycerol, or NEFA. Moreover, feelings of satiety were increased with MSF of all oils, compared to water ingestion. This short increase in rated satiety following MSF is clearly a sensory effect, when absorptive effects are absent ${ }^{28}$. These effects on feelings of satiety following MSF may be mediated by satiety related metabolites and hormones. Heath et al observed increased feelings of fullness during 5 hours when a meal was preceded by MSF one hour earlier. This effect was accompanied by a sustained decline of plasma ghrelin concentrations following $\mathrm{MSF}^{25}$.

These findings suggest that increased oral exposure may enhance satiety.

The duration of the effects we observed as increased glucose concentrations and insulin concentrations indicate that not just a cephalic response but also vagal stimulation appeared to be achieved by $\mathrm{MSF}^{29}$. Similar effects in 
plasma glucose and insulin concentrations following MSF with saturated fat have been observed by Robertson et $\mathrm{al}^{7}$. It is not likely that the effects we observed on plasma concentrations following MSF are produced by the ingestion of food, as shown by the high total recovery of the weights of the expectorated meals. Earlier oral stimulation studies have shown that amount of food which is accidentally swallowed during MSF is a few grams ${ }^{14,16,17,19-}$ $21,24,25$

In two treatments, i.e. with olive oil and linoleic acid we found that NEFA increased significantly after MSF compared to the water condition (Fig. 3a,b and Fig. 4 a,b). With these treatments oral stimulation seems to increase the availability of oxidizable metabolites, without receiving any exogenous nutrients. Previous studies using the MSF technique observed a sustained decline in plasma NEFA concentrations $7,22,25$. The differences in macronutrient compositions and fat sources of the meals between our study and the previous studies may account for the differences in NEFA responses. The meals we used in our study contained less carbohydrates and more fat. These differences may have affected the regulation of NEFA concentrations indirectly through effects on insulin or glucagon, which are both involved in lipolysis ${ }^{30,31}$.

MSF provoked a significantly higher increase in triacylglycerol compared to the water condition only with the linoleic acid treatment. Because we observed this effect with the linoleic acid treatment and to a smaller extend with the olive oil treatment but not with the oleic acid treatment, oral stimulation with specific fatty acids may be required to induce a rise in NEFA's and triacylglycerol. Additionally, the individual ability to detect specific fatty acids might, in this case oleic acid and linoleic acid, play a role in the observed effects. A study performed by Kamphuis et al. has shown that low concentrations of linoleic acid were detected by a higher percentage of the subjects than the same low concentrations of oleic acid ${ }^{32}$.

Thus, if a specific fatty acid is not detected, it cannot provoke a response, as may be the case in this experiment with oleic acid. Postprandial studies in which sequential meals were used show that when a second meal is ingested 4-6 $\mathrm{h}$ after the first meal there is a rapid appearance of chylomicrons in the circulation, with a peak $1 \mathrm{~h}$ after the second meal.

These chylomicrons have been shown to carry fat ingested in the first meal 33-35. It has been suggested that a proportion of fat from the first meal remains in the gut lumen or in the enterocyte and enters the plasma pool after ingesting a second meal ${ }^{26}$. Jackson et al. and Robertson et al. observed no elevation of plasma triacylglycerol, triacylglycerol-rich lipoprotein (TRL) and TRL-retinyl ester concentrations when MSF with either a low-fat or moderate-fat meal was performed 5 hours after a high-fat breakfast ${ }^{7,21}$. In a different study Jackson et al. did observe that ingestion of a high fat breakfast produced a rapid peak in triacylglycerol, retinyl esters, and apo B- 
48 chylomicrons after a second meal which was very low in fat $(6 \mathrm{~g})^{26}$. These findings suggest that fat from the first meal is released in preformed chylomicrons and that the observed effects were not attributable to the second meal. Further evidence for this "storage theory" is supported by the findings of Mattes et al. They observed a release of fats from the previous (evening) meal following MSF with fat in combination with a fat load the next morning ${ }^{16}$. Previous experiments performed by Mattes et al. focused on lipid metabolism using MSF with different dietary fats in combination with a fat load. The observed effects on lipid metabolism from these studies imply a taste component to dietary fats ${ }^{14-17,19}$. More recent experiments have observed increased plasma triacylglycerol concentrations when MSF was performed 1 hour before a meal ${ }^{24,25}$.

Summarizing it appears that the metabolic effects observed after the consumption of high-fat foodstuffs is at least partly influenced by the oral exposure to fats and the preceding meal. However, the mechanisms behind these effects still need to be clarified. Because the subjects in the olive oil treatment group are significantly older compared to the subjects in the oleic acid treatment group and the linoleic acid treatment group, comparing the results of the olive oil treatment group to the result of the other groups is not completely justified. Age-related changes in body-composition and metabolism may have contributed to the absence of significant differences in insulin concentrations comparing the three conditions (water, MSF and eating) in the olive oil group, and the higher responses (expressed as \% of change) in NEFA and triacylglycerol in the olive oil group compared to the two other groups, as they are thought to contribute to a deterioration in insulin action and blood lipid profile ${ }^{36-40}$. The significance of MSF with i.e. fats lays in the possible relationship of sensory perception and metabolic effects. Here we have shown that just perception, without swallowing evokes the appearance of metabolites and satiety. Probably the increase in satiety was due to the increase of metabolites and hormones concomitant with a development of satiety ${ }^{41}$.

This study not only confirmed the observations reported by Robertson et al. 7,20-25 and Mattes et al. ${ }^{14-19}$, but also extended their findings to other fats i.e. oil rich in linoleic acid, oil rich in oleic acid and olive oil, showing differences depending on the type of fats and moreover, showing effects on satiety. Following experiments should shed light on satiety hormones to assess the mechanism of satiety, and possible effects on substrate oxidation and thermogenesis.

\section{Acknowledgements}

We thank Ilse Nijs, Joan Senden, Jos Stegen, Wendy Sluijsmans and Chantalle Moors for their contributions to the study. 


\section{References}

1. James PT, Rigby N, Leach R. The obesity epidemic, metabolic syndrome and future prevention strategies. Eur J Cardiovasc Prev Rehabil 2004;11(1):3-8.

2. Strubbe JH. Parasympathetic involvement in rapid meal-associated conditioned insulin secretion in the rat. Am J Physiol 1992;263(3 Pt 2):R615-8.

3. Rasmussen H, Zawalich KC, Ganesan S, Calle R, Zawalich WS. Physiology and pathophysiology of insulin secretion. Diabetes Care 1990;13(6):655-66.

4. Konturek SJ, Pepera J, Zabielski K, Konturek PC, Pawlik T, Szlachcic A, Hahn EG. Brain-gut axis in pancreatic secretion and appetite control. J Physiol Pharmacol 2003;54(3):293-317.

5. Naim M, Kare MR, Merrie AM. Effects of oral stimulation on the cephalic phase of pancreatic exocrine in dogs. Physiol Behav 1978;20(5):563-70.

6. Hopman WP, Jansen JB, Rosenbusch G, Lamers CB. Cephalic stimulation of gallbladder contraction in humans: role of cholecystokinin and the cholinergic system. Digestion 1987;38(4):197-203.

7. Robertson MD, Jackson KG, Williams CM, Fielding BA, Frayn KN. Prolonged effects of modified sham feeding on energy substrate mobilization. Am J Clin Nutr 2001;73(1):111-7.

8. Drewnowski A. Energy intake and sensory properties of food. Am J Clin Nutr 1995;62(5 Suppl):1081S-1085S.

9. Drewnowski A. Taste preference and food intake. Ann Rev Nutr 1997;17:237-53.

10. Rolls ET, Critchley HD, Browning AS, Hernadi I, Lenard L. Responses tot the sensory properties of fat of neurons in the primate orbitofrontal cortex. $\mathrm{J}$ Neuroscience 1999;19(4):1532-40.

11. Schemmel R, Mickelsen O, Gill JL. Dietary obesity in rats: Body weight and body fat accretion in seven strains of rats. J Nutr 1970;100(9):1041-48.

12. Gilbertson TA, Fontenot DT, Liu L, Zhang H, Monroe WT. Fatty acid modulation of $\mathrm{K}+$ channels in taste receptor cells: gustatory cues for dietary fat. Am J Physiol 1997;272(4 Pt 1):C1203-10.

13. Kamphuis MM, Saris WH, Westerterp-Plantenga MS. The effect of addition of linoleic acid on food intake regulation in linoleic acid tasters and linoleic acid non-tasters. Br J Nutr 2003;90(1):199-206.

14. Mattes RD. Oral exposure to butter, but not fat replacers elevates postprandial triacylglycerol concentration in humans. J Nutr 2001;131(5):1491-96.

15. Mattes RD. The taste of fat elevates postprandial triacylglycerol. Physiol Behav 2001;74(3):343-48.

16. Mattes RD. Oral fat exposure increases the first phase triacylglycerol concentration due to release of stored lipid in humans. J Nutr 2002;132(12):3656-62.

17. Tittelbach TJ, Mattes RD. Oral stimulation influences postprandial 
triacylglycerol concentrations in humans: nutrient specificity. J Am Coll Nutr 2001;20(5):485-93.

18. Tittlebach TJ, Mattes RD. Effect of orosensory stimulation on postprandial thermogenesis in humans. Physiol Behav. 2002;75(1-2):71-81.

19. Mattes RD. Oral fat exposure alters postprandial lipid metabolism in humans. Am J Clin Nutr 1996;63(6):911-17.

20. Jackson KG, Robertson MD, Deane LO, Fielding BA, Frayn KN, Williams $\mathrm{CM}$. The effect of modified sham-feeding meals of varying fat content on postprandial triacylglycerol, insulin and glucose response. Proc Nutr Soc 2000;59:14A.

21. Jackson KG, Robertson MD, Fielding BA, Frayn KN, Williams CM. Second meal effects: modified sham feeding does not provoke the release of stored triacylglycerol from a previous high-fat meal. Br J Nutr 2001;85(2):149-56.

22. Robertson MD, Jackson KG, Fielding BA, Williams CM, Frayn KN. Modified sham feeding of a modest-fat meal suppresses plasma nonesterified fatty acids. Proc Nutr Soc 1999;59:123A.

23. Robertson MD, Mason AO, Frayn KN. Oro-sensory stimulation prior to fat ingestion impairs postprandial fat tolerance. Int J Obesity 2000;24:S55.

24. Robertson MD, Mason AO, Frayn KN. Timing of vagal stimulation affects postprandial lipid metabolism in humans. Am J Clin Nutr 2002;76(1):71-7.

25. Heath RB, Jones R, Frayn KN, Robertson MD. Vagal stimulation exaggerates the inhibitory ghrelin response to oral fat in humans. J Endocrinol 2004;180(2):273-81.

26. Jackson KG, Robertson MD, Fielding BA, Frayn KN, Williams CM. Olive oil increases of triacylglycerol-rich chylomicron particles compared with other oils: an effect retained when a second meal is fed. Am J Clin Nutr 2002;76(5):942-9.

27. Stunkard AJ, Messick S. The three-factor eating questionnaire to measure dietary restraint, disinhibition and hunger. J Psychosom Res 1985;29(1):7183 .

28. Blundell JE, Hill AJ, Rogers PJ. Hunger and the satiety cascade - their importance for food acceptance in the late 20th century. In: Thompson DMH, ed. Food acceptability. 1988:233-50.

29. Ahren B, Holst JJ. The cephalic insulin response to meal ingestion in humans is dependent on both cholinergic and noncholinergic mechanisms and is important for postprandial glycemia. Diabetes 2001;50(5):1030-8.

30. Perea A, Clemente F, Martinell J, Villanueva-Penacarrillo ML, Valverde I. Physiological effect of glucagon in human isolated adipocytes. Horm Metab Res 1995;27(8):372-5.

31. Evans K, Clark ML, Frayn KN. Effects of an oral and intravenous fat load on adipose tissue and forearm lipid metabolism. Am J Physiol 1999;276(2 Pt 1):E241-8.

32. Kamphuis MM, Westerterp-Plantenga MS. The role of linoleic acid taste perception in the etiology og obesity. Submitted for publication. 
33. Peel AS, Zampelas A, Williams CM, Gould BJ. A novel antiserum specific to apolipoprotein B-48: application in the investigation of postprandial lipidaemia in humans. Clin Sci (Lond) 1993;85(5):521-4.

34. Fielding BA, Callow J, Owen RM, Samra JS, Matthews DR, Frayn KN. Postprandial lipemia: the origin of an early peak studied by specific dietary fatty acid intake during sequential meals. Am J Clin Nutr 1996;63(1):36-41.

35. Evans K, Kuusela PJ, Cruz ML, Wilhelmova I, Fielding BA, Frayn KN. Rapid chylomicron appearance following sequential meals: effects of second meal composition. Br J Nutr 1998;79(5):425-9.

36. Kelley DE. Skeletal muscle triglycerides: an aspect of regional adiposity and insulin resistance. Ann N Y Acad Sci 2002;967:135-45.

37. Kelley DE, Goodpaster B, Wing RR, Simoneau JA. Skeletal muscle fatty acid metabolism in association with insulin resistance, obesity, and weight loss. Am J Physiol 1999;277(6 Pt 1):E1130-41.

38. Kissebah AH, Alfarsi S, Adams PW, Wynn V. Role of insulin resistance in adipose tissue and liver in the pathogenesis of endogenous hypertriglyceridaemia in man. Diabetologia 1976;12(6):563-71.

39. Kohrt WM, Kirwan JP, Staten MA, Bourey RE, King DS, Holloszy JO. Insulin resistance in aging is related to abdominal obesity. Diabetes 1993;42(2):273-81.

40. Vessby B, Tengblad S, Lithell H. Insulin sensitivity is related to the fatty acid composition of serum lipids and skeletal muscle phospholipids in 70year-old men. Diabetologia 1994;37(10):1044-50.

41. Woods SC. Gastrointestinal satiety signals I. An overview of gastrointestinal signals that influence food intake. Am J Physiol Gastrointest Liver Physiol 2004;286(1):G7-13. 

3

\section{Oral exposure and sensory-specific satiety}

Astrid J.P.G. Smeets and Margriet S. Westerterp-Plantenga

Based on: Oral exposure and sensory-specific satiety, Physiology \& Behavior 89 (2006) 281-286. 


\begin{abstract}
Satiety has been shown after oral exposure to food that was chewed but not eaten (Modified Sham Feeding (MSF)). The aim of the study was to explore the role of sensory specific satiety (SSS) in satiety development with MSF. Subjects were studied on three test days; they received, in random order, water, MSF, or a meal. At the start and the end of each course of the lunch condition subjects evaluated appetite sensations, taste perception and pleasantness of taste using Visual Analogue Scales. SSS was present when eating soup and salad. SSS also occurred with MSF of salad. When eating the soup no significant changes in appetite ratings occurred. Hunger decreased and satiety increased while the salad was eaten $(p<0.0004)$. In this condition taste perception did not change significantly and a decrease in pleasantness coincided with an increase in satiety. During the MSF salad taste perception changed, i.e. creaminess and intensity increased $(p<0.05$ and $\mathrm{p}<0.02$, respectively). When the salad was eaten we observed an increase in satiety and a decrease in hunger and desire to eat (DTE). Chewing the salad resulted only in a decrease in DTE. In this experiment merely chewing a salad produced SSS. We conclude that when SSS takes place during feeding, it is related to an increase in satiety, and a decrease in hunger and DTE. With SSS during MSF, satiety does not increase, nor does hunger decrease, yet DTE decreases. Thus MSF is sufficient for a sensory decrease in DTE despite of lack of satiety.
\end{abstract}




\section{Introduction}

As a food is consumed to satiety, its perceived pleasantness of taste declines compared to that of foods that have not been consumed. This phenomenon is referred to as sensory-specific satiety ${ }^{1}$. These declines in pleasantness of taste are greatest within the first 20 minutes following consumption, suggesting that these effects are primarily based on sensory cues, and less on postingestive or postabsorptive cues. Sensory-specific satiety promotes the consumption of meals with greater nutrient variety and thus may lead to increased intake ${ }^{1,2}$. The magnitude of sensory-specific satiety of a specific food is dependent on its texture, flavour and colour ${ }^{3,4}$. Although it has been reported that the macronutrient composition of a food also appears to influence its sensory-specific satiety ${ }^{5-10}$, the time framing of SSS and the finding that one does not need ingestion suggest that SSS is a sensory-based phenomenon ${ }^{4}$, i.e. foods high in protein, sweet carbohydrates and fatty acids have been suggested to have a relatively greater sensory-specific satiety ${ }^{6,7,11-}$ 14. Accordingly, Modified Sham Feeding (MSF) showed that the specific metabolites triggered by sensory perception give rise to sensory satiety ${ }^{15}$. Experiments using oral stimulation may shed some light on the consequences of vagal stimulation with food. Previous oral stimulation experiments using the MSF technique have revealed effects on metabolites, hormones and satiety ${ }^{16-26}$. MSF experiments performed by Mattes and Jackson and colleagues have shown that fat can be tasted ${ }^{17,19-22}$, and had subsequent effects in particular with butter compared with after oral exposure to fat replacers ${ }^{20}$. Studies investigating the relative contribution of oral, gastric and intestinal exposure to food on satiation and satiety have shown that orosensory information is essential in the process of satiety development and appetite regulation. Oral exposure to food enhances the effects of gastric and intestinal exposure to food on appetite and subsequent food intake ${ }^{27-30}$.

Experiments performed by Rolls and colleagues gave insight in the neural mechanisms of sensory-specific satiety. They have shown that the identity of the taste is represented in the primary taste cortex, and the hedonic quality of the taste is computed and represented in the secondary taste cortex ${ }^{31-33}$. In humans the orbitofrontal cortex seems to be related to the hedonic evaluation of a food and thus to sensory specific satiety.

In addition to sensory specific satiety for a food eaten to satiety, other forms of sensory specific satiety have been observed such as olfactory and visual sensory specific satiety ${ }^{4,34}$. In an experiment conducted by Rolls and Rolls chewing foods, without swallowing them, for as long they would be eaten in a meal, was enough to produce sensory specific satiety ${ }^{4}$. However, the decrease in pleasantness of taste of the chewed food was not as large as the decrease in pleasantness of taste of the eaten food. In this experiment also a significant reduction in the intensity of both the taste of the chewed and eaten food was observed. The authors conclude that olfactory stimulation 
together with food in the mouth is, at least partially, able to produce sensory specific satiety, without the presence of food in the gastrointestinal system. In a recent experiment we observed a short increase in feelings of satiety following oral fat stimulation (without food ingestion) in the postprandial state ${ }^{15}$. This short increase in rated satiety following MSF is probably the result of the cephalic response in the satiety cascade. We hypothesised that this short increase in rated satiety is mainly sensory in nature. Therefore we approached the issue by analyzing the possible difference in SSS between after a food is sham-fed and after it is eaten.

Sensory specific satiety appears to play a role when offering subjects a variety of foods that may be identical in composition, but differ in sensory properties; this increases food and energy intake ${ }^{35}$. Interestingly, in all of the experiments comparing ad libitum food intake of variety of foods to ad libitum food intake of a single food which have assessed subjective appetite sensations, changes in feelings of hunger and satiety do not differ between eating until satiated on a single course meal from eating until satiated on a multiple course meal; variety increased intake, while there was no diet effect on hunger ratings ${ }^{36-38}$.

Hence, appetite sensations and taste perception may mainly contribute to the complexity of sensory specific satiety, but to what extend and do they interact?

To investigate the sensory role in sensory specific satiety we made a distinction between oral exposure (in this experiment Modified Sham Feeding also referred to as 'chewed') and oral exposure plus gastrointestinal exposure (in this experiment eating). We studied sensory specific satiety and changes in the appetite profile as well as changes in taste perception in a two-course meal comparing Modified Sham Feeding to eating the meal.

\section{Subjects and Methods}

Subjects

Twenty-four subjects were recruited for this study (6 males and 18 females). The subjects were screened on health, medication, smoking and dieting parameters; they had to be normal weight and dietary unrestraint. The subjects had a mean \pm SD age of $23 \pm 6.9$ years, and had a BMI of $22.2 \pm$ 1.3. Their mean $\pm \mathrm{SD}$ restrained eating score on the Three Factor Eating Questionnaire of the female and male subjects was $3.3 \pm 3$ and $2.0 \pm 2.1$, respectively ${ }^{39}$. All subjects were healthy, not taking medication, nonsmoking and not dieting. All subjects gave written informed consent and the study was approved by the Maastricht University Ethics Committee.

\section{Study protocol}

Each test day the subjects came to the University for lunch at 13:00.

Subjects were instructed to eat nothing between breakfast and lunch and to drink only water. The subjects were offered two courses: a tomato soup and 
a salad. Both courses were prepared with commercially available products, according to a recipe we developed ourselves. The first course was $213 \mathrm{~g}$ of tomato soup, which contained $656.3 \mathrm{~kJ}, 2 \mathrm{~g}$ (5.2 energy\%) protein, $13 \mathrm{~g}(73.3$ energy $\%)$ fat, and $7 \mathrm{~g}(18.1$ energy\%) carbohydrates. The soup was served at a temperature of $65^{\circ} \mathrm{C}$. The second course was $230 \mathrm{~g}$ of salad $(100 \mathrm{~g}$ iceberg lettuce, $100 \mathrm{~g}$ cucumber and dressing), which contained $754.5 \mathrm{~kJ}, 1.8 \mathrm{~g}(4.1$ energy\%) protein, $18.2 \mathrm{~g}$ (89.3 energy\%) fat and $2.7 \mathrm{~g}$ (6.1 energy\%) carbohydrates.

The subjects were studied on three test days and they received, in random order, the water, Modified Sham Feeding (MSF), or meal condition.

Before and after the first bite and the last bite of each course of the lunch meal subjects were asked to fill in 100mm Visual Analogue Scales (VAS) on their feelings of hunger, fullness, appetite, satiety, thirst, prospective food consumption and desire to eat. At the first and the last bite of each course the subjects were also asked to fill in a $100 \mathrm{~mm}$ Visual Analogue Scales (VAS) on the actual pleasantness of taste, sweetness, saltiness, bitterness, sourness, creaminess, crispiness, intensity and richness in their mouth of each course (Figure 1). The scales were anchored from "not at all" on the left to "extremely" on the right. The separate rating scales performed at the start of the experiment, after chewing and after eating, were provided on separate sheets that were collected at the end of each part of the experiment.

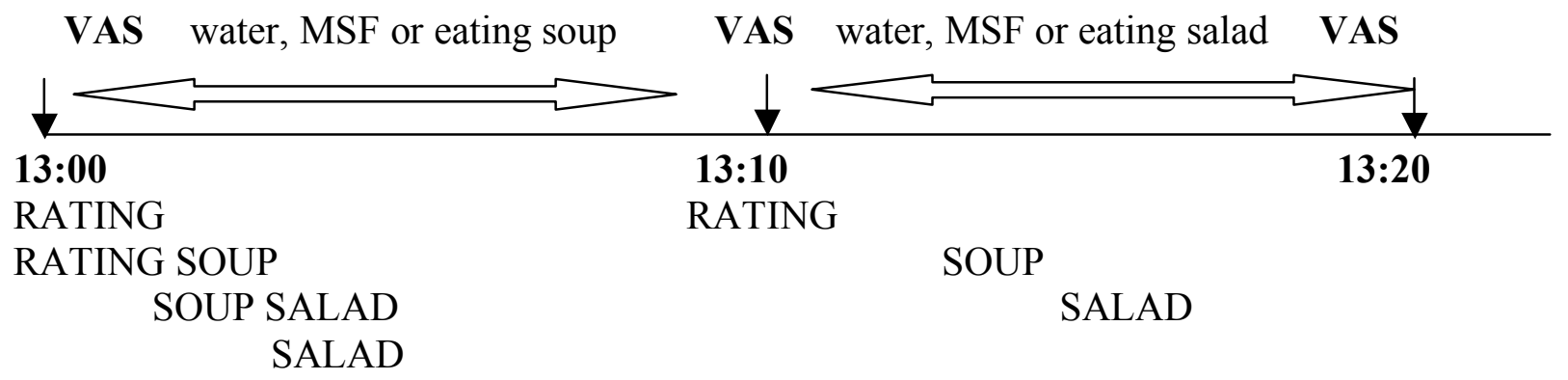

Figure 1. Time-scale of the experiment

Each course, independent of the condition was set to last $10 \mathrm{~min}$. The subjects were instructed to drink the same weight of water as the weight of the lunch over 20 minutes. In the MSF condition the subjects were presented with the test meal and were instructed to chew or hold the food in their mouth until the point at which they would normally swallow and then to expectorate the food into a plastic cup. They were continually instructed not to swallow any food. The subjects repeated the procedure until the meal had been fed completely. Weights of each meal were measured before and after MSF. 


\section{Statistical analysis}

VAS ratings were measured in millimetres from the left ("not at all") end of the scale. Changes in ratings were determined by subtracting the ratings at the end of a test meal from the ratings at the start of a test meal. All data are presented as means $\pm \mathrm{SD}$. To compare the change in scores on the VAS ANOVA repeated measures was used. Post hoc analysis was done with a Scheffe F-test or a Fisher PLSD test. Thus, the changes in ratings (last bite first bite) during the first course were compared between conditions, as well as the changes in ratings during the second course. Specifically, the change in pleasantness of taste over a course was compared between foods that were eaten vs. not eaten (water condition) or that were sham fed vs. not sham fed (water condition). Relationships of changes in pleasantness of taste with changes in hunger, satiety, and desire to eat were assessed; furthermore relationships between changes in pleasantness of taste with changes in perception were assessed using regression analyses. All of the statistical analyses were done with Statview SE Graphics ${ }^{\mathrm{TM}}$ software (version 4.5, Abacus Concepts Inc, Berkeley, CA, USA), and the criteria for significance was set at $\mathrm{p}<0.05$.

\section{Results}

The subjects rated the palatability of the soup and the salad, which were completely novel to them, $65 \pm 16 \mathrm{~mm}$ and $68 \pm 16 \mathrm{~mm}$, respectively. The weights of the MSF meal before and after chewing were compared; this yielded a mean $( \pm \mathrm{SEM})$ recovery rate of $101.8 \pm 8.7 \%$. The average number of spoons of soup was in both conditions (MSF and eating) $24 \pm 5$ spoons. The average number of bites of salad was in the MSF condition $26 \pm 8$ bites and in the eating condition $32 \pm 8$ bites $(\mathrm{p}<0.02$, unpaired Students t-test). In the eating condition, both with soup and salad foods eaten decreased significantly more in pleasantness of taste compared to the foods not eaten (Figure 2a,b). These findings indicate that both the soup and the salad produced sensory-specific satiety when they were eaten. 


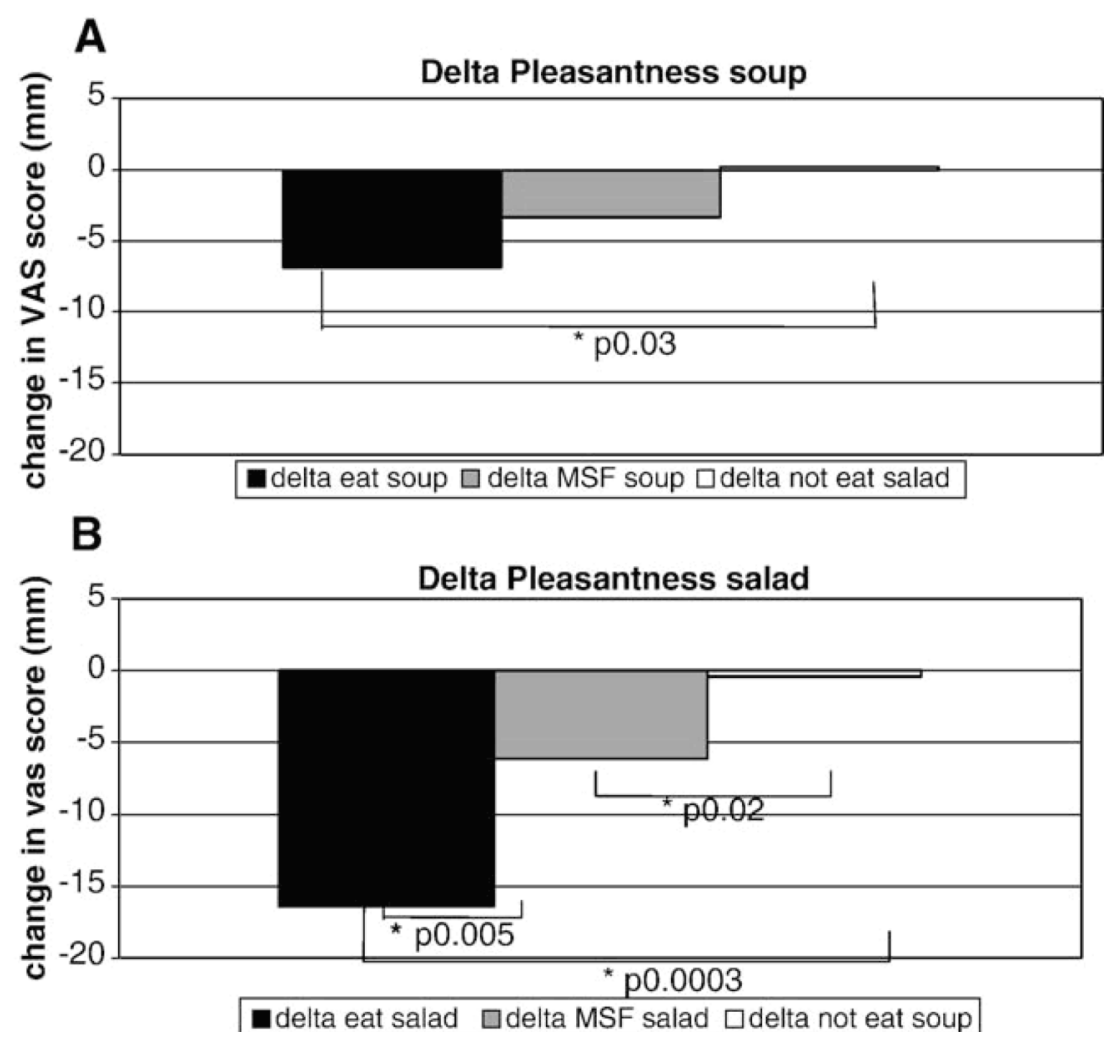

Figure 2. (A) Mean changes (last bite-first bite) in pleasantness of taste (mm) of the eaten MSF food (soup) compared to the uneaten food (salad). * Significantly different by paired one-tailed t-test. (B) Mean changes (last bite-first bite) in pleasantness of taste $(\mathrm{mm})$ of the eaten MSF food (salad) compared to the uneaten food (soup). * Significantly different by paired one-tailed t-test

In the MSF condition (when the soup was only "chewed") we did not observe a significant decrease in pleasantness of taste of the soup compared to the uneaten salad (Figure 1a). When the soup was eaten, a decrease in pleasantness of taste was significantly related to a decrease in hunger $(\mathrm{y}=$ $\left.0.55 \mathrm{x}+1.94 ; \mathrm{R}^{2}=0.20 ; \mathrm{p}=0.03\right)$, and desire to eat $\left(\mathrm{y}=0.71 \mathrm{x}-2.32 ; \mathrm{R}^{2}=\right.$ $0.25 ; \mathrm{p}=0.01)$, and an increase in satiety $\left(\mathrm{y}=-0.57 \mathrm{x}-2.37 ; \mathrm{R}^{2}=0.26\right.$; $\mathrm{p}=0.01$ ). Interestingly, in the MSF condition we observed SSS, i.e. a significant decrease in the pleasantness of taste of the salad compared to the uneaten soup (Figure 1b). Hence, the oral exposure to the salad was sufficient to induce sensory-specific satiety. The starting ratings of feelings of satiety, hunger and desire to eat are presented in Table 1. 
Table 1. Starting ratings of feelings of satiety, hunger and desire to eat

\begin{tabular}{|llll|}
\hline & $\begin{array}{l}\text { Hunger } \\
(\mathbf{m m})\end{array}$ & $\begin{array}{l}\text { Satiety } \\
\mathbf{( m m})\end{array}$ & $\begin{array}{l}\text { Desire to } \\
\text { eat }(\mathbf{m m})\end{array}$ \\
\hline Water & $31 \pm 20$ & $46 \pm 20$ & $28 \pm 17$ \\
MSF & $48 \pm 22$ & $33 \pm 20$ & $52 \pm 20$ \\
Eating & $52 \pm 22$ & $32 \pm 20$ & $54 \pm 23$ \\
\hline
\end{tabular}

The feelings of hunger decreased significantly more when the salad was eaten compared to the MSF salad $(\mathrm{p}=0.00023)$ or $(\mathrm{p}=0.00005)$ not eaten (Figure 3 ). The feelings of satiety increased significantly more when the salad was eaten compared to the MSF salad $(\mathrm{p}=0.04)$ or $(\mathrm{p}=0.0008)$ not eaten (Figure 4). We observed a significant decrease in desire to eat (Figure 5) even with the MSF salad, and also with the salad eaten compared to not eaten ( $\mathrm{p}=0.002$ and $\mathrm{p}=0.0001$, respectively).

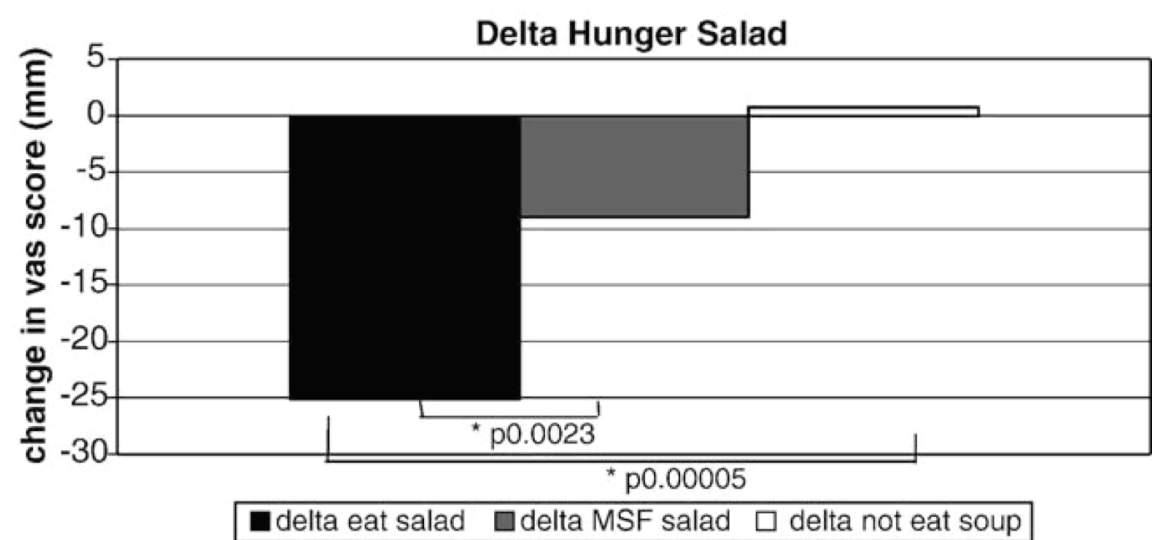

Figure 3. Mean changes in hunger ( $\mathrm{mm}$ ) of the eaten MSF food (salad) compared to the uneaten food (soup). *Significantly different by paired one-tailed t-test

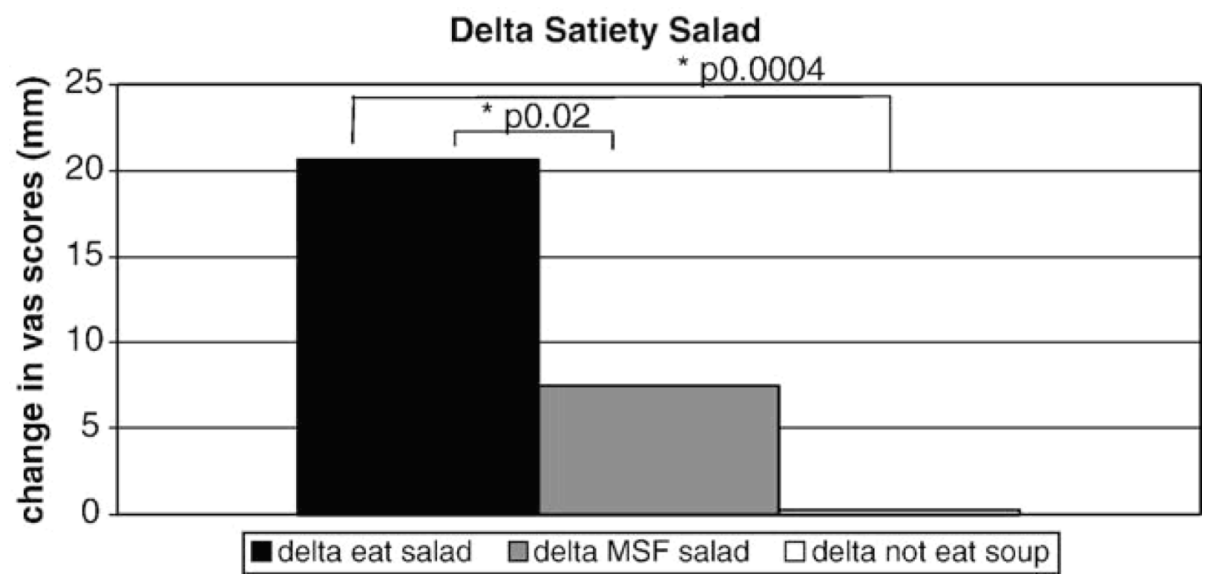

Figure 4. Mean changes in satiety (mm) of the eaten MSF food (soup). * Significantly different by paired one-tailed t-test 


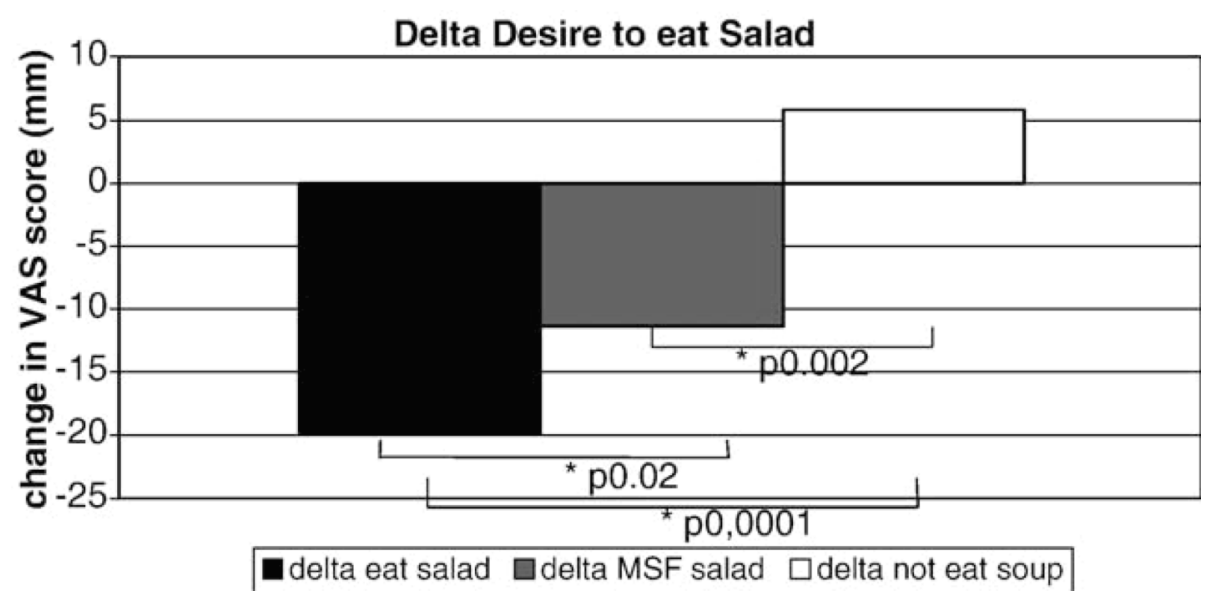

Figure 5. Mean changes in desire to eat $(\mathrm{mm})$ of the eaten MSF food (salad) compared to the uneaten food (soup). * Significantly different by paired one tailed t-test

When the salad was eaten we did not observe significant changes in any of the taste characteristics. After the MSF salad the perceived creaminess and intensity were significantly higher compared to the start of the salad $(\mathrm{p}=0.05$ and $\mathrm{p}=0.02$, respectively), indicating an increase in perception of taste.

Taken together, we observed sensory specific satiety when the soup was eaten, but not when it was merely chewed. We observed sensory specific satiety when the salad was eaten or chewed. When the salad was eaten we observed an increase satiety and a decrease in hunger and desire to eat. Chewing the salad resulted only in a decrease in desire to eat. Ratings of perceived taste characteristics, including intensity, at the end of eating the salad were not significantly different compared to the ratings at the start. However, perceived creaminess and intensity were rated significantly higher at the end of chewing the salad compared to the ratings at the start.

\section{Discussion}

The definition of sensory specific satiety (SSS) states that when a food is consumed to satiety, its perceived pleasantness of taste declines compared to that of foods that have not been consumed. It appeared that SSS also occurred when not every aspect of the original definition is present. Even when a food is eaten, but not to satiety SSS occurred, which was the case with the soup as well as with the salad. Moreover, even in the case of the MSF salad SSS also occurred. It is likely that exposure with the soup during MSF was insufficient to produce SSS. When eating a food that produced a larger satiating effect, SSS was also stronger, as was the case with the salad eaten.

A second remarkable factor in the development of SSS appears to be the desire to eat. The desire to eat was significantly decreased with the MSF salad and the salad eaten compared to not eaten, whereas no significant difference in the decrease in hunger and the increase in satiety with the MSF salad compared to not eaten was observed. Furthermore, the decrease in pleasantness of taste was related to a decrease in desire to eat when the soup 
was eaten. Here we see that a suppression of desire to eat independent of lack of satiation. This may be explained by the difference between homeostatic and non-homeostatic feeding. Homeostatic feeding relates to energy balance, mainly regulated through 'brainstem' satiety, while nonhomeostatic feeding relates to reward, represented in the cortex ${ }^{40,41}$. MSF may first increase the rewarding effect of food through oral perception implying pleasantness, which decreases transiently. Thus, with MSF SSS appears as a decrease in desire to eat, based upon a decrease in pleasantness of taste, with respect to a particular food, after sufficient exposure, e.g. 20 minutes, without the necessity of increased satiety. Foods high in protein, sweet carbohydrates and fatty acids, which have been suggested to have a relatively greater sensory-specific satiety, may influence the rewarding system in the cortex to a greater extent compared to foodstuffs characterised by a more 'bland' oral perception, and therefore have a greater SSS ${ }^{6,7,11-14}$.

The duration of the oral exposure to a food was important, because we observed sensory specific satiety only when the salad was chewed (duration 15-20min.) and not when the soup was chewed (duration $<5 \mathrm{~min}$ ). In a similar experiment Rolls and Rolls observed sensory specific satiety when foods were chewed for 5 minutes ${ }^{4}$. Hence, the period necessary to produce sensory specific satiety will probably be at least 5 minutes. Proposed theoretical explanations of SSS include habituation and sensory fatigue ${ }^{5,42}$. The definition of habituation in the field of biology states that habituation is a decrease in the strength of an organism's response to a consequence-less stimulus ${ }^{43}$. Habituation could therefore never be an explanation for SSS as tasting or ingestion of food is always followed by consequences. The few studies that have looked at the reasons why people stop eating have come up with inconsistent results. Obese subjects reported to stop eating 'when they thought they had eaten enough' or 'when all the food was gone' ${ }^{44}$. Normal weight subjects indicated they stopped eating when they felt full in two studies ${ }^{45,46}$.

Yet only women, both in the Zylan article and the Hetherington article, indicated that an important reason they stopped eating was because 'the food stopped tasting good' or 'they got tired of the eating that food'. The latter finding was hypothesised to be sensory fatigue. However, these women were not assessed on restrained eating behaviour. Next to this does the statement 'I got tired of the eating that food' not apply to the biological definition of fatigue, which is a decrease in the strength of an organism's response to repeated stimuli without physiological (muscle) tired-ness ${ }^{43}$. The difference in energy density of the soup and the salad does not explain the lack of SSS with the MSF soup as several studies have found no relationship between energy density on SSS ${ }^{47-49}$.

The intensity ratings stayed constant in most conditions, which means the subjects were able to distinguish between intensity and pleasantness. The effects we observed on pleasantness of taste, hunger, satiety and desire to eat were always larger after eating a food compared to after chewing a food. In 
the sensory specific satiety experiment performed by Rolls and Rolls, the decline in pleasantness was larger after eating compared to after chewing as well ${ }^{4}$. The larger effects following eating are most likely due to the fact that the small and large intestines are exposed to food, which may lead to additional satiety signals ${ }^{50-53}$. In those cases SSS is supported by increased post-ingestive satiety and subsequent decreases in hunger. Although the lunch was small in the present study, SSS still occurred. The evaluation of the foods was not confounded by "learned effects", since the foods used were completely novel to the subjects.

With the MSF salad satiety was inversely related to creaminess perception (data not shown). Perception of creaminess and intensity increased with the MSF salad. However a greater development of satiety was related to a decrease of perception of creaminess. It may well be that breaking down creaminess enhances satiety and sensory specific satiety. Observations by de Wijk et al. ${ }^{54}$ support this hypothesis. De Wijk et al. observed a positive relationship between perceived creaminess and bite size. In single bites of vanilla custard dessert, sensations of perceived creaminess were enhanced with bite size ${ }^{54}$. Creaminess has a hedonic value as it is generally well correlated with consumer preference ${ }^{55-57}$. Furthermore, is creaminess often used as a term to describe oral coating; the material that is retained in the oral cavity after swallowing ${ }^{58}$. Towards the end of the meal bite size as well as coating decreases ${ }^{59,60}$. A decrease in creaminess, describing oral coating, might be a conditioned stimulus for meal-termination.

Summarizing, SSS for a particular food during eating is supported by an increase in satiety, a decrease in hunger, a decrease in desire to eat, and expressed as a decrease in pleasantness of taste compared to uneaten foods. SSS during mere exposure without eating is supported by just a decrease in desire to eat and expressed as a decrease in pleasantness of taste compared to foods not being exposed to. In conclusion SSS as reduces pleasantness of taste is primarily expressed as reduced desire to eat.

\section{Acknowledgements}

We thank Chantalle Moors for her contributions to the study. 


\section{References}

1. Rolls BJ, Rolls ET, Rowe EA, Sweeney K. Sensory specific satiety in man. Physiol Behav 1981;27(1):137-42.

2. Rolls BJ, Van Duijvenvoorde PM, Rolls ET. Pleasantness changes and food intake in a varied four-course meal. Appetite 1984;5(4):337-48.

3. Rolls BJ, Rowe EA, Rolls ET, Kingston B, Megson A, Gunary R. Variety in a meal enhances food intake in man. Physiol Behav 1981;26(2):215-21.

4. Rolls ET, Rolls JH. Olfactory sensory-specific satiety in humans. Physiol Behav 1997;61(3):461-73.

5. Hetherington MM. Sensory-specific satiety and its importance in meal termination. Neurosci Biobehav Rev 1996;20(1):113-7.

6. Johnson J, Vickers Z. Factors influencing sensory-specific satiety. Appetite 1992;19(1):15-31.

7. Johnson J, Vickers Z. Effects of flavor and macronutrient composition of food servings on liking, hunger and subsequent intake. Appetite 1993;21(1):25-39.

8. Miller DL, Bell EA, Pelkman CL, Peters JC, Rolls BJ. Effects of dietary fat, nutrition labels, and repeated consumption on sensory-specific satiety. Physiol Behav 2000;71(1-2):153-8.

9. Rolls BJ, Fedoroff IC, Guthrie JF, Laster LJ. Foods with different satiating effects in humans. Appetite 1990;15(2):115-26.

10. Westerterp-Plantenga MS, MJ IJ, Wijckmans-Duijsens NE. The role of macronutrient selection in determining patterns of food intake in obese and non-obese women. Eur J Clin Nutr 1996;50(9):580-91.

11. de Graaf C, Schreurs A, Blauw YH. Short-term effects of different amounts of sweet and nonsweet carbohydrates on satiety and energy intake. Physiol Behav 1993;54(5):833-43.

12. Kamphuis MM, Westerterp-Plantenga MS, Saris WH. Fat-specific satiety in humans for fat high in linoleic acid vs fat high in oleic acid. Eur J Clin Nutr 2001;55(6):499-508.

13. Vandewater K, Vickers Z. Higher-protein foods produce greater sensoryspecific satiety. Physiol Behav 1996;59(3):579-83.

14. Vickers Z, Holton E, Wang J. Effect of yoghurt sweetness on sensoryspecific satiety. J Sensory Stud 1998;13:377-88.

15. Smeets AJ, Westerterp-Plantenga MS. Satiety and substrate mobilization after oral fat stimulation. Br J Nutr 2006;95(4):795-801.

16. Heath RB, Jones R, Frayn KN, Robertson MD. Vagal stimulation exaggerates the inhibitory ghrelin response to oral fat in humans. J Endocrinol 2004;180(2):273-81.

17. Jackson KG, Robertson MD, Deane LO, Fielding BA, Frayn KN, Williams $\mathrm{CM}$. The effect of modified sham-feeding meals of varying fat content on postprandial triacylglycerol, insulin and glucose response. Proc Nutr Soc 2000;59:14A. 
18. Jackson KG, Robertson MD, Fielding BA, Frayn KN, Williams CM. Second meal effects: modified sham feeding does not provoke the release of stored triacylglycerol from a previous high-fat meal. Br J Nutr 2001;85(2):149-56.

19. Mattes RD. Oral fat exposure alters postprandial lipid metabolism in humans. Am J Clin Nutr 1996;63(6):911-17.

20. Mattes RD. Oral exposure to butter, but not fat replacers elevates postprandial triacylglycerol concentration in humans. J Nutr 2001;131(5):1491-96.

21. Mattes RD. The taste of fat elevates postprandial triacylglycerol. Physiol Behav 2001;74(3):343-48.

22. Mattes RD. Oral fat exposure increases the first phase triacylglycerol concentration due to release of stored lipid in humans. J Nutr 2002;132(12):3656-62.

23. Robertson MD, Jackson KG, Fielding BA, Williams CM, Frayn KN. Modified sham feeding of a modest-fat meal suppresses plasma nonesterified fatty acids. Proc Nutr Soc 1999;59:123A.

24. Robertson MD, Jackson KG, Williams CM, Fielding BA, Frayn KN. Prolonged effects of modified sham feeding on energy substrate mobilization. Am J Clin Nutr 2001;73(1):111-7.

25. Robertson MD, Mason AO, Frayn KN. Oro-sensory stimulation prior to fat ingestion impairs postprandial fat tolerance. Int J Obesity 2000;24:S55.

26. Robertson MD, Mason AO, Frayn KN. Timing of vagal stimulation affects postprandial lipid metabolism in humans. Am J Clin Nutr 2002;76(1):71-7.

27. Cecil JE, Francis J, Read NW. Relative contributions of intestinal, gastric, oro-sensory influences and information to changes in appetite induced by the same liquid meal. Appetite 1998;31(3):377-90.

28. Cecil JE, Francis J, Read NW. Comparison of the effects of a high-fat and high-carbohydrate soup delivered orally and intragastrically on gastric emptying, appetite, and eating behaviour. Physiol Behav 1999;67(2):299306.

29. French SJ, Cecil JE. Oral, gastric and intestinal influences on human feeding. Physiol Behav 2001;74(4-5):729-34.

30. Lavin JH, French SJ, Ruxton CH, Read NW. An investigation of the role of oro-sensory stimulation in sugar satiety? Int J Obes Relat Metab Disord 2002;26(3):384-8.

31. Rolls ET. Taste, olfactory, and food texture processing in the brain, and the control of food intake. Physiol Behav 2005;85(1):45-56.

32. Baylis LL, Rolls ET, Baylis GC. Afferent connections of the caudolateral orbitofrontal cortex taste area of the primate. Neuroscience 1995;64(3):80112.

33. Ongur D, Price JL. The organization of networks within the orbital and medial prefrontal cortex of rats, monkeys and humans. Cereb Cortex 2000;10(3):206-19. 
34. Rolls ET, Rolls BJ, Rowe EA. Sensory-specific and motivation-specific satiety for the sight and taste of food and water in man. Physiol Behav 1983;30(2):185-92.

35. Sorensen LB, Moller P, Flint A, Martens M, Raben A. Effect of sensory perception of foods on appetite and food intake: a review of studies on humans. Int J Obes Relat Metab Disord 2003;27(10):1152-66.

36. Wisniewski L, Epstein LH, Caggiula AR. Effect of food change on consumption, hedonics, and salivation. Physiol Behav 1992;52(1):21-6.

37. Porrini M, Santangelo A, Crovetti R, Riso P, Testolin G, Blundell JE. Weight, protein, fat, and timing of preloads affect food intake. Physiol Behav 1997;62(3):563-70.

38. Stubbs RJ, Johnstone AM, Mazlan N, Mbaiwa SE, Ferris S. Effect of altering the variety of sensorially distinct foods, of the same macronutrient content, on food intake and body weight in men. Eur J Clin Nutr 2001;55(1):19-28.

39. Stunkard AJ, Messick S. The three-factor eating questionnaire to measure dietary restraint, disinhibition and hunger. J Psychosom Res 1985;29(1):7183.

40. Berthoud HR. Multiple neural systems controlling food intake and body weight. Neurosci Biobehav Rev 2002;26(4):393-428.

41. Berthoud HR. Mind versus metabolism in the control of food intake and energy balance. Physiol Behav 2004;81(5):781-93.

42. Hetherington M, Rolls BJ, Burley VJ. The time course of sensory-specific satiety. Appetite 1989;12(1):57-68.

43. van Rhijn JG, Westerterp-Plantenga MS. Ethologie: Veroorzaking, ontwikkeling, functie en evolutie van gedrag. Open Universiteit, Heerlen: Wolters-Noordhoff; 1989.

44. Tuomisto T, Tuomisto MT, Hetherington M, Lappalainen R. Reasons for initiation and cessation of eating in obese men and women and the affective consequences of eating in everyday situations. Appetite 1998;30(2):211-22.

45. Mook DG, Votaw MC. How important is hedonism? Reasons given by college students for ending a meal. Appetite 1992;18(1):69-75.

46. Zylan KD. Gender differences in the reasons given for meal termination. Appetite 1996;26(1):37-44.

47. Bell EA, Roe LS, Rolls BJ. Sensory-specific satiety is affected more by volume than by energy content of a liquid food. Physiol Behav 2003;78(45):593-600.

48. Norton GN, Anderson AS, Hetherington MM. Volume and variety: Relative effects on food intake. Physiol Behav 2006.

49. Rolls BJ, Hetherington M, Burley VJ. Sensory stimulation and energy density in the development of satiety. Physiol Behav 1988;44(6):727-33.

50. Dockray G. Gut endocrine secretions and their relevance to satiety. Curr Opin Pharmacol 2004;4(6):557-60.

51. Murphy KG, Bloom SR. Gut hormones in the control of appetite. Exp Physiol 2004;89(5):507-16. 
52. Orr J, Davy B. Dietary influences on peripheral hormones regulating energy intake: potential applications for weight management. J Am Diet Assoc 2005;105(7):1115-24.

53. Strader AD, Woods SC. Gastrointestinal hormones and food intake. Gastroenterology 2005;128(1):175-91.

54. de Wijk RA, Engelen, L., Prinz, J.F., Weenen, H. . The influence of bite size and multiple bites on oral texture sensations. Submitted for publication.

55. Drewnowski A, Shrager EE, Lipsky C, Stellar E, Greenwood MR. Sugar and fat: sensory and hedonic evaluation of liquid and solid foods. Physiol Behav 1989;45(1):177-83.

56. Elmore JR, Heymann H, Johnson J, Hewett JE. Preference mapping:

Relating acceptance of "creaminess" to a descriptive map of a semi-solid. Food Quality and Preference 1999;10:465-475.

57. Ward CDW, Stampanoni Koeferli C, Piccinali Schwegler P, Schaeppi D, Plemmons LE. European strawberry yoghurt analysis with a case study on acceptance drivers for children in Spain using principal component analysis and partial least squares regression. Food Quality \& Preference 1999;10:387-400.

58. Palmer JB, Hiiemae KM, Liu J. Tongue-jaw linkages in human feeding: a preliminary videofluorographic study. Arch Oral Biol 1997;42(6):429-41.

59. Malone ME, Appelqvist IAM, Norton IT. Oral behavior of food hydrocolloids and emulsions. Part 1. Lubrication and deposition considerations. Food Hydrocolloids 2003;17:763-73.

60. Westerterp-Plantenga MS. Eating behavior in humans, characterized by cumulative food intake curves--a review. Neurosci Biobehav Rev 2000;24(2):239-48. 

4

The second meal effect of oral fat perception compared to fat ingestion on energy expenditure, hormones and appetite profile

Astrid J. Smeets, Manuela P. Lejeune and Margriet S. Westerterp-Plantenga Submitted for publication 


\begin{abstract}
Previously, we have shown that satiety and metabolites increased for a short period after high-fat modified sham feeding. The aim of the study was to assess possible metabolic effects due to oral stimulation with a high-fat sham fed 'meal', in comparison to a high-fat fed meal and to water, in the postprandial state. Fourteen healthy women aged $18-40 \mathrm{y}$, BMI $22.5 \pm 3 \mathrm{~kg} / \mathrm{m}^{2}$, were fed in energy balance during 4 days with a carbohydrate/protein/fat of $50 / 15 / 35$ energy-\% menu. On the fourth day, the subjects were given 1 out of 3 test lunches, five hours after a high-fat breakfast, in random order: a high-fat Modified Sham Fed (MSF) lunch, water (W) or the same lunch to be eaten $(\mathrm{E})$, during their $36 \mathrm{~h}$ stay in the respiration chamber, where substrate oxidation, 24-h energy expenditure (EE), and appetite profile were measured. Oral fat stimulation by MSF increased $\mathrm{EE}$ (W;MSF;E: $6.3 \pm 0.8 \mathrm{~kJ} / \mathrm{min} ; 6.9 \pm 1.0 \mathrm{~kJ} / \mathrm{min} ; 6.8 \pm 0.7 \mathrm{~kJ} / \mathrm{min}, \mathrm{p}<0.04$ ) for one hour, increased plasma insulin concentrations (W;MSF;E: 10.0 $3.4 \mathrm{U} / 1$; $13.2 \pm 4.0 \mathrm{U} / 1 ; 22.3 \pm 3.3 \mathrm{U} / 1, \mathrm{p}<0.05)$ at $\mathrm{t}=15$, attenuated the changes in plasma non-esterified fatty acid concentrations ( $\mathrm{t}=15$ : W;MSF;E: $432 \pm 108 \mu \mathrm{mol} / \mathrm{l}$; $418 \pm 146 \mu \mathrm{mol} / 1 ; \quad 282 \pm 72 \mu \mathrm{mol} / 1, \quad \mathrm{p}<0.01), \quad$ plasma triacylglycerol concentrations $\quad(\mathrm{t}=60: \quad$ W;MSF;E: $\quad 1092 \pm 548 \mu \mathrm{mol} / 1 ; \quad 1116 \pm 493 \mu \mathrm{mol} / \mathrm{l}$; $1350 \pm 352 \mu \mathrm{mol} / 1, \quad \mathrm{p}<0.05)$ and plasma glycerol concentrations $(\mathrm{t}=60$ : W;MSF;E: $87 \pm 29 \mu \mathrm{mol} / \mathrm{l} ; \quad 74 \pm 34 \mu \mathrm{mol} / \mathrm{l} ; \quad 67 \pm 18 \mu \mathrm{mol} / \mathrm{l}, \mathrm{p}<0.05)$. Over a longer period of time, oral fat stimulation had no effects on substrate oxidation, diet induced thermogenesis, or total EE. In addition to the previously observed metabolic effects of oral stimulation with fat, EE is stimulated up to 1 hour after the MSF meal.
\end{abstract}




\section{Introduction}

Obesity is associated with increased risk for hypertension, dyslipidemia, type 2 diabetes, coronary heart disease, stroke, and certain cancers ${ }^{1}$. The prevalence of obesity is still increasing. To reverse this trend, a sustained and effective treatment strategy is needed. Sustaining satiety, while decreasing the amount of energy ingested, is one of the targets in an effective obesity treatment. In a state of energy balance, energy intake meets energy expenditure. Meal size and meal frequency determine total energy intake. Sensory satiety plays a role in meal termination and therefore also in meals size 2. Metabolic satiety, characterized by substrate use and availability, affects the inter-meal interval and therefore meal-frequency. The inter-meal interval is determined by the metabolic satiety, and related to for instance the size and macronutrient composition, of the preceding meal 3. However the question remains whether sensory satiety has an effect on metabolic satiety, and if so the magnitude of this effect.

In a recent study we have observed a short increase in concentrations of metabolites and satiety after oral stimulation with high-fat foods. Oral stimulation (with fat) experiments by other researchers using the Modified Sham Feeding (MSF) technique, have shown effects on metabolites, hormones and satiety as well ${ }^{4-10} 11-15$. Oral stimulation seems to increase the availability of oxidizable metabolites, without receiving any exogenous nutrients. Whether these oxidizable metabolites are oxidized is not clear. Stable isotope techniques are useful tools to investigate the origin of the oxidizable metabolites. In this study we have used deuterium labeled palmitic acid, added to a high fat breakfast, to investigate the effect of sensory stimulation with fat on substrate utilization.

Until now few studies have examined the effects of oral stimulation on thermogenesis ${ }^{8,16-19}$. In addition to energy expenditure measurements, plasma glucose and insulin concentrations, and the appetite profile were determined in most studies. In the current study we investigated possible effects of sensory satiety on metabolic satiety, i.e. substrate oxidation and energy expenditure, in energy balance, in a highly controlled environment.

\section{Subjects and Methods}

Subjects

Sixteen women were initially selected based on age, height, weight, BMI and restrained eating score (F1 score) on the Three Factor Eating Questionnaire (TFEQ) ${ }^{20}$, and two women dropped-out because of personal reasons. Eating behavior was assessed using a validated Dutch translation of the TFEQ. Cognitive restrained and unrestrained eating behavior (Factor 1), emotional eating and disinhibition (Factor 2), and the subjective feeling of hunger (Factor 3) were scored. Fourteen females (BMI: 23.2 \pm 2.7 , age: 24.4 \pm 7.1 yrs, TFEQ F1: $4 \pm 3$, body fat $\%$ : $27.4 \pm 6.9$ ) were studied on three 
occasions. All subjects were healthy, not taking medication, non-smoking and not dieting. Subjects were excluded from participation if their factor 1 score on the TFEQ was $>9$. All subjects gave written informed consent and the study was approved by the Maastricht University Ethics Committee.

\section{Study protocol}

The study had a randomized crossover design and 3 experimental conditions. Subjects underwent three $36 \mathrm{~h}$ sessions in energy balance in a respiration chamber for measurements of energy expenditure and substrate oxidation. The three $36 \mathrm{~h}$ sessions were conducted 4 weeks apart to ensure that each subject was in the same phase of her menstrual cycle. Three days prior to each $36 \mathrm{~h}$ session, subjects were provided with a diet in energy balance, and with the same macronutrient composition $(\%$ energy from carbohydrate/protein $/$ fat $=50 / 35 / 15$ ), at home.

The subjects entered the respiration chamber at 18:00h and subsequently received the dinner of the third day prior to the $36 \mathrm{~h}$ session. Subjects were instructed to go to bed around $11 \mathrm{pm}$. After an overnight stay in the respiration chamber the test day started the following morning at 8:00h. On each test day subjects consumed breakfast at 8:00h, which consisted of 2 croissants with butter and a cup of chocolate milk (\% energy from carbohydrate/protein/fat $=40 / 20 / 40)$. At 12:00h $(\mathrm{t}=0)$ the subjects were given 1 of 3 test lunches in random order: a high-fat lunch, which consisted of a soup and a salad (\% energy from carbohydrate/protein/fat $=25 / 7 / 68)$, the same lunch as MSF, or water. Dinner consisted of pasta with a vegetarian tomato-sauce, orange jus and yogurt with fruits, and was served at 16:30h to make the protocol more convenient for the subjects. Twentyfour-hour energy intake was compensated at dinner to keep the subjects in energy balance over $24 \mathrm{~h}$.

\section{Energy intake}

During each experimental session subjects were fed in energy balance. The energy content of the diet that the subjects consumed at home was based on Basal Metabolic Rate (BMR) calculated with the equation of HarrisBenedict ${ }^{21}$, and multiplied by an activity index of $1.7^{22}$. In the respiration chamber energy requirements were calculated based on Sleeping Metabolic Rate (SMR) measured during the first night and multiplied by an activity index of $1.5^{22}$. Energy intake in the water and MSF lunch condition was divided over the meals as $30 \%$ for breakfast $(08: 00 \mathrm{~h})$, and $70 \%$ for dinner (16:30h). In the eaten lunch condition energy intake was divided over the meals as $30 \%$ for breakfast $(08: 00 \mathrm{~h}), 20 \%$ for lunch $(12: 00 \mathrm{~h})$, and $50 \%$ for dinner (16:30h). The macronutrient composition of each 24 hour diet was $15 \%$ energy from protein, $35 \%$ energy from fat, and 50\% energy from carbohydrates. 
$M S F$

In the MSF condition the subjects were presented with the test lunch and were instructed to chew the food until the point at which they would normally swallow and then to expectorate the food into a plastic bowl. They were continually instructed not to swallow any food. The subjects repeated the procedure until the meal had been fed completely $(15-20 \mathrm{~min})$. Wet and freeze dried weights of each meal after MSF and a duplicate meal (which was not used for MSF) were measured.

\section{Blood collection and analytical methods}

One hour prior to the lunch, a Teflon catheter was placed in the antecubital vein for blood sampling. Blood samples were collected $60(\mathrm{t}=-1)$ and $5(\mathrm{t}=$ $0)$ min. before and $15(t=1), 30(t=2), 60(t=3)$, and $120(t=4)$ min. after the lunch in tubes containing EDTA to prevent clotting. Plasma was obtained by centrifugation $\left(4^{\circ} \mathrm{C}, 3000 \mathrm{rpm}, 10 \mathrm{~min}\right)$ and stored at $-20^{\circ} \mathrm{C}$ until analysis of glucose by a hexokinase method (ABX Diagnostics), insulin (RIA kit, Linco Research), non-esterified fatty acids (NEFA C-kit Wako 994-75409, Sopar Biochemicals), triacylglycerol (GPO-trinder 337, Sigma) and glycerol by a glycerolkinase-lipase method (Boehringer, Mannheim, Germany) using a semi-automated centrifugal spectrophometer (Cobas Fara, Roche Diagnostics). Plasma concentrations of active ghrelin were measured by RIA (Linco Research Inc., St. Charles, Missouri, USA). Plasma active ghrelin concentrations were measured in acidified plasma with $50 \mu \mathrm{l}$ of $1 \mathrm{~N}$ $\mathrm{HCl}$ and addition of $10 \mu \mathrm{l}$ of Phenylmethylsulfonyl fluoride (PMSF) per 1 $\mathrm{ml}$ of plasma. Sensitivity of the RIA assay was $7.8 \mathrm{pg} / \mathrm{ml}$ and the difference between duplicate results of a sample was $<10 \% \mathrm{CV}$. The specificity for human ghrelin was $100 \%$. Plasma active GLP-1 samples were analyzed using ELISA (EGLP-35K; Linco Research Inc., St. Charles, Missouri, USA). Plasma active GLP-1 concentrations were measured in plasma after addition of $10 \mu \mathrm{LPP}-\mathrm{IV}$ inhibitor per milliliter of blood. Sensitivity of the ELISA assay was $2 \mathrm{pM}$, and the difference between duplicate results of a sample was $<10 \% \mathrm{CV}$. The specificity for active GLP-1 was $100 \%$. Plasma leptin concentrations were measured using the human leptin RIA-kit (Linco Research Inc., St. Charles, Missouri, USA). Sensitivity of the leptin RIA assay was $0.05 \mathrm{ng} / \mathrm{ml}$ and the difference between duplicate results of a sample was $<10 \% \mathrm{CV}$. The specificity for human leptin was $100 \%$.

\section{Appetite profile}

Appetite profile was measured using anchored $100-\mathrm{mm}$ visual analogue scales (VAS). During each respiration chamber session these questionnaires were completed before and after every meal on feelings of hunger, fullness, appetite, satiety, thirst, prospective food consumption, and desire to eat. The scale was anchored from "not at all" on the left to "extremely" on the right. During each respiration chamber session these questionnaires were 
completed before $(7: 50 \mathrm{~h})$ and after $(8: 20 \mathrm{~h})$ breakfast, at 10:45, before $(12: 00 \mathrm{~h})$ and after $(12: 20 \mathrm{~h})$ lunch, at $13: 15 \mathrm{~h}$, at $14: 15 \mathrm{~h}$, before $(16: 30 \mathrm{~h})$ and after (17:00h) dinner, and on the next morning (8:00h).

\section{Body composition}

Body composition was determined by underwater weighing in the fasted state. Body mass in air and underwater was determined on a digital balance, accurate to $0.01 \mathrm{~kg}$ (Sauter type E1200). Lung volume was measured simultaneously with the helium dilution technique using a spirometer (Volugraph 2000, Mijnhardt, The Netherlands). Body density was used to calculate body fat according to the two-compartment model with the equation of $\mathrm{Siri}^{23}$.

\section{Indirect calorimetry}

Oxygen consumption and carbon dioxide production were measured in the respiration chamber ${ }^{24}$. The respiration chamber is a $14-\mathrm{m} 3$ room furnished with a bed, chair, computer, television, radio cassette player, telephone, intercom, sink, and toilet. The room was ventilated with fresh air at a rate of $70-80 \mathrm{~L} / \mathrm{min}$. The ventilation rate was measured with a dry gas meter (type 4; Schlumberger, Dordrecht, Netherlands). The concentrations of oxygen and carbon dioxide were measured with the use of an infrared carbon dioxide analyzer (Uras 3G; Hartmann and Braun, Frankfurt, Germany) and 2 paramagnetic oxygen analyzers: Magnos 6G (Hartmann and Braun) and type OA184A (Servomex, Crowborough, United Kingdom). During each 15-min period, 6 samples of outgoing air for each chamber, 1 sample of fresh air, zero gas, and calibration gas were measured. The gas samples to be measured were selected by a computer that also stored and processed the data $^{24}$.

\section{Energy expenditure and substrate oxidation}

Twenty-four-hour energy expenditure consists of SMR, DIT, and activityinduced energy expenditure (AEE); 24-h energy expenditure and 24-h respiratory quotient (RQ) were measured from 0800 on day 4 to 0800 on day 5. Activity was monitored with a radar system based on the Doppler principle. SMR was defined as the lowest mean energy expenditure measured over 3 consecutive hours between 0000 and 0700. DIT was calculated by plotting energy expenditure against radar output; both were averaged over 30 -min periods. The intercept of the regression line at the lowest radar output represents the energy expenditure in the inactive state (resting metabolic rate; RMR), which consists of SMR and DIT ${ }^{25}$. DIT was determined by subtracting SMR from RMR. AEE was determined by subtracting SMR and DIT from 24-h energy expenditure. Carbohydrate, fat, and protein oxidation were calculated from the measurements of oxygen consumption, carbon dioxide production, and urinary nitrogen excretion by using the formula of Brouwer ${ }^{26}$. Urine samples $(24 \mathrm{~h})$ were collected from 
the second void on day 4 until the first void on day 5. Samples were collected in containers with $10 \mathrm{ml} \mathrm{H} 2 \mathrm{SO} 4$ to prevent nitrogen loss through evaporation. Volume and nitrogen concentration were measured, the latter with a nitrogen analyzer (CHN-O-Rapid; Heraeus, Hanau, Germany).

\section{Dietary fat oxidation}

Labelled fatty acids were obtained from Cambridge Isotope, Andover, MA. Deuterium labeled palmitic acid: d31-palmitic acid (DLM-215) was 98 atom $\%$. Deuterium labeled palmitic acid $(20 \mathrm{mg} / \mathrm{kg}$ bodyweight) was added to chocolate milk, which was heated up to $65^{\circ} \mathrm{C}$, and consumed by the subjects at breakfast. Urine was collected every 2 hours after breakfast up to 20:00h. Recovery of the stable isotopes was calculated at 2, 4, 6, 8, 10, 12 and $24 \mathrm{~h}$ post-dose according to the method described by Votruba ${ }^{27}$. Cumulative recovery of deuterium from labeled palmitic acid (\%) over $24 \mathrm{~h}$ in the urine was used as a measure of dietary fat oxidation.

\section{Statistical analysis}

Data are presented as means \pm standard deviations (SD), unless otherwise indicated. A repeated-measures ANOVA or ANCOVA, with value of parameter at $\mathrm{t}=0$ as covariate, was carried out to determine possible differences between the conditions. Post-hoc comparisons were made with the Fisher PLSD test. Significance was defined as $p<0.05$. All of the statistical analyses were executed with Statview SE Graphics ${ }^{\mathrm{TM}}$ software (version 4.5, Abacus Concepts Inc, Berkeley, CA, USA).

\section{Results}

The results on 24h energy expenditure are shown in Table 1.

There were no differences between the conditions in total energy expenditure, $24 \mathrm{~h}$ diet induced thermogenesis, sleeping metabolic rate, activity-induced energy expenditure, and $24 \mathrm{~h}$ non-protein respiratory quotient.

In all conditions the subjects were in energy balance (energy intake minus energy expenditure was: W; MSF; E; $0.83 \pm 0.8 \mathrm{MJ} /$ day; $0.74 \pm 0.8 \mathrm{MJ} /$ day; $0.73 \pm 0.7 \mathrm{MJ} /$ day; $\mathrm{NS}$ ).

The continuous measurement of energy expenditure from the moment the subjects entered the respiration chamber until the test-lunch revealed no differences between the three conditions. The subjects were thus in an identical metabolic state before lunch. During the 60 minutes prior to the lunch, energy expenditure was equal in all conditions (Table 1). However, energy expenditure during the first hour after the eaten and MSF lunch was significantly higher compared to after water (W; MSF; E; $6.3 \pm 0.8 \mathrm{~kJ} / \mathrm{min}$; $6.9 \pm 1.0 \mathrm{~kJ} / \mathrm{min} ; 6.8 \pm 0.7 \mathrm{~kJ} / \mathrm{min}$, ANOVA, $\mathrm{p}<0.04)$. This difference in energy expenditure between conditions was no longer present in the second hour after MSF and eaten lunch. 
Twenty-four hour fat oxidation (W; MSF; E; 53g $\pm 35 ; 50 \mathrm{~g} \pm 25 ; 65 \mathrm{~g} \pm 29$ ), and 24-hour carbohydrate oxidation (W; MSF; E; 293 $\pm 73 \mathrm{~g} ; 289 \pm 73 \mathrm{~g} ; 252 \pm 60 \mathrm{~g}$ ) were not significantly different between conditions.

Table 1. Total energy expenditure, components of energy expenditure and non-protein RQ during the three conditions (Means \pm SD)

\begin{tabular}{|c|c|c|c|}
\hline & Water & MSF & Eat \\
\hline 24h npRQ ${ }^{1}$ & $0.92 \pm 0.05$ & $0.92 \pm 0.04$ & $0.89 \pm 0.05$ \\
\hline $\mathrm{TEE}^{2}(\mathrm{MJ} / \mathrm{day})$ & $8.44 \pm 1.03$ & $8.53 \pm 0.88$ & $8.45 \pm 0.67$ \\
\hline DIT $^{3}$ (MJ/day) & $0.83 \pm 0.27$ & $0.82 \pm 0.20$ & $0.90 \pm 0.28$ \\
\hline DIT (\%EI) & $9.01 \pm 2.91$ & $8.94 \pm 2.38$ & $9.78 \pm 3.22$ \\
\hline SMR $^{4}$ (MJ/day) & $6.07 \pm 0.73$ & $6.09 \pm 0.51$ & $6.05 \pm 0.44$ \\
\hline $\mathrm{AEE}^{5}(\mathrm{MJ} / \mathrm{day})$ & $1.54 \pm 0.58$ & $1.68 \pm 0.47$ & $1.50 \pm 0.39$ \\
\hline $\mathrm{EE}^{6}(\mathrm{~kJ} / \mathrm{min})-60-0 \mathrm{~min}$ & $6.13 \pm 0.67$ & $6.47 \pm 0.82$ & $6.42 \pm 0.72$ \\
\hline EE $(\mathrm{kJ} / \mathrm{min}) 0-60 \mathrm{~min}$ & $6.31 \pm 0.77^{*}$ & $6.86 \pm 0.97$ & $6.78 \pm 0.73$ \\
\hline EE $(\mathrm{kJ} / \mathrm{min}) 60-120 \mathrm{~min}$ & $5.94 \pm 0.80$ & $5.91 \pm 0.70$ & $6.04 \pm 0.60$ \\
\hline
\end{tabular}

${ }^{1}$ Non-protein respiratory quotient

${ }^{2}$ Total energy expenditure over $24 \mathrm{~h}$

${ }^{3}$ Diet induced thermogenesis

${ }^{4}$ Sleeping metabolic rate

${ }^{5}$ Activity-induced energy expenditure

${ }^{6}$ Mean energy expenditure during one hour before the lunch (-60 - $\left.0 \mathrm{~min}\right)$, the first hour after the lunch $(0-60 \mathrm{~min})$, and during the second hour after the lunch $(60-120 \mathrm{~min})$.* $^{*}$ after eating (E) or modified sham feeding (S) significantly different from after water (W), $\mathrm{P}<0.05$ by repeated measures ANOVA

The percentage deuterium labeled palmitic acid recovered over $24 \mathrm{~h}$ was not different between the three conditions (W; MSF; E; 22.3\% $\pm 5.1 ; 22.4 \% \pm 5.1$; $19.8 \% \pm 4.6$, Figure 1).

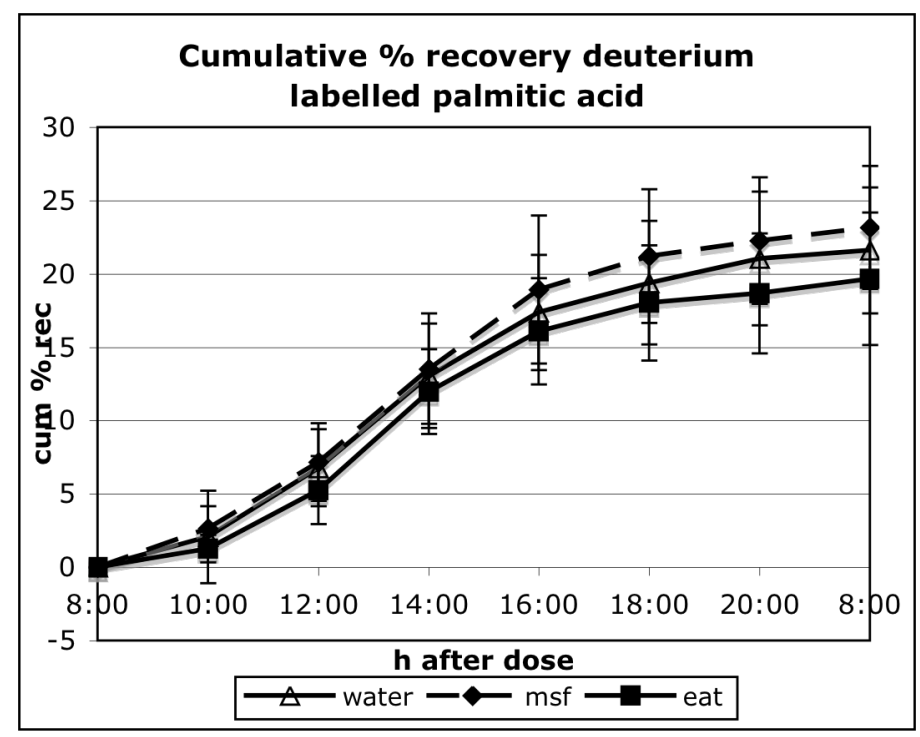

Figure 1. Mean cumulative \% recovery of deuterium. Eaten lunch (E), modified sham fed lunch $(\mathrm{S})$, water lunch $(\mathrm{W})$ 


\section{Expectorated meals}

The weights of the MSF meal before and after chewing were compared; this yielded a mean $( \pm \mathrm{SEM})$ recovery rate of $101.8 \pm 8.5 \%$ for total weight, and $96.2 \pm 3.1 \%$ for dehydrated weight.

\section{Blood samples}

Glucose

Changes in plasma glucose concentrations in response to the lunch condition are presented in Figure 2. Fifteen minutes after the lunch absolute plasma glucose concentrations were significantly higher after eating than after the MSF and water condition (W; MSF; E; $5.1 \pm 0.4 \mathrm{mmol} / \mathrm{L} ; 5.1 \pm 0.3 \mathrm{mmol} / \mathrm{L}$; $5.5 \pm 0.3 \mathrm{mmol} / \mathrm{L}$, ANCOVA, $\mathrm{p}<0.0001$, data not shown).

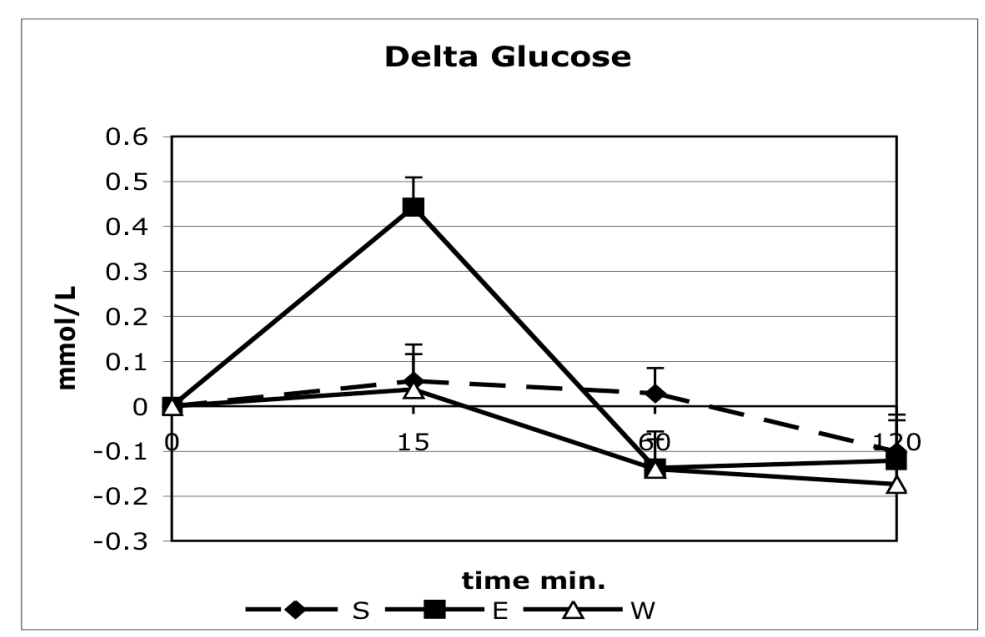

Figure 2. Mean \pm SEM percentage of change in plasma glucose concentrations. * after eating (E) or modified sham feeding (S) significantly different from after water (W), $\mathrm{P}<0.05$ by repeated measures ANOVA

Insulin

Absolute plasma insulin concentrations were significantly different between the three conditions 15 min after the lunch, with the highest plasma insulin concentrations in the eating condition and the lowest plasma insulin concentrations in the water condition (ANCOVA, $\mathrm{p}<0.0001$, data not shown). 


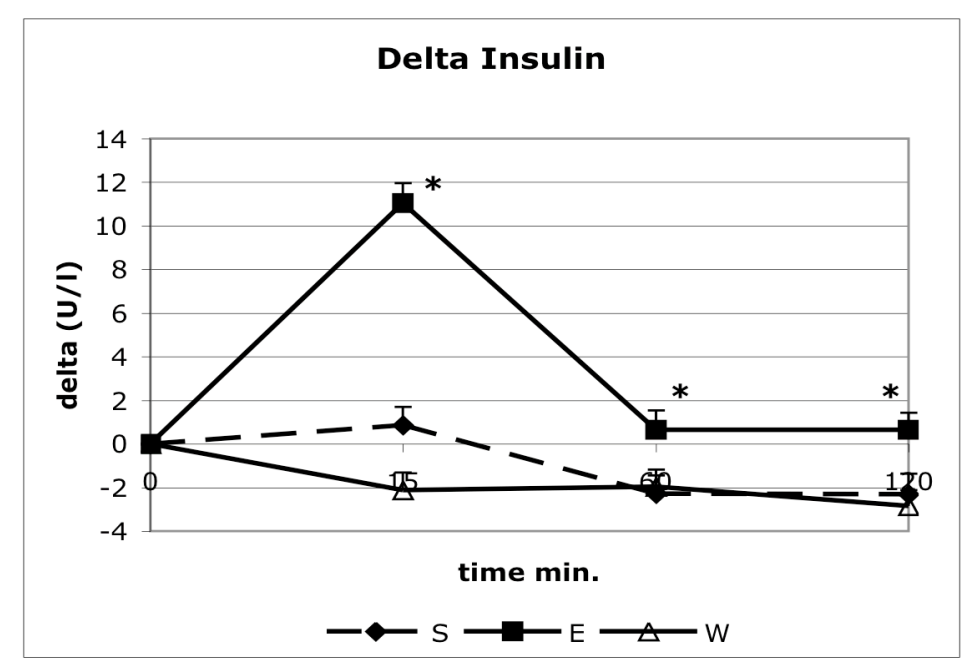

Figure 3. Mean \pm SEM percentage of change in plasma insulin concentrations. ${ }^{*}$ after eating $(\mathrm{E})$ or modified sham feeding $(\mathrm{S})$ significantly different from after water (W), $\mathrm{P}<0.05$ by repeated measures ANOVA

The increase in plasma insulin concentrations $15 \mathrm{~min}$ after the lunch was significantly higher in the eating condition compared to the MSF and water condition (ANOVA, $\mathrm{p}<0.0001$, Figure 3). Hundred-and-twenty minutes after the lunch absolute plasma insulin concentrations were significantly higher in the eating condition compared to the MSF and water condition (ANCOVA, $\mathrm{p}<0.02$, data not shown).

Non-esterified fatty acids

Fifteen and 60 minutes after the lunch absolute plasma NEFA concentrations were significantly higher after MSF and the water condition compared to after the eaten condition (ANCOVA, $\mathrm{p}<0.0001$, data not shown). The change in NEFA plasma concentrations 15 minutes after the was significantly different between the three conditions, with an increase NEFA plasma concentrations in the MSF and the water condition and a decrease NEFA plasma concentrations in the eating condition (ANOVA, $p<0.0001$, Figure 4). Sixty minutes after the lunch the changes in NEFA plasma concentrations were still significantly different after MSF and the water condition compared to after the eaten condition (ANOVA, $p<0.0001$, Figure 4). Two hours after the lunch condition differences in NEFA plasma concentrations between the conditions were no longer observed. 


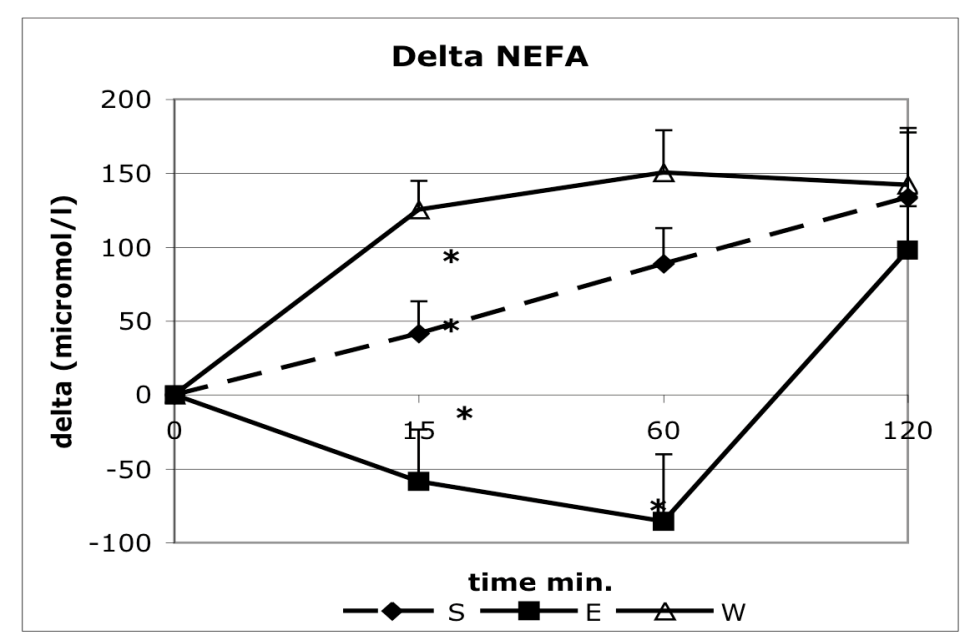

Figure 4. Mean \pm SEM percentage of change in plasma non-esterified fatty acid concentrations. * after eating (E) or modified sham feeding (S) significantly different from after water $(\mathrm{W}), \mathrm{P}<0.05$ by repeated measures ANOVA

Triacylglycerol and glycerol

Absolute plasma triacylglycerol concentrations were significantly different between the three conditions $15 \mathrm{~min}$ after the lunch, with the highest plasma triacylglycerol concentrations in the water condition and the lowest plasma triacylglycerol concentrations in the MSF condition (ANCOVA, $p<0.03$, data not shown). Sixty minutes after the lunch absolute plasma triacylglycerol concentrations were significantly lower after MSF and the water condition compared to after the eaten condition (ANCOVA, $\mathrm{p}<0.02$, data not shown). Hundred-and-twenty minutes after the lunch absolute plasma triacylglycerol concentrations were no longer significantly different between the MSF and eating condition (ANCOVA, data not shown). MSF and eating provoked a significantly less decrease in triacylglycerol concentrations compared to the water condition, calculated as AUC delta (ANOVA, $\mathrm{p}<0.0002$ ) and 60 minutes (ANOVA, $\mathrm{p}<0.0001$ ) and 120 minutes (ANOVA, $\mathrm{p}<0.0001$ ) after the lunch conditions (Figure 5). 


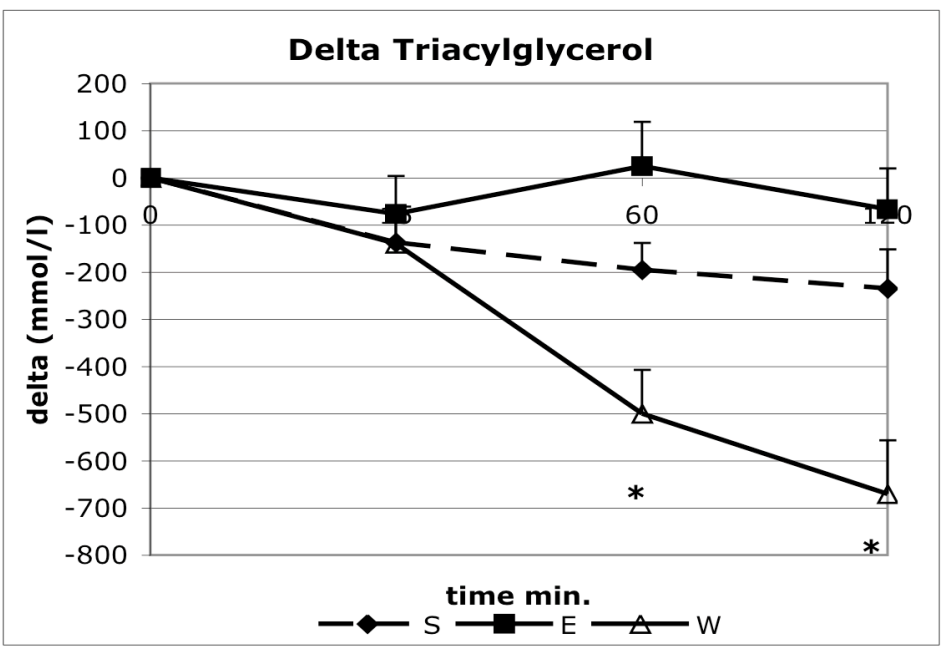

Figure 5. Mean \pm SEM percentage of change in plasma triacylglycerol concentrations. * after eating (E) or modified sham feeding (S) significantly different from after water (W), $\mathrm{P}<0.05$ by repeated measures ANOVA

Absolute plasma glycerol concentrations were significantly higher 15 minutes $(p<0.008)$ after the water lunch and $60 \mathrm{~min}(\mathrm{p}<0.03)$ after the water and MSF lunch compared to after the eaten lunch (ANCOVA, data not shown). The increase in plasma glycerol concentrations 15 minutes after the water lunch was significantly different from the decrease in plasma glycerol concentrations 15 minutes after the MSF and eating lunch (ANOVA, $\mathrm{p}<0.007$, Figure 6).

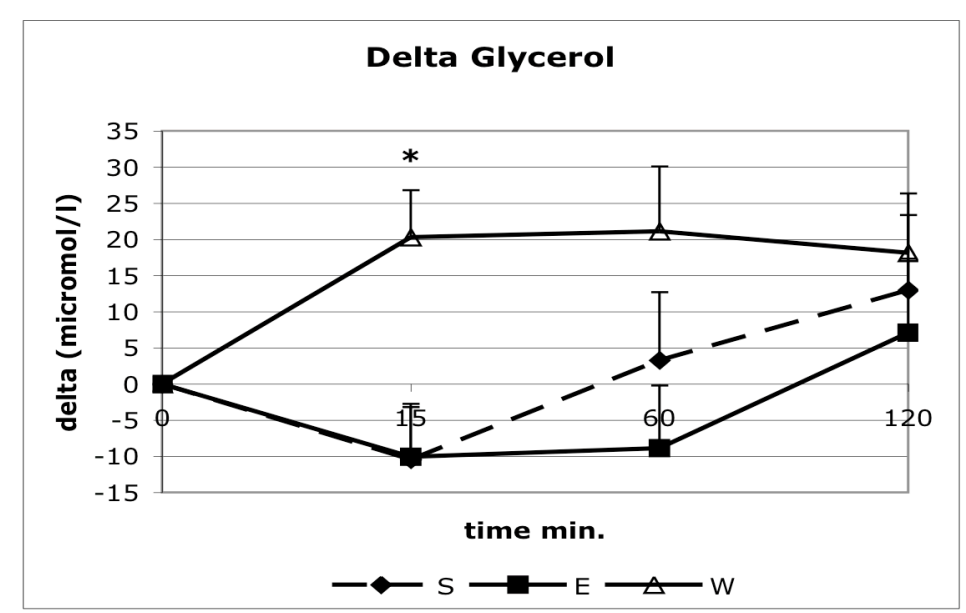

Figure 6. Mean \pm SEM percentage of change in plasma glycerol concentrations. * after eating $(\mathrm{E})$ or modified sham feeding $(\mathrm{S})$ significantly different from after water $(\mathrm{W})$, $\mathrm{P}<0.05$ by repeated measures ANOVA

\section{GLP-1}

Absolute plasma GLP-1 concentrations were significantly lower 15 minutes after the water lunch compared to after the MSF lunch. However, this was completely explained by significant differences in plasma GLP-1 concentrations at $\mathrm{t}=0$ (ANCOVA, $\mathrm{p}<0.01$, data not shown). Thirty and 120 minutes after the water lunch, absolute plasma GLP-1 concentrations were 
significantly lower compared to after the eaten lunch (ANCOVA, $\mathrm{p}<0.04$, data not shown). The increase in plasma GLP-1 concentrations in the eating condition was significantly different from the MSF and water condition at all time-points after lunch (ANOVA, $\mathrm{p}<0.01$, Figure 7).

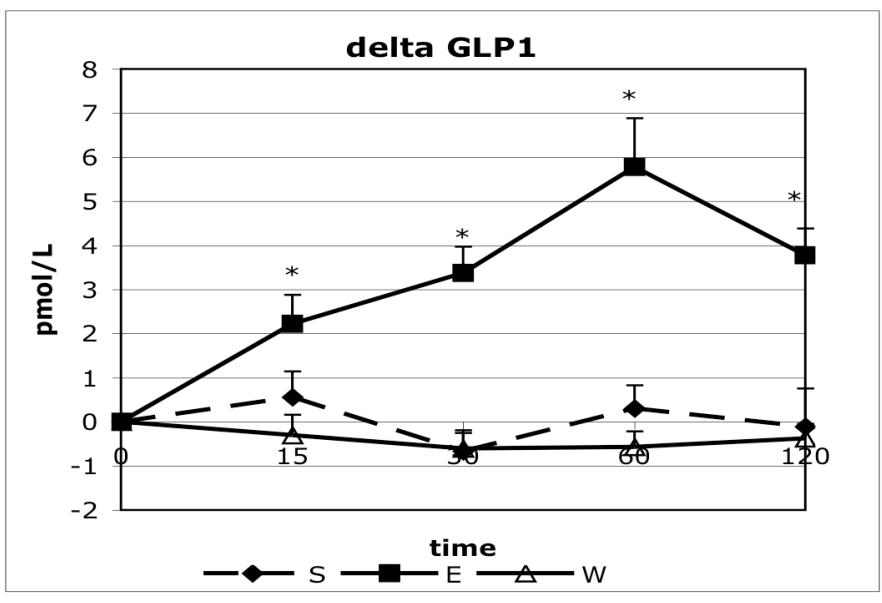

Figure 7. Mean \pm SEM percentage of change in plasma GLP-1 concentrations. * after eating $(\mathrm{E})$ or modified sham feeding $(\mathrm{S})$ significantly different from after water $(\mathrm{W})$, $\mathrm{P}<0.05$ by repeated measures ANOVA

Ghrelin

Absolute plasma total active ghrelin concentrations were significantly higher 30 minutes after the water lunch compared to after the eaten lunch (ANCOVA, $\mathrm{p}<0.05$, data not shown). The decrease in plasma total active ghrelin concentrations 30 minutes after the MSF and eaten lunch was significantly different from the increase in plasma total active ghrelin concentrations 30 minutes after the water lunch (ANOVA, p $<0.04$, Figure 8).

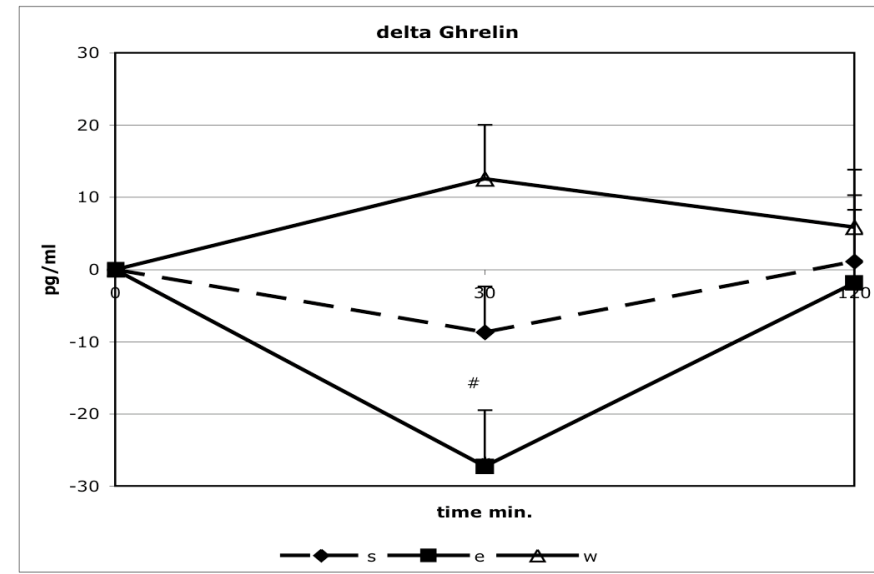

Figure 8. Mean \pm SEM percentage of change in plasma active ghrelin concentrations. * after eating (E) or modified sham feeding (S) significantly different from after water (W), $\mathrm{P}<0.05$ by repeated measures ANOVA 
Leptin

Eating, MSF, and water ingestion had no effects on plasma leptin concentrations (Figure 9).

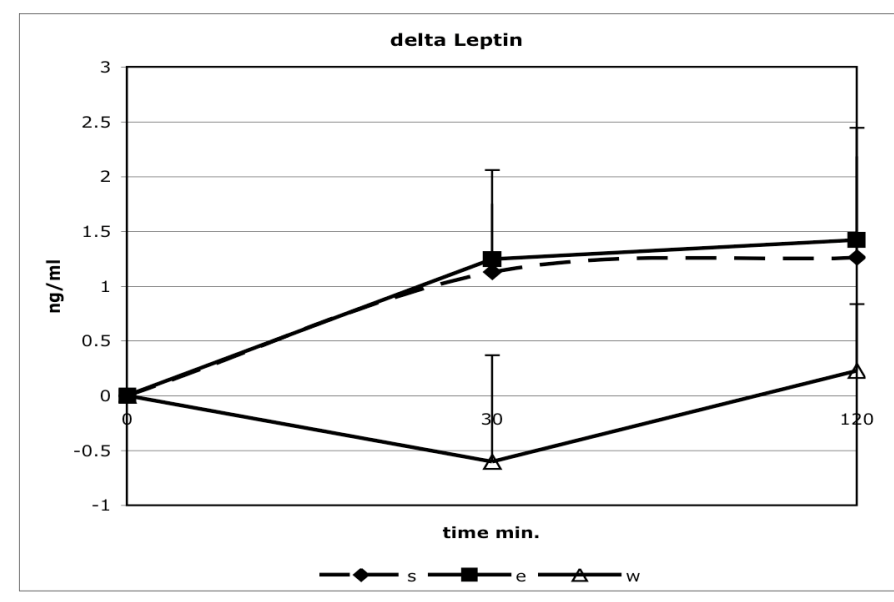

Figure 9. Mean \pm SEM percentage of change in plasma leptin concentrations. * after eating $(E)$ or modified sham feeding $(S)$ significantly different from after water $(W)$, $\mathrm{P}<0.05$ by repeated measures ANOVA

\section{Appetite profile}

The increase in VAS scores for satiety in the eating condition was significantly different from the MSF and water condition $85 \mathrm{~min}(\mathrm{p}<0.004)$ and $250 \mathrm{~min}(\mathrm{p}<0.02)$ after lunch (ANOVA, Figure 10). The area under the curve of VAS scores for satiety (AUC W; MSF; E; 425 \pm 144 mmVAS.h; $402 \pm 110$ mmVAS.h; 500 \pm 147 mmVAS.h) were significantly different between the MSF condition or water condition, and the eating condition, but not between the water and MSF condition (ANOVA, $\mathrm{p}<0.0003$ ).

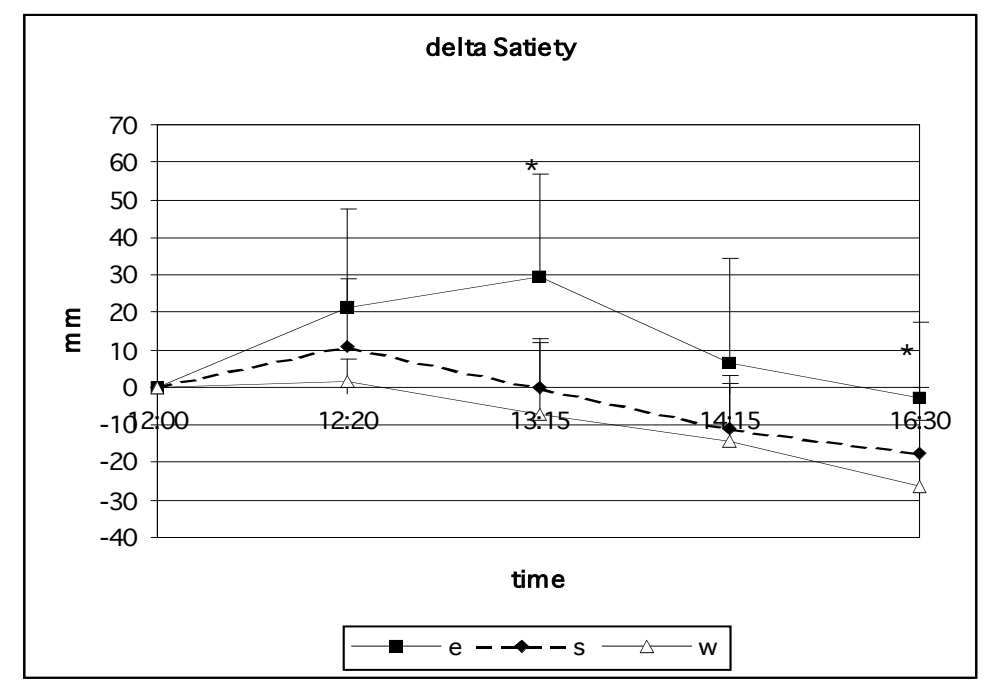

Figure 10. Mean $\pm \mathrm{SD}$ of change satiety scores over 4.5 hours after the lunch condition * after eating (E) or modified sham feeding $(\mathrm{S})$ significantly different from after water $(\mathrm{W})$, $\mathrm{P}<0.05$ by repeated measures ANOVA 


\section{Discussion}

In this study, oral fat stimulation by MSF increased energy expenditure, plasma NEFA concentrations, and attenuated the decrease in plasma triacylglycerol and the increase in glycerol and active ghrelin concentrations up to one hour after the MSF meal. Over a longer period of time, i.e. 24 hours, oral fat stimulation had no effects on substrate oxidation, diet induced thermogenesis, or total energy expenditure.

We kept circumstances before the test-lunch as equal as possible.

Previously, we have observed increased sensory specific satiety as well as increases in metabolite concentrations in the blood, following oral fat stimulation by MSF 28,29. Here, we add an increase in post-MSF thermogenesis, for 1 hour, to this. However, in the present study, the increase in satiety following MSF failed to reach significance.

The observed effects of oral fat stimulation by MSF and eating, a few hours after a high fat breakfast, on plasma metabolites (NEFA, triacylglycerol, and glycerol) has been named a 'second meal effect'. This 'second meal effect' has been observed in previous experiments 4-6,9,11-15,30, which have led to a "storage theory'. The appearance after a second meal of chylomicrons, containing fat from the first meal, has led to the idea, that a proportion of fat from the first meal remains in the gut lumen or in the enterocyte and enters the plasma pool after ingesting a second meal 31 32-34. In the present study, MSF attenuated the decrease in triglycerides, which was observed 60 and 120 minutes after water ingestion. This observation may be due to oral stimulation with fat as we showed previously ${ }^{29}$.

In line with this "storage theory', we hypothesized that deuterium labeled palmitic acid added to a high fat breakfast will reappear in the circulation and will subsequently be oxidized after a second, MSF or eaten, high fat meal. However, the 24-hour recovery of the deuterium labeled palmitic acid in urine was not statistically different between the three conditions. This indicates that oral fat stimulation by MSF or eating equally increased the oxidation of deuterium labeled palmitic acid from the breakfast after possible reappearance. Furthermore, did the plasma fatty acid profile not change after MSF (data not shown), which suggest that the observed increase in plasma NEFA was due to the release of NEFA from a mixed pool rather than from the previous meal (breakfast). The latter observation is supported by the similar 24-hour recovery of the deuterium labeled palmitic acid added to the breakfast in the three conditions.

We observed a short effect of oral fat stimulation by MSF on plasma GLP-1 concentrations. After oral nutrient ingestion, GLP-1 is released into the circulation in a biphasic pattern ${ }^{35}$. The early phase of GLP-1 secretion (after 10-15 minutes) has been suggested to be mediated by the autonomic nervous system rather than by direct nutrient contact with the L-cells ${ }^{36,37}$. However, the higher plasma GLP-1 concentrations 15 after the MSF lunch are due to 
the significantly higher plasma GLP-1 concentrations before the MSF lunch compared to the two other lunches.

In the present study, oral fat stimulation by MSF suppressed active plasma ghrelin concentrations. This is in line with the observed significant suppression of plasma ghrelin when a meal was preceded by MSF by Heath et $\mathrm{al}^{38}$.

Plasma leptin concentrations were not affected by eating or oral stimulation by MSF of fat over the course of 2 hours. The effects observed following MSF are unlikely to be produced by the ingestion of food, as shown by the high total recovery of the weights of the expectorated meals. Earlier oral stimulation studies have shown that amount of food which is accidentally swallowed during MSF is no more than a few grams $4,6,7,9,11,12,15,38$.

The increase in MSF-induced energy expenditure similar to DIT of eating for 1 hour shows the duration of the cephalic response.

Until now the cephalic response has been observed as pre-absorptive insulin response ${ }^{39,40}$, by comparing eating the same foods yet hedonically different ${ }^{41}$, or by consumption of unfamiliar food. Here we show for the first time that MSF induces oral exposure to food, without ingestion of nutrients, induces anticipatory responses to food that result in increased energy expenditure comparable to the DIT of the same food being eaten, for 1 hour. These findings indicate that metabolism is triggered during eating even before nutrients are absorbed. This triggering mechanism may serve as a feed-forward system to optimise the absorption and utilisation of nutrients ${ }^{44}$. The physiological anticipatory responses to food due to mere sensory exposure may be interpreted as being advantageous and disadvantageous.

If the available metabolites (after re-appearance) will be oxidized, then a greater amount of dietary fat will be oxidized and not stored in fat tissue. Recently, a difference in trafficking of dietary fat was shown in obesityprone and obesity-resistant rats ${ }^{45}$. The obesity resistant phenotype was associated with greater oxidation and less storage of dietary fat than was the obesity prone phenotype. In a recent study in humans, dietary fat oxidation was negatively related to percentage body fat, and lean subjects had the highest and obese subjects the lowest values ${ }^{36}$. Thus, increasing the availability of oxidizable metabolites due to mere sensory exposure may be beneficial for dietary fat oxidation. However, this effect on dietary fat oxidation may be rather small, because we observed no effect of mere sensory exposure on dietary fat oxidation over a period of 2-24 hours.

Raised triacylglycerols and NEFA in the postprandial state contribute to the obesity-associated pathologies such as type 2 diabetes, atherosclerosis and hypertension. It is therefore of importance to clarify the mechanisms behind the metabolic effects observed after the consumption of high-fat foods, and whether these are influenced by the oral exposure to fats and the preceding meal. 
Summarizing, mere sensory exposure to meals rich in specific fatty acids, has effects on physiological and metabolic variables that resemble the effects observed after eating, which last up to one hour.

This implies that non-homeostatic effects, as evoked by the appearance of food (sight, smell, texture, flavor), has a carry-over effect in that sensory satiety affects metabolic satiety for up to 1 hour.

\section{Acknowledgements}

We thank Maartje Spetter, Krista Morren, Loek Wouters, and Paul Schoffelen for their contributions to the study. 


\section{References}

1. National Heart Lung, and Blood Institute. Clinical guidelines on the identification, evaluation, and treatment of overweight and obesity in adults: the evidence report. Bethesda, MD: US Department of Health and Human Services, NIH; 1998. Available at http://www.nhlbi.nih.gov/guidelines/obesity/ob gdlns.htm (accessed 10 October 2007).

2. Poothullil JM. Role of oral sensory signals in determining meal size in lean women. Nutrition 2002;18(6):479-83.

3. Schilstra AJ. Meal-interval correlations: what can they tell us? Physiol Behav 1981;27(2):299-304.

4. Mattes RD. Oral exposure to butter, but not fat replacers elevates postprandial triacylglycerol concentration in humans. J Nutr 2001;131(5):1491-96.

5. Mattes RD. The taste of fat elevates postprandial triacylglycerol. Physiol Behav 2001;74(3):343-48.

6. Mattes RD. Oral fat exposure increases the first phase triacylglycerol concentration due to release of stored lipid in humans. J Nutr 2002;132(12):3656-62.

7. Tittelbach TJ, Mattes RD. Oral stimulation influences postprandial triacylglycerol concentrations in humans: nutrient specificity. J Am Coll Nutr 2001;20(5):485-93.

8. Tittlebach TJ, Mattes RD. Effect of orosensory stimulation on postprandial thermogenesis in humans. Physiol Behav. 2002;75(1-2):71-81.

9. Mattes RD. Oral fat exposure alters postprandial lipid metabolism in humans. Am J Clin Nutr 1996;63(6):911-17.

10. Coelho SB, de Sales RL, Iyer SS, Bressan J, Costa NM, Lokko P, Mattes R. Effects of peanut oil load on energy expenditure, body composition, lipid profile, and appetite in lean and overweight adults. Nutrition 2006;22(6):585-92.

11. Jackson KG, Robertson MD, Deane LO, Fielding BA, Frayn KN, Williams $\mathrm{CM}$. The effect of modified sham-feeding meals of varying fat content on postprandial triacylglycerol, insulin and glucose response. Proc Nutr Soc 2000;59:14A.

12. Jackson KG, Robertson MD, Fielding BA, Frayn KN, Williams CM. Second meal effects: modified sham feeding does not provoke the release of stored triacylglycerol from a previous high-fat meal. Br J Nutr 2001;85(2):149-56.

13. Robertson MD, Jackson KG, Fielding BA, Williams CM, Frayn KN. Modified sham feeding of a modest-fat meal suppresses plasma nonesterified fatty acids. Proc Nutr Soc 1999;59:123A.

14. Robertson MD, Mason AO, Frayn KN. Oro-sensory stimulation prior to fat ingestion impairs postprandial fat tolerance. Int J Obesity 2000;24:S55.

15. Robertson MD, Mason AO, Frayn KN. Timing of vagal stimulation affects postprandial lipid metabolism in humans. Am J Clin Nutr 2002;76(1):71-7. 
16. LeBlanc J, Cabanac M. Cephalic postprandial thermogenesis in human subjects. Physiol Behav 1989;46(3):479-82.

17. LeBlanc J, Soucy J. Interactions between postprandial thermogenesis, sensory stimulation of feeding, and hunger. Am J Physiol 1996;271(4 Pt 2):R936-40.

18. Brondel L, Fricker J, Fantino M. Postprandial thermogenesis and alimentary sensory stimulation in human subjects. Int J Obes Relat Metab Disord 1999;23(1):34-40.

19. Prat-Larquemin L, Oppert JM, Bellisle F, Guy-Grand B. Sweet taste of aspartame and sucrose: effects on diet-induced thermogenesis. Appetite 2000;34(3):245-51.

20. Stunkard AJ, Messick S. The three-factor eating questionnaire to measure dietary restraint, disinhibition and hunger. J Psychosom Res 1985;29(1):7183.

21. Harris JA, Benedict FG. A Biometric Study of Human Basal Metabolism. Proc Natl Acad Sci U S A 1918;4(12):370-3.

22. Westerterp KR. Exercise and energy balance. Westerterp-Plantenga MS, Steffens, A. B. \& Tremblay, A., Milan, Italy: Edra, Medical publishing \& New Media; 1999. 349-361.

23. Siri WE. The gross composition of the body. Adv Biol Med Phys 1956;4:239-80.

24. Schoffelen PF, Westerterp KR, Saris WH, Ten Hoor F. A dual-respiration chamber system with automated calibration. J Appl Physiol 1997;83(6):2064-72.

25. Westerterp KR, Wilson SA, Rolland V. Diet induced thermogenesis measured over $24 \mathrm{~h}$ in a respiration chamber: effect of diet composition. Int $\mathrm{J}$ Obes Relat Metab Disord 1999;23(3):287-92.

26. Brouwer E. On simple formulae for calculating the heat expenditure and the quantities of carbohydrate and fat oxidized in metabolism of men and animals, from gaseous exchange (Oxygen intake and carbonic acid output) and urine-N. Acta Physiol Pharmacol Neerl 1957;6:795-802.

27. Votruba SB, Zeddun SM, Schoeller DA. Validation of deuterium labeled fatty acids for the measurement of dietary fat oxidation: a method for measuring fat-oxidation in free-living subjects. Int J Obes Relat Metab Disord 2001;25(8):1240-5.

28. Smeets AJ, Westerterp-Plantenga MS. Oral exposure and sensory-specific satiety. Physiol Behav 2006;89(2):281-6.

29. Smeets AJ, Westerterp-Plantenga MS. Satiety and substrate mobilization after oral fat stimulation. Br J Nutr 2006;95(4):795-801.

30. Robertson MD, Jackson KG, Williams CM, Fielding BA, Frayn KN.

Prolonged effects of modified sham feeding on energy substrate mobilization.Am J Clin Nutr2001;73(1):111-7 
31. Jackson KG, Robertson MD, Fielding BA, Frayn KN, Williams CM. Olive oil increases of triacylglycerol-rich chylomicron particles compared with other oils: an effect retained when a second meal is fed. Am J Clin Nutr 2002;76(5):942-9.

32. Peel AS, Zampelas A, Williams CM, Gould BJ. A novel antiserum specific to apolipoprotein B-48: application in the investigation of postprandial lipidaemia in humans. Clin Sci (Lond) 1993;85(5):521-4.

33. Fielding BA, Callow J, Owen RM, Samra JS, Matthews DR, Frayn KN. Postprandial lipemia: the origin of an early peak studied by specific dietary fatty acid intake during sequential meals. Am J Clin Nutr 1996;63(1):36-41.

34. Evans K, Kuusela PJ, Cruz ML, Wilhelmova I, Fielding BA, Frayn KN. Rapid chylomicron appearance following sequential meals: effects of second meal composition. Br J Nutr 1998;79(5):425-9.

35. Herrmann C, Goke R, Richter G, Fehmann HC, Arnold R, Goke B. Glucagon-like peptide-1 and glucose-dependent insulin-releasing polypeptide plasma levels in response to nutrients. Digestion 1995;56(2):117-26.

36. Balks HJ, Holst JJ, von zur Muhlen A, Brabant G. Rapid oscillations in plasma glucagon-like peptide-1 (GLP-1) in humans: cholinergic control of GLP-1 secretion via muscarinic receptors. J Clin Endocrinol Metab 1997;82(3):786-90.

37. Rocca AS, Brubaker PL. Role of the vagus nerve in mediating proximal nutrient-induced glucagon-like peptide-1 secretion. Endocrinology 1999;140(4):1687-94.

38. Heath RB, Jones R, Frayn KN, Robertson MD. Vagal stimulation exaggerates the inhibitory ghrelin response to oral fat in humans. J Endocrinol 2004;180(2):273-81.

39. Bellisle F, Louis-Sylvestre J, Demozay F, Blazy D, Le Magnen J. Cephalic phase of insulin secretion and food stimulation in humans: a new perspective. Am J Physiol 1985;249(6 Pt 1):E639-45.

40. Strubbe JH. Parasympathetic involvement in rapid meal-associated conditioned insulin secretion in the rat. Am J Physiol 1992;263(3 Pt 2):R615-8.

41. LeBlanc J, Brondel L. Role of palatability on meal-induced thermogenesis in human subjects. Am J Physiol 1985;248(3 Pt 1):E333-6. 


\section{5}

\section{Taste sensitivity for monosodium glutamate and an increased liking of dietary protein}

Natalie D. Luscombe-Marsh, Astrid J.P.G. Smeets and Margriet S. Westerterp-Plantenga

Based on: Taste sensitivity for monosodium glutamate and an increased liking of dietary protein, Br J Nutr. 99 (2008) 904-8 


\begin{abstract}
The aim of this study was to determine individuals' taste threshold for monosodium glutamate (MSG) alone and in combination with inosine 5'monophosphate (IMP'5) and, to examine if this threshold was related to an increase in sensory properties (including pleasantness of taste) and/or, to ones' preference for dietary protein over carbohydrate and fat. Using the triangle tasting method, the taste threshold was determined for 36 women and $24 \mathrm{men}$. Thresholds varied from 0 to infinite as determined using a clear soup with added MSG in the concentration range of 0.1 to $0.8 \%(\mathrm{w} / \mathrm{w})$ MSG. Subjects rated 14 sensory properties of the soup and also their 'liking', 'eating frequency' and 'preference' of 22 common high-protein, high-carbohydrate and high-fat food items. The taste threshold (and therefore sensitivity) of MSG was lowered from $0.33 \pm 0.24 \%$ to $0.26 \pm 0.22 \% \mathrm{MSG}$ when $[0.25 \%](\mathrm{w} / \mathrm{w})$ of IMP' 5 was added. None of the sensory properties assessed were associated with the taste threshold of MSG $\pm[0.25 \%]$ IMP'5 in the overall study population. However, the taste descriptor 'meatiness' was associated to the threshold data for individuals who could taste concentrations of $\leq 0.4 \% \mathrm{MSG}$. 'Liking' and 'preference' scores for protein were found to be related to the threshold of MSG $\pm[0.25 \%]$ IMP'5. From this study population we conclude the taste threshold of MSG in combination with IMP'5 does appear to predict ones' 'liking' of as well as 'preference' for high protein foods.
\end{abstract}




\section{Introduction}

The taste of the amino acid glutamate, alone and in combination with the ribonucleotide inosine 5'-monophosphate (IMP'5) is thought to represent the taste of dietary protein. Glutamate is found in nearly all protein-containing foods (e.g. cheese, fish, meat, poultry, eggs) and many vegetables (e.g. tomatoes, mushrooms, cabbage, corn, green asparagus) and IMP'5 is found primarily in meat and some types of fish such as tuna ${ }^{8}$. The taste of glutamate [administered orally in the form of monosodium glutamate (MSG)] has been described as 'Umami' by the Japanese (meaning savoury deliciousness) or as 'meaty, broth-like, savoury' by Westerners'. The Umami taste is recognised and coded as a unique quality by the taste system and is therefore considered the fifth basic taste ${ }^{3,4}$. A special quality of glutamate is its' ability to enhance several specific flavour characteristics of food $^{5-10}$. Moreover, behavioural and electrophysiological studies in humans and non-humans have found that glutamate interacts synergistically with certain other stimuli such as IMP'5 to accentuate the intensity of the Umami taste even when only a low concentration of free glutamate is naturally present in food ${ }^{11,12}$.

Evidence for glutamate and IMP'5 representing the taste of protein however remains scarce. Studies in rats, non-primates and humans have demonstrated that a preference for dietary protein (or liking of) is almost certainly related, in part, to the way the body senses and tastes MSG \pm IMP'5 and on the body's protein requirements and stores at the time ${ }^{13-19}$. Recent studies in alpha-gustducin and rod alpha-transducin knock-out mice have shown that Umami taste detection involves the activation of these two G-proteincoupled receptors which are located in specialized epithelial cells of the anterior taste bud ${ }^{14-15}$. In addition, taste buds at the back of the tongue respond to Umami compounds independently of the G-protein subunits ${ }^{14}$. Given that a specialized tasting system exists to recognise the Umami taste, it is only natural to speculate this distinctive taste functions as a signal to regulate protein intake. Supporting this notion is the finding that persons with low nutritional/protein status preferred higher concentrations of MSG in solution than those who were better nourished ${ }^{20}$.

The aim of this study was to determine individuals' taste threshold for MSG (alone and in combination with IMP'5) and, to examine if this threshold was related to an increase in sensory properties (including pleasantness of taste) and/or, to ones' preference for dietary protein over carbohydrate and fat.

\section{Subjects and Methods}

Subjects

Sixty subjects aged 19 to 63 years were recruited from responders to advertisements in a local newspaper and around the Maastricht University. Inclusion criteria were healthy, non-smokers, on no medication (except the 
contraceptive pill), not known to be allergic to monosodium glutamate or other foods, not dietary restrained (assessed using the Three Factor Eating Questionnaire $^{21}$, low to moderate alcohol uses (i.e. $\leq 2$ standard drinks per day for no more than 5 days per week) and, a BMI between 20 to $30 \mathrm{~kg} / \mathrm{m}^{2}$ and weight stable $(<3 \%$ change over the 3 months prior to screening). Fat and fat-free mass was determined for each subject from the measurement of total body water using deuterium dilution and the assumption that total body water occupies an approximate average of $73,2 \%$ of the fat free mass ${ }^{22,23}$. Thirty-six women (mean \pm SD age $31 \pm 15 \mathrm{yrs}$; BMI $23.5 \pm 2.5 \mathrm{~kg} / \mathrm{m}^{2}$; fat mass $20.3 \pm 6.9 \mathrm{~kg}$; fat-free mass $46.1 \pm 5.4 \mathrm{~kg}$, dietary restraint score $6.3 \pm 2.9)$ and 24 men (age $38 \pm 15 \mathrm{yrs}$; BMI $25.9 \pm 2.4 \mathrm{~kg} / \mathrm{m}^{2}$; fat mass $21.3 \pm 12.0 \mathrm{~kg}$; fatfree mass $63.0 \pm 7.4 \mathrm{~kg}$, dietary restraint score $8.5 \pm 3.8$ ) were enrolled in the study that was approved by the Medical Ethics Committee of Maastricht University. All subjects gave written informed consent to participate.

\section{Study protocol}

On two separate experimental sessions, at least 1-week apart, each subject participated in a series of single-blinded 'triangle taste tests' to determine the taste threshold of glutamate (i.e. the lowest concentration correctly recognized) in a clear soup when MSG alone or, in combination with IMP' $5^{24}$, is added. On each day, subjects completed questionnaires regarding the sensory properties of the soup and their 'liking' and 'eating frequency' of high carbohydrate, fat and protein food items.

\section{Preparation of soup, monosodium glutamate (MSG) and inosine 5'- monophosphate (IMP'5)}

The soup stock was prepared with $20 \mathrm{~g}$ of Vectra ${ }^{\circledR}$ vegetable boullion (Natudis B.V., 3480 AJ, Harderwijk, The Netherlands) to $1 \mathrm{~L}$ of water and heated to $\sim 65^{\circ} \mathrm{C}$. Herbs were strained from the stock so that only a clear broth was used for the taste tests. The manufacturers' nutritional analysis of the soup documented it as containing no glutamate. MSG and IMP'5 were purchased as salts from Ajinomoto Foods Germany GmbH. (Hamburg, Germany) and they were thoroughly mixed into the soup a few minutes in advance of tasting. For triangle taste tests determining the recognition threshold MSG alone, the concentration of MSG added to the soup ranged from 0.1 to $0.8 \%$ [weight of MSG/ weight soup]. When determining the recognition threshold MSG in combination with IMP'5, a constant concentration of $0.25 \%[\mathrm{w} / \mathrm{w}$ ] of IMP' 5 was added to the MSG soup solution. All concentrations of MSG and IMP' 5 were within the range that is typically added to commercial food and is similar to levels of naturally occurring glutamate found in traditional dishes ${ }^{25,26}$.

\section{Triangle taste tests and characterization of tasters of MSG \pm IMP'5}

Using the 'Triangle tasting method" ${ }^{24}$ the taste threshold of MSG \pm IMP' 5 for individuals was determined. Each 'triangle taste test' involved the 
presentation of 10 rows of triplicate cups with $8 \mathrm{ml}$ of soup (total of 30 cups). Within each triplicate, either 1 or 2 cups contained soup with added MSG \pm IMP'5. The remaining cups contained soup with no additive(s). Subjects were instructed to taste (but not swallow) half the volume of each soup cup and they were allowed to re-taste each sample if necessary. They were asked to "identify the soup with the added ingredient(s)" and "how certain they were about their choice". The first 4 series of "triangle taste tests' had only MSG added and the starting concentration was $[0.4 \%$ w/w]MSG. If they could correctly recognise the soup with added $[0.4 \%]$ MSG for $\geq 8$ of the triplicates then the concentration was decreased (or if not, it was increased) by a step of $0.1 \%$ until the threshold for the taste of MSG was determined (within the concentration range of $0.1-0.8 \%$ ). Thereafter, another series of 'triangle taste tests' were administered where the starting concentration of MSG was the lowest concentration previously tasted plus, [0.25\%]IMP'5. The reason for the second series of triangles was to determine if addition of [0.25\%]IMP' 5 could lower the concentration of MSG recognised. Between each cup within the 'triangle taste test', subjects were encouraged to rinse their mouth with water and chew on plain white bread (but not swallow) to get rid of previous tastes. Moreover, a 10-15min break was taken between each consecutive set of 'triangle taste tests' so that subjects could again rinse their mouth with water or chew on plain white bread to get rid of previous tastes. On each experimental session, subjects required a total of between 4 to 8 'triangle taste tests' to determine their taste threshold; each experimental session took between 2 to 3 hours.

\section{Sensory ratings for the taste properties of the soup}

Sensory-ratings (e.g. pleasantness, savoury, meaty, salty, heartiness, sour, sweet, bitter, creamy, fatty) were measured after every 'triangle taste test' using a validated $100 \mathrm{~mm}$ visual analogue scale $(\mathrm{VAS})^{27}$. The scale ranged from 'entirely not' on the left to 'extremely' on the right. For each sensory property, the change in the sensory property score was calculated as the score given during tasting of the soup at the first concentration presented (i.e. $[0.4 \%] \mathrm{MSG}$ ) minus their score given at their threshold concentration (their lowest concentration tasted].

\section{'Liking' and 'Eating frequency' scores for protein, fat and carbohydrate} food items, and 'Protein preference' scores

Subjects completed a questionnaire asking them about their 'liking' and 'eating frequency' of 22 high-protein, 22 high-fat and 22 high-carbohydrate food items (total of 66 common food items eaten in the Netherlands) ${ }^{28}$. For each item on this questionnaire, subjects had to rate "How nice do you find...' using a 4-point scale where a score of 1 indicated 'not at all nice' and 4 indicated 'delicious' and 'How often do you eat' where a score of 1 
indicated 'never' and 4 indicated 'at least 1 time per week'. For each macronutrient, the answers were summed to give a 'Liking' and 'Eating frequency' score (a score of 88 was the maximum achievable score for any single macronutrient). Ones' preference for dietary protein was assessed using: 1. 'The Protein Liking ratio'- calculated as the protein liking score divided by the total liking scores of protein + fat + carbohydrate; and, 2. 'The Eating freq. Ratio'- calculated the protein eating frequency score divided by the total eating frequency scores of protein + fat + carbohydrate.

\section{Statistical analysis}

All data are presented as the mean \pm SEM unless stated otherwise. Statistical analyses were made using SPSS for Windows version 11.5 (SPSS Inc, Chicago, U.S.A), and the criterion for significance (two-tailed) was set at $\mathrm{P}<0.05$. Outcomes measured on experimental session 1 were compared to those from experimental session 2 using Student's paired t-test. Several outcomes [i.e. sensory properties and liking, eating frequency and protein preference scores] were found to be different on day 2 compared to day 1 . Accordingly, only data from test day 2 was analysed which should have in turn excluded learning effects. A frequency distribution of thresholds for the taste of MSG $\pm I M P$ ' 5 was determined for the study population. Pearson's correlation and linear regression analyses were performed to examine the relationships between the threshold of $\mathrm{MSG}^{\prime} I M P^{\prime} 5$ and $i$. the change in sensory properties, and ii. protein liking, eating frequency and preference scores.

\section{Results}

Taste threshold of MSG alone and in combination with IMP'5

There was no difference between the lowest concentration of MSG alone recognised on experimental session 1 as compared to experimental session 2 $(0.33 \pm 0.04$ Vs. $0.30 \pm 0.03, \mathrm{df}=58, \mathrm{t}=0.81, \mathrm{P}=0.5)$.

There was also no difference between the lowest concentration of MSG+[0.25\%] IMP'5 identified on experimental session 1 as compared to experimental session $2(0.30 \pm 0.04$ Vs. $0.23 \pm 0.03, \mathrm{df}=53, \mathrm{t}=1.67, \mathrm{P}=0.1)$.

Figure 1 shows the frequency distribution of the taste thresholds for all individuals who completed experimental session 2. The percent frequency of individuals who could taste MSG within the concentration range was $82.8 \%$ when only MSG was added and, was $79.3 \%$ when MSG was added in combination with [0.25\%]IMP'5. The taste threshold of MSG was lowered from $0.33 \pm 0.24 \%$ to $0.26 \pm 0.22 \%$ when [0.25\%]IMP'5 was added $(\mathrm{t}=3.25$, $\mathrm{df}=42, \mathrm{P}=0.002)$. There was no effect of gender on the lowest concentration of MSG tasted when tested alone $(\mathrm{P}=0.7)$ or in combination with IMP'5 $(\mathrm{P}>0.38)$. 
Relationships between the taste threshold of MSG+IMP'5 and the sensory properties of the soup

For the overall study population, the taste threshold of MSG+[0.25\%]IMP' 5 was not significantly associated with any of the expected sensory properties (i.e. pleasantness, savoury, meaty, hearty, salty). This finding remained the same even when the non-tasters at any concentration within the 0.1 to $0.8 \%$ range were excluded from the analysis. A strong association however was observed between the taste property 'meatiness' and the taste threshold of individuals who correctly identified the presence of MSG in soup when concentrations of $\leq 0.4 \% \mathrm{MSG}$ were added $(\mathrm{F}[1,31]=5.6, \mathrm{R}=0.40, \mathrm{P}=0.02)$.

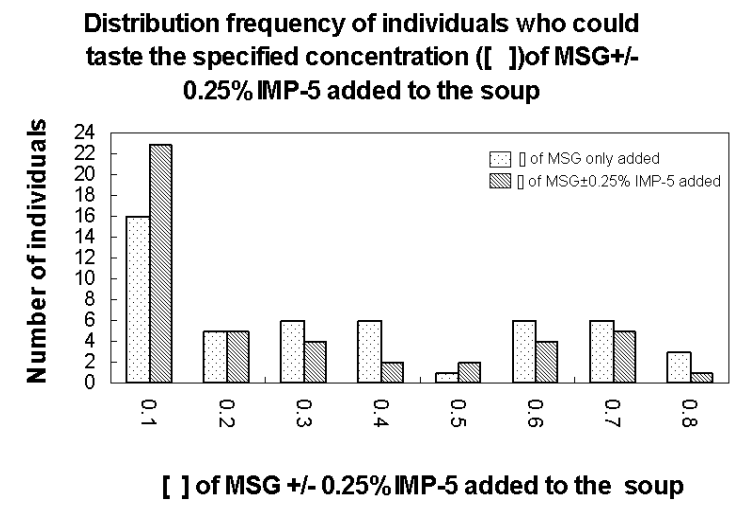

Figure 1. Frequency distribution of the taste thresholds of MSG alone and in combination with $0.25 \%$ IMP' 5 for the 35 women and 24 men who completed experimental session 2. Within the concentration range of 0.1 to $0.8,10$ subjects could not taste MSG at all when added alone to soup and 12 subjects could not taste MSG when added in combination with $0.25 \%$ IMP' 5 ; these subjects are not shown in the frequency distribution graph.

The effect of MSG+IMP'5 taster threshold on the liking and eating frequency scores of protein, fat and carbohydrate

The mean \pm S.E.M 'liking' scores were not significantly different for protein, carbohydrate and fat, respectively $(59.6 \pm 1.1$ vs. $64.1 \pm 1.2$ vs. $61.5 \pm 1.2)$ and neither were the 'Eating frequency' scores $(59.6 \pm 1.1$ Vs. $65.3 \pm 1.2$ Vs. $54.8 \pm 1$, respectively). 'Protein preference' expressed as the ratio of protein 'liking' scores over the total scores for all 3 macronutrients was found to be $0.32 \pm 0.004$. When expressed as the ratio of protein 'eating frequency' over the total for all 3 macronutrients, protein preference was $0.33 \pm 0.005$. 


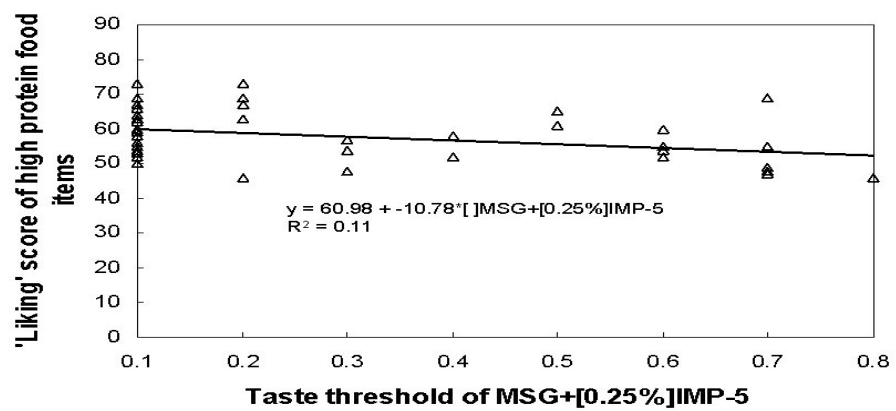

$2 \mathrm{a}$.

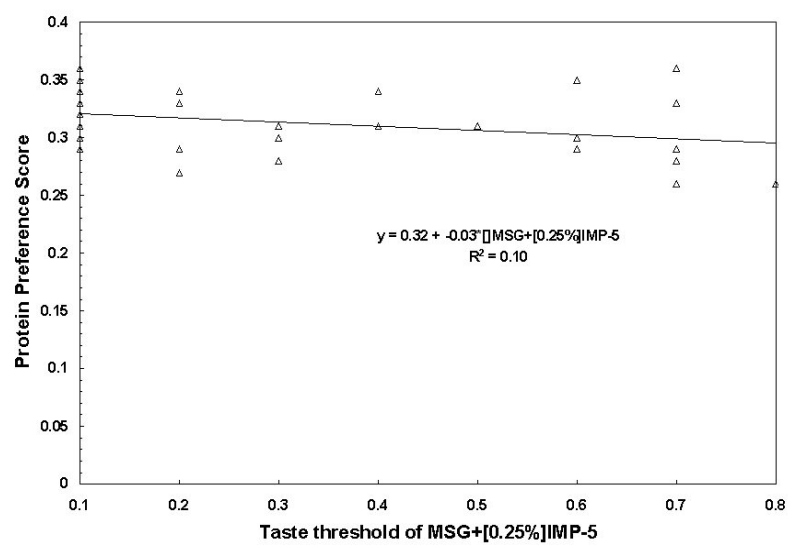

$2 b$.

Figure 2. The taste threshold of MSG, when combined with [0.25\%]IMP, was associated with the 'liking' score of high-protein foods $[\mathrm{F}[1,57]=7.1,, \mathrm{R}=0.34, \mathrm{P}=0.01]$ (Fig. 2a.) and, the 'Protein preference' score (as assessed using the ratio of 'liking' score of protein over the sum of scores for protein, fat and carbohydrate) $[\mathrm{F}[1,57]=5.9, \mathrm{R}=0.31, \mathrm{P}=0.02]$ ), in the overall study population (Fig. 2b)

Relationships between the taste threshold of MSG+[0.25\%]IMP'5 and the 'Liking', 'Eating frequency' and 'Preference' scores of high protein foods For the overall study population, the taste threshold of MSG+[0.25\%]IMP' 5 was associated with the 'liking' $(\mathrm{r}=-0.34, \mathrm{P}=0.01)$ and 'preference' $(\mathrm{r}=-0.31$, $\mathrm{P}<0.02)$ score for high-protein foods (Fig. 2). The 'eating frequency' score for protein was not related to the taste threshold for MSG+[0.25\%]IMP'5. Similar associations were found when the 12 individuals who could not taste any concentration of MSG within the range of 0.1 to $0.8 \%$ were removed $(\mathrm{r}=-0.34, \mathrm{P}=0.02$ for the association between the taste threshold and protein 'liking' score and, $\mathrm{r}=-0.31, \mathrm{P}=0.04$ for the association between the taste threshold and protein 'preference').

\section{Discussion}

The main findings from this study are: (i.) the taste threshold for MSG alone and in combination with IMP'5 is stable when determined on separate 
occasions; (ii.) addition of IMP to MSG enriched foods can lower the taste threshold of MSG; (iii.) the taste threshold of MSG \pm IMP' 5 is not associated with sensory properties of taste; the exception being with 'meatiness' of taste; and (iv.) the taste threshold of MSG \pm IMP' 5 is associated with the 'liking' of high protein foods.

In this Dutch population, the addition of [0.25\%]IMP to the MSG flavoured soup lowered the taste threshold of MSG from $0.33 \pm 0.24 \%$ [w/w] to $0.26 \pm 0.22 \%$. A previous Dutch study reported that the mean taste threshold of MSG alone was $0.2 \%[\mathrm{w} / \mathrm{w}$ ] for 21 elderly men and women (aged 60-75 years) and $\sim 0.15 \%[\mathrm{w} / \mathrm{w}]$ for 21 young men and women (aged 19-33 years) ${ }^{29}$. They also showed that the threshold of IMP' 5 for elderly men was $1 \%$ [w/w] compared to $0.48 \%[\mathrm{w} / \mathrm{w}$ ] for the women and, for young men and women it was $0.13 \%$ vs. $0.24 \%$. That water was used as the vehicle of tastant may explain, at least in part, the different mean taste thresholds of MSG in their study compared to ours. We used a clear vegetable broth as the tastant vehicle because MSG at $0.094-6.0 \%$ concentrations in aqueous solutions have been reported as neutral or unpleasant and are therefore not considered to be representative for testing real-life taste preferences ${ }^{25,30}$. In a study of young Americans where canned chicken broth was used as the tastant vehicle, the taste threshold of MSG was $0.345 \pm 0.181 \%$. This was in complete agreement with our findings ${ }^{31}$, they did not however examine the taste thresholds of MSG in combination with IMP'5. In this study, the observed improved sensitivity to MSG when IMP'5 was added may have been due, at least in part, to a learning effect given that the MSG+IMP'5 triangle tests always took place after the MSG alone tests.

For the overall study population, descriptive taste properties such as pleasant, savoury, salty, hearty, and meaty were not related to the taste threshold of the MSG+[0.25\%]IMP'5 enriched soup. This was somewhat surprising given that long-standing research has documented the usefulness of MSG in combination with IMP'5 as a 'flavour enhancer' ${ }^{4-10}$ and reported the use of 'meatiness' as a descriptor for the taste of $\mathrm{MSG}^{30}$. On the other hand, given i. the existence of multiple glutamate taste receptor types in the taste cells; ii. the presence of several transduction pathways, and iii. that $\mathrm{Na}$ ions are sensed separately to the glutamate ions, it was not completely unexpected that in the overall study population exhibited a large degree of variation in their perceptions of the taste of $\mathrm{MSG}^{32}$. However, when we narrowed the population to only individuals who correctly identified the presence of MSG when low concentrations were added ( 0.1 to $0.4 \%$ ), we did observe a strong association between 'meatiness' and the taste threshold. Since meaty flavours are used to described different types of animal proteins it can be argued that the taste of MSG may be one compound that represents the taste of dietary protein.

Another interesting finding in this study was that of an inverse association between the taste threshold and 'liking' and 'preference' scores for dietary 
protein for the overall study population. This finding is comparable to that observed for food adventurous 6-n-popylthiouracil (PROP) tasters who had a greater liking of a variety of strong-tasting bitter, hot and pungent foods than PROP tasters who were less adventurous with their food choices ${ }^{33}$. Such findings lend to cautious speculation by the medical community that dietary therapies recommended to treat certain diseases may be better tailored to the macronutrient preference of the treated individual.

We do however, acknowledge that the perceived pleasure derived from eating foods we like only partially determines our overall food intake and this is definitely reflected by the strength of the association observed in this population; other factors include our immediate psychological and physiological states, and where, when and with whom we are eating ${ }^{34}$.

From this study population we conclude that the taste threshold of MSG improves when combined with IMP'5. Moreover, the taste threshold of MSG in combination with IMP' 5 was best described by the taste descriptor 'meatiness', and it appears to predict the 'liking' of and 'preference' for high protein foods, at least in a proportion of subjects within this population.

Further investigation in a larger population of individuals is warranted to confirm these relationships.

\section{Acknowledgements}

We would like to thank Loek Wouters for analysing the deuterium-labelled urine samples for determination of body composition. 


\section{References}

1. Ninomiya K (2002) Umami: A universal taste. Food Rev Internat 18(1):2328.

2. Yamaguchi S \& Ninomiya K (2000) Umami and food palatability. J Nutr 130(4S Suppl):921S-6S.

3. Rolls ET (2000) The representation of umami taste in the taste cortex. J Nutr 130(4S Suppl):960S-5S.

4. Chaudhari N, Landin AM \& Roper SD (2000) A metabotropic glutamate receptor variant functions as a taste receptor. Nat Neurosci 3(2):113-9.

5. Bellisle F, Tournier A \& Louis-Sylvestre J (1989) Monosodium glutamate and the acquistion of food preferences in a Europrean context. Food Qual Pref 1:103-108.

6. Bellisle F, Monneuse MO, Chabert M, Larue-Achagiotis C, Lanteaume MT \& Louis-Sylvestre J (1991) Monosodium glutamate as a palatability enhancer in the European diet. Physiol Behav 49(5):869-73.

7. Bellisle F, Dalix AM, Chapppuis AS, Rossi F, Fiquet P, Gaudin V, Assoun $M$ \& Slama G (1996) Monosodium glutamate affects mealtime food selection in diabetic patients. Appetite 26(3):267-75.

8. Rogers PJ \& Blundell JE (1990) Umami and appetite: effects of monosodium glutamate on hunger and food intake in human subjects. Physiol Behav 48(6):801-4.

9. Schiffman SS (2000) Intensification of sensory properties of foods for the elderly. J Nutr 130(4S Suppl):927S-30S.

10. Prescott J (2004) Effects of added glutamate on liking for novel food flavours. Appetite 42(2):143-50.

11. Kurihara K \& Kashiwayanagi M (2000) Physiological studies on umami taste. J Nutr 130(4S Suppl):931S-4S.

12. Delay ER, Beaver AJ, Wagner KA, Stapleton JR, Harbaugh JO, Catron KD $\&$ Roper SD (2000) Taste preference synergy between glutamate receptor agonists and inosine monophosphate in rats. Chem Senses. 25(5):507-15.

13. Smriga M \& Torii K (2000) Release of hypothalamic norepinephrine during MSG intake in rats fed normal and nonprotein diet. Physiol Behav 70(34):413-5.

14. He W, Yasumatsu K, Varadarajan V, Yamada A, Lem J, Ninomiya Y, Margolskee RF \& Damak S (2004) Umami taste responses are mediated by alpha-transducin and alpha-gustducin. J Neurosci 24(35):7674-80.

15. Ruiz CJ, Wray K, Delay E, Margolskee RF \& Kinnamon SC Behavioural evidence for a role of alpha-gustducin in glutamate taste. (2003) Chem Senses 28(7):573-9.

16. Naim M, Ohara I, Kare MR \& Levinson M (1991) Interaction of MSG taste with nutrition: perspectives in consummatory behaviour and digestion. Physiol Behav 49(5):1019-24. 
17. Mori M, Kawada T, Ono T \& Torii K (1991) Taste preference and protein nutrition and L-amino acid homeostasis in male Sprague-Dawley rats. Physiol Behav 49(5):987-95.

18. Kondoh T, Mori M, Ono T \& Torii K (2000) Mechanisms of umami taste preference and aversion in rats. J Nutr 130(4S Suppl):966S-70S.

19. Laska M, Hernandez Salazar LT (2004) Gustatory responsiveness to monosodium glutamate and sodium chloride in four species of nonhuman primates. J Exp Zoolog A Comp Exp Biol 301(11):898-905.

20. Murphy C (1987) Flavour preference for monosodium glutamate and casein hydrolysate in young and elderly persons. In Y.Kawamura \& M.R.Kare (Eds.). Umami: A basic taste (pp.139-51). New York: Marcel Dekker.

21. Stunkard AJ \& Messick S (1985) The three-factor eating questionnaire to measure dietary restraint, disinhibition and hunger. J Psychosom Res 29(1):71-83.

22. Westerterp KR, Wouters L, \& Marken-Lichtenbelt vd W (1995) The Maastricht protocol for the measurements of body composition and energy expenditure with labeled water. Obesity Research 3: 49-57.

23. Westerterp KR (1999) Body composition, water turnover and energy turnover assessment with labelled water. Proceedings of the nutrition society. 58:945-951.

24. Kamphuis MM, Saris WH \& Westerterp-Plantenga MS (2003) The effect of addition of linoleic acid on food intake regulation in linoleic acid tasters and linoleic acid non-tasters. Br J Nutr 90(1):199-206.

25. Bellisle F (1999) Glutamate and the Umami taste: sensory, metabolic, nutritional and behavioural considerations. A review of the literature published in the last 10 years. Neurosci Biobehav Rev 23:423-38.

26. Homsey C (2001 Oct) Food product design elements; Flavour enhancement: Taking taste from so-so to spectacular.

http://www.foodproductdesign.com/archive/2001/1001de.html

27. Chapman IM, Goble EA, Wittert GA \& Horowitz M (1999) Effects of small-intestinal fat and carbohydrate infusions on appetite and food intake in obese and nonobese men. Am J Clin Nutr 69(1):6-12.

28. Kovacs EM, Lejeune MP \& Westerterp-Plantenga MS (2003) The effects of enterostatin intake on food intake and energy expenditure. Br J Nutr 90(1):207-14.

29. Mojet J, Christ-Hazelhof E \& Heidema J (2001) Taste perception with age: generic or specific losses in threshold sensitivity to the five basic tastes? Chem Senses 26(7):845-60.

30. Okiyama A \& Beauchamp GK (1998) Taste dimensions of monosodium glutamate (MSG) in a food system: role of glutamate in young American subjects. Physiol Behav 65(1):177-81.

31. Schiffman SS, Sattely-Miller EA, Zimmerman IA, Graham BG, \& Erickson RP (1994) Taste perception of monosodium glutamate in foods in young and elderly subjects. Physiol. Behav 56:265-276. 
32. Lugaz O, Pillias AM, Faurion A (2002) A new specific ageusia: some humans cannot taste L-glutamate. Chem Senses 27(2):105-15.

33. Ullrich NV, Touger-Decker R, O'sullivan-Maillet J \& Tepper BJ (2004) PROP taster status and self-perceived food adventurousness influence food preferences. J Am Diet Assoc 104(4):543-9.

34. Mela DJ (2001) Determinants of food choice: relationships with obesity and weight control. Obes Res 9 (Suppl 4):249S-255S. 


\section{6 Effects of a high-protein diet with MSG and IMP' 5 on metabolism and appetite}

Astrid J.P.G. Smeets, Natalie D. Luscombe-Marsh, Manuela P.G.M. Lejeune, Margriet S. Westerterp-Plantenga

Submitted for publication 


\begin{abstract}
Condiments, such as monosodium-glutamate (MSG), have been shown to increase thermogenesis. The aim of the study was to determine if addition of MSG in combination with inosine-monophosphate-5 (IMP'5) to a high protein diet has an effect on energy expenditure, substrate oxidation, appetite profile and relevant metabolites. Twelve subjects ( 6 male/ 6 female; age: 26 $\pm 9 \mathrm{yr}, \mathrm{BMI}: 22.6 \pm 2.2 \mathrm{~kg} / \mathrm{m}^{2}$ ) were fed a high-protein diet during three $36-\mathrm{h}$ respiration chamber experiments. In a randomized cross-over design they received a lunch meal 1. without added MSG+IMP'5; 2. with added MSG+IMP'5; or 3. with MSG+IMP'5 in capsules. The concentrations of MSG and IMP'5 added were $0.6 \%[\mathrm{w} / \mathrm{w}]$ and $0.25 \%$ [wt $/ \mathrm{wt}]$ respectively. Appetite profile, energy expenditure and its components, substrate oxidation, and GLP-1, ghrelin, leptin, insulin and glucose concentrations were measured.

Desire to eat (24-h area under the curve) was significantly lower in the highprotein diet with added MSG+IMP'5 compared to the high-protein diet without MSG+IMP'5 (833 \pm 372 versus $1079 \pm 344$, $\mathrm{p}<0.05)$. No significant differences were seen in hunger, satiety, fullness or prospective consumption between the three conditions. With respect to energy expenditure and its components, substrate oxidation and hormone concentrations no significant differences were found between the three conditions.

In conclusion, addition of MSG in combination with IMP-5 to a high-protein diet, either added to the food or in capsules, decreased overall desire to eat without affecting hunger and satiety. Moreover, it did not affect energy metabolism, substrate oxidation, or hormone concentrations.
\end{abstract}




\section{Introduction}

High-protein diets, as compared to normal-protein diets, can cause greater total weight and fat loss as well as improved weight maintenance ${ }^{1-3}$. Protein has been observed to increase satiety to a greater extent than carbohydrate and fat ${ }^{4,5}$. Furthermore, protein has the highest and most prolonged thermic effect $^{6}$. Despite the benefits of higher-protein diets, compliance to them is poor $^{7-9}$.

Two specific food components that have received some attention as oral stimulators of appetite and metabolism are monosodium glutamate (MSG) and inosine-monophosphate-5 (IMP'5). Because of its natural association with protein-containing foods, glutamate is often described as the taste of protein; to Western palates its taste may best be described as savory, meaty or broth-like, and to Asian palates it is described as UMAMI (Japanese word for deliciousness) ${ }^{10}$. IMP'5 is a nucleotide mono-phosphate that is found primarily in meats and some fish (e.g. tuna) and also exudes the UMAMI taste. It interacts synergistically with MSG to accentuate the intensity of the UMAMI taste ${ }^{11}$.

It is established that the addition of low concentrations of MSG to a variety of foods increases their pleasantness. This causes an increase in the spontaneous intake and also seems to emphasize sensoric satiety of those foods. The accelerated satiety may reduce overall energy intake.

We hypothesize that the addition of a low concentration of MSG in combination with IMP'5 as a flavor enhancer to isocaloric meals high in protein may increase satiety and reduce hunger more than if no MSG is added. If that is the case, it is expected that there will be differences in the excretion of satiety related hormones such as GLP-1, leptin, insulin and ghrelin after the consumption of high-protein meals with and without added MSG and IMP' $5{ }^{12}$.

Our second aim was to investigate in human subjects whether the addition of MSG and IMP'5 to food has effects on energy expenditure and substrate oxidation. In rat studies, the addition of MSG to food increases the thermic effect of feeding ${ }^{13}$ and causes a rapid switch in substrate utilization ${ }^{14}$. Furthermore, Niijima et al. ${ }^{15}$ showed that MSG administration stimulates vagal nerve activity and thereby can increase energy expenditure.

Our third aim was to investigate whether ingestion of MSG and IMP'5 mixed through a high-protein meal has different effects on satiety, satiety related hormones and energy expenditure compared to ingestion of MSG and IMP' 5 in capsules with a high-protein meal. In rat studies, the effects on metabolism after addition of MSG to food have been observed in the cephalic phase, which indicates that the oral exposure to MSG may by of importance. However, since glutamate sensors are found not only in the oral cavity, but also in the gut ${ }^{16}$, it is of interest to investigate to what extent stimulation of only the gut sensors by administrating MSG and IMP'5 in 
capsules lead to stimulation of satiety, satiety related hormones and energy expenditure.

Summarizing, the aim of the study was to determine if addition of MSG in combination with IMP'5 to a high-protein diet, either mixed through the food or given in capsules, has an effect on appetite profile, energy expenditure, substrate oxidation and relevant satiety related hormones.

\section{Subjects and Methods}

Subjects

Twelve healthy volunteers (6 men/6 women, BMI: $20-25 \mathrm{~kg} / \mathrm{m}^{2}$, age: $18-45$

y) were recruited by advertisements placed on notice boards at the university. All subjects underwent a medical screening and all were in good health, non-smokers, not using medication and at most moderate alcohol users. Baseline characteristics of the subjects are presented in Table 1. Written informed consent was obtained from all participants. The Medical Ethics Committee of the Academic Hospital in Maastricht approved of the study.

Table 1. Subject characteristics

\begin{tabular}{lc}
\hline & Mean $\pm \mathbf{s d}$ \\
\hline Age $(\mathbf{y r})$ & $26 \pm 9$ \\
Body weight $(\mathbf{k g})$ & $71.2 \pm 12.5$ \\
Height $(\mathbf{m})$ & $1.77 \pm 0.12$ \\
BMI $\left(\mathbf{k g} / \mathbf{m}^{\mathbf{2}}\right)$ & $22.6 \pm 2.2$ \\
Fat mass $(\mathbf{k g})$ & $13.7 \pm 5.4$ \\
Fat free mass $(\mathbf{k g})$ & $56.5 \pm 12.3$ \\
Body fat $(\%)$ & $19.8 \pm 8.0$ \\
\hline
\end{tabular}

Values are means \pm sd. $n=12$ (6 men / 6 women)

\section{Study protocol}

The study had a randomized, cross-over design. Subjects underwent three $36 \mathrm{~h}$ sessions in a respiration chamber for measurements of energy expenditure and substrate oxidation. Three days prior to each session, subjects were provided with a standardized diet to consume at home.

\section{Energy intake and diets}

During each experimental session subjects were fed with a study diet designed to provide energy balance. The energy content of the diet that the subjects consumed at home was based on Basal Metabolic Rate (BMR) as calculated with the equation of Harris-Benedict ${ }^{17}$. BMR was multiplied by an activity index of $1.7^{18}$. To determine the appropriate level of energy intake for attaining energy balance in the respiration chamber, the Sleeping Metabolic Rate (SMR) was measured during the first night and multiplied by an activity index of $1.5^{18}$. Energy intake was divided over the meals as $20 \%$ for breakfast $(08: 00 \mathrm{~h}), 40 \%$ for lunch $(12: 00 \mathrm{~h})$, and $40 \%$ for dinner 
(18:00h). The diet composition of the diets (\% of energy protein/carbohydrate/fat) was 30/40/30 during the three days at home, as well as during day 4 in the respiration chamber. However, the lunch on day 4 was higher in protein (50/30/20) and this was compensated during breakfast and dinner, so that on daily level the diet composition was 30/40/30. At lunch during day 4 the actual test meal was provided. In random order subjects received a lunch without added MSG and IMP'5, a lunch with MSG and IMP'5 mixed through to the food, and a lunch with MSG and IMP'5 in capsules that had to be consumed together with the food. The concentrations MSG and IMP'5 added were $0.6 \%[\mathrm{w} / \mathrm{w}]$ and $0.25 \%$ $[\mathrm{wt} / \mathrm{wt}]$ respectively, representing a level that is perceived by the majority of the population (personal communication, Luscombe 2007). The MSG and IMP'5 were purchased as salts from Ajinomoto Foods Germany GmbH. (Hamburg, Germany). Each lunch consisted of three courses: salad, pasta with tomato sauce, and yoghurt.

\section{Blood sampling}

Before the lunch of day 4, a Teflon catheter was placed in the antecubital vein for blood sampling. During each respiration chamber session 8 blood samples $(12: 00 \mathrm{~h}, 12: 35 \mathrm{~h}, 12: 50 \mathrm{~h}, 13: 20 \mathrm{~h}, 13: 50 \mathrm{~h}, 14: 20 \mathrm{~h}, 14: 50 \mathrm{~h}$, and 15:20h) were taken to determine plasma ghrelin, GLP-1, leptin, insulin and glucose concentrations. The blood was centrifuged immediately. All obtained samples were frozen in liquid nitrogen and stored at $-80{ }^{\circ} \mathrm{C}$ until analyzed. Plasma concentrations of active ghrelin were measured by RIA (Linco Research Inc., St. Charles, Missouri, USA). Plasma active GLP-1 samples were analyzed using ELISA (EGLP-35K; Linco Research Inc., St Charles, Missouri, USA). Leptin concentrations were measured by RIA (double-antibody RIA, human leptin specific RIA kit, Linco Research Inc., St. Charles, Missouri, USA). Insulin samples were analyzed using a RIA kit (Insulin RIA-100, Pharmacia, Uppsala, Sweden) and glucose samples were analyzed with the hexokinase method (Glucose HK 125 kit, ABX diagnostics, Montpellier, France).

\section{Appetite profile}

Appetite profile (hunger, satiety, desire to eat, fullness and prospective consumption) was measured using anchored $100-\mathrm{mm}$ visual analogue scales (VAS). During each respiration chamber session these questionnaires were completed before and after every meal and, at every hour in between meals (a total 14 times a day). For the calculation of the 24-h area under the curve (AUC) the VAS ratings were interpolated from the latest measurement at night until the first measurement in the morning. 
Body composition

Body composition was determined by the three compartment model, using the hydrodensitometry and deuterium dilution $\left({ }^{2} \mathrm{H}_{2} \mathrm{O}\right)$ technique ${ }^{19,20}$, and was calculated using the combined equation of $\mathrm{Siri}^{21}$.

\section{Indirect calorimetry}

Oxygen consumption and carbon dioxide production were measured in the respiration chamber ${ }^{22}$. The respiration chamber is a $14 \mathrm{~m}^{3}$ room which is furnished with a bed, chair, computer, television, radio-cassette player, telephone, intercom, sink and toilet. The room was ventilated with fresh air at a rate of 70-80 1/min. The ventilation rate was measured with a dry gas meter (type 4, Schlumberger, Dordrecht, the Netherlands). The concentrations of oxygen and carbon dioxide were measured using a paramagnetic $\mathrm{O}_{2}$ analyzer (Magnos 6G, Hartmann and Braun, Frankfurt, Germany; and type OA184A, Servomex, Crowborough, United Kingdom) and an infrared $\mathrm{CO}_{2}$ analyzer (Uras 3G, Hartmann and Braun, Frankfurt, Germany). During each 15-min period, six samples of outgoing air for each chamber, and one sample of fresh air, zero gas, and calibration gas were measured. The gas samples to be measured were selected by a computer that also stored and processed the data ${ }^{22}$.

\section{Energy expenditure and substrate oxidation}

24h energy expenditure consists of SMR, diet-induced thermogenesis (DIT), and activity-induced energy expenditure. $24 \mathrm{~h}$ energy expenditure and $24 \mathrm{~h}$ respiratory quotient (RQ) were measured from $08: 00 \mathrm{~h}$ on day 4 to $08: 00 \mathrm{~h}$ on day 5. Activity was monitored using a radar system which is based on the Doppler principle. SMR was defined as the lowest mean energy expenditure measured over three consecutive hours between 00:00h and 07:00h. DIT was calculated by plotting energy expenditure against radar output; both averaged over 30 -min periods. The intercept of the regression line at the lowest radar output represents the energy expenditure in the inactive state (Resting Metabolic Rate; RMR), consisting of SMR and DIT ${ }^{5}$. DIT was determined by subtracting SMR from RMR. Activity-induced energy expenditure (AEE) was determined by subtracting SMR and DIT from $24 \mathrm{~h}$ energy expenditure. Carbohydrate, fat, and protein oxidation were calculated from the measurements of $\mathrm{O}_{2}$ consumption, $\mathrm{CO}_{2}$ production and urinary nitrogen excretion, using the formula of Brouwer ${ }^{23}$. 24h urine was collected from the second voiding on day 4 until the first voiding on day 5. Samples were collected in containers with $10 \mathrm{ml} \mathrm{H}_{2} \mathrm{SO}_{4}$ to prevent nitrogen loss through evaporation. Volume and nitrogen concentration were measured, the latter using a nitrogen analyzer (Elemental Analyzer, CHN-O-Rapid, Heraeus). 
Adverse events

Adverse events during each experimental session were recorded and the severity and outcome specified.

\section{Statistical analysis}

Data are presented as mean \pm standard deviation, unless otherwise indicated. A repeated measures ANOVA was carried out to determine possible differences between conditions in energy expenditure, substrate oxidation, and appetite profile. Post hoc analyses were done with the Scheffe F-test. To detect possible time by treatment effects in hormone concentrations, a twofactor repeated measures ANOVA was used. Significance was defined as $\mathrm{p}<0.05$. All statistical tests were performed using Statview SE+ Graphics (Abacus Concepts, Berkeley, CA, 1988).

\section{Results}

The appetite profile (Table 2) shows that the general desire to eat over $24 \mathrm{~h}$, expressed as area under the curve, was significantly reduced when MSG+IMP'5 was added to the lunch meal compared to when no MSG+IMP'5 was added. At the same time, no effects were seen in hunger, satiety, fullness, or prospective consumption, and results were highly reproducible.

Table 2. The appetite profile (24-h area under the curve) during the three conditions $(\mathrm{n}=12)$

\begin{tabular}{lccc}
\hline & $\begin{array}{l}\text { Without } \\
\text { MSG+IMP'5 }\end{array}$ & $\begin{array}{l}\text { With } \\
\text { MSG+IMP'5 } \\
\text { added to } \\
\text { food }\end{array}$ & $\begin{array}{l}\text { With } \\
\text { MSG+IMP' } \\
\text { 5 in capsules }\end{array}$ \\
\hline Hunger & $911 \pm 381$ & $877 \pm 318$ & $858 \pm 293$ \\
Satiety & $1078 \pm 461$ & $1159 \pm 498$ & $1101 \pm 429$ \\
Desire to eat & $1079 \pm 344$ & $833 \pm 372^{*}$ & $902 \pm 417$ \\
$\begin{array}{l}\text { Fullness } \\
\text { Prospective } \\
\text { consumption }\end{array}$ & $1038 \pm 426$ & $1044 \pm 457$ & $1155 \pm 380$ \\
\hline Vans & $1120 \pm 327$ & $1000 \pm 377$ & $1020 \pm 345$ \\
\hline
\end{tabular}

Values are means $\pm \mathrm{sd} .{ }^{*} \mathrm{P}<0.05$ compared to the condition without MSG+IMP'5 (ANOVA repeated measures)

Furthermore, the results show that the three experiments were also highly reproducible with respect to effects on thermogenesis and hormone concentrations, without further significant differences between conditions. The addition of MSG in combination with IMP'5 to a high-protein diet either added to the food or in capsules, had no effect on energy expenditure or its components (Table 3 ). 
Table 3. Total energy expenditure, components of energy expenditure, energy intake and RQ during the three conditions $(\mathrm{n}=12)$

\begin{tabular}{lccc}
\hline & $\begin{array}{l}\text { Without } \\
\text { MSG+IMP'5 }\end{array}$ & $\begin{array}{l}\text { With } \\
\text { MSG+IMP'5 } \\
\text { added to food }\end{array}$ & $\begin{array}{l}\text { With } \\
\text { MSG+IMP' } \\
\text { 5 in capsules }\end{array}$ \\
\hline TEE (MJ/d) & $9.1 \pm 1.2$ & $9.2 \pm 1.0$ & $9.0 \pm 1.1$ \\
EI (MJ/d) & $9.7 \pm 1.2$ & $9.7 \pm 1.2$ & $9.7 \pm 1.2$ \\
SMR (MJ/d) & $6.4 \pm 0.8$ & $6.8 \pm 0.8$ & $6.4 \pm 0.8$ \\
DIT (MJ/d) & $0.9 \pm 0.4$ & $0.8 \pm 0.3$ & $0.8 \pm 0.5$ \\
DIT (\%EI) & $9.4 \pm 3.6$ & $8.1 \pm 2.0$ & $8.8 \pm 6.3$ \\
AEE (MJ/d) & $1.9 \pm 0.5$ & $2.1 \pm 0.6$ & $1.9 \pm 0.7$ \\
RQ & $0.85 \pm 0.02$ & $0.84 \pm 0.02$ & $0.84 \pm 0.02$ \\
\hline
\end{tabular}

TEE: Total energy expenditure; EI: Energy intake; SMR: Sleeping metabolic rate; DIT: Diet-induced thermogenesis; AEE: Activity-induced energy expenditure; RQ:

Respiratory quotient. Values are means $\pm \mathrm{sd}$. No significant differences were seen between conditions (ANOVA repeated measures).

The substrate balances shown in Figure 1. indicate no significant differences in substrate balances between the three conditions. Thus energy expenditure and substrate oxidation were highly reproducible and not affected by addition of MSG and IMP to the food.

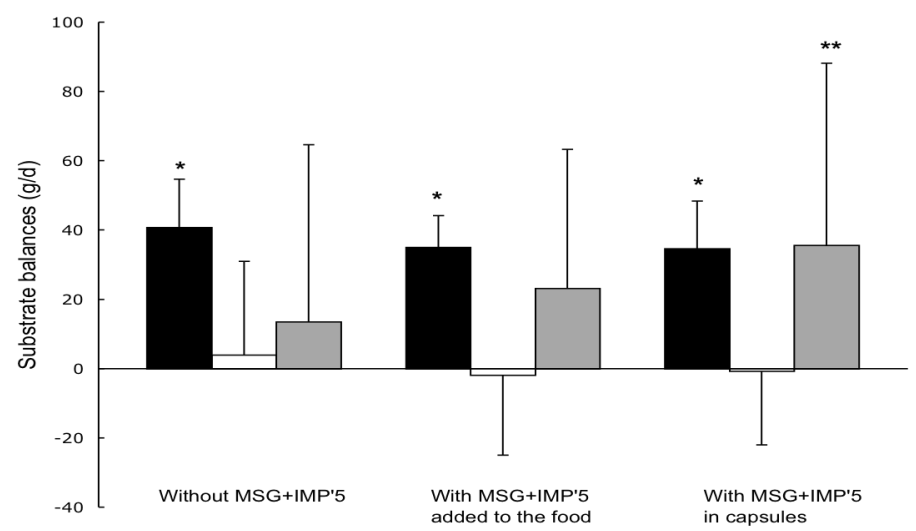

Figure 1. Substrate balances for the three different conditions. Protein balances $(\mathrm{n}=10)$ are indicated with black bars, fat balances $(\mathrm{n}=10)$ are indicated with white bars, and carbohydrate balances $(\mathrm{n}=10)$ are indicated with grey bars. Values are means $\pm \mathrm{sd} .{ }^{*} \mathrm{P}$ $<0.0001$ compared to zero; $* * \mathrm{P}<0.05$ compared to zero

Plasma GLP-1, insulin, and glucose concentrations increased immediately after lunch in all three conditions (Figure 2 - 4). 


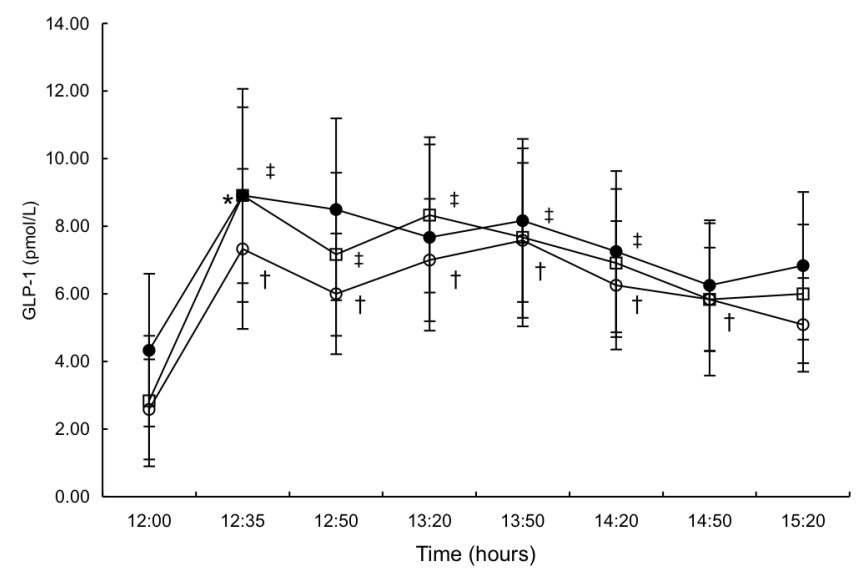

Figure 2. GLP-1 concentrations during the condition without MSG+IMP' 5 (open circles; $\mathrm{n}=12$ ), with MSG+IMP' 5 added to the food (filled circles; $\mathrm{n}=12$ ) and with MSG+IMP' 5 in capsules (open squares; $n=12$ ). Values are means \pm sd. There were no significant time $\mathrm{x}$ treatment effects (two-factor repeated measures ANOVA). For the condition without MSG+IMP' 5: $\dagger \mathrm{P}<0.005$ compared to 12:00h; for the condition with MSG+IMP'5 added to the food: * $\mathrm{P}<0.05$ compared to $12: 00 \mathrm{~h}$; for the condition with MSG+IMP'5 in capsules: $+\mathrm{P}<0.005$ compared to $12: 00 \mathrm{~h}$ (repeated measures ANOVA)

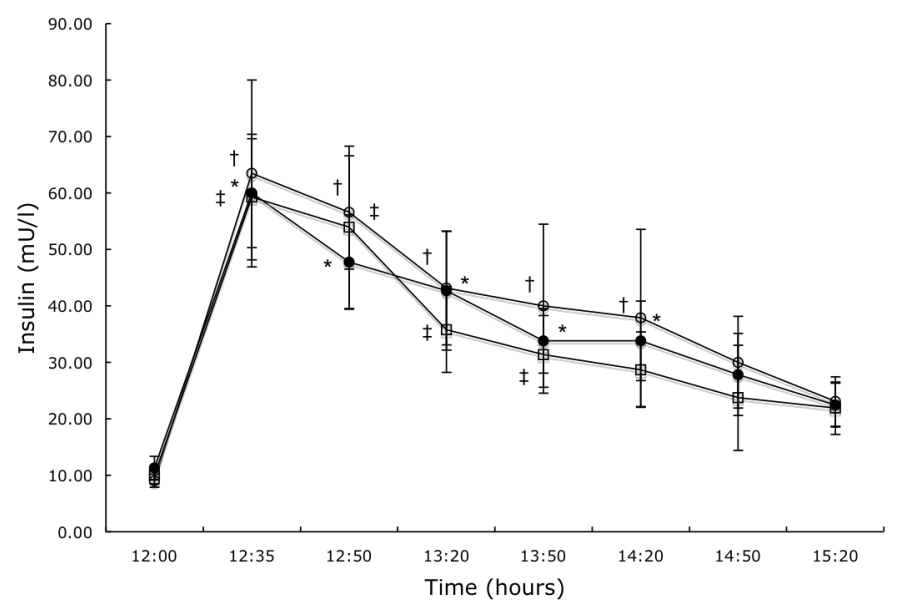

Figure 3. Insulin concentrations during the condition without MSG+IMP' 5 (open circles; $\mathrm{n}=12$ ), with MSG+IMP' 5 added to the food (filled circles; $n=12$ ) and with MSG+IMP' 5 in capsules (open squares; $n=12$ ). Values are means $\pm s d$. There were no significant time $\mathrm{x}$ treatment effects (two-factor repeated measures ANOVA). For the condition without MSG+IMP' 5: $\uparrow \mathrm{P}<0.05$ compared to $12: 00 \mathrm{~h}$; for the condition with MSG+IMP' 5 added to the food: * $\mathrm{P}<0.05$ compared to $12: 00 \mathrm{~h}$; for the condition with MSG+IMP' 5 in capsules: $\$ \mathrm{P}<0.05$ compared to $12: 00 \mathrm{~h}$ (repeated measures ANOVA) 


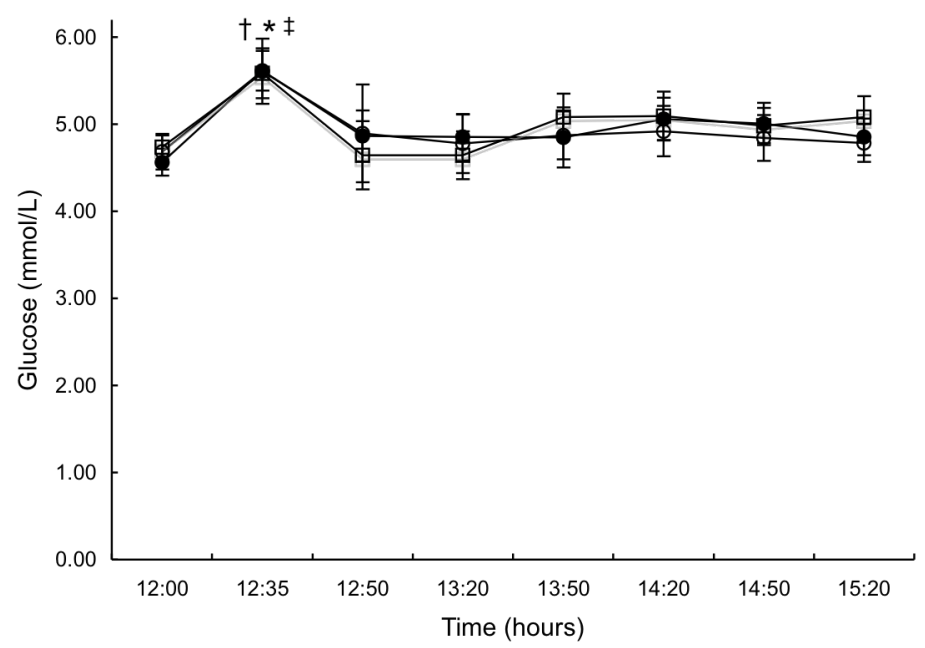

Figure 4. Glucose concentrations during the condition without MSG+IMP' 5 (open circles; $n=12$ ), with MSG+IMP'5 added to the food (filled circles; $n=12$ ) and with MSG+IMP' 5 in capsules (open squares; $n=12$ ). Values are means $\pm s d$. There were no significant time $\mathrm{x}$ treatment effects (two-factor repeated measures ANOVA). For the condition without MSG+IMP' $5: \dagger \mathrm{P}<0.01$ compared to $12: 00 \mathrm{~h}$; for the condition with MSG+IMP' 5 added to the food: * $\mathrm{P}<0.0001$ compared to $12: 00 \mathrm{~h}$; for the condition with MSG+IMP'5 in capsules: $\$ \mathrm{P}<0.01$ compared to $12: 00 \mathrm{~h}$ (repeated measures ANOVA)

Decreases in plasma active ghrelin concentrations were found in all three conditions (Figure 5).

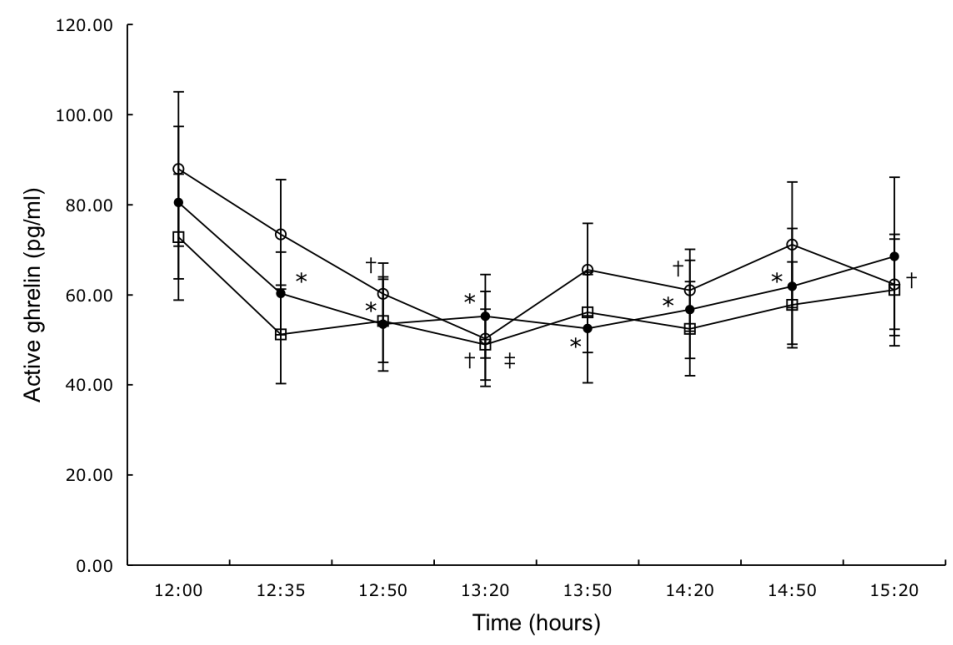

Figure 5. Active ghrelin concentrations during the condition without MSG+IMP'5 (open circles; $n=12$ ), with MSG+IMP' 5 added to the food (filled circles; $n=12$ ) and with MSG+IMP' 5 in capsules (open squares; $n=12$ ). Values are means $\pm \mathrm{sd}$. There were no significant time $\mathrm{x}$ treatment effects (two-factor repeated measures ANOVA). For the condition without MSG+IMP' $5: \dagger \mathrm{P}<0.05$ compared to $12: 00 \mathrm{~h}$; for the condition with MSG+IMP'5 added to the food: $* \mathrm{P}<0.05$ compared to $12: 00 \mathrm{~h}$; for the condition with MSG+IMP' 5 in capsules: $\$ \mathrm{P}<0.05$ compared to $12: 00 \mathrm{~h}$ (repeated measures ANOVA) 


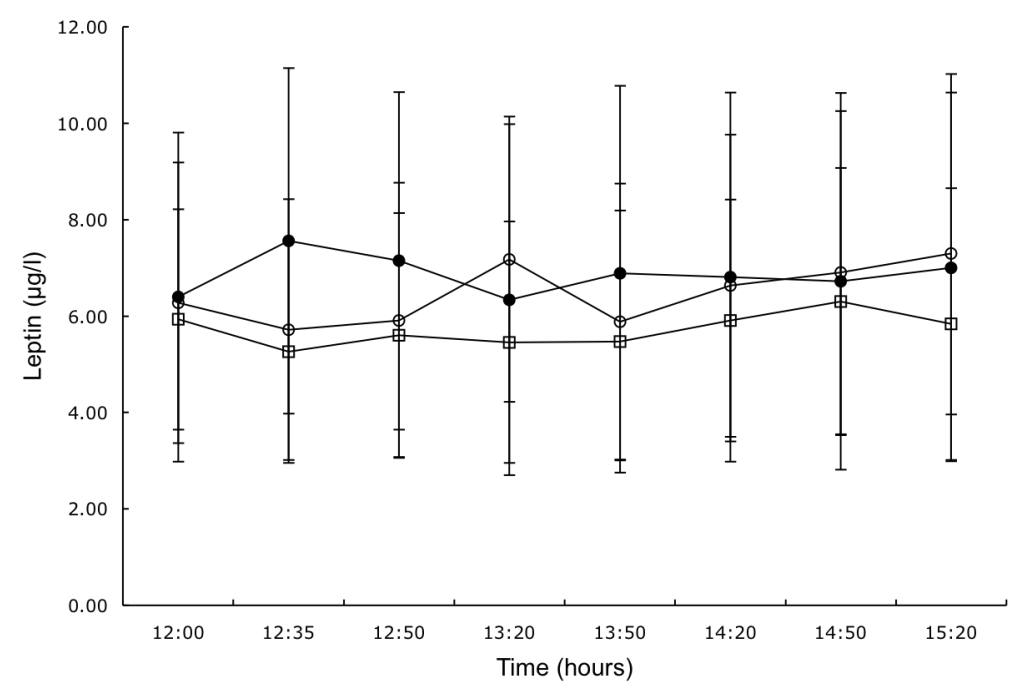

Figure 6. Leptin concentrations during the condition without MSG+IMP' 5 (open circles; $\mathrm{n}=12$ ), with MSG+IMP'5 added to the food (filled circles; $\mathrm{n}=12$ ) and with MSG+IMP'5 in capsules (open squares; $n=12$ ). Values are means $\pm \mathrm{sd}$. There were no significant time $\mathrm{x}$ treatment effects (two-factor repeated measures ANOVA)

In all three conditions, plasma leptin concentrations did not change significantly (Figure 6). No time by treatment effects were found in any of the hormone concentrations. There are different baseline concentrations of GLP-1 and ghrelin between conditions, although not significant. Therefore an analysis of the delta's was executed, that showed no significant differences in the change of these hormones.Also excursions in blood hormone

concentrations were highly reproducible and not affected by MSG and IMP addition to the food.

\section{Discussion}

Addition of MSG in combination with IMP'5 to a high-protein meal was shown to decrease $24 \mathrm{~h}$ desire to eat. Similarly, Rogers \& Blundell ${ }^{24}$ observed that soups containing MSG reduced desire to eat in general and increased fullness. In the present study, the decrease $24 \mathrm{~h}$ desire to eat was only found when MSG+IMP'5 is added to the food and not when it is ingested in capsules. Although glutamate sensors are also found in the gut ${ }^{16}$, stimulation of only the gut sensors by administrating MSG+IMP'5 in capsules does not lead to changes in the appetite profile. So, sensory effects of MSG+IMP'5 appear only to occur when it is added to food, and not when taken separately in capsules. In addition to the metabolic satiety due to high protein diets ${ }^{4,25}$ sensory satiety may play a role when the taste of high protein foods is enhanced by adding MSG and IMP'5. 
The addition of MSG did not elicit an effect on energy expenditure or substrate oxidation as was shown in rats by Viarouge et al. ${ }^{13,14}$. Probably the dosage of MSG was that low that it did not affect energy and substrate metabolism. However, the mean daily intake of added MSG is $4 \mathrm{~g}$ in the Eastern regions of the world and $<1 \mathrm{~g}$ in the West ${ }^{26}$. So, for human standards the intake of MSG (between 4.6 - $7.2 \mathrm{~g}$ of added MSG) was relatively high. The dosage was determined by a pilot experiment to yield an optimal palatability of the food. Viarouge et al. ${ }^{13,14}$ suggest that MSG is metabolically effective only when it is added to a high caloric diet.

The meals provided a subject specific energy load, providing energy balance, with a high amount of protein. A high protein intake is associated with an increase in energy expenditure and changes in substrate oxidation ${ }^{4,27}$. It may well be that the effects of the high protein content of the diet have overruled the effects of MSG and IMP'5. The intake of MSG has been associated with negative side effects, also referred to as the Chinese Restaurant Syndrome ${ }^{28}$. The symptoms of this syndrome are acute and temporary, and can occur after consumption of MSG that is present in Chinese foods. Several studies have investigated the relationship between the latter two, but could not confirm that MSG was the causal agent of this syndrome ${ }^{28,29}$. Also in the present study no negative side effects occurred. In conclusion, addition of MSG in combination with IMP-5 to a high-protein diet, either added to the food or in capsules, decreased overall desire to eat without affecting hunger and satiety. Moreover, it did not affect energy metabolism, substrate oxidation, or hormone concentrations.

Further studies should investigate whether the addition of MSG+IMP'5 to high-protein foods may facilitate adherence to high high-protein diets by increasing palatability and may facilitate adherence to weight-loss or weight maintenance high-protein diets by decreasing desire to eat.

\section{Acknowledgments}

We gratefully acknowledge Jiske van der Meulen, Wendy Sluijsmans, Jos Stegen, Loek Wouters and Paul Schoffelen for their assistance. 


\section{References}

1. Lejeune MP, Kovacs EM, Westerterp-Plantenga MS. Additional protein intake limits weight regain after weight loss in humans. Br J Nutr 2005;93(2):281-9.

2. Skov AR, Toubro S, Ronn B, Holm L, Astrup A. Randomized trial on protein vs carbohydrate in ad libitum fat reduced diet for the treatment of obesity. Int J Obes Relat Metab Disord 1999;23(5):528-36.

3. Westerterp-Plantenga MS, Lejeune MP, Nijs I, van Ooijen M, Kovacs EM. High protein intake sustains weight maintenance after body weight loss in humans. Int J Obes Relat Metab Disord 2004;28(1):57-64.

4. Lejeune MP, Westerterp KR, Adam TC, Luscombe-Marsh ND, WesterterpPlantenga MS. Ghrelin and glucagon-like peptide 1 concentrations, 24-h satiety, and energy and substrate metabolism during a high-protein diet and measured in a respiration chamber. Am J Clin Nutr 2006;83(1):89-94.

5. Westerterp KR, Wilson SA, Rolland V. Diet induced thermogenesis measured over $24 \mathrm{~h}$ in a respiration chamber: effect of diet composition. Int $\mathbf{J}$ Obes Relat Metab Disord 1999;23(3):287-92.

6. Tappy L. Thermic effect of food and sympathetic nervous system activity in humans. Reprod Nutr Dev 1996;36(4):391-7.

7. Foster GD, Wyatt HR, Hill JO, McGuckin BG, Brill C, Mohammed BS, Szapary PO, Rader DJ, Edman JS, Klein S. A randomized trial of a lowcarbohydrate diet for obesity. N Engl J Med 2003;348(21):2082-90.

8. St Jeor ST, Howard BV, Prewitt TE, Bovee V, Bazzarre T, Eckel RH. Dietary protein and weight reduction: a statement for healthcare professionals from the Nutrition Committee of the Council on Nutrition, Physical Activity, and Metabolism of the American Heart Association. Circulation 2001;104(15):1869-74.

9. Brinkworth GD, Noakes M, Keogh JB, Luscombe ND, Wittert GA, Clifton PM. Long-term effects of a high-protein, low-carbohydrate diet on weight control and cardiovascular risk markers in obese hyperinsulinemic subjects. Int J Obes Relat Metab Disord 2004;28(5):661-70.

10. Yamaguchi S, Ninomiya K. Umami and food palatability. J Nutr 2000;130(4S Suppl):921S-6S.

11. Kurihara K, Kashiwayanagi M. Physiological studies on umami taste. J Nutr 2000;130(4S Suppl):931S-4S.

12. Steffens AB, Leuvenink H, Scheurink AJ. Effects of monosodium glutamate (umami taste) with and without guanosine 5'-monophosphate on rat autonomic responses to meals. Physiol Behav 1994;56(1):59-63.

13. Viarouge C, Caulliez R, Nicolaidis S. Umami taste of monosodium glutamate enhances the thermic effect of food and affects the respiratory quotient in the rat. Physiol Behav 1992;52(5):879-84. 
14. Viarouge C, Even P, Rougeot C, Nicolaidis S. Effects on metabolic and hormonal parameters of monosodium glutamate (umami taste) ingestion in the rat. Physiol Behav 1991;49(5):1013-8.

15. Niijima A. Effects of oral and intestinal stimulation with umami substance on gastric vagus activity. Physiol Behav 1991;49(5):1025-8.

16. Niijima A. Reflex effects of oral, gastrointestinal and hepatoportal glutamate sensors on vagal nerve activity. J Nutr 2000;130(4S Suppl):971S-3S.

17. Harris JA, Benedict FG. A Biometric Study of Human Basal Metabolism. Proc Natl Acad Sci U S A 1918;4(12):370-3.

18. Westerterp KR. Exercise and energy balance. Westerterp-Plantenga MS, Steffens, A. B. \& Tremblay, A., editor. Milan, Italy: Edra, Medical publishing \& New Media; 1999. 349-361 p.

19. Schoeller DA, van Santen E, Peterson DW, Dietz W, Jaspan J, Klein PD. Total body water measurement in humans with $18 \mathrm{O}$ and $2 \mathrm{H}$ labeled water. Am J Clin Nutr 1980;33(12):2686-93.

20. van Marken Lichtenbelt WD, Westerterp KR, Wouters L. Deuterium dilution as a method for determining total body water: effect of test protocol and sampling time. Br J Nutr 1994;72(4):491-7.

21. Siri WE. The gross composition of the body. Adv Biol Med Phys 1956;4:239-80.

22. Schoffelen PF, Westerterp KR, Saris WH, Ten Hoor F. A dual-respiration chamber system with automated calibration. J Appl Physiol 1997;83(6):2064-72.

23. Brouwer E. On simple formulae for calculating the heat expenditure and the quantities of carbohydrate and fat oxidized in metabolism of men and animals, from gaseous exchange (Oxygen intake and carbonic acid output) and urine-N. Acta Physiol Pharmacol Neerl 1957;6:795-802.

24. Rogers PJ, Blundell JE. Umami and appetite: effects of monosodium glutamate on hunger and food intake in human subjects. Physiol Behav 1990;48(6):801-4.

25. Westerterp-Plantenga MS, Rolland V, Wilson SA, Westerterp KR. Satiety related to $24 \mathrm{~h}$ diet-induced thermogenesis during high protein/carbohydrate vs high fat diets measured in a respiration chamber. Eur J Clin Nutr 1999;53(6):495-502.

26. Bellisle F. Glutamate and the UMAMI taste: sensory, metabolic, nutritional and behavioural considerations. A review of the literature published in the last 10 years. Neurosci Biobehav Rev 1999;23(3):423-38.

27. Westerterp-Plantenga MS, Luscombe-Marsh ND, Lejeune MP, Diepvens K, Nieuwenhuizen A, Engelen MP, Deutz NE, Azzout-Marniche D, Tome D, Westerterp KR. Dietary protein, metabolism, and body-weight regulation: dose-response effects. Int J Obes 2006;30:S16-23.

28. Walker R, Lupien JR. The safety evaluation of monosodium glutamate. J Nutr 2000;130(4S Supp1):1049S-52S.

29. Tarasoff L, Kelly MF. Monosodium L-glutamate: a double-blind study and review. Food Chem Toxicol 1993;31(12):1019-35. 
Energy expenditure, plasma ghrelin, glucagon-like peptide 1, PYY concentrations, and satiety following a single high protein lunch

Astrid J. Smeets, Stijn Soenen, Natalie D. Luscombe-Marsh, Øydis Ueland and Margriet S. Westerterp-Plantenga

Based on: Energy expenditure, plasma ghrelin, glucagon-like peptide 1, PYY concentrations, and satiety following a single high protein lunch, Journal of Nutrition 138(4) (2008) 698-702. 


\begin{abstract}
High-protein foods are more satiating and have a higher thermogenic effect than normal protein foods, over the short as well as over the long-term. We hypothesized that acute effects of higher protein intake on satiety may be related to acute metabolic and hormonal responses. The study had a single blind, randomized, crossover design. Subjects underwent two indirect calorimetry tests for measurement of energy expenditure (EE) and substrate oxidation. After a standard subject-specific breakfast, subjects received one of two randomly assigned treatments: an appropriate protein (AP) lunch $(10 \% \mathrm{E}$ protein, $60 \% \mathrm{E}$ carbohydrate, $30 \% \mathrm{E}$ fat), or a high-protein (HP) lunch $(25 \% \mathrm{E}$ protein, $45 \% \mathrm{E}$ carbohydrate, $30 \% \mathrm{E}$ fat). The increase in post-lunch tended to be greater after the HP lunch $(0.85 \pm 0.32 \mathrm{~kJ} / \mathrm{min})$ than after the AP lunch $(0.73 \pm 0.22 \mathrm{~kJ} / \mathrm{min})(\mathrm{p}=0.07)$. The respiratory quotient did not differ between the HP $(0.84 \pm 0.04)$ and the AP $(0.86 \pm 0.04)$ treatments. Satiety Visual Analog Scales (VAS) scores were significantly higher 30 and $120 \mathrm{~min}$ after the HP lunch than after the AP lunch. The AUC of the VAS score for satiety was significantly higher after HP lunch $(263 \pm 61 \mathrm{~mm} / \mathrm{h})$ than after AP lunch (AP $236 \pm 76 \mathrm{~mm} h)(\mathrm{p}<0.02)$. Effects of the meals on satiety and dietinduced thermogenesis did not happen simultaneously with changes in plasma ghrelin, GLP-1 and PYY concentrations. A single HP lunch, therefore, does not exert its acute effect on satiety through increased concentrations of satiety related hormones. Other factors, which may explain the HP effect on satiety, may be metabolites or amino acids.
\end{abstract}




\section{Introduction}

High-protein foods are more satiating and have a higher thermogenic effect than normal protein foods, over the short as well as over the long-term ${ }^{1-13}$. However, the mechanisms or factors that may play a role in the observed effects of high protein foods are yet to be discovered. Gut-hormones, and their effects on hunger and metabolic speed, are the first candidate-factors to be studied. Ghrelin is a peptide secreted from the stomach and it appears to be a hunger signal ${ }^{14,15}$; intravenous infusion of ghrelin increases food intake and enhances appetite ${ }^{15,16}$. In addition, plasma ghrelin concentrations rise gradually before a meal and decrease immediately after eating ${ }^{17,18}$. Glucagon-like peptide 1 (GLP-1) is a thirty amino acid peptide hormone that is released from intestinal $L$ cells into the circulation after a mixed meal ${ }^{19-21}$. Peripheral GLP-1 administration compared with saline infusions reduced food intake and suppressed appetite in normal weight-subjects ${ }^{22}$ and led to lower hunger ratings and decreased energy intake during an ad libitum meal in obese subjects ${ }^{21}$. Peptide tyrosine-tyrosine (PYY) is a gut-derived hormone. Like proglucagon-derived peptides, PYY is synthesized and released from endocrine L-cells from the distal gut in response to food consumption ${ }^{23}$. Fat is a strong stimulus for PYY release ${ }^{24,25}$.

In a recent study Lejeune et al. ${ }^{6}$ showed that a high-protein diet, compared with an adequate-protein diet, when consumed in energy balance over $4 \mathrm{~d}$, increased $24 \mathrm{~h}$ satiety, thermogenesis, sleeping metabolic rate, protein balance, and fat oxidation. In the high-protein condition, satiety was related to protein intake and incidentally to plasma ghrelin and GLP-1 concentrations. It has not been determined whether these effects of a high protein diet occur with exposure to 1 meal. Therefore, the aim of this study was to test the acute effects of a high-protein lunch (HP) on energy expenditure (diet-induced thermogenesis, DIT), substrate oxidation, satiety related hormones (GLP-1, ghrelin, and PYY), and satiety. We hypothesized that a single HP meal compared with a single adequate-protein meal (AP) may increase satiety, diet induced thermogenesis, plasma GLP-1 and PYY concentrations, and fat oxidation, and decrease plasma ghrelin concentrations and respiratory quotient (RQ).

\section{Subjects and Methods}

Subjects

Thirty healthy subjects $(19 \mathrm{f} / 11 \mathrm{~m})$ with a body mass index (BMI; in $\mathrm{kg} / \mathrm{m}^{2}$ ) of 20-30 and aged 18-60 y were recruited by advertisements in local newspapers and on notice boards at Maastricht University. All subjects underwent a medical screening, and all were in good health, non-smokers, not using medication, and at most moderate alcohol users. Eating behavior was assessed using a validated Dutch translation of the Three Factor Eating Questionnaire (TFEQ). Cognitive restrained and unrestrained eating behavior (Factor 1), emotional eating and disinhibition (Factor 2), and the 
subjective feeling of hunger (Factor 3) were scored ${ }^{26}$. The characteristics of the subjects are presented in Table 1. Written informed consent was obtained from all participants. The Medical Ethics Committee of the Academic Hospital in Maastricht approved the study.

Table 1. Subject characteristics

\begin{tabular}{ll}
\hline Age $(\mathbf{y})$ & $31 \pm 14$ \\
Body weight $(\mathbf{k g})$ & $72 \pm 12$ \\
Height $(\mathbf{m})$ & $1.73 \pm 0.09$ \\
BMI $\left(\mathbf{k g} / \mathbf{m}^{\mathbf{2}}\right)$ & $23.8 \pm 2.8$ \\
Body fat $\mathbf{( \% )}$ & $25.6 \pm 8.8$ \\
Dietary restrained $^{\mathbf{2}}$ & $4.3 \pm 2.6$ \\
\hline
\end{tabular}

1 Values are means $\pm \mathrm{SD}, \mathrm{n}=30$

2 Factor 1 of the Three-Factor Eating Questionnaire was used ${ }^{26}$

\section{Experimental sessions}

The study had a single blind, randomized, crossover design. The subjects underwent two indirect calorimetry tests for the measurement of energy expenditure (EE) and substrate oxidation. On the morning before the test (08:00), the subjects received a subject specific breakfast (Drinkontbijt, Campina, Woerden, The Netherlands), which provided $15 \%$ of each subject's individual daily energy requirements. Subject specific daily energy requirements were calculated based on basal metabolic rate (BMR), which was calculated with the equation of Harris-Benedict ${ }^{27}$. BMR was multiplied by an activity index of 1.5. After the breakfast, subjects were not allowed to eat or drink during the morning except water and 1 cup of coffee or tea without milk or sugar. One $\mathrm{h}$ before the test lunch was served (11:00), baseline EE and substrate oxidation were measured by means of an opencircuit, ventilated-hood system with subjects lying supine for at least $30 \mathrm{~min}$. At 12:00 the subjects received a lunch of one of two randomly assigned treatments: AP lunch, which provided 10\% of energy from protein, $60 \%$ of energy from carbohydrate, and 30\% of energy from fat, or HP lunch, which provided $25 \%$ of energy from protein, $45 \%$ of energy from carbohydrate, and $30 \%$ of energy from fat. Subjects were asked to consume all of the meal within $30 \mathrm{~min}$. Both lunches provided $35 \%$ of each subject's individual daily energy requirements and consisted of pasta (Budapest University of Technology and Economics, Budapest, Hungary), sausages (with either a high or adequate level of protein; Matforsk, Ås, Norway), and tomato sauce (Heinz, Elst, The Netherlands). AP lunch and HP lunch were equal in energy content $(\mathrm{kJ})$, weight $(\mathrm{g})$ and energy density $(\mathrm{kJ} / \mathrm{g})$. Post-lunch $\mathrm{EE}$ and substrate oxidation were measured for 210 min after ingestion of the lunch. 


\section{Energy expenditure and substrate oxidation}

On the test days, baseline and post-lunch EE and substrate oxidation were measured with an open-circuit, ventilated-hood system with the subjects lying supine ${ }^{28}$. Gas analysis was performed by a paramagnetic $\mathrm{O}_{2}$ analyzer (OmniCal type 1155B; Crowborough, Sussex, UK) and an IR $\mathrm{CO}_{2}$ analyzer (OmniCal type 1520/1507). EE was calculated using Brouwer's formula ${ }^{29}$. The RQ was calculated as $\mathrm{CO}_{2}$ produced/ $\mathrm{O}_{2}$ consumed. The non-protein RQ was calculated using the formula: $\left[\mathrm{VCO}_{2}(\mathrm{~L})-4.8 \mathrm{xN}(\mathrm{g})\right) /\left(\mathrm{VO}_{2}(\mathrm{~L})-\right.$ $6 \mathrm{xN}(\mathrm{g})]$. Carbohydrate, fat, and protein oxidation were calculated from the measurements of oxygen consumption, carbon dioxide production, and urinary nitrogen excretion by using the formula of Brouwer ${ }^{29}$. Urine samples were collected from the first void after the start of the test day (11:00) until the last void on the test day (16:00). Subjects voided their bladder before the start of the test day (before 11:00) Samples were collected in containers with $10 \mathrm{~mL} \mathrm{H} \mathrm{H}_{2} \mathrm{SO}_{4}$ to prevent nitrogen loss through evaporation. Volume and nitrogen concentration were measured, the latter with a nitrogen analyzer (CHN-O-Rapid; Heraeus, Hanau, Germany).

\section{Blood sampling}

One hour before the lunch was served (11:00), a polytetrafluoroethylene catheter was placed in the antecubital vein for blood sampling. During each test day, 1 blood sample just before the lunch (at $0 \mathrm{~min}$ ) and 4 blood samples after lunch (at $45 \mathrm{~min}, 60 \mathrm{~min}, 120 \mathrm{~min}$, and $180 \mathrm{~min}$ ) were taken for measurement of plasma ghrelin, GLP-1, and PYY concentrations. Blood samples were collected in tubes containing EDTA to prevent clotting. Plasma was obtained by centrifugation $\left(4^{\circ} \mathrm{C}, 1000 \mathrm{x} \mathrm{g}, 10 \mathrm{~min}\right)$ and stored at $-80{ }^{\circ} \mathrm{C}$ until analyzed. Plasma concentrations of active ghrelin were measured by radioimmunoassay (Linco Research Inc, St. Charles, MO). Plasma active GLP-1 samples were analyzed by enzyme-linked immunoradiometric assay (EGLP- 35K; Linco Research Inc, St Charles, MO). PYY was measured with a specific and sensitive radioimmunoassay, which measures, both the full length (PYY1-36) and the fragment (PYY336) (Linco Research Inc, St. Charles, MO).

\section{Appetite profile}

Appetite profile was measured with the use of anchored $100-\mathrm{mm}$ visual analogue scales (VAS). During each test-day these questionnaires were completed at several time points before and after the lunch. The questions were, "How hungry are you?" and "How satiated are you?" and were anchored by "not at all" and "very." 


\section{Body composition}

Body composition was measured by using the deuterium dilution technique. ${ }^{2} \mathrm{H}_{2} \mathrm{O}$ dilution was used to measure total body water (TBW). Deuterium was measured in the urine samples with an isotope ratio mass spectrometer (VGIsogas Aqua Sira; VG Isogas, Middlewich, England). TBW was obtained by dividing the measured deuterium dilution space by 1.04. Fat-free mass (FFM) was calculated by dividing TBW by the hydration factor 0.73 . Fat mass (FM) was determined as BW - FFM ${ }^{30-32}$.

\section{Statistical analysis}

Data are presented as means \pm SD unless otherwise indicated. Repeated measures ANOVA were used to compare the HP and AP data. Factorial ANOVA was used to analyze possible differences between gender and BMI groups. Post-hoc comparisons were made with the Fisher PLSD test. Linear regression analysis was performed to determine the relations between selected variables and Pearson's correlations are reported. All statistical tests were performed by using Statview SE Graphics software (version 4.5; Abacus Concepts Inc, Berkeley, CA, USA).

\section{Results}

Energy expenditure and substrate oxidation

Baseline energy expenditure did not before the HP $(4.80 \pm 0.71 \mathrm{~kJ} / \mathrm{min})$ and AP $(4.79 \pm 0.81 \mathrm{~kJ} / \mathrm{min})$ lunches. The increase in post-lunch tended to be greater after the HP lunch $(0.85 \pm 0.32 \mathrm{~kJ} / \mathrm{min})$ than after the AP lunch $(0.73 \pm 0.22 \mathrm{~kJ} / \mathrm{min})(\mathrm{p}=0.07)$. Total post-lunch energy expenditure above baseline energy expenditure over $210 \mathrm{~min}$ tended to be greater after the HP lunch $(177.60 \pm 67.30 \mathrm{~kJ})$ than after the AP lunch $(153.50 \pm 46.40 \mathrm{~kJ})$ $(\mathrm{p}=0.07)$. Total post-lunch energy expenditure above baseline energy expenditure over $210 \mathrm{~min}$ as percentage of the energy content of the lunch tended to be greater after the HP lunch $(4.93 \pm 1.56 \%)$ than after the AP lunch $(4.32 \pm 1.20 \%)(\mathrm{p}=0.1)$.

The respiratory quotient did not differ between the HP $(0.84 \pm 0.04)$ and the AP $(0.86 \pm 0.04)$ treatments. The non-protein RQ did not differ between the HP $(0.85 \pm 0.05)$ and the AP $(0.87 \pm 0.05)$ treatments. Substrate oxidation did not differ between the HP condition (protein oxidation: 17.4 $\pm 5.9 \mathrm{~g}$; carbohydrate oxidation: $34.2 \pm 11.5 \mathrm{~g}$; fat oxidation: $15.8 \pm 6.9 \mathrm{~g}$ ) and the AP condition (protein oxidation: $16.9 \pm 6.2 \mathrm{~g}$; carbohydrate oxidation: $37.3 \pm 12.4 \mathrm{~g}$; fat oxidation: $13.2 \pm 6.4 \mathrm{~g}$ ).

\section{Plasma hormones}

The plasma hormone concentrations did not differ between the 2 treatments at baseline before the lunches were consumed. Changes in hormone concentrations in response to the lunches are expressed as the change from baseline. Plasma GLP-1 responses were lower 15 min after the HP lunch than after the AP lunch ( $<<0.01$, Figure 1A). Plasma active ghrelin responses 
to the HP and AP lunches did not differ at any of the time points measured (Figure 1B). The plasma active ghrelin response 15 minutes after the

AP lunch differed between men $[-35.4 \pm 36.8 \mathrm{pg} / \mathrm{mL}(-10.6 \pm 11.1 \mathrm{pmol} / \mathrm{L})]$ and women $[6.9 \pm 55.5 \mathrm{pg} / \mathrm{mL}(2.1 \pm 16.7 \mathrm{pmol} / \mathrm{L}), \mathrm{p}<0.05]$. Plasma PYY responses to the HP and AP lunches did not differ at any of the time points measured (Figure 1C). The plasma PYY response 15 minutes after the HP lunch differed between subjects with a BMI over $25 \mathrm{~kg} / \mathrm{m}^{2}[-7.9 \pm 16.5 \mathrm{pg} / \mathrm{mL}$ $(-1.8 \pm 3.8 \mathrm{pmol} / \mathrm{L})]$ and subjects with a BMI under $25 \mathrm{~kg} / \mathrm{m}^{2}[12.8 \pm 22.8$ $\mathrm{pg} / \mathrm{mL}(3.0 \pm 5.3 \mathrm{pmol} / \mathrm{L}), \mathrm{p}<0.05]$.

A

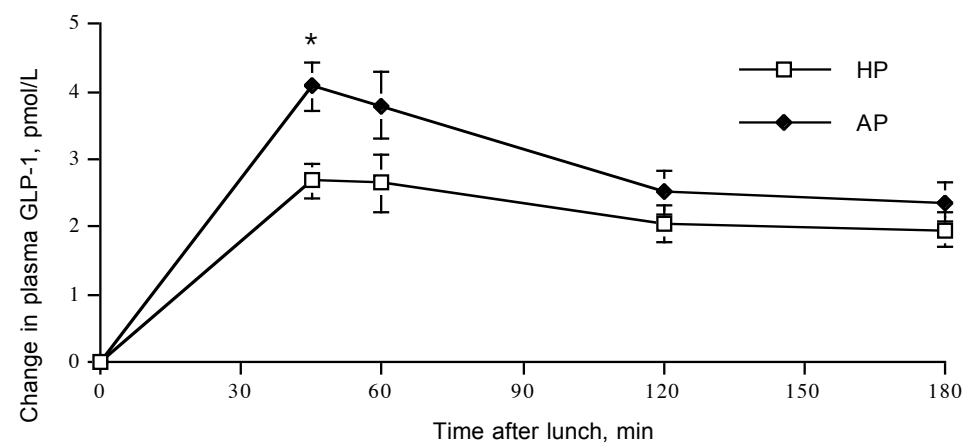

B

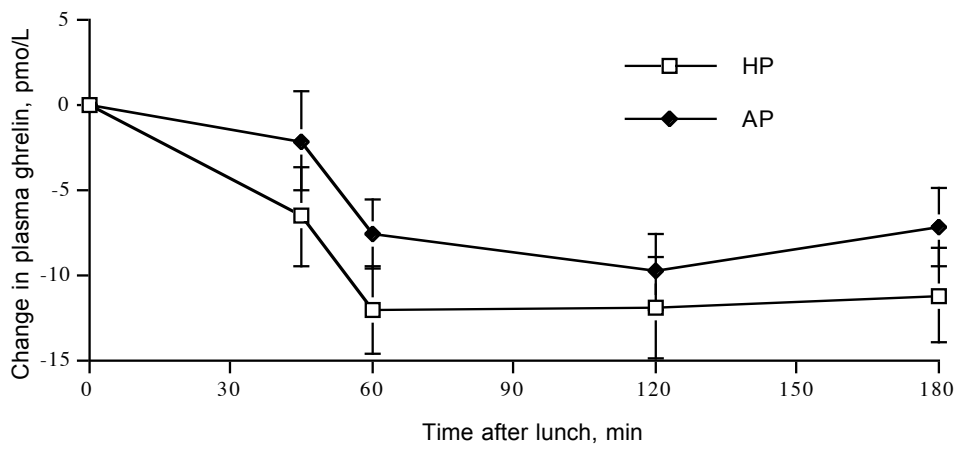

C

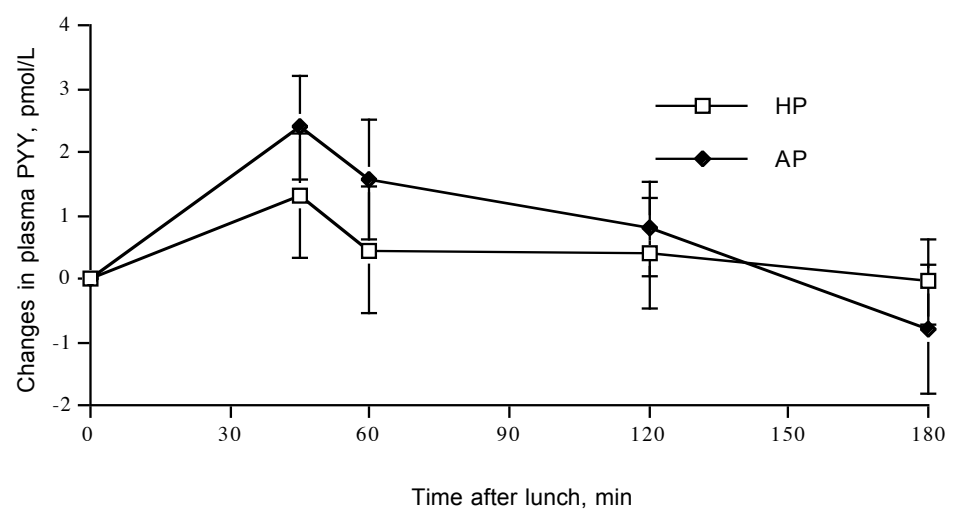

Figure 1. Changes in plasma GLP-1 (A), active ghrelin (B), and PYY (C) concentrations in subjects after they consumed the HP and AP lunches. Values are means \pm SEM. * Different between HP and AP at that time, $\mathrm{p}<0.05$ 
Appetite profile

Immediately before and after lunch, satiety VAS scores did not differ when subjects consumed the HP and AP lunches but they were higher 30 and 120min after the HP lunch than after the AP lunch.

The AUC of the VAS score for satiety was significantly higher after the HP lunch $(263 \pm 61 \mathrm{~mm} \cdot \mathrm{h})$ than after the AP lunch $(236 \pm 76 \mathrm{~mm} \cdot \mathrm{h})(\mathrm{p}<0.02$, Figure 2). Satiety VAS scores were not correlated with plasma GLP-1, ghrelin, and PYY concentrations at any time-point or when expressed as AUC.

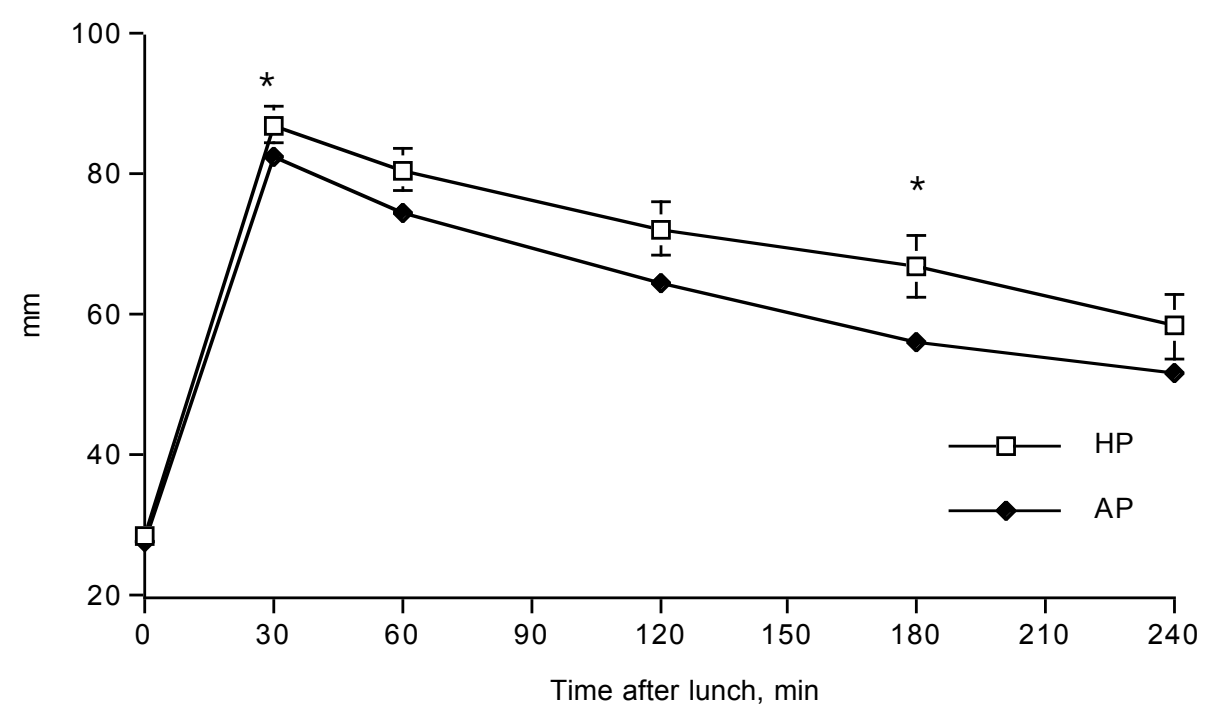

Figure 2. Satiety ratings measured with the use of an anchored $100-\mathrm{mm}$ visual analogue scale of subjects after they consumed the HP and AP lunches. Values are means \pm SEM. * Different between HP and AP at that time, $\mathrm{p}<0.05$

\section{Discussion}

A single HP meal in the postprandial phase increased feelings of satiety and tended to increase DIT. The observed effects on satiety did not happen simultaneously with effects on plasma ghrelin, GLP-1 and PYY concentrations. A single HP lunch, therefore, seems to exert its acute effect on satiety not through concentrations of these hormones.

Most studies that observed effects on satiety used a higher percentage of energy from protein, e.g. $43 \%-68 \%$, in the HP meal compared to our study 2,9-11,33-36. Our study and the study of Hill and Blundell ${ }^{34}$ showed that when using mixed meals, satiety is already increased at $25 \%$ energy from protein compared to satiety at $10 \%$ of energy from protein. These findings are very relevant to the human diet, because $25 \%$ of energy from protein can easily be achieved using typically consumed foods. Barkeling et al. ${ }^{36}$ had subjects 
consume $43 \%$ of energy from protein using typically consumed foods in a mixed high-protein meal. This high-protein meal increased satiety compared to the mixed meal with $10 \%$ of energy from protein, but also caused taste aversion for high-protein foods. The development of taste aversion may contribute more to satiation (terminating a meal) rather than to satiety (postponing the next meal). In the present study, however, taste aversion cannot play a role, since the sausages used to manipulate the protein content of the treatment meals were exactly the same in taste, texture and appearance. Here, the short-term effect of the single high protein meal (after $30 \mathrm{~min}$ ) on satiety may reflect satiation rather than satiety because the subjects were aware that it was single fixed meal they had to finish and after which they would not receive any other foods. Strong feelings of satiety over a short period after ingestion of a meal may be interpreted as the wish to terminate the eating episode rather than the wish to postpone the next eating episode.

Energy expenditure after the HP lunch tended to be higher than after the AP lunch. The effect of protein on $24 \mathrm{~h}$ thermogenesis has repetitively been observed by others ${ }^{2,4-7,37}$.

The increase in thermogenesis over $24 \mathrm{~h}$ is thought to be one of the mechanisms that increase feelings of satiety after a HP meal. The relationship between DIT and satiety, however, reflects a condition of a high protein diet that the subjects experience ${ }^{6}$, or appears after extremely high contents of protein in the meal ${ }^{2}$. For instance Crovetti et al. ${ }^{2}$ observed a correlation between DIT and fullness ratings over $7 \mathrm{~h}$ (HP meal contained $68 \%$ energy from protein). Lejeune et al. ${ }^{6}$ did observe a relationship between DIT and satiety with $30 \%$ energy from protein in a respiration chamber study lasting $36 \mathrm{~h}$. In these studies DIT was measured over a longer period compared to the present study, which may have contributed to a stronger relationship between appetite ratings and DIT as well.

We observed no difference in plasma ghrelin, GLP-1 and PYY. In a recent study Lejeune et al. ${ }^{6}$ observed higher plasma GLP-1 responses following a HP dinner than after a AP dinner. The plasma GLP-1 response after the HP lunch in that study was, however, not different from the plasma GLP-1 response after the AP lunch. The exchange of percentage of energy from carbohydrate for protein in both the Lejeune study and our study complicates the interpretation of the plasma GLP-1 responses. A larger availability of carbohydrates may have lead to an increased contact of carbohydrates with the small intestine. Increased contact of carbohydrates with the small increases plasma GLP-1 responses to mixed meals ${ }^{38}$. Although GLP-1 is often considered to be a satiety hormone, in the present study, plasma GLP-1 responses were not correlated to satiety. Several other studies have not observed a relationship between the increased plasma concentrations of GLP-1 and satiety, which suggests that the effect of peripheral GLP-1 on satiety may be influenced by the central sensitivity for GLP-1 or interactions 
with other hormones ${ }^{19,38-40}$. In previous studies, effects of protein on plasma ghrelin responses have been conflicting ${ }^{6,41-43}$. The amount of carbohydrate, through glucose and insulin, and the food form, through gastric emptying, may influence plasma ghrelin responses to a meal. In the present study, plasma ghrelin concentrations did not contribute to the observed effects of the HP lunch on satiety. This is in line with Lejeune et al., who observed no differences in plasma ghrelin responses following HP meals throughout the day compared with AP meals ${ }^{6}$.

We observed no effect of the HP and AP lunch on plasma PYY responses. Plasma PYY responses are influenced by energy intake and meal composition. In a recent study, by Batterham et al. ${ }^{44}$ observed significantly higher plasma PYY responses to a high protein meal in both lean and obese subjects. In that study, the size of the meals and the amount of protein was much bigger than in our study. The size of the meals used in the present study, which ranged from $2.8-4.5 \mathrm{MJ}$ (35\% of subject specific daily energy needs), may have been too small to evoke an acute response in plasma PYY in the postprandial state. The range of the measured plasma hormone responses was quite large at some time-points. This variability in responses was due to, among other things, different responses between men and women ${ }^{45}$, and between subjects that are normal weight or overweight according to their BMI ${ }^{46}$. Studying a heterogeneous group of subjects, however, makes the outcomes more applicable to the general population.

Apart from the hormones measured in the present study, other hormones, which have been shown to be induced by protein ingestion, such as cholecystokinin (CCK), insulin and gastric inhibitory polypeptide (GIP), may have contributed to the satiating effect of the high protein meal ${ }^{47-49}$.

The present results should be interpreted with caution, because this study was conducted at lunch in the postprandial state. Most studies of single high protein meals have been conducted at breakfast in subjects in the post absorptive state, which makes them difficult to compare with the present study.

We conclude that a single high-protein meal of $25 \%$ of energy from protein rather than $10 \%$ of energy from protein, where protein was exchanged with carbohydrates and furthermore contained the same foods, has a larger effect on satiety. The effects of a single high protein meal in the postprandial state are not mediated by increases in plasma GLP-1 or PYY concentrations, and decreases in plasma ghrelin concentrations. Over the longer term (meals or days), plasma GLP-1, PYY and ghrelin responses most probably augment and, as a result, may contribute to the increased satiety observed for high protein foods and diets. Obviously, there is a marked difference between the satiety effect due to a continuous high protein diet and an acute high protein lunch. The short-term effect of the single high protein meal on satiety in the present study may reflect satiation rather than satiety. Other factors, which may explain the HP effect on satiety, may be metabolites or amino acids. In a recent study, Veldhorst et al. ${ }^{50}$ showed that the satiating effect of a high 
protein breakfast was positively related to plasma concentrations of specific amino acids up to $4 \mathrm{~h}$. In future studies, protein metabolites, plasma amino acids, and central effects of satiety related hormones may give more insight in the acute effects of high protein meals on satiety.

\section{Acknowledgements}

We gratefully acknowledge Janna Bitnes at Matforsk for providing us with the sausages and Helene Reinbach, Tímea Gelencser, Maartje Spetter, Rick Hursel, Tine Horsten and Lizette den Hollander for their assistance. 


\section{References}

1. Bensaid A, Tome D, Gietzen D, Even P, Morens C, Gausseres N, Fromentin G. Protein is more potent than carbohydrate for reducing appetite in rats. Physiol Behav 2002;75(4):577-82.

2. Crovetti R, Porrini M, Santangelo A, Testolin G. The influence of thermic effect of food on satiety. Eur J Clin Nutr 1998;52(7):482-8.

3. Johnstone AM, Stubbs RJ, Harbron CG. Effect of overfeeding macronutrients on day-to-day food intake in man. Eur J Clin Nutr 1996;50(7):418-30.

4. Karst H, Steiniger J, Noack R, Steglich HD. Diet-induced thermogenesis in man: thermic effects of single proteins, carbohydrates and fats depending on their energy amount. Ann Nutr Metab 1984;28(4):245-52.

5. LeBlanc J, Diamond P, Nadeau A. Thermogenic and hormonal responses to palatable protein and carbohydrate rich food. Horm Metab Res 1991;23(7):336-40.

6. Lejeune MP, Westerterp KR, Adam TC, Luscombe-Marsh ND, WesterterpPlantenga MS. Ghrelin and glucagon-like peptide 1 concentrations, 24-h satiety, and energy and substrate metabolism during a high-protein diet and measured in a respiration chamber. Am J Clin Nutr 2006;83(1):89-94.

7. Luscombe ND, Clifton PM, Noakes M, Farnsworth E, Wittert G. Effect of a high-protein, energy-restricted diet on weight loss and energy expenditure after weight stabilization in hyperinsulinemic subjects. Int J Obes Relat Metab Disord 2003;27(5):582-90.

8. Mikkelsen PB, Toubro S, Astrup A. Effect of fat-reduced diets on 24-h energy expenditure: comparisons between animal protein, vegetable protein, and carbohydrate. Am J Clin Nutr 2000;72(5):1135-41.

9. Poppitt SD, McCormack D, Buffenstein R. Short-term effects of macronutrient preloads on appetite and energy intake in lean women. Physiol Behav 1998;64(3):279-85.

10. Porrini M, Crovetti R, Testolin G, Silva S. Evaluation of satiety sensations and food intake after different preloads. Appetite 1995;25(1):17-30.

11. Stubbs RJ, van Wyk MC, Johnstone AM, Harbron CG. Breakfasts high in protein, fat or carbohydrate: effect on within-day appetite and energy balance. Eur J Clin Nutr 1996;50(7):409-17.

12. Weigle DS, Breen PA, Matthys CC, Callahan HS, Meeuws KE, Burden VR, Purnell JQ. A high-protein diet induces sustained reductions in appetite, ad libitum caloric intake, and body weight despite compensatory changes in diurnal plasma leptin and ghrelin concentrations. Am J Clin Nutr 2005;82(1):41-8.

13. Westerterp-Plantenga MS, Rolland V, Wilson SA, Westerterp KR. Satiety related to $24 \mathrm{~h}$ diet-induced thermogenesis during high protein/carbohydrate vs high fat diets measured in a respiration chamber. Eur J Clin Nutr 1999;53(6):495-502. 
14. Nakazato M, Murakami N, Date Y, Kojima M, Matsuo H, Kangawa K, Matsukura S. A role for ghrelin in the central regulation of feeding. Nature 2001;409(6817):194-8.

15. Wren AM, Seal LJ, Cohen MA, Brynes AE, Frost GS, Murphy KG, Dhillo WS, Ghatei MA, Bloom SR. Ghrelin enhances appetite and increases food intake in humans. J Clin Endocrinol Metab 2001;86(12):5992.

16. Cuntz U, Fruhauf E, Wawarta R, Tschop M, Folwaczny C, Riepl R, Lehnert $\mathrm{P}$, Fichter M, Otto B. A role for the novel weight-regulating hormone ghrelin in anorexia nervosa. Am Clin Lab 2002;21(4):22-3.

17. Cummings DE, Purnell JQ, Frayo RS, Schmidova K, Wisse BE, Weigle DS. A preprandial rise in plasma ghrelin levels suggests a role in meal initiation in humans. Diabetes 2001;50(8):1714-9.

18. Shiiya T, Nakazato M, Mizuta M, Date Y, Mondal MS, Tanaka M, Nozoe S, Hosoda H, Kangawa K, Matsukura S. Plasma ghrelin levels in lean and obese humans and the effect of glucose on ghrelin secretion. J Clin Endocrinol Metab 2002;87(1):240-4.

19. Adam TC, Westerterp-Plantenga MS. Nutrient-stimulated GLP-1 release in normal-weight men and women. Horm Metab Res 2005;37(2):111-7.

20. Holst JJ. Glucagonlike peptide 1: a newly discovered gastrointestinal hormone. Gastroenterology 1994;107(6):1848-55.

21. Naslund E, Barkeling B, King N, Gutniak M, Blundell JE, Holst JJ, Rossner S, Hellstrom PM. Energy intake and appetite are suppressed by glucagonlike peptide-1 (GLP-1) in obese men. Int J Obes Relat Metab Disord 1999;23(3):304-11.

22. Flint A, Raben A, Ersboll AK, Holst JJ, Astrup A. The effect of physiological levels of glucagon-like peptide-1 on appetite, gastric emptying, energy and substrate metabolism in obesity. Int J Obes Relat Metab Disord 2001;25(6):781-92.

23. Adrian TE, Long RG, Fuessl HS, Bloom SR. Plasma peptide YY (PYY) in dumping syndrome. Dig Dis Sci 1985;30(12):1145-8.

24. Batterham RL, Cowley MA, Small CJ, Herzog H, Cohen MA, Dakin CL, Wren AM, Brynes AE, Low MJ, Ghatei MA and others. Gut hormone PYY(3-36) physiologically inhibits food intake. Nature 2002;418(6898):650-4.

25. Grandt D, Schimiczek M, Beglinger C, Layer P, Goebell H, Eysselein VE, Reeve JR, Jr. Two molecular forms of peptide YY (PYY) are abundant in human blood: characterization of a radioimmunoassay recognizing PYY 136 and PYY 3-36. Regul Pept 1994;51(2):151-9.

26. Stunkard AJ, Messick S. The three-factor eating questionnaire to measure dietary restraint, disinhibition and hunger. J Psychosom Res 1985;29(1):7183.

27. Harris JA, Benedict FG. A Biometric Study of Human Basal Metabolism. Proc Natl Acad Sci U S A 1918;4(12):370-3. 
28. Schoffelen PF, Westerterp KR, Saris WH, Ten Hoor F. A dual-respiration chamber system with automated calibration. J Appl Physiol 1997;83(6):2064-72.

29. Brouwer E. On simple formulae for calculating the heat expenditure and the quantities of carbohydrate and fat oxidized in metabolism of men and animals, from gaseous exchange (Oxygen intake and carbonic acid output) and urine-N. Acta Physiol Pharmacol Neerl 1957;6:795-802.

30. Schoeller DA, van Santen E, Peterson DW, Dietz W, Jaspan J, Klein PD. Total body water measurement in humans with $18 \mathrm{O}$ and $2 \mathrm{H}$ labeled water. Am J Clin Nutr 1980;33(12):2686-93.

31. van Marken Lichtenbelt WD, Westerterp KR, Wouters L. Deuterium dilution as a method for determining total body water: effect of test protocol and sampling time. Br J Nutr 1994;72(4):491-7.

32. Westerterp KR, Wouters L, van Marken Lichtenbelt WD. The Maastricht protocol for the measurement of body composition and energy expenditure with labeled water. Obes Res 1995;3 Suppl 1:49-57.

33. Westerterp KR, Wilson SA, Rolland V. Diet induced thermogenesis measured over $24 \mathrm{~h}$ in a respiration chamber: effect of diet composition. Int J Obes Relat Metab Disord 1999;23(3):287-92.

34. Hill AJ, Blundell JE. Macronutrients and satiety: the effects of high carbohydrate and high protein meals on subjective motivation to eat and preferences. Nutr Behav 1986;3:133-44.

35. Johnson J, Vickers Z. Effects of flavor and macronutrient composition of food servings on liking, hunger and subsequent intake. Appetite 1993;21(1):25-39.

36. Barkeling B, Rossner S, Bjorvell H. Effects of a high-protein meal (meat) and a high-carbohydrate meal (vegetarian) on satiety measured by automated computerized monitoring of subsequent food intake, motivation to eat and food preferences. Int J Obes 1990;14(9):743-51.

37. Nair KS, Halliday D, Garrow JS. Thermic response to isoenergetic protein, carbohydrate or fat meals in lean and obese subjects. Clin Sci (Lond) 1983;65(3):307-12.

38. Adam TC, Lejeune MP, Westerterp-Plantenga MS. Nutrient-stimulated glucagon-like peptide 1 release after body-weight loss and weight maintenance in human subjects. Br J Nutr 2006;95(1):160-7.

39. Oesch S, Degen L, Beglinger C. Effect of a protein preload on food intake and satiety feelings in response to duodenal fat perfusions in healthy male subjects. Am J Physiol Regul Integr Comp Physiol 2005;289(4):R1042-7.

40. Raben A, Agerholm-Larsen L, Flint A, Holst JJ, Astrup A. Meals with similar energy densities but rich in protein, fat, carbohydrate, or alcohol have different effects on energy expenditure and substrate metabolism but not on appetite and energy intake. Am J Clin Nutr 2003;77(1):91-100.

41. Blom WA, Lluch A, Stafleu A, Vinoy S, Holst JJ, Schaafsma G, Hendriks HF. Effect of a high-protein breakfast on the postprandial ghrelin response. Am J Clin Nutr 2006;83(2):211-20. 
42. Erdmann J, Lippl F, Schusdziarra V. Differential effect of protein and fat on plasma ghrelin levels in man. Regul Pept 2003;116(1-3):101-7.

43. Marzullo P, Caumo A, Savia G, Verti B, Walker GE, Maestrini S, Tagliaferri A, Di Blasio AM, Liuzzi A. Predictors of postabsorptive ghrelin secretion after intake of different macronutrients. J Clin Endocrinol Metab 2006;91(10):4124-30.

44. Batterham RL, Heffron H, Kapoor S, Chivers JE, Chandarana K, Herzog H, Le Roux CW, Thomas EL, Bell JD, Withers DJ. Critical role for peptide YY in protein-mediated satiation and body-weight regulation. Cell Metab 2006;4(3):223-33.

45. Makovey J, Naganathan V, Seibel M, Sambrook P. Gender differences in plasma ghrelin and its relations to body composition and bone - an oppositesex twin study. Clin Endocrinol (Oxf) 2007;66(4):530-7.

46. Batterham RL, Bloom SR. The gut hormone peptide YY regulates appetite. Ann N Y Acad Sci 2003;994:162-8.

47. Calbet JA, MacLean DA. Plasma glucagon and insulin responses depend on the rate of appearance of amino acids after ingestion of different protein solutions in humans. J Nutr 2002;132(8):2174-82.

48. Liddle RA, Goldfine ID, Rosen MS, Taplitz RA, Williams JA. Cholecystokinin bioactivity in human plasma. Molecular forms, responses to feeding, and relationship to gallbladder contraction. J Clin Invest 1985;75(4):1144-52.

49. Wolfe MM, Zhao KB, Glazier KD, Jarboe LA, Tseng CC. Regulation of glucose-dependent insulinotropic polypeptide release by protein in the rat. Am J Physiol Gastrointest Liver Physiol 2000;279(3):G561-6.

50. Veldhorst MAB, Nieuwenhuizen AG, Hochstenbach-Waelen A, Westerterp KR, Engelen MPKJ, Brummer RJ, Deutz NEP, Westerterp-Plantenga MS. Effects of high or normal casein-, soy-, or whey with or without GMPprotein breakfasts on satiety, 'satiety' hormones, and plasma amino acid responses. Appetite 2007;49(1):336. 



\section{8}

\section{The acute effects of a lunch containing resistant starch on energy and substrate utilization, ghrelin, glucagon-like peptide- 1, PYY concentrations, and satiety}

Astrid J. Smeets, Tìmea Gelencser, Andras Salgo and Margriet S.

Westerterp-Plantenga

Submitted for publication 


\begin{abstract}
Observations of epidemiological studies indicate that dietary fibre intake is involved in body weight control. A dietary fibre component that may be of specific importance is resistant starch (RS). Acute effects of RS on energy expenditure and substrate oxidation have hardly been studied. In addition, the effects of RS on ghrelin, PYY and GLP-1, in relation to changes in hunger and satiety are unknown.

Thirty subjects (age: $31 \pm 14 \mathrm{y}, \mathrm{BMI}: 23.8 \pm 2.8 \mathrm{~kg} / \mathrm{m} 2$ ) were studied 2 times in a randomized controlled crossover design. After 30 minutes resting on a bed, resting metabolic rate was measured by a ventilated hood system. Subsequently lunch (35\% of daily energy intake) was served. The two lunch conditions were: i) normal pasta and ii) resistant starch pasta. The macronutrient composition (energy \%) of the lunches was: $60 \%$ carbohydrates/ $10 \%$ protein/ $30 \%$ fat. During 3 hours after the lunch diet induced energy expenditure (DEE) was measured. Furthermore anchored $100 \mathrm{~mm}$ visual analogue scales on the appetite profile were collected before the lunch and after the lunch, and blood samples were taken for analysis of GLP-1, PYY, and ghrelin concentrations, before and at different time points after the lunch.

Satiety and energy expenditure were not different after RS lunch compared with the control lunch. Ghrelin, GLP-1 and PYY responses were not different between the RS lunch and the control lunch.

In conclusion, RS supplementation has no acute effect on substrate utilisation appetite feelings and gut derived hormones.
\end{abstract}




\section{Introduction}

Obesity and related disorders such as type 2 diabetes and the metabolic syndrome are rapidly growing nutrition related diseases worldwide ${ }^{1}$. Research has been focusing on specific food components, which may have favourable effects on weight-loss, weight-maintenance, and metabolism. Observations of epidemiological studies indicate that dietary fibre intake is involved in body weight control. A dietary fibre component that may be of specific importance is resistant starch. Resistant starch (RS) is starch that is not digested in the small intestine but passes to the large intestine ${ }^{2}$. In the large intestine, RS is a potential substrate for fermentation, a process that results in the formation of short-chain fatty acids (SCFA), which can be absorbed and utilised as an energy source. Three types of RS can be identified: $\mathrm{RS}_{1}$ is $\mathrm{RS}$ present in foods having a dense or rigid structure, e.g. whole-grain cereals and legumes; $\mathrm{RS}_{2}$ is $\mathrm{RS}$ present in granules in raw foods, e.g. bananas; $\mathrm{RS}_{3}$ is $\mathrm{RS}$ in foods that have been cooked and subsequently cooled, e.g. bread and breakfast cereals.

It is known that the replacement of digestible starch with RS may reduce post-prandial glycemia and insulinemia, and may increase post-prandial satiety $^{3}$.

Recent rat studies have shown, that prolonged ingestion of RS resulted in increased plasma levels of the satiety related hormones glucagon-like peptide 1 (GLP-1) and peptide YY (PYY), and a decrease in plasma levels of the hunger related hormone ghrelin, in addition to the effects of fermentation in the colon ${ }^{4,5}$. Therefore, it is relevant to assess effects of RS ingestion on these hormones during a number of hours following a meal that includes RS, thereby hypothesising that these contribute to the satiating effect of RS. Also Adam et al. found a clear effect of fibre ingestion on GLP-1 release ${ }^{6}$. As is known, glucagon-like peptide (GLP-1) is a thirty amino acid peptide hormone that is released from intestinal $\mathrm{L}$ cells into the circulation after a mixed meal ${ }^{6-8}$. Like proglucagon-derived peptides, PYY is synthesized and released from endocrine L-cells from the distal gut in response to food consumption ${ }^{9}$. Ghrelin is a peptide secreted from the stomach and appears to be a hunger signal ${ }^{10,11}$; intravenous infusion of ghrelin increases food intake and enhances appetite ${ }^{11,12}$. Therefore it is of importance to asses whether appetite related hormones originating from the gastrointestinal tract (i.e., GLP-1, PYY and ghrelin) play a role in satiating properties of RS in humans. Moreover it has been reported that RS consumption lowered diet-induced thermogenesis (DIT), but increased fat oxidation ${ }^{13-15}$, yet it is unclear whether this is an effect of fermentation caused by RS, or whether it is an acute effects of RS, incorporated into a 'real' meal.

The aim of this study was to test the acute effects of a lunch containing resistant starch (RS) on energy expenditure, substrate oxidation, appetite related hormones (GLP-1, ghrelin, and PYY) and satiety. We hypothesized 
that a single RS meal compared with a single control meal may increase satiety, plasma PYY and GLP-1 concentrations, and fat oxidation, and decrease plasma ghrelin concentrations, diet induced thermogenesis, and respiratory quotient (RQ).

\section{Subjects and Methods}

Subjects

Thirty healthy subjects (19 women and 11 men) with a body mass index (BMI; in $\mathrm{kg} / \mathrm{m}^{2}$ ) of $20-30$ and aged $18-60$ y were recruited by advertisements in local newspapers and on notice boards at Maastricht University. All subjects underwent a medical screening, and all were in good health, non-smokers, not using medication, and at most moderate alcohol users. Eating behaviour was assessed using a validated Dutch translation of the TFEQ. Cognitive restrained and unrestrained eating behaviour (Factor 1), emotional eating and disinhibition (Factor 2), and the subjective feeling of hunger (Factor 3) were scored ${ }^{16}$. The baseline characteristics of the subjects are presented in Table 1.

Written informed consent was obtained from all participants. The Medical Ethics Committee of the Academic Hospital in Maastricht approved the study.

Table 1. Subject characteristics $(n=30)$

\begin{tabular}{ll}
\hline & Value \\
\hline Age $(\mathbf{y})$ & $31 \pm 14$ \\
Body weight $(\mathbf{k g})$ & $72 \pm 12$ \\
Height $(\mathbf{m})$ & $1.73 \pm 0.09$ \\
BMI $\left(\mathbf{k g} / \mathbf{m}^{2}\right)$ & $23.8 \pm 2.8$ \\
Body fat $(\%)$ & $25.6 \pm 8.8$ \\
Dietary restrained $^{\mathbf{2}}$ & $4.3 \pm 2.6$ \\
\hline
\end{tabular}

1 All values are mean \pm SD

2 Factor 1 of the Three-Factor Eating Questionnaire was used ${ }^{16}$

\section{Study protocol}

The study had a single blind, randomized, crossover design. The subjects underwent two indirect calorimetry tests for the measurement of energy expenditure (EE) and substrate oxidation. On the morning before the test $(8: 00 \mathrm{am})$, the subjects received a subject specific breakfast (Campina Drinkontbijt), which provided $15 \%$ of each subject's individual daily energy requirements. Subject specific daily energy requirements were calculated based on basal metabolic rate (BMR), which was calculated with the equation of Harris-Benedict ${ }^{17}$. BMR was multiplied by an activity index of 
1.5. After the breakfast, subjects were not allowed to eat or drink during the morning except water and 1 cup of coffee or tea without milk or sugar. One hour before the test lunch was served (11:00 am), baseline EE and substrate oxidation were measured by means of an open-circuit, ventilated-hood system with subjects lying supine for at least $30 \mathrm{~min}$. At 12:00am the subjects received a lunch, which was consumed within $15 \mathrm{~min}$., of one of two randomly assigned treatments: control lunch, which provided $10 \%$ of energy from protein, $60 \%$ of energy from carbohydrate, and $30 \%$ of energy from fat, or RS lunch, which provided $10 \%$ of energy from protein, $60 \%$ of energy from carbohydrate, $30 \%$ of energy from fat. Both lunches provided $35 \%$ of each subject's individual daily energy requirements and consisted of pasta (Technical University of Budapest, Department of Biochemistry and Food Technology, Budapest, Hungary), sausages (Matforsk, Ås, Norway), and tomato sauce (Heinz, Elst, The Netherlands). After cooking the RS content of the pasta in the control lunch was $4.5 \mathrm{~g} / 100 \mathrm{~g}$ and the RS content of the pasta in the RS lunch was $7.8 \mathrm{~g} / 100 \mathrm{~g}$. The RS content of the pasta was measured by the Megazyme method (Megazyme. 2004. AOAC Method 2002.02/ AACC Method 32-40. Resistant starch assay procedure) without modifications. With the procedure we used to determine the RS content of the pasta it is not possible to separate RS2 and RS3 content. The pastas before cooking might have RS2 content (it is mainly the amylose content of the starches) while after cooking the RS might be RS3 due to the heat treatment that causes the retrogradation of starches. The meals were designed in order to be iso-energetically, therefore in the RS meals the unmetabolizable energy was complemented with as much as RS pasta to reach the same metabolizable energy content of the control meal.

Post-lunch EE and substrate oxidation were measured for 210 min after ingestion of the lunch.

Table 2. Composition of the two test lunches

\begin{tabular}{|c|c|c|c|c|c|c|}
\hline & $\begin{array}{l}\text { Energy } \\
(\mathbf{k J})\end{array}$ & $\begin{array}{l}\text { Weight } \\
\text { (g) }\end{array}$ & $\begin{array}{l}\text { Carbohydrates }{ }^{\S} \\
\text { (g) }\end{array}$ & $\begin{array}{l}\text { Protein } \\
\text { (g) }\end{array}$ & $\begin{array}{l}\text { Fat } \\
\text { (g) }\end{array}$ & RS (g) \\
\hline $\begin{array}{l}\text { RS } \\
\text { lunch }\end{array}$ & $3543 \pm 508$ & $506 \pm 101$ & $122 \pm 17$ & $23 \pm 4$ & $27 \pm 4$ & $7.6 \pm 1.2$ \\
\hline $\begin{array}{l}\text { Control } \\
\text { lunch }\end{array}$ & $3543 \pm 508$ & $488 \pm 97$ & $122 \pm 16$ & $25 \pm 5$ & $27 \pm 4$ & $4.4 \pm 0.7$ \\
\hline
\end{tabular}

Means \pm SD $\S$ available carbohydrates

\section{Energy expenditure and substrate oxidation}

On the test days, baseline and post-lunch EE and substrate oxidation were measured with an open-circuit, ventilated-hood system with the subjects lying supine ${ }^{18}$. Gas analysis was performed by a paramagnetic $\mathrm{O}_{2}$ analyzer (OmniCal type 1155B; Crowborough, Sussex, UK) and an IR $\mathrm{CO}_{2}$ analyzer (OmniCal type 1520/1507). EE was calculated using Brouwer's formula ${ }^{19}$. 
The RQ was calculated as $\mathrm{CO}_{2}$ produced $/ \mathrm{O}_{2}$ consumed. Carbohydrate, fat, and protein oxidation were calculated from the measurements of oxygen consumption, carbon dioxide production, and urinary nitrogen excretion by using the formula of Brouwer ${ }^{19}$. Urine samples were collected from the first void after the start of the test day $(11: 00 \mathrm{am})$ until the last void on the test day $(4: 00 \mathrm{pm})$. Subjects voided their bladder before the start of the test day (before 11:00am) Samples were collected in containers with $10 \mathrm{ml} \mathrm{H}_{2} \mathrm{SO}_{4}$ to prevent nitrogen loss through evaporation. Volume and nitrogen concentration were measured, the latter with a nitrogen analyzer (CHN-ORapid; Heraeus, Hanau, Germany).

\section{Blood sampling}

One hour before the lunch was served (11:00 am), a polytetrafluoroethylene catheter was placed in the antecubital vein for blood sampling. During each test day, 1 blood sample just before the lunch (at $0 \mathrm{~min}$ ) and 4 blood samples after lunch (at $45 \mathrm{~min}, 60 \mathrm{~min}, 120 \mathrm{~min}$, and $180 \mathrm{~min}$ ) were taken for measurement of plasma ghrelin, GLP-1, and PYY concentrations. Blood samples were collected in tubes containing EDTA to prevent clotting. Plasma was obtained by centrifugation $\left(4^{\circ} \mathrm{C}, 3000 \mathrm{rpm}, 10 \mathrm{~min}\right)$ and stored at $-80{ }^{\circ} \mathrm{C}$ until analyzed. Plasma concentrations of active ghrelin were measured by RIA (Linco Research Inc., St. Charles, Missouri, USA). Plasma active ghrelin concentrations were measured in acidified plasma with $50 \mu \mathrm{l}$ of $1 \mathrm{~N} \mathrm{HCl}$ and addition of $10 \mu \mathrm{l}$ of Phenylmethylsulfonyl fluoride (PMSF) per $1 \mathrm{ml}$ of plasma. Sensitivity of the RIA assay was 7.8 $\mathrm{pg} / \mathrm{ml}$ and the difference between duplicate results of a sample was $<10 \%$ CV. The specificity for human ghrelin was $100 \%$. Plasma active GLP-1 samples were analyzed using ELISA (EGLP-35K; Linco Research Inc., St. Charles, Missouri, USA). Plasma active GLP-1 concentrations were measured in plasma after addition of $10 \mu \mathrm{LPP}-\mathrm{IV}$ inhibitor per millilitre of blood. Sensitivity of the ELISA assay was $2 \mathrm{pM}$, and the difference between duplicate results of a sample was $<10 \% \mathrm{CV}$. The specificity for active GLP1 was $100 \%$. Plasma leptin concentrations were measured using the human leptin RIA-kit (Linco Research Inc., St. Charles, Missouri, USA). Sensitivity of the leptin RIA assay was $0.05 \mathrm{ng} / \mathrm{ml}$ and the difference between duplicate results of a sample was $<10 \% \mathrm{CV}$. The specificity for human leptin was $100 \%$.

\section{Appetite profile}

Appetite profile was measured with the use of anchored 100-mm visual analogue scales (VAS). During each test-day these questionnaires were completed at several time points before and after the lunch. The questions were, "How hungry are you?" and "How satiated are you?" and were anchored by "not at all" and "very." 


\section{Body composition}

Body composition was measured by using the deuterium dilution technique. ${ }^{2} \mathrm{H}_{2} \mathrm{O}$ dilution was used to measure total body water (TBW). The subjects were asked to collect a urine sample in the evening just before drinking the deuterium-enriched water solution. After ingestion of this solution, the subjects went to bed and no additional consumption was allowed for this period. Ten hours after drinking the water solution, another urine sample was collected. The dilution of the deuterium isotope is a measure of the TBW of the subject. Deuterium was measured in the urine samples with an isotope ratio mass spectrometer (VG-Isogas Aqua Sira; VG Isogas, Middlewich, England). TBW was obtained by dividing the measured deuterium dilution space by 1.04. Fat-free mass (FFM) was calculated by dividing TBW by the hydration factor 0.73 . Fat mass (FM) was determined as BW - FFM ${ }^{20-22}$.

\section{Statistical analysis}

Data are presented as means \pm SDs unless otherwise indicated. ANOVA repeated measures were performed to determine possible differences between conditions. Regression analyses were performed to determine the relations between selected variables. All statistical tests were performed by using Statview SE Graphics software (version 4.5; Abacus Concepts Inc, Berkeley, CA, USA).

\section{Results}

Energy expenditure and substrate oxidation

Baseline energy expenditure was $4.67 \pm 0.84 \mathrm{~kJ} / \mathrm{min}$ before the RS lunch and $4.77 \pm 0.81 \mathrm{~kJ} / \mathrm{min}$ before the control lunch (NS).

Post-lunch energy expenditure increased $0.69 \pm 0.27 \mathrm{~kJ} / \mathrm{min}$ after the RS lunch and $0.72 \pm 0.22 \mathrm{~kJ} / \mathrm{min}$ after the control lunch (NS).

Total post-lunch energy expenditure above baseline energy expenditure over 210 min was $148.03 \pm 57.31 \mathrm{~kJ}$ after the RS lunch and $151.34 \pm 47.09 \mathrm{~kJ}$ after the control lunch (NS). Total post-lunch energy expenditure above baseline energy expenditure over $210 \mathrm{~min}$ as percentage of the energy content of the lunch was $4.0 \pm 1.5 \%$ after the RS lunch and $4.3 \pm 1.2 \%$ after the control lunch (NS).

RQ was $0.86 \pm 0.05$ in the RS condition and $0.86 \pm 0.04$ in the control condition (NS). Non-protein RQ was $0.87 \pm 0.06$ in the RS condition and $0.87 \pm 0.05$ in the control condition (NS).

Substrate oxidation was not different in the RS condition from the control condition (protein oxidation RS: $16.4 \pm 5.4 \mathrm{~g}$, control: $16.9 \pm 6.2 \mathrm{~g}$, carbohydrate oxidation RS: $35.4 \pm 12.5 \mathrm{~g}$, control: $37.3 \pm 12.4 \mathrm{~g}$, fat oxidation RS: $12.6 \pm 6.9 \mathrm{~g}$, control: $13.2 \pm 6.4 \mathrm{~g})$. 
Blood parameters

All blood parameters before lunch, here named baseline, were not different between conditions.

GLP-1

Plasma GLP-1 responses to the RS and control lunch are shown in Figure 1. Plasma GLP-1 responses expressed as change from baseline were not significantly different at any of the measured time points after the RS and control lunch. AUC of plasma GLP-1 response was $192 \pm 100$ pM.h after RS lunch, and 191 \pm 94 pM.h after control lunch (NS).

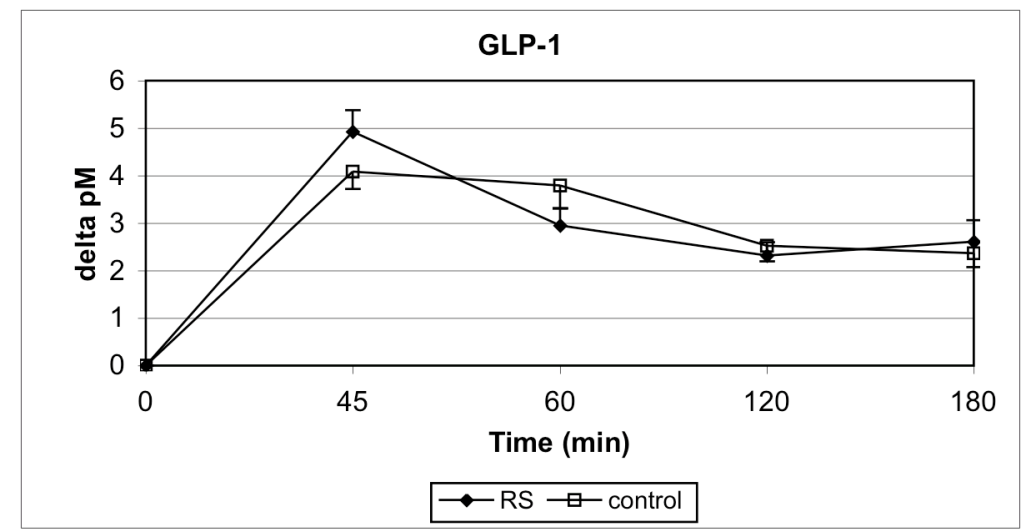

Figure 1. Mean $( \pm$ SEM) changes in GLP-1 plasma concentrations for the $R S(n=30)$ and control lunch $(n=30)$

Ghrelin

Plasma active ghrelin responses to the RS and control lunch are shown in Figure 2. Plasma active ghrelin responses expressed as change from baseline were not significantly different at any of the measured time points after the RS and control lunch. AUC of plasma active ghrelin response was $1450 \pm 3377$ (pg/ml).h after RS lunch, and $-1334 \pm 1886$ (pg/ml).h after control lunch (NS). 


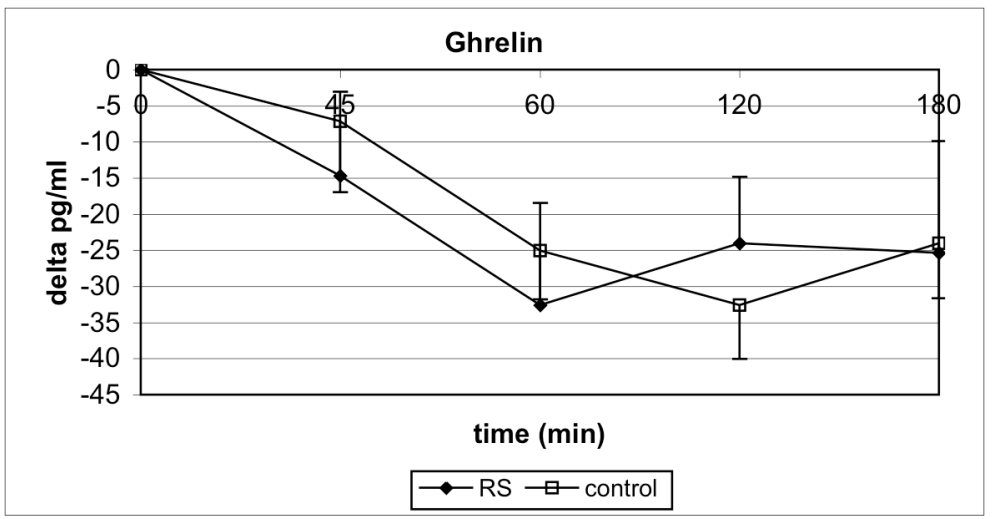

Figure 2. Mean $( \pm \mathrm{SEM})$ changes in active ghrelin plasma concentrations for the RS (n $=30)$ and control lunch $(n=30)$

PYY

Plasma PYY responses to the RS and control lunch are shown in Figure 3. Plasma PYY responses expressed as change from baseline were not significantly different at any of the measured time points after the RS and control lunch. AUC of plasma PYY response was $-119 \pm 975$ (pg/ml).h after RS lunch, and 259 \pm 880 (pg/ml).h after control lunch (NS).

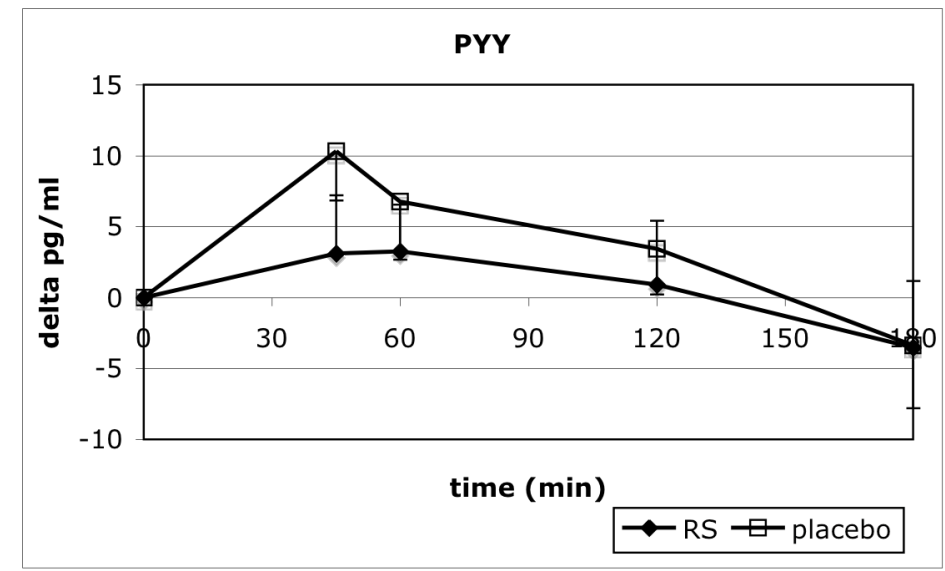

Figure 3. Mean $( \pm$ SEM) changes in PYY plasma concentrations for the for the RS $(n=$ $30)$ and control lunch $(n=30)$

\section{Appetite profile}

Satiety VAS scores were not significantly different at any of the measured time points after the RS and control lunch (Figure 4A). AUC satiety VAS score was not significantly different after the RS and control lunch (Figure 4B). 

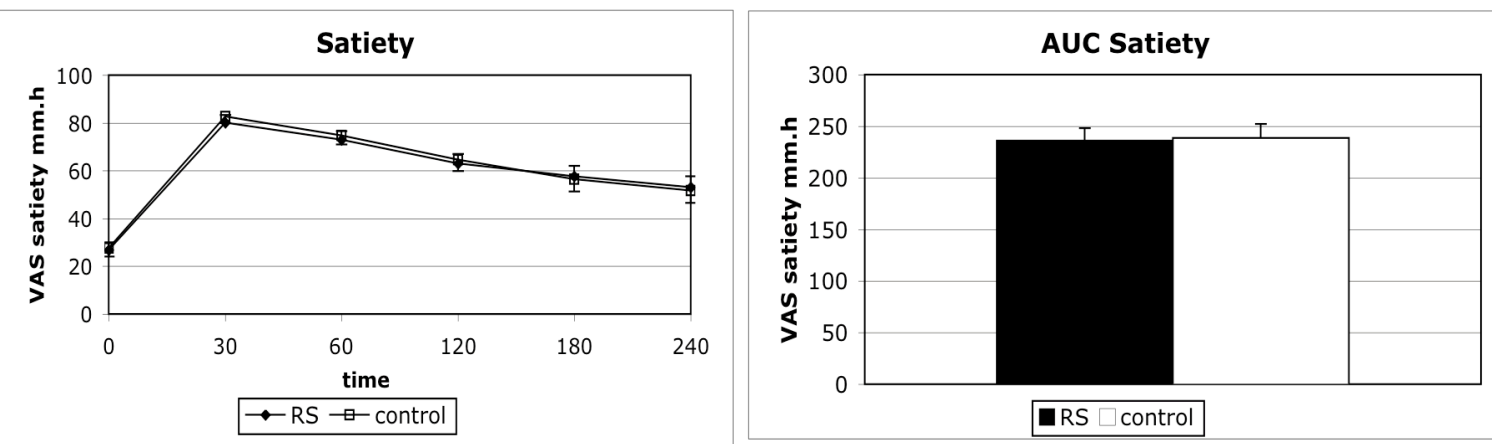

Figure 4A and B. Mean ( \pm SEM) satiety ratings measured with the use of an anchored $100-\mathrm{mm}$ visual analogue scale (left) for the for the RS $(n=30)$ and control lunch $(n=30)$. Mean $( \pm$ SEM) area under the curve satiety visual analogue scale scores (right) for the for the RS $(n=30)$ and control lunch $(n=30)$

\section{Relationships appetite profile and blood analysis}

Satiety VAS scores were not related to plasma GLP-1, ghrelin, and PYY concentrations at neither time-points nor expressed as AUC in both the RS and control condition.

\section{Discussion}

In the present study, a single meal in the postprandial phase with a 1.5 times higher amount of RS compared to a control meal did not affect satiety, DIT, substrate oxidation, plasma GLP-1, ghrelin and PYY responses for a period of 3 hours.

A study, in which the difference in $\mathrm{g}$ of RS between a single test meal and control meal was comparable to our test and control meal, showed that a difference of $\pm 4 \mathrm{~g}$ of RS between the test meal and the control meal, while the energy content of the two meals was equal, resulted in significant higher feelings of satiety 4 hours after the test meal with $\pm 4 \mathrm{~g}$ more RS compared to the control meal ${ }^{23}$. Important differences between the latter study and our study, which may explain the differences in satiety outcomes, are the total energy content of the test and control meals $( \pm 1.5 \mathrm{MJ}$ vs. $\pm 3.5 \mathrm{MJ})$ and the metabolic state (post absorptive vs. postprandial). Although physiologically important, the postprandial state may have masked the differences in feelings of satiety after the RS compared to the control meal. When comparing meals with different amounts of RS it is very important to keeping the metabolizable energy content of test and control meals equal, because effects on appetite feelings are largely dependent volume and weight. Studies reporting lower feelings of satiety after consumption of a meal with a high RS content, like the study by Raben et al. and Achour et al. in which the energy content of the meal containing RS was considerably 
lower compared to the control meal, should therefore be considered carefully regarding the difference in metabolizable energy (apart from the RS content) of the test and control meals ${ }^{24,25}$.

The energy content of test and control meals is also important when comparing effects of RS on DIT. Heijnen et al. observed lower DIT after a meal that contained $27 \mathrm{~g}$ of RS compared to after a meal that contained no RS ${ }^{13}$. However, this difference in DIT was completely explained by the difference in digestible carbohydrates in the meals. DIT expressed as $\%$ of the metabolizable energy of the meals is a parameter, which can be used to correct for differences in energy content between meals. In two studies DIT expressed as $\%$ of the metabolizable energy was not different between a meal containing up to $25 \mathrm{~g}$ of RS and a control meal ${ }^{15,24}$. We hypothesised that in the present study DIT would be lower after the RS lunch compared to the control lunch, because it will be blunted. Namely, the bacterial fermentation of RS in the large intestine, which leads to the formation of metabolizable short chain fatty acids (SCFA), occurs several hours later than the period in which we measured DIT ${ }^{26}$. Yet, although we were not able to measure the possible contribution of SCFA, DIT was not different after the RS and control lunch.

We observed no differences in substrate oxidation between the RS and control condition. In a study by Higgins et al., fat oxidation was significantly higher after a meal, which contained $5 \mathrm{~g}$ of RS compared to after the control meal ${ }^{14}$. Higher fat oxidation and lower carbohydrate oxidation has also been reported after a meal containing $27 \mathrm{~g}$ of RS. However, the data of this study are difficult to interpret, because the metabolizable energy content of the meal containing RS was considerably lower compared to the control meal ${ }^{15}$. Since the carbohydrate and energy content of their meals was lower, fat oxidation must have started earlier and was therefore higher. Two other studies observed no differences in carbohydrate and fat oxidation compared to a control meal containing no RS over 6 and 8 hours after a meal containing $30 \mathrm{~g}$ and $25 \mathrm{~g}$ of RS, respectively ${ }^{24,27}$.

We observed no differences in plasma GLP-1, ghrelin and PYY responses between the RS condition and control condition. Very few human studies have looked at the effects of RS supplementation on gut-derived hormones. A breakfast consisting of guar gum together with galactose increased GLP-1 response in women; moreover, this increase in GLP-1 was related to an increase in satiety ${ }^{6}$. A lower plasma GLP-1 response was reported after ingestion of the meal, which contained $25 \mathrm{~g}$ of RS compared to after the control meal ${ }^{25}$. This lower plasma GLP-1 response was, however, most probably due to the much lower metabolizable energy and readily digestible starch content. Four weeks of supplementation with $30 \mathrm{~g}$ RS a day resulted in higher fasting plasma total ghrelin concentrations, but had no effects on plasma leptin and GLP-1 concentrations ${ }^{28}$, showing that with respect to gut hormone responses, longer term experiments do not affect the outcome. The 
responses of these gut-derived hormones are dependent on energy load and macronutrient composition of the test meal, time of the day, and sex, which makes them difficult to compare between studies ${ }^{29}$. However, keeping in mind the convincing results of RS supplementation on GLP-1, PYY and ghrelin from animal studies, more research is needed to investigate possible effects of RS supplementation on gut-derived hormones, probably by administering RS to each meal for 2-3 days.

Over 24 hours, RS supplementation has shown to lower postprandial plasma glucose and insulin concentrations ${ }^{30}$, lower and delay postprandial carbohydrate oxidation, and lower hunger feelings, while total energy intake was equal ${ }^{31}$. The data of the present paper indicate that modest RS supplementation of 1 meal has no effects substrate utilisation, appetite feelings and gut derived hormones. Over the longer term (meals or days), previously observed effects of RS supplementation on, in particular, fat oxidation and carbohydrate handling most probably build up and, as a result of that, may contribute to the increased satiety observed for foods containing RS.

The phenomena that, in comparison with other studies we did not observe acute effects of RS on any of the measured parameters may be due to the study-designs. Most of those studies have added large amounts of RS2 afterwards to the test meal, or have used unusual foods like raw potato starch.

Summarizing, studies assessing RS effects on satiety should meet the following requirements: the metabolizable energy content of the meal with RS should be equal to the metabolizable energy content of the control meal, and the amount of digestible carbohydrates of the meal with RS should be equal to the amount of digestible carbohydrates of the control meal.

In conclusion, RS supplementation has no acute effect on substrate utilisation appetite feelings and gut derived hormones. It is likely that a possible effect will be built up over a couple of days.

\section{Acknowledgment}

We gratefully acknowledge Helene Reinbach, Maartje Spetter, Rick Hursel, Tine Horsten and Lizette den Hollander for their assistance. 


\section{References}

1. National Heart L, and Blood Institute. Clinical guidelines on the identification, evaluation, and treatment of overweight and obesity in adults: the evidence report. Bethesda, MD: US Department of Health and Human Services, National Institutes of Health; 1998. Available at http://www.nhlbi.nih.gov/guidelines/obesity/ob gdlns.htm (accessed 10 October 2007).

2. Andoh A, Tsujikawa T, Fujiyama Y. Role of dietary fiber and short-chain fatty acids in the colon. Curr Pharm Des 2003;9(4):347-58.

3. Higgins JA. Resistant starch: metabolic effects and potential health benefits. J AOAC Int 2004;87(3):761-8.

4. Cani PD, Dewever C, Delzenne NM. Inulin-type fructans modulate gastrointestinal peptides involved in appetite regulation (glucagon-like peptide-1 and ghrelin) in rats. Br J Nutr 2004;92(3):521-6.

5. Keenan MJ, Zhou J, McCutcheon KL, Raggio AM, Bateman HG, Todd E, Jones CK, Tulley RT, Melton S, Martin RJ and others. Effects of resistant starch, a non-digestible fermentable fiber, on reducing body fat. Obesity (Silver Spring) 2006;14(9):1523-34.

6. Adam TC, Westerterp-Plantenga MS. Nutrient-stimulated GLP-1 release in normal-weight men and women. Horm Metab Res 2005;37(2):111-7.

7. Holst JJ. Glucagonlike peptide 1: a newly discovered gastrointestinal hormone. Gastroenterology 1994;107(6):1848-55.

8. Naslund E, Barkeling B, King N, Gutniak M, Blundell JE, Holst JJ, Rossner S, Hellstrom PM. Energy intake and appetite are suppressed by glucagonlike peptide-1 (GLP-1) in obese men. Int J Obes Relat Metab Disord 1999;23(3):304-11.

9. Adrian TE, Long RG, Fuessl HS, Bloom SR. Plasma peptide YY (PYY) in dumping syndrome. Dig Dis Sci 1985;30(12):1145-8.

10. Nakazato M, Murakami N, Date Y, Kojima M, Matsuo H, Kangawa K, Matsukura S. A role for ghrelin in the central regulation of feeding. Nature 2001;409(6817):194-8.

11. Wren AM, Seal LJ, Cohen MA, Brynes AE, Frost GS, Murphy KG, Dhillo WS, Ghatei MA, Bloom SR. Ghrelin enhances appetite and increases food intake in humans. J Clin Endocrinol Metab 2001;86(12):5992.

12. Cuntz U, Fruhauf E, Wawarta R, Tschop M, Folwaczny C, Riepl R, Lehnert $\mathrm{P}$, Fichter M, Otto B. A role for the novel weight-regulating hormone ghrelin in anorexia nervosa. Am Clin Lab 2002;21(4):22-3.

13. Heijnen ML, Deurenberg P, van Amelsvoort JM, Beynen AC. Replacement of digestible by resistant starch lowers diet-induced thermogenesis in healthy men. Br J Nutr 1995;73(3):423-32.

14. Higgins JA, Higbee DR, Donahoo WT, Brown IL, Bell ML, Bessesen DH. Resistant starch consumption promotes lipid oxidation. Nutr Metab (Lond) 2004;1(1):8. 
15. Tagliabue A, Raben A, Heijnen ML, Deurenberg P, Pasquali E, Astrup A. The effect of raw potato starch on energy expenditure and substrate oxidation. Am J Clin Nutr 1995;61(5):1070-5.

16. Stunkard AJ, Messick S. The three-factor eating questionnaire to measure dietary restraint, disinhibition and hunger. J Psychosom Res 1985;29(1):7183.

17. Harris JA, Benedict FG. A Biometric Study of Human Basal Metabolism. Proc Natl Acad Sci U S A 1918;4(12):370-3.

18. Schoffelen PF, Westerterp KR, Saris WH, Ten Hoor F. A dual-respiration chamber system with automated calibration. J Appl Physiol 1997;83(6):2064-72.

19. Brouwer E. On simple formulae for calculating the heat expenditure and the quantities of carbohydrate and fat oxidized in metabolism of men and animals, from gaseous exchange (Oxygen intake and carbonic acid output) and urine-N. Acta Physiol Pharmacol Neerl 1957;6:795-802.

20. Schoeller DA, van Santen E, Peterson DW, Dietz W, Jaspan J, Klein PD. Total body water measurement in humans with $18 \mathrm{O}$ and $2 \mathrm{H}$ labeled water. Am J Clin Nutr 1980;33(12):2686-93.

21. van Marken Lichtenbelt WD, Westerterp KR, Wouters L. Deuterium dilution as a method for determining total body water: effect of test protocol and sampling time. Br J Nutr 1994;72(4):491-7.

22. Westerterp KR, Wouters L, van Marken Lichtenbelt WD. The Maastricht protocol for the measurement of body composition and energy expenditure with labeled water. Obes Res 1995;3 Suppl 1:49-57.

23. Liljeberg HG, Akerberg AK, Bjorck IM. Effect of the glycemic index and content of indigestible carbohydrates of cereal-based breakfast meals on glucose tolerance at lunch in healthy subjects. Am J Clin Nutr 1999;69(4):647-55.

24. Achour L, Flourie B, Briet F, Franchisseur C, Bornet F, Champ M, Rambaud JC, Messing B. Metabolic effects of digestible and partially indigestible cornstarch: a study in the absorptive and postabsorptive periods in healthy humans. Am J Clin Nutr 1997;66(5):1151-9.

25. Raben A, Tagliabue A, Christensen NJ, Madsen J, Holst JJ, Astrup A. Resistant starch: the effect on postprandial glycemia, hormonal response, and satiety. Am J Clin Nutr 1994;60(4):544-51.

26. Topping DL, Clifton PM. Short-chain fatty acids and human colonic function: roles of resistant starch and nonstarch polysaccharides. Physiol Rev 2001;81(3):1031-64.

27. Ranganathan S, Champ M, Pechard C, Blanchard P, Nguyen M, Colonna P, Krempf M. Comparative study of the acute effects of resistant starch and dietary fibers on metabolic indexes in men. Am J Clin Nutr 1994;59(4):87983. 
28. Robertson MD, Currie JM, Morgan LM, Jewell DP, Frayn KN. Prior shortterm consumption of resistant starch enhances postprandial insulin sensitivity in healthy subjects. Diabetologia 2003;46(5):659-65.

29. Wren AM, Bloom SR. Gut hormones and appetite control. Gastroenterology 2007;132(6):2116-30.

30. Robertson MD, Bickerton AS, Dennis AL, Vidal H, Frayn KN. Insulinsensitizing effects of dietary resistant starch and effects on skeletal muscle and adipose tissue metabolism. Am J Clin Nutr 2005;82(3):559-67.

31. Sparti A, Milon H, Di Vetta V, Schneiter P, Tappy L, Jequier E, Schutz Y. Effect of diets high or low in unavailable and slowly digestible carbohydrates on the pattern of 24-h substrate oxidation and feelings of hunger in humans. Am J Clin Nutr 2000;72(6):1461-8. 



\section{9}

\section{The acute effects of a lunch containing capsaicin on energy and substrate utilization, hormones, and satiety}

Astrid J. Smeets and Margriet S. Westerterp-Plantenga

Submitted for publication 


\begin{abstract}
Addition of capsaicin to the diet has been shown to increase satiety and thermogenesis. The effects of capsaicin on ghrelin, PYY and GLP-1, in relation to changes in hunger and satiety are unknown.

Thirty subjects (age: $31 \pm 14$ y, BMI: $23.8 \pm 2.8 \mathrm{~kg} / \mathrm{m} 2$ ) were studied 2 times in a randomized controlled crossover design. After 30 minutes resting on a bed, resting metabolic rate was measured by a ventilated hood system. Subsequently lunch (35\% of daily energy intake) was served. The two lunch conditions were: i) lunch without capsaicin and ii) lunch with capsaicin (CAPS). The macronutrient composition (energy \%) of the lunches was: $60 \%$ carbohydrates/ $10 \%$ protein/ $30 \%$ fat. During 3 hours after the lunch diet induced energy expenditure was measured. Furthermore anchored $100 \mathrm{~mm}$ visual analogue scales on the appetite profile were collected and blood samples were taken for analysis of GLP1, PYY, and ghrelin concentrations, before and at different time-points after lunch.

Satiety and energy expenditure were not different after CAPS lunch compared with the control lunch. Fifteen minutes after lunch CAPS lunch increased GLP-1 $(p<0.05)$ and tended to decrease ghrelin $(p=0.07)$ compared with the control lunch. PYY responses were not different between the CAPS lunch and the control lunch.

Acute lunch containing capsaicin had no effect on satiety, EE, and PYY, but increased GLP-1 and tended to decrease ghrelin.
\end{abstract}




\section{Introduction}

The global increase of obesity and associated comorbidities urges for effective and satisfying treatments ${ }^{1}$. Obesity is the ultimate result of an imbalance between energy intake and energy expenditure ${ }^{2}$. Weight loss can be achieved by reducing energy intake and/or increasing energy expenditure.

Research has been focusing on specific food components, which may have favourable effects on weight-loss, weight-maintenance, and metabolism. One of these specific food components is capsaicin, the pungent principle of hot red pepper. Capsaicin has been reported to have favourable effects on energy expenditure, fat oxidation, and appetite control ${ }^{2-6}$. The effects of capsaicin on energy and lipid metabolism are associated with an increase in sympathetic nervous system activity ${ }^{3,5-7}$.

In a recent study we have shown that the satiating effect of capsaicin is present after gastrointestinal exposure, and is even more profound after the combination of sensory and gastrointestinal exposure ${ }^{4}$.

Capsaicin sensitive primary afferent sensory nerves are found in the nerves innervating the whole gastrointestinal tract ${ }^{8-10}$. From predominantly animal studies we know that capsaicin may affect gastrointestinal physiology. Interestingly, capsaicin was found to increase blood flow and secretion in the gastrointestinal tract ${ }^{11-14}$. Furthermore, have capsaicin sensitive primary afferent sensory nerves been suggested to be involved in the effects of nutrients on gut-derived hormones, such as cholescystokinin, ghrelin, PYY, GLP-1, and gastric motility and emptying in rats ${ }^{15-18}$.

Few studies have looked at the effects of capsaicin on gastrointestinal physiology, i.e. gastric emptying and isolated intestinal muscle strip relaxation, in humans ${ }^{19,20}$. Whether capsaicin affects the secretion of gutderived hormones, and whether this is associated with the satiating effects of capsaicin is unknown. Therefore, the aim of this study was to test the acute effects of a lunch containing capsaicin on gut derived hormones (GLP-1, ghrelin, and PYY). In addition, we investigated the acute effects of a meal containing capsaicin on energy expenditure, substrate oxidation and satiety at lunch in the postrandial state. We hypothesized that a single meal containing capsaicin compared with a single control meal might increase satiety, diet induced thermogenesis, plasma PYY and GLP-1 concentrations, and fat oxidation, and decrease plasma ghrelin concentrations, and respiratory quotient (RQ). 


\section{Subjects and Methods}

Subjects

Thirty healthy subjects (19 women and 11 men) with a body mass index (BMI; in $\mathrm{kg} / \mathrm{m}^{2}$ ) of $20-30$ and aged $18-60$ y were recruited by advertisements in local newspapers and on notice boards at Maastricht University. All subjects underwent a medical screening, and all were in good health, non-smokers, not using medication, and at most moderate alcohol users. Eating behaviour was assessed using a validated Dutch translation of the TFEQ. Cognitive restrained and unrestrained eating behaviour (Factor 1), emotional eating and disinhibition (Factor 2), and the subjective feeling of hunger (Factor 3 ) were scored ${ }^{21}$. The baseline characteristics of the subjects are presented in Table 1. Written informed consent was obtained from all participants. The Medical Ethics Committee of the Academic Hospital in Maastricht approved the study.

Table 1. Subject characteristics $(n=30)$

\begin{tabular}{ll}
\hline & Value \\
\hline Age $(\mathbf{y})$ & $31 \pm 14$ \\
Body weight (kg) & $72 \pm 12$ \\
Height $(\mathbf{m})$ & $1.73 \pm 0.09$ \\
BMI (kg/m $\mathbf{m}^{\mathbf{2}}$ & $23.8 \pm 2.8$ \\
Body fat $(\%)$ & $25.6 \pm 8.8$ \\
Dietary restrained $^{\mathbf{2}}$ & $4.3 \pm 2.6$ \\
\hline
\end{tabular}

1 All values are mean \pm SD

2 Factor 1 (dietary restraint) of the Three-Factor Eating Questionnaire was used ${ }^{21}$

\section{Experimental sessions}

The study had a single blind, randomized, crossover design. The subjects underwent two indirect calorimetry tests for the measurement of energy expenditure (EE) and substrate oxidation. On the morning before the test (8:00 am), the subjects received a subject specific breakfast (Campina Drinkontbijt), which provided $15 \%$ of each subject's individual daily energy requirements. Subject specific daily energy requirements were calculated based on basal metabolic rate (BMR), which was calculated with the equation of Harris-Benedict ${ }^{22}$. BMR was multiplied by an activity index of 1.5. After the breakfast, subjects were not allowed to eat or drink during the morning except water and 1 cup of coffee or tea without milk or sugar. One hour before the test lunch was served (11:00 am), baseline EE and substrate oxidation were measured by means of an open-circuit, ventilated-hood system with subjects lying supine for at least $30 \mathrm{~min}$. At 12:00am the subjects received a lunch, which was consumed within 15 min., of one of two randomly assigned treatments: control lunch or the lunch supplemented with $1030 \mathrm{mg}$ red pepper equivalent to 80,000 
Scoville Heat Units of capsaicin (Cayenne, Solaray, Park City, UT, USA). This dose of capsaicin was chosen based on our experiences concerning the highest tolerable dose in a previous study. Both lunches provided 35\% of each subject's individual daily energy requirements, provided $10 \%$ of energy from protein, $60 \%$ of energy from carbohydrate, $30 \%$ of energy from fat, and consisted of pasta (Technical University of Budapest, Department of Biochemistry and Food Technology, Budapest, Hungary), sausages (Matforsk, Ås, Norway), and tomato sauce (Heinz, Elst, The Netherlands). The spiciness of the meal with capsaicin was well tolerated by all subjects. Post-lunch EE and substrate oxidation were measured for 210 min after ingestion of the lunch.

\section{Energy expenditure and substrate oxidation}

On the test days, baseline and post-lunch EE and substrate oxidation were measured with an open-circuit, ventilated-hood system with the subjects lying supine ${ }^{23}$. Gas analysis was performed by a paramagnetic $\mathrm{O}_{2}$ analyzer (OmniCal type 1155B; Crowborough, Sussex, UK) and an IR $\mathrm{CO}_{2}$ analyzer (OmniCal type 1520/1507). EE was calculated using Brouwer's formula ${ }^{24}$. The RQ was calculated as $\mathrm{CO}_{2}$ produced $/ \mathrm{O}_{2}$ consumed. Carbohydrate, fat, and protein oxidation were calculated from the measurements of oxygen consumption, carbon dioxide production, and urinary nitrogen excretion by using the formula of Brouwer ${ }^{24}$. Urine samples were collected from the first void after the start of the test day $(11: 00 \mathrm{am})$ until the last void on the test day $(4: 00 \mathrm{pm})$. Subjects voided their bladder before the start of the test day (before 11:00am) Samples were collected in containers with $10 \mathrm{ml} \mathrm{H}_{2} \mathrm{SO}_{4}$ to prevent nitrogen loss through evaporation. Volume and nitrogen concentration were measured, the latter with a nitrogen analyzer (CHN-O-Rapid; Heraeus, Hanau, Germany).

\section{Blood sampling}

One hour before the lunch was served (11:00 am), a polytetrafluoroethylene catheter was placed in the antecubital vein for blood sampling. During each test day, 1 blood sample just before the lunch (at $0 \mathrm{~min}$ ) and 4 blood samples after lunch (at $45 \mathrm{~min}, 60 \mathrm{~min}, 120$ min, and $180 \mathrm{~min}$ ) were taken for measurement of plasma ghrelin, GLP-1, and PYY concentrations. Blood samples were collected in tubes containing EDTA to prevent clotting. Plasma was obtained by centrifugation $\left(4^{\circ} \mathrm{C}, 3000 \mathrm{rpm}, 10 \mathrm{~min}\right)$ and stored at $-80{ }^{\circ} \mathrm{C}$ until analyzed. Plasma concentrations of active ghrelin were measured by RIA (Linco Research Inc., St. Charles, Missouri, USA). Plasma active ghrelin concentrations were measured in acidified plasma with $50 \mu \mathrm{l}$ of $1 \mathrm{~N} \mathrm{HCl}$ 
and addition of $10 \mu \mathrm{l}$ of Phenylmethylsulfonyl fluoride (PMSF) per $1 \mathrm{ml}$ of plasma. Sensitivity of the RIA assay was $7.8 \mathrm{pg} / \mathrm{ml}$ and the difference between duplicate results of a sample was $<10 \% \mathrm{CV}$. The specificity for human ghrelin was $100 \%$. Plasma active GLP-1 samples were analyzed using ELISA (EGLP-35K; Linco Research Inc., St. Charles, Missouri, USA). Plasma active GLP-1 concentrations were measured in plasma after addition of $10 \mu \mathrm{l}$ DPP-IV inhibitor per milliliter of blood. Sensitivity of the ELISA assay was $2 \mathrm{pM}$, and the difference between duplicate results of a sample was $<10 \% \mathrm{CV}$. The specificity for active GLP-1 was $100 \%$. Plasma leptin concentrations were measured using the human leptin RIA-kit (Linco Research Inc., St. Charles, Missouri, USA). Sensitivity of the leptin RIA assay was $0.05 \mathrm{ng} / \mathrm{ml}$ and the difference between duplicate results of a sample was $<10 \% \mathrm{CV}$. The specificity for human leptin was $100 \%$.

\section{Appetite profile}

Appetite profile was measured with the use of anchored $100-\mathrm{mm}$ visual analogue scales (VAS). During each test-day these questionnaires were completed at several time points before and after the lunch. The questions were, "How hungry are you?" and "How satiated are you?" and were anchored by "not at all" and "very."

\section{Body composition}

Body composition was measured by using the deuterium dilution technique. ${ }^{2} \mathrm{H}_{2} \mathrm{O}$ dilution was used to measure total body water (TBW). The subjects were asked to collect a urine sample in the evening just before drinking the deuterium-enriched water solution. After ingestion of this solution, the subjects went to bed and no additional consumption was allowed for this period. Ten hours after drinking the water solution, another urine sample was collected. The dilution of the deuterium isotope is a measure of the TBW of the subject. Deuterium was measured in the urine samples with an isotope ratio mass spectrometer (VG-Isogas Aqua Sira; VG Isogas, Middlewich, England). TBW was obtained by dividing the measured deuterium dilution space by 1.04. Fat-free mass (FFM) was calculated by dividing TBW by the hydration factor 0.73 . Fat mass (FM) was determined as BW $-\mathrm{FFM}^{25-27}$.

\section{Statistical analysis}

Data are presented as means \pm SDs unless otherwise indicated. ANOVA repeated measures were performed to determine possible differences between conditions. Regression analyses were performed to determine the relations between selected variables. All statistical tests were performed by using Statview SE Graphics software (version 4.5; Abacus Concepts Inc, Berkeley, CA, USA). 


\section{Results}

Energy expenditure and substrate oxidation

Baseline energy expenditure was $4.87 \pm 0.72 \mathrm{~kJ} / \mathrm{min}$ before the CAPS lunch and $4.77 \pm 0.81 \mathrm{~kJ} / \mathrm{min}$ before the control lunch (NS). Post-lunch energy expenditure increased $0.62 \pm 0.28 \mathrm{~kJ} / \mathrm{min}$ after the CAPS lunch and $0.72 \pm 0.22 \mathrm{~kJ} / \mathrm{min}$ after the control lunch (NS). Total post-lunch energy expenditure above baseline energy expenditure over $210 \mathrm{~min}$ was $133.7 \pm 58.3 \mathrm{~kJ}$ after the CAPS lunch and $151.34 \pm 47.09 \mathrm{~kJ}$ after the control lunch (NS). Total post-lunch energy expenditure above baseline energy expenditure over $210 \mathrm{~min}$ as percentage of the energy content of the lunch was $3.9 \pm 1.4 \%$ after the CAPS lunch and $4.3 \pm 1.2 \%$ after the control lunch (NS).

RQ was $0.85 \pm 0.05$ in the CAPS condition and $0.86 \pm 0.04$ in the control condition (NS). Non-protein RQ was $0.86 \pm 0.05$ in the CAPS condition and $0.87 \pm 0.05$ in the control condition (NS). Substrate oxidation was not different in the CAPS condition from the control condition (protein oxidation CAPS: $15.2 \pm 4.7 \mathrm{~g}$, control: $16.9 \pm 6.2 \mathrm{~g}$, carbohydrate oxidation CAPS: $34.4 \pm 12.8 \mathrm{~g}$, control: $37.3 \pm 12.4 \mathrm{~g}$, fat oxidation CAPS: $15.2 \pm 7.2 \mathrm{~g}$, control: $13.2 \pm 6.4 \mathrm{~g})$.

\section{Blood parameters}

All blood parameters before lunch, here named baseline, were not different between conditions.

GLP-1

Plasma GLP-1 responses to the CAPS and control lunch are shown in Figure 1.

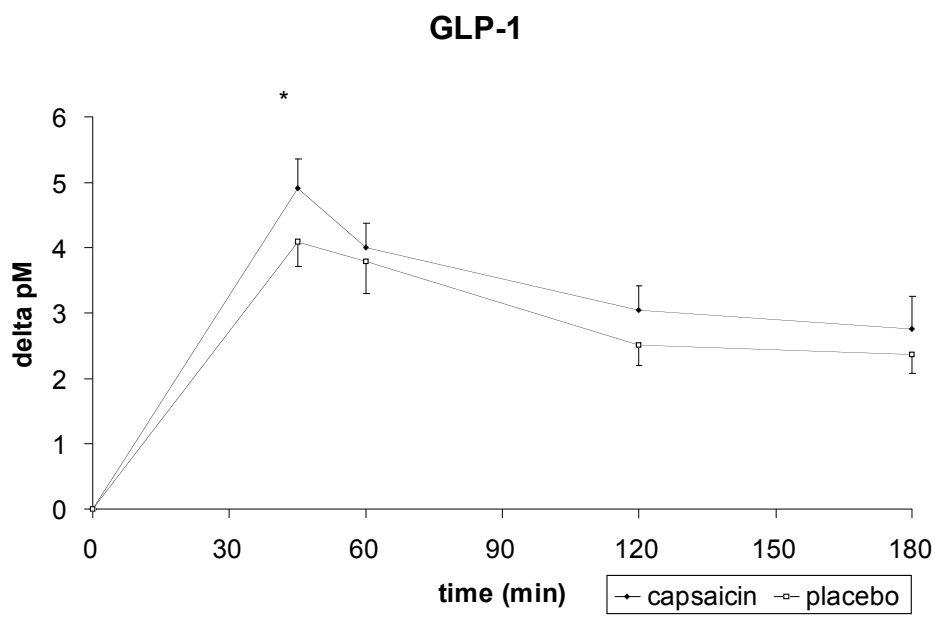

Figure 1. Mean $( \pm$ SEM) changes in GLP-1 plasma concentrations from baseline for the capsaicin $(n=30)$ and control $(n=30)$ lunch. $* p<0.05$ 
Fifteen minutes after CAPS lunch was the plasma GLP-1 response expressed as change from baseline significantly higher compared to after the control lunch $(\mathrm{p}<0.05)$. AUC of plasma GLP-1 response was $221 \pm 91$ pM.h after CAPS lunch, and 191 \pm 94 pM.h after control lunch (NS).

Ghrelin

Plasma active ghrelin responses to the CAPS and control lunch are shown in Figure 2. Fifteen minutes after CAPS lunch was the plasma active ghrelin response expressed as change from baseline tended to be lower compared to after the control lunch $(\mathrm{p}<0.07)$. AUC of plasma active ghrelin response was $-1869 \pm 2281(\mathrm{pg} / \mathrm{ml}) . \mathrm{h}$ after CAPS lunch, and $1334 \pm 1886(\mathrm{pg} / \mathrm{ml}) . h$ after control lunch (NS).

Ghrelin

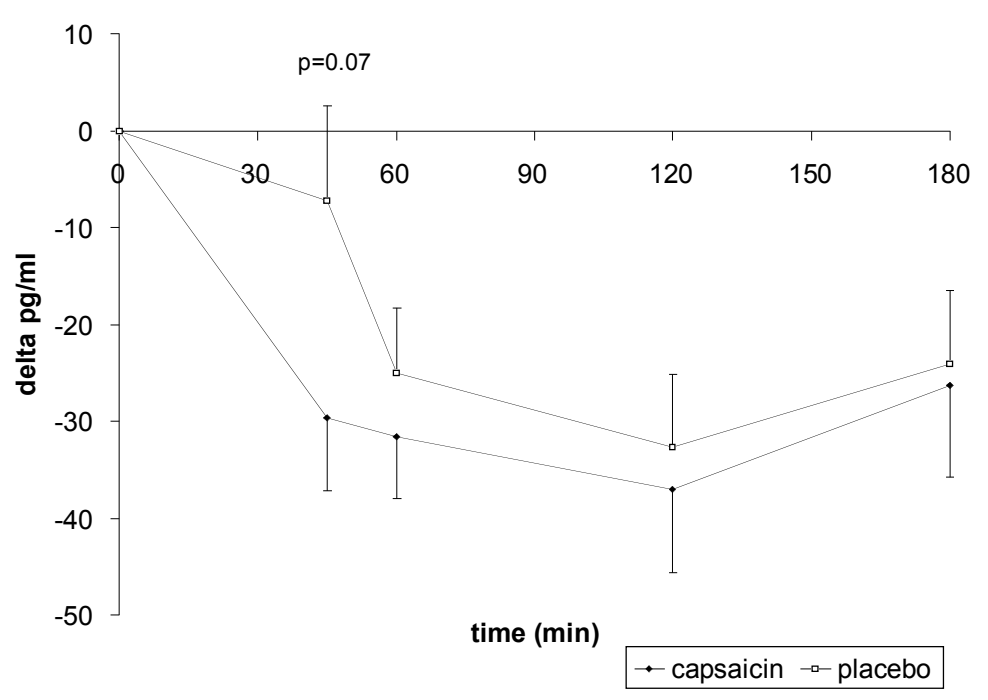

Figure 2. Mean $( \pm \mathrm{SEM})$ changes in active ghrelin plasma concentrations from baseline for the capsaicin $(n=30)$ and control $(n=30)$ lunch

\section{PYY}

Plasma PYY responses to the CAPS and control lunch are shown in Figure 3. Plasma PYY responses expressed as change from baseline were not significantly different at any of the measured time points after the CAPS and control lunch. AUC of plasma PYY response was $- \pm(\mathrm{pg} / \mathrm{ml}) . \mathrm{h}$ after CAPS lunch, and 259 \pm 880 (pg/ml).h after control lunch (NS). 


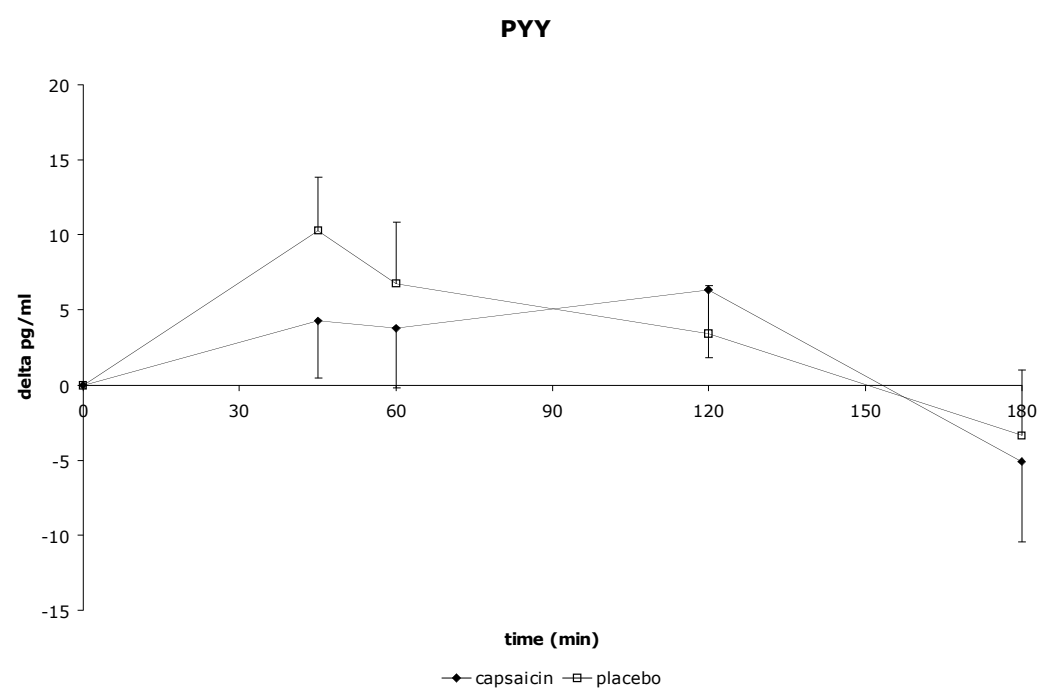

Figure 3. Mean ( \pm SEM) changes in PYY plasma concentrations from baseline for the capsaicin $(n=30)$ and control $(n=30)$ lunch

\section{Appetite profile}

Satiety VAS scores were not significantly different at any of the measured time points after the CAPS and control lunch (Figure 4A). AUC satiety VAS score was not significantly different after the CAPS and control lunch (Figure 4B).
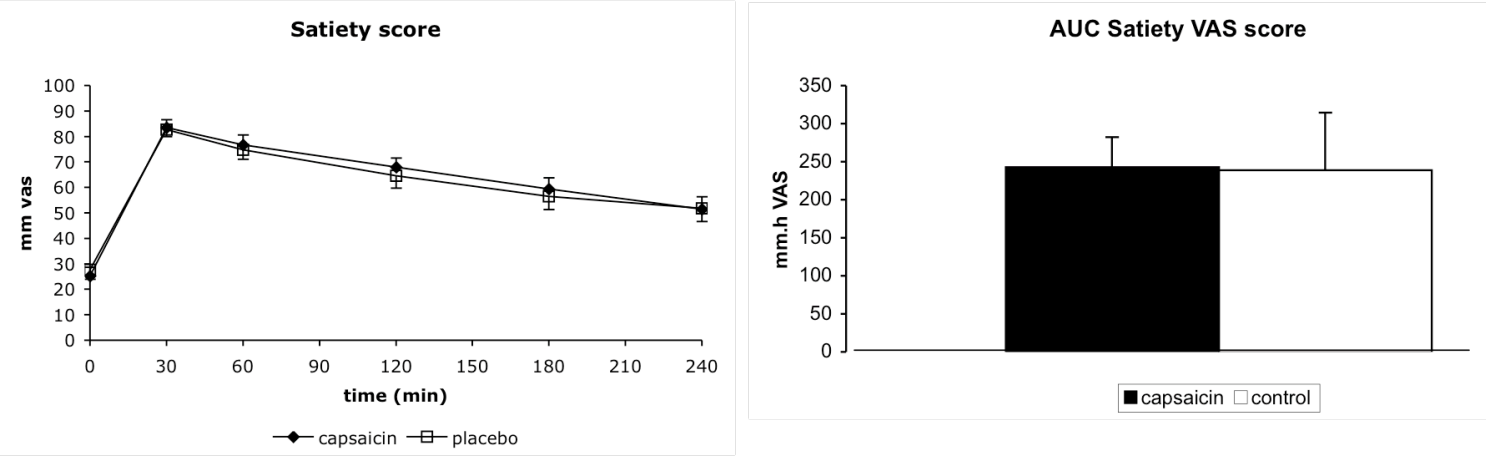

Figure 4A and B. Mean $( \pm$ SEM $)$ satiety ratings measured with the use of an anchored $100-\mathrm{mm}$ visual analogue scale (left) for the capsaicin $(\mathrm{n}=30)$ and control $(\mathrm{n}=30)$ lunch. Mean $( \pm$ SEM) area under the curve satiety visual analogue scale scores (right) for the capsaicin $(n=30)$ and control $(n=30)$ lunch 
Relationships appetite profile and blood analysis

Satiety VAS scores were not related to plasma GLP-1, ghrelin, and PYY concentrations at neither time-points nor expressed as AUC in both the CAPS and control condition.

\section{Discussion}

In the present study, a single meal with $1030 \mathrm{mg}$ red pepper equivalent to 80.000 SHU of capsaicin in the postprandial phase, did not affect satiety, DIT, substrate oxidation, and plasma PYY responses for a period of 3 hours compared to a control meal. Over a short period of time, i.e. 15 minutes, a single meal with capsaicin in the postprandial phase, significantly increased plasma GLP-1 concentrations and tended to decrease plasma ghrelin concentrations compared to a control meal.

In a study by Yoshioka, the addition of $30 \mathrm{mg}$ capsaicin to a high fat breakfast and a high carbohydrate breakfast significantly decreased prospective food consumption at lunch ${ }^{5}$. Furthermore, were desire to eat and hunger significantly decreased after the high fat breakfast with capsaicin. An important difference between the latter study and our study, which may explain the differences in satiety outcomes, is that we tested the addition of capsaicin at lunch.

Although physiologically important, the postprandial state may have masked the differences in feelings of satiety after the CAPS compared to the control meal. In a recent study we observed that satiety was significantly higher after capsaicin supplementation over 2 days compared to placebo, which suggests that effect of capsaicin on satiety may need to build up ${ }^{4}$.

In the present study, we observed no differences in DIT between the CAPS and the control condition. We hypothesised that DIT would be higher after the CAPS meal compared to after the control meal. Capsaicin is perceived as a hot substance ${ }^{28}$. Because the ingestion of hot substances can lead to an increase in body temperature, feedback mechanisms are activated to lower body temperature, such as blood vessel dilatation and sweating. The greater heat loss, due to blood vessel dilatation and sweating, after capsaicin ingestion may contribute to a higher DIT. Again, in the present study the postprandial state may have masked the effect of CAPS on DIT. The previously observed small and short effect of capsaicin on energy expenditure, in the post absorptive state, may have been too small to be distinguished during the postprandial state ${ }^{6}$.

We observed no differences in substrate oxidation between the CAPS and control condition. Capsaicin has been reported to increase carbohydrate oxidation over the short term (after 1 breakfast exposure) and to increase fat oxidation over the long term (in fasted state after 3 months exposure) 6,29 
Fifteen minutes after the CAPS lunch, plasma GLP-1 concentrations were significantly increased and there was a trend for plasma ghrelin concentrations to be decreased compared to after the control lunch. Capsaicin was found to increase gastric emptying in a study by Debreceni et $\mathrm{al}^{30}$. In the present study, increased gastric emptying after the CAPS lunch may have resulted in earlier exposure of the small intestine to nutrients, which subsequently may have led to a stronger effect on gutderived hormones over a short period of time. As far as we know, no other human studies have looked at the effects of CAPS supplementation on gut-derived hormones. Therefore, more research is needed to investigate the mechanisms behind the possible effects of capsaicin on gut-derived hormones.

In comparison with other studies we observed no acute effects of CAPS on satiety, DIT, substrate oxidation, and plasma PYY responses for a period of 3 hours. Over a short period of time, i.e. 15 minutes, a single meal with capsaicin in the postprandial phase, significantly increased plasma GLP-1 concentrations and tended to decrease plasma ghrelin concentrations.

The present results should be interpreted with caution, because this study was conducted at lunch in the postprandial state. Most studies on single meals containing CAPS have been conducted at breakfast in the post absorptive state, which makes them difficult to compare with the present study.

The data of the present paper indicate that the CAPS supplementation of 1 meal in a postprandial state has no effects substrate utilisation, appetite feelings and PYY responses, however, positive effects on GLP-1 and ghrelin responses warrant for more intensive research on the possible health promoting effects of capsaicin.

\section{Acknowledgment}

We gratefully acknowledge Helene Reinbach, Maartje Spetter, Rick Hursel, Tine Horsten and Lizette den Hollander for their assistance. 


\section{Reference}

1. Obesity: preventing and managing the global epidemic. Report of a WHO consultation. World Health Organ Tech Rep Ser 2000;894:i-xii, 1-253.

2. Kawabata F, Inoue N, Yazawa S, Kawada T, Inoue K, Fushiki T. Effects of CH-19 sweet, a non-pungent cultivar of red pepper, in decreasing the body weight and suppressing body fat accumulation by sympathetic nerve activation in humans. Biosci Biotechnol Biochem 2006;70(12):2824-35.

3. Kawada T, Watanabe T, Takaishi T, Tanaka T, Iwai K. Capsaicin-induced beta-adrenergic action on energy metabolism in rats: influence of capsaicin on oxygen consumption, the respiratory quotient, and substrate utilization. Proc Soc Exp Biol Med 1986;183(2):250-6.

4. Westerterp-Plantenga MS, Smeets A, Lejeune MP. Sensory and gastrointestinal satiety effects of capsaicin on food intake. Int J Obes (Lond) 2005;29(6):682-8.

5. Yoshioka M, St-Pierre S, Drapeau V, Dionne I, Doucet E, Suzuki M, Tremblay A. Effects of red pepper on appetite and energy intake. Br J Nutr 1999;82(2):115-23.

6. Yoshioka M, St-Pierre S, Suzuki M, Tremblay A. Effects of red pepper added to high-fat and high-carbohydrate meals on energy metabolism and substrate utilization in Japanese women. Br J Nutr 1998;80(6):503-10.

7. Kawada T, Sakabe S, Watanabe T, Yamamoto M, Iwai K. Some pungent principles of spices cause the adrenal medulla to secrete catecholamine in anesthetized rats. Proc Soc Exp Biol Med 1988;188(2):229-33.

8. Holzer-Petsche U, Seitz H, Lembeck F. Effect of capsaicin on gastric corpus smooth muscle of the rat in vitro. Eur J Pharmacol 1989;162(1):29-36.

9. Maggi CA, Manzini S, Giuliani S, Santicioli P, Meli A. Extrinsic origin of the capsaicin-sensitive innervation of rat duodenum: possible involvement of calcitonin gene-related peptide (CGRP) in the capsaicin-induced activation of intramural non-adrenergic non-cholinergic neurons. Naunyn Schmiedebergs Arch Pharmacol 1986;334(2):172-80.

10. Maggi CA, Meli A, Santicioli P. Four motor effects of capsaicin on guinea-pig distal colon. Br J Pharmacol 1987;90(4):651-60.

11. Chen RY, Li DS, Guth PH. Role of calcitonin gene-related peptide in capsaicin-induced gastric submucosal arteriolar dilation. Am J Physiol 1992;262(5 Pt 2):H1350-5.

12. Manzini S, Perretti F. Vascular effects of capsaicin in isolated perfused rat mesenteric bed. Eur J Pharmacol 1988;148(2):153-9.

13. Myers BM, Smith JL, Graham DY. Effect of red pepper and black pepper on the stomach. Am J Gastroenterol 1987;82(3):211-4.

14. Solanke TF. The effect of red pepper (Capsicum frutescens) on gastric acid secretion. J Surg Res 1973;15(6):385-90. 
15. Ahren B. Sensory nerves contribute to insulin secretion by glucagon-like peptide-1 in mice. Am J Physiol Regul Integr Comp Physiol 2004;286(2):R269-72.

16. Fu-Cheng X, Anini Y, Chariot J, Castex N, Galmiche JP, Roze C. Mechanisms of peptide YY release induced by an intraduodenal meal in rats: neural regulation by proximal gut. Pflugers Arch 1997;433(5):571-9.

17. Fukuda H, Mizuta Y, Isomoto H, Takeshima F, Ohnita K, Ohba K, Omagari K, Taniyama K, Kohno S. Ghrelin enhances gastric motility through direct stimulation of intrinsic neural pathways and capsaicinsensitive afferent neurones in rats. Scand J Gastroenterol 2004;39(12):1209-14.

18. Raybould HE, Tache Y. Cholecystokinin inhibits gastric motility and emptying via a capsaicin-sensitive vagal pathway in rats. Am J Physiol 1988;255(2 Pt 1):G242-6.

19. Giuliani S, Turini D, Barbanti G, Maggi CA. Ruthenium red as a selective capsaicin antagonist of the motor response to capsaicin in the human isolated ileum. Eur J Pharmacol 1991;196(3):331-3.

20. Maggi CA, Theodorsson E, Santicioli P, Patacchini R, Barbanti G, Turini $\mathrm{D}$, Renzi D, Giachetti A. Motor response of the human isolated colon to capsaicin and its relationship to release of vasoactive intestinal polypeptide. Neuroscience 1990;39(3):833-41.

21. Stunkard AJ, Messick S. The three-factor eating questionnaire to measure dietary restraint, disinhibition and hunger. J Psychosom Res 1985;29(1):71-83.

22. Harris JA, Benedict FG. A Biometric Study of Human Basal Metabolism. Proc Natl Acad Sci U S A 1918;4(12):370-3.

23. Schoffelen PF, Westerterp KR, Saris WH, Ten Hoor F. A dual-respiration chamber system with automated calibration. J Appl Physiol 1997;83(6):2064-72.

24. Brouwer E. On simple formulae for calculating the heat expenditure and the quantities of carbohydrate and fat oxidized in metabolism of men and animals, from gaseous exchange (Oxygen intake and carbonic acid output) and urine-N. Acta Physiol Pharmacol Neerl 1957;6:795-802.

25. Schoeller DA, van Santen E, Peterson DW, Dietz W, Jaspan J, Klein PD. Total body water measurement in humans with $18 \mathrm{O}$ and $2 \mathrm{H}$ labeled water. Am J Clin Nutr 1980;33(12):2686-93.

26. van Marken Lichtenbelt WD, Westerterp KR, Wouters L. Deuterium dilution as a method for determining total body water: effect of test protocol and sampling time. Br J Nutr 1994;72(4):491-7.

27. Westerterp KR, Wouters L, van Marken Lichtenbelt WD. The Maastricht protocol for the measurement of body composition and energy expenditure with labeled water. Obes Res 1995;3 Suppl 1:49-57. 
28. Rolls ET, Verhagen JV, Kadohisa M. Representations of the texture of food in the primate orbitofrontal cortex: neurons responding to viscosity, grittiness, and capsaicin. J Neurophysiol 2003;90(6):3711-24.

29. Lejeune MP, Kovacs EM, Westerterp-Plantenga MS. Effect of capsaicin on substrate oxidation and weight maintenance after modest body-weight loss in human subjects. Br J Nutr 2003;90(3):651-59.

30. Debreceni A, Abdel-Salam OM, Figler M, Juricskay I, Szolcsanyi J, Mozsik G. Capsaicin increases gastric emptying rate in healthy human subjects measured by 13C-labeled octanoic acid breath test. J Physiol Paris 1999;93(5):455-60. 


\section{0 \\ General discussion}


Plasticity of the fine-tuning mechanism of energy intake to energy expenditure was assessed, in order to find modulators that affect physiological variables mediating appetite related sensations. An effective modulator must sustain satiety under energy deficit conditions or increase satiety under iso-energetic conditions, through physiological variables and at the same time, preferably have stimulating effects on energy expenditure. Here, the plasticity of the fine-tuning mechanism of energy intake is described based upon the short-term effects of food-related triggers for food intake regulation.

Candidate modulators for appetite related sensations may exert sensory or metabolic effects. Sensory effects, although short-lived, may trigger or underscore appetite related sensations at a sensory and cognitive level and have an effect on food intake regulation. Metabolic effects may trigger or underscore appetite related sensations at a physiological level and have an effect on food intake regulation.

\section{Sensory effects}

To gain insight to what extent mere sensory perception under energy deficit conditions can influence appetite related sensations, we studied the effect of mere sensory perception, thus without ingestion of nutrients, in order to separate sensory from metabolic triggers, on appetite sensations and taste perception during the development of sensory-specific satiety. Satiety consists of a sensory and a metabolic aspect. With respect to sensory satiety, the phenomenon of sensory specific satiety due to sham feeding, i.e. oral exposure to food without eating was assessed. The definition of sensoryspecific satiety (SSS) states that when a food is consumed to satiety, its perceived pleasantness of taste declines compared to that of foods that have not been consumed. We observed that SSS for a particular food during mere exposure without eating, expressed as a decrease in pleasantness of taste compared to foods not being exposed to, is supported by a decrease in desire to eat, while SSS for a particular food during eating is supported not only by a decrease in desire to eat, but also by an increase in satiety and a decrease in hunger. It appeared that SSS also occurred when not every aspect of the original definition is present. Even when a food is eaten, but not to satiety, SSS occurred. Moreover, even during mere exposure without eating, SSS also occurred. Several forms of sensory-specific satiety have been observed in previous experiments, such as olfactory and visual sensory-specific satiety ${ }^{1}$. In an experiment conducted by Rolls and Rolls chewing foods, without swallowing them, for as long they would be eaten in a meal, was enough to produce sensory-specific satiety ${ }^{2}$. However, the decrease in pleasantness of taste of the chewed food was not as large as the decrease in pleasantness of taste of the eaten food, which is in line with our observations. 
The larger effects following eating are most likely due to the fact that the small and large intestines are exposed to food, which may lead to additional satiety signals ${ }^{3-6}$. In those cases SSS is supported by increased postingestive satiety and subsequent decreases in hunger.

A second remarkable factor in the development of SSS appears to be the desire to eat. The desire to eat was significantly decreased after mere exposure without eating, whereas obviously no significant changes in feelings of hunger and satiety after mere exposure without eating was observed. This suppression of desire to eat independent of lack of satiation may be explained by the difference between homeostatic and nonhomeostatic feeding. Homeostatic feeding relates to energy balance, mainly regulated through 'brainstem' satiety, while non-homeostatic feeding relates to reward, represented in the cortex ${ }^{7,8}$. Mere exposure without eating may first increase the rewarding effect of food through oral perception implying pleasantness, which decreases transiently. Thus, with mere exposure without eating SSS appears as a decrease in desire to eat, based upon a decrease in pleasantness of taste, with respect to a particular food, without the necessity of increased satiety. This implies that the sensory part of satiety may serve as a tool for food intake regulation, e.g. to determine meal-size, by decreasing pleasantness and the desire to eat for a particular food during ingestion, independent of energy balance.

Furthermore, we studied to what extent mere sensory perception under energy deficit conditions can actually influence physiological and metabolic mechanisms underlying appetite related sensations. Here also the duration of metabolic effects due to mere sensory stimulation was assessed.

Mere sensory exposure to meals rich in specific fatty acids, i.e. olive oil and linoleic oil, appeared to increase the release of triacylglycerol or NEFA. Moreover, feelings of satiety were increased after mere sensory exposure to meals rich in all tested oils, compared with water ingestion. In two treatments, i.e. with olive oil and linoleic acid, we found that NEFA increased significantly after mere sensory exposure compared with water ingestion. With these treatments, sensory exposure seems to increase the availability of oxidizable metabolites, without the subject receiving any exogenous nutrients. In a subsequent study, mere sensory exposure to a meal rich in linoleic acid increased energy expenditure, plasma NEFA concentrations, and attenuated the decrease in plasma triacylglycerol and the increase in glycerol and active ghrelin concentrations up to one hour after the MSF meal. Over a longer period of time, i.e. 24 hours, mere sensory exposure had no effects on substrate oxidation, diet induced thermogenesis, or total energy expenditure. Furthermore, mere sensory exposure did suppress active plasma ghrelin concentrations. This is in line with the observed significant suppression of plasma ghrelin when a meal was 
preceded by MSF by Heath et al. ${ }^{9}$. Plasma leptin concentrations were not affected by eating or mere sensory exposure over the course of 2 hours. Previous experiments performed by Mattes and co-workers focused on lipid metabolism using MSF with different dietary fats in combination with a fat load. The observed effects on lipid metabolism from these studies imply a taste component of dietary fats ${ }^{10-15}$. In our experiments, mere sensory exposure to meals rich in specific fats (e.i. oil rich in linoleic acid, oil rich in oleic acid, olive oil) differed in the effects on physiological variables between the specific fats. We observed most profound effects after mere sensory exposure to a meal rich in linoleic acid, which implies that the magnitude of the modulating effects of mere sensory exposure is dependent on the specificity of the trigger. Additionally, the individual ability to detect the specific trigger, in this case a fatty acid, might play a role in the observed effects. A study performed by Kamphuis et al. has shown that low concentrations of linoleic acid were detected by a higher percentage of the subjects than the same low concentrations of oleic acid ${ }^{16}$. Thus, if a specific fatty acid is not detected, it cannot provoke a response, as may be the case in our experiment with the specific trigger oleic acid.

Postprandial studies in which sequential meals were used show that when a second meal is ingested 4-6 h after the first meal, there is a rapid appearance of chylomicrons in the circulation, with a peak $1 \mathrm{~h}$ after the second meal. These chylomicrons have been shown to carry fat ingested in the first meal 17-19. It has been suggested that a proportion of fat from the first meal remains in the gut lumen or in the enterocyte and enters the plasma pool after ingesting a second meal ${ }^{20}$. This is called the "second meal effect". Whether this "second meal effect" occurs when the second meal is replaced by mere exposure to a meal rich in fat has also been studied by others. Jackson et al. and Robertson et al. observed no elevation of plasma triacylglycerol, triacylglycerol-rich lipoprotein or triacylglycerol-rich lipoprotein-retinyl ester concentrations when mere sensory exposure with either a low-fat or a moderate-fat meal was performed $5 \mathrm{~h}$ after a high-fat breakfast, which implies a specific role for fat perception in the second meal effect $^{21,22}$. In a different study, Jackson et al. observed that the ingestion of a high-fat breakfast produced a rapid peak in triacylglycerol, retinyl esters and apo B48 chylomicrons after a second meal that was very low $(6 \mathrm{~g})$ in fat ${ }^{20}$. Mattes et al. did supportive findings for the 'second meal theory'. They observed a release of fats from the previous (evening) meal following mere sensory exposure with fat in combination with a fat load the next morning ${ }^{13}$. More recent experiments have observed increased plasma triacylglycerol concentrations when mere sensory exposure was performed $1 \mathrm{~h}$ before a meal ${ }^{9,23}$.

The increase in the availability of oxidizable metabolites due to mere sensory exposure may both be advantageous and disadvantageous. If the available metabolites (after re-appearance) will be oxidized, then a greater amount of dietary fat will be oxidized and not stored in fat tissue. 
Recently, a difference in trafficking of dietary fat was shown in obesityprone and obesity-resistant rats ${ }^{24}$. The obesity resistant phenotype was associated with greater oxidation and less storage of dietary fat than was the obesity prone phenotype. In a recent study in humans, dietary fat oxidation was negatively related to percentage body fat, and lean subjects had the highest and obese subjects the lowest values ${ }^{25}$. Thus, increasing the availability of oxidizable metabolites due to mere sensory exposure may be beneficial for dietary fat oxidation. However, this effect on dietary fat oxidation may be rather small, because we observed no effect of mere sensory exposure on dietary fat oxidation over a period of 2-24 hours.

Raised triacylglycerols and NEFA in the postprandial state contribute to the obesity-associated pathologies such as type 2 diabetes, atherosclerosis and hypertension. It is therefore of importance to clarify the mechanisms behind the metabolic effects observed after the consumption of high-fat foods, and whether these are influenced by the oral exposure to fats and the preceding meal.

Summarizing, mere sensory exposure to meals rich in specific fatty acids, has effects on physiological and metabolic variables that resemble the effects observed after eating, which last up to one hour. This implies that non-homeostatic effects, as evoked by the appearance of food (sight, smell, texture, flavor), has a carry-over effect in that sensory satiety affects metabolic satiety for up to 1 hour.

Under iso-energetic conditions, food-related triggers may underscore appetite related sensations by means of sensory and metabolic effects. Differences in sensory sensitivity for a specific trigger may modulate the size of possible sensory and metabolic effects, which may ultimately result in differences food intake regulation. This was studied in the two taste enhancers monosodium glutamate (MSG) and inosine-monophosphate-5 (IMP'5). The taste sensitivity for one of the tested taste enhancer (MSG) was improved by the addition of the other tested taste enhancer (IMP'5). A high taste sensitivity for one of the tested energy neutral triggers (MSG) was associated with the perception of "meatiness". The taste sensitivity for one of the tested energy neutral triggers (MSG) after addition of the other tested energy neutral trigger (IMP'5) was associated with the "liking" and "preference", but not with "eating frequency" of high protein foods. Furthermore, did the addition of the two taste enhancers to a high-protein diet decrease $24 \mathrm{~h}$ desire to eat.

Studies in rats, non-primates and humans have demonstrated that a preference for dietary protein (or liking of) is almost certainly related, in part, to the way the body senses and tastes MSG \pm IMP'5 and on the body's protein requirements and stores at the time ${ }^{26-32}$. Recent findings indicate that a specialized tasting system exists to recognise the Umami taste, therefore, it is only natural to speculate this distinctive taste functions as a signal to 
regulate protein intake. Supporting this notion is the finding that persons with low nutritional/protein status preferred higher concentrations of MSG in solution than those who were better nourished ${ }^{33}$. In a study of young Americans where canned chicken broth was used as the tastant vehicle, the taste threshold of MSG was $0.345 \pm 0.181 \%{ }^{34}$. This was in agreement with our findings. Similarly, Rogers \& Blundell observed that soups containing MSG reduced desire to eat in general and increased fullness ${ }^{35}$. In our study, the decrease $24 \mathrm{~h}$ desire to eat was only found when MSG+IMP'5 is added to the food and not when it is ingested in capsules. Although glutamate sensors are also found in the gut ${ }^{36}$, stimulation of only the gut sensors by administrating MSG+IMP'5 in capsules does not lead to changes in the appetite profile.

So, sensory effects of MSG+IMP'5 appear only to occur when it is added to food, and not when taken separately in capsules. In addition to the metabolic satiety due to high protein diets ${ }^{37,38}$ sensory satiety may play a role when the taste of high protein foods is enhanced by adding MSG and IMP'5. Further studies should investigate whether the addition of MSG+IMP'5 to highprotein foods may facilitate adherence to high high-protein diets by increasing palatability and may facilitate adherence to weight-loss or weight maintenance high-protein diets by decreasing desire to eat.

\section{Metabolic effects}

Metabolic effects may trigger or underscore appetite related sensations at a physiological level through different mechanisms. Under iso-energetic conditions, carbohydrate can be exchanged by protein. Protein is known for its satiating effect, however, the contribution of physiological mechanisms such as gut-derived hormones or thermogenesis to this satiating effect is unclear. Obviously, there is a difference between the effects on appetite related sensations due to a continuous high protein diet and an acute high protein lunch. Here we focussed on acute metabolic effects of exchanging carbohydrate for protein under iso-energetic conditions.

Exchanging protein iso-energetically with carbohydrates $(25 \%$ of energy from protein vs. $10 \%$ of energy from protein) in a single meal in the postprandial phase, results in increased feelings of satiety and tends to increase DIT. The effects of a single high protein meal in the postprandial state are not mediated by increases in plasma GLP-1 and PYY concentrations, and decreases in plasma ghrelin concentrations.

Most studies that observed effects on satiety used a higher percentage of energy from protein than our study ${ }^{39-46}$. Our study and the study of Hill and Blundell showed that when using mixed meals, satiety is already increased at $25 \%$ energy from protein compared to satiety at $10 \%$ of energy from $\operatorname{protein}^{41}$. 
These findings are very relevant to the human diet, because $25 \%$ of energy from protein is representative for average daily intake, and can easily be achieved using typically consumed foods. In a recent study Lejeune et al. observed higher plasma GLP-1 responses following a HP dinner than after a AP dinner ${ }^{37}$. The plasma GLP-1 response after the HP lunch in that study was, however, not different from the plasma GLP-1 response after the AP lunch. The exchange of percentage of energy from carbohydrate for protein in both the Lejeune study and our study complicates the interpretation of the plasma GLP-1 responses. A larger availability of carbohydrates may have lead to an increased contact of carbohydrates with the small intestine. Increased contact of carbohydrates with the small increases plasma GLP-1 responses to mixed meals ${ }^{47}$. Although GLP-1 is often considered to be a satiety hormone, in our study, plasma GLP-1 responses were not correlated to satiety. Several other studies have not observed a relationship between the increased plasma concentrations of GLP-1 and satiety, which suggests that the effect of peripheral GLP-1 on satiety may be influenced by the central sensitivity for GLP-1 or interactions with other hormones ${ }^{47-50}$. In previous studies, effects of protein on plasma ghrelin responses have been conflicting ${ }^{37,51-53}$. The amount of carbohydrate, through glucose and insulin, and the food form, through gastric emptying, may influence plasma ghrelin responses to a meal. In the present study plasma ghrelin concentrations did not contribute to the observed effects of the HP lunch on satiety. This is in line with Lejeune et al., who observed no differences in plasma ghrelin responses following HP meals throughout the day compared with AP meals ${ }^{37}$. We observed no effect of the HP and AP lunch on plasma PYY responses. Plasma PYY responses are influenced by caloric intake and meal composition. In a recent study by Batterham et al. observed significantly higher plasma PYY responses to a high protein meal in both lean and obese subjects. In that study, the size of the meals and the amount of protein was much bigger than in our study ${ }^{54}$. Over the longer term (meals or days), plasma GLP-1, PYY and ghrelin responses most probably build up and, as a result of that, may contribute to the increased satiety observed for high protein foods and diets. In future studies, the contribution of metabolic effects on for instance protein metabolites, plasma amino acids, and central effects of satiety related hormones may give more insight in the acute effects of high protein meals on satiety.

The acute effect on satiety due to an increased amount of protein (exchanging protein iso-energetically with carbohydrate), which is even observed in a postprandial state, implies that dietary protein has metabolic effects that may be hypothesized to be strong enough to sustain satiety under energy deficit conditions. This implication is supported by recent observations that increased levels of protein in an ad libitum diet result in a decrease in voluntary energy intake ${ }^{55}$. 
Spices as energy neutral food-related triggers may underscore appetite related sensations by means of sensory and metabolic effects. The spicy food component capsaicin may enhance sympathetic nervous system activity and affect the gastrointestinal tract ${ }^{56-61}$. Stimulation of the sympathetic nervous system and sensory nerves in the gastrointestinal tract by this energy neutral trigger may affect appetite related sensations. A single exposure to the energy neutral trigger capsaicin, does not affect satiety, nor does it affect physiological and metabolic variables such as, DIT, substrate oxidation, and plasma PYY responses for a period of 3 hours compared to a control meal. Over a short period of time, i.e. 15 minutes, a single exposure to capsaicin in the postprandial phase, significantly increased plasma GLP-1 concentrations and tended to decrease plasma ghrelin concentrations compared to a control meal.

In a study by Yoshioka, the addition of $30 \mathrm{mg}$ capsaicin to a high fat breakfast and a high carbohydrate breakfast significantly decreased prospective food consumption at lunch ${ }^{62}$. Furthermore, were desire to eat and hunger significantly decreased after the high fat breakfast with capsaicin. An important difference between the latter study and our study, which may explain the differences in satiety outcomes, is that we tested the addition of capsaicin at lunch. Although physiologically important, the postprandial state may have masked the differences in feelings of satiety after the meal supplemented with capsaicin compared to the control meal. In a recent study we observed that satiety was significantly higher after capsaicin supplementation over 2 days compared to placebo, which suggests that effect of capsaicin on satiety may need to build up ${ }^{63}$.

We observed no differences in substrate oxidation between the capsaicin and control condition. Yet, capsaicin has been reported to increase carbohydrate oxidation over the short term (after 1 breakfast exposure) and to increase fat oxidation over the long term (in fasted state after 3 months exposure) ${ }^{64,65}$. Capsaicin was found to increase gastric emptying in a study by Debreceni et al. ${ }^{66}$. In the present study, increased gastric emptying after the lunch supplemented with capsaicin may have resulted in earlier exposure of the small intestine to nutrients, which subsequently may have led to a stronger effect on gut-derived hormones over a short period of time. As far as we know, no other human studies have looked at the effects of capsaicin supplementation on gut-derived hormones. Therefore, more research is needed to investigate the mechanisms behind the possible effects of capsaicin on gut-derived hormones. The effects of acute capsaicin supplementation on gut-derived hormones, possibly due to increased gastric emptying rate, were in our study too small to trigger or underscore appetite related sensations. However, prolonged exposure to capsaicin supplementation, capsaicin in combination with other energy neutral triggers or capsaicin supplementation in a different state of energy balance may serve as more suitable conditions for the metabolic effects of capsaicin to trigger or underscore appetite related sensations. 


\section{Delaying metabolic effects}

By using the energy neutral trigger resistant starch, which spreads the amount of available energy after energy intake over a longer period of time ${ }^{67}$, appetite related sensations may be mediated through metabolic effects. A single exposure to the energy neutral trigger resistant starch, does not affect satiety, nor does it affect physiological and metabolic variables such as, DIT, substrate oxidation, and plasma ghrelin, GLP-1 and PYY responses for a period of 3 hours compared to a control meal.

A study, in which the difference in $\mathrm{g}$ of RS between a single test meal and control meal was comparable to our test and control meal, showed that a difference of $\pm 4 \mathrm{~g}$ of RS between the test meal and the control meal, while the energy content of the two meals was equal, resulted in significant higher feelings of satiety 4 hours after the test meal with $\pm 4 \mathrm{~g}$ more RS compared to the control meal ${ }^{68}$. Important differences between the latter study and our study, which may explain the differences in satiety outcomes, are the total energy content of the test and control meals $( \pm 1.5 \mathrm{MJ}$ vs. $\pm 3.5 \mathrm{MJ})$ and the metabolic state (post absorptive vs. postprandial).

Although physiologically important, the postprandial state may have masked the differences in feelings of satiety after the RS compared to the control meal. When comparing meals with different amounts of RS it is very important to keeping the metabolizable energy content of test and control meals equal to compare possible effects of RS iso-energetically. Studies reporting lower feelings of satiety after consumption of a meal with a high RS content, like the study by Raben et al. and Achour et al. in which the energy content of the meal containing RS was considerably lower compared to the control meal, should therefore be considered carefully regarding the difference in metabolizable energy (apart from the RS content) of the test and control meals ${ }^{69,70}$. The energy content of test and control meals is also important when comparing effects of RS on DIT. Heijnen et al. observed lower DIT after a meal that contained $27 \mathrm{~g}$ of RS compared to after a meal that contained no $\mathrm{RS}^{71}$. However, this difference in DIT was completely explained by the difference in digestible carbohydrates in the meals. DIT expressed as $\%$ of the metabolizable energy of the meals is a parameter, which can be used to correct for differences in energy content between meals. In two studies DIT expressed as \% of the metabolizable energy was not different between a meal containing up to $25 \mathrm{~g}$ of RS and a control meal 69,72 . In our study, DIT was not different after the RS and control lunch when measured over $3 \mathrm{~h}$ post-ingestion. The bacterial fermentation of RS in the large intestine, which leads to the formation of metabolizable short chain fatty acids (SCFA), occurs several hours later than the period in which we measured DIT ${ }^{73}$. We therefore expected that without the contribution of SCFA, DIT would be lower after the RS and control lunch when measured over $3 \mathrm{~h}$ post-ingestion. 
In a study by Higgins et al., fat oxidation was significantly higher after a meal, which contained $5 \mathrm{~g}$ of RS compared to after the control meal ${ }^{74}$. Higher fat oxidation and lower carbohydrate oxidation has also been reported after a meal containing $27 \mathrm{~g}$ of RS. However, the data of that study are difficult to interpret, because the metabolizable energy content of the meal containing RS was considerably lower compared to the control meal ${ }^{72}$. Since the carbohydrate and energy content of their meals was lower, fat oxidation must have started earlier and was therefore higher. Two other studies observed no differences in carbohydrate and fat oxidation compared to a control meal containing no RS over 6 and 8 hours after a meal containing $30 \mathrm{~g}$ and $25 \mathrm{~g}$ of RS, respectively ${ }^{69,75}$. Very few human studies have looked at the effects of RS supplementation on gut-derived hormones. A breakfast consisting of guar gum together with galactose increased GLP-1 response in women; moreover, this increase in GLP-1 was related to an increase in satiety ${ }^{48}$. A lower plasma GLP-1 response was reported after ingestion of the meal, which contained $25 \mathrm{~g}$ of RS compared to after the control meal ${ }^{70}$. This lower plasma GLP-1 response was, however, most probably due to the much lower metabolizable energy and readily digestible starch content. Four weeks of supplementation with $30 \mathrm{~g}$ RS a day resulted in higher fasting plasma total ghrelin concentrations, but had no effects on plasma leptin and GLP-1 concentrations ${ }^{76}$, showing that with respect to gutderived hormone responses, longer term experiments do not affect the outcome. The responses of these gut-derived hormones are dependent on energy load and macronutrient composition of the test meal, time of the day, and sex, which makes them difficult to compare between studies ${ }^{77}$. However, keeping in mind the convincing results of RS supplementation on GLP-1, PYY and ghrelin from animal studies, more research is needed to investigate possible effects of RS supplementation on gut-derived hormones, probably by administering RS to each meal for 2-3 days. Over 24 hours, RS supplementation has shown to lower postprandial plasma glucose and insulin concentrations ${ }^{78}$, lower and delay postprandial carbohydrate oxidation, and lower hunger feelings, while total energy intake was equal ${ }^{79}$.

Acute RS supplementation under iso-energetic conditions did not affect appetite related sensations or any of the metabolic parameters measured. Together with previous findings this implies that RS supplementation may need specific conditions such as prolonged exposure, synergistic effects or a specific state of energy balance to trigger or underscore appetite related sensations through metabolic effects.

\section{Conclusion}

The studies described in this thesis show that physiological variables mediating appetite related sensations can be influenced by energy neutral triggers (sensory exposure, iso-energetic exchange with dietary protein, capsaicin), at least over a short period of time, e.g. $15 \mathrm{~min}-24$ hours. 
This means that the fine-tuning mechanism of energy intake can be 'mislead' to a certain extent.

The most effective modulators (sensory exposure, iso-energetic exchange with dietary protein) did increase satiety through physiological variables and/or stimulating effects on energy expenditure. Some of the effective modulators exerted predominantly sensory effects (sensory exposure, MSG+IMP'5), while others exerted predominantly metabolic effects (isoenergetic exchange with dietary protein). The sensory effects sustained over a short period of time (sensory exposure), while some of the metabolic effects were sustained for a couple of hours (iso-energetic exchange with dietary protein). This implies that sensory and metabolic effects of foodrelated triggers may be useful in different elements of food intake regulation, e.g. intra-meal appetite related sensations and inter-meal appetite related sensations, respectively.

The trigger tested under energy deficit conditions (sensory exposure), affected sensory and metabolic effects to a certain extent, which implies that certain triggers may overcome the effects of a negative energy balance on the fine-tuning mechanism of energy intake. The triggers that were tested under iso-energetic conditions (MSG+IMP'5, iso-energetic exchange with dietary protein) underscored the effects of energy intake on the fine-tuning mechanism of energy intake. Whether the observed effects of the modulators persist in different states of energy balance, and whether some effects were dependent on the level of exposure to the modulators should be subject to further studies.

\section{Future research suggestions}

Since the modulators described in this thesis have an effect on different mechanisms and pathways of the mechanism for fine-tuning energy intake to energy expenditure, it is necessary to study the synergistic effects of these food-related components. With respect to the treatment of obesity, synergism is required since body weight regulation is a redundant system, therefore different pathways should be influenced at the same time. The effectiveness of modulators in pathways of the fine-tuning mechanism of energy intake involving the sympathetic nervous system (SNS) may be dependent on the state of energy balance, because SNS activity is positively correlated with energy balance ${ }^{80-82}$. As all of the studies described in this thesis were performed with subjects in a state of energy balance, it would be of interest to see whether a combination of modulators would be able to overcome a decrease in SNS activity and appetite related sensations induced by a negative energy balance through combined effects on physiological variables, with an emphasis on possible functional effects of bioactive components. Combinations of bioactive components have shown to increase thermogenesis in obese subjects and after weight-loss ${ }^{83-85}$. However, little is 
known about possible effects on appetite related sensations or energy intake of this increase in energy expenditure.

In our studies we have focused on oral exposure with or without gastrointestinal exposure to modulators with respect to the plasticity of the fine-tuning mechanism of energy intake. It remains to be determined what the importance of gastrointestinal exposure in the fine-tuning mechanism of energy intake is. Candidate pathways to be studied are effects of modulators in the gastro-intestinal tract on physiological variables such as gut-derived hormones, with an emphasis on possible mechanisms of separate bioactive components. A potent stimulator of physiological variables, such gutderived hormones, gastric emptying and gut motility, is for instance the presence of fat in the small intestine ${ }^{86}$. The sensitivity for stimulators and their effects on physiological variables seem to be dependent on the form and previous exposure to the stimulator. Furthermore, with respect to sensitivity for stimulators, the site of exposure and the timing of exposure may play a role, because the effects of nutrient exposure on food intake and appetite related sensations differ between parts of the gastro-intestinal tract and time of day ${ }^{87-89}$. 


\section{References}

1. Rolls ET, Rolls BJ, Rowe EA. Sensory-specific and motivation-specific satiety for the sight and taste of food and water in man. Physiol Behav.

2. Rolls ET, Rolls JH. Olfactory sensory-specific satiety in humans. Physiol Behav 1997;61(3):461-73.

3. Dockray G. Gut endocrine secretions and their relevance to satiety. Curr Opin Pharmacol 2004;4(6):557-60.

4. Murphy KG, Bloom SR. Gut hormones in the control of appetite. Exp Physiol 2004;89(5):507-16.

5. Orr J, Davy B. Dietary influences on peripheral hormones regulating energy intake: potential applications for weight management. J Am Diet Assoc 2005;105(7):1115-24.

6. Strader AD, Woods SC. Gastrointestinal hormones and food intake. Gastroenterology 2005;128(1):175-91.

7. Berthoud HR. Multiple neural systems controlling food intake and body weight. Neurosci Biobehav Rev 2002;26(4):393-428.

8. Berthoud HR. Mind versus metabolism in the control of food intake and energy balance. Physiol Behav 2004;81(5):781-93.

9. Heath RB, Jones R, Frayn KN, Robertson MD. Vagal stimulation exaggerates the inhibitory ghrelin response to oral fat in humans. $\mathrm{J}$ Endocrinol 2004;180(2):273-81.

10. Mattes RD. Oral fat exposure alters postprandial lipid metabolism in humans. Am J Clin Nutr 1996;63(6):911-17.

11. Mattes RD. Oral exposure to butter, but not fat replacers elevates postprandial triacylglycerol concentration in humans. J Nutr 2001;131(5):1491-96.

12. Mattes RD. The taste of fat elevates postprandial triacylglycerol. Physiol Behav 2001;74(3):343-48.

13. Mattes RD. Oral fat exposure increases the first phase triacylglycerol concentration due to release of stored lipid in humans. J Nutr 2002;132(12):3656-62.

14. Tittelbach TJ, Mattes RD. Oral stimulation influences postprandial triacylglycerol concentrations in humans: nutrient specificity. J Am Coll Nutr 2001;20(5):485-93.

15. Tittlebach TJ, Mattes RD. Effect of orosensory stimulation on postprandial thermogenesis in humans. Physiol Behav. 2002;75(1-2):71-81.

16. Kamphuis MM, Saris WH, Westerterp-Plantenga MS. The effect of addition of linoleic acid on food intake regulation in linoleic acid tasters and linoleic acid non-tasters. Br J Nutr 2003;90(1):199-206.

17. Evans K, Kuusela PJ, Cruz ML, Wilhelmova I, Fielding BA, Frayn KN. Rapid chylomicron appearance following sequential meals: effects of second meal composition. Br J Nutr 1998;79(5):425-9.

18. Fielding BA, Callow J, Owen RM, Samra JS, Matthews DR, Frayn KN. 
Postprandial lipemia: the origin of an early peak studied by specific dietary fatty acid intake during sequential meals. Am J Clin Nutr 1996;63(1):36-41.

19. Peel AS, Zampelas A, Williams CM, Gould BJ. A novel antiserum specific to apolipoprotein B-48: application in the investigation of postprandial lipidaemia in humans. Clin Sci (Lond) 1993;85(5):521-4.

20. Jackson KG, Robertson MD, Fielding BA, Frayn KN, Williams CM. Olive oil increases of triacylglycerol-rich chylomicron particles compared with other oils: an effect retained when a second meal is fed. Am J Clin Nutr 2002;76(5):942-9.

21. Jackson KG, Robertson MD, Fielding BA, Frayn KN, Williams CM. Second meal effects: modified sham feeding does not provoke the release of stored triacylglycerol from a previous high-fat meal. Br J Nutr 2001;85(2):149-56.

22. Robertson MD, Jackson KG, Williams CM, Fielding BA, Frayn KN.

Prolonged effects of modified sham feeding on energy substrate mobilization. Am J Clin Nutr 2001;73(1):111-7.

23. Robertson MD, Mason AO, Frayn KN. Timing of vagal stimulation affects postprandial lipid metabolism in humans. Am J Clin Nutr 2002;76(1):71-7.

24. Jackman MR, Kramer RE, Maclean PS, Bessesen D. Trafficking of dietary fat in obesity prone and obesity resistant rats. Am J Physiol Endocrinol Metab 2006.

25. Westerterp KR, Smeets A, Lejeune MP, Wouters-Adriaens MP, WesterterpPlantenga MS. Dietary fat oxidation as a function of body fat. Am J Clin Nutr 2008;87(1):132-5.

26. He W, Yasumatsu K, Varadarajan V, Yamada A, Lem J, Ninomiya Y, Margolskee RF, Damak S. Umami taste responses are mediated by alphatransducin and alpha-gustducin. J Neurosci 2004;24(35):7674-80.

27. Kondoh T, Mori M, Ono T, Torii K. Mechanisms of umami taste preference and aversion in rats. J Nutr 2000;130(4S Suppl):966S-70S.

28. Laska M, Hernandez Salazar LT. Gustatory responsiveness to monosodium glutamate and sodium chloride in four species of nonhuman primates. J Exp Zoolog A Comp Exp Biol 2004;301(11):898-905.

29. Mori M, Kawada T, Ono T, Torii K. Taste preference and protein nutrition and L-amino acid homeostasis in male Sprague-Dawley rats. Physiol Behav 1991;49(5):987-95.

30. Naim M, Ohara I, Kare MR, Levinson M. Interaction of MSG taste with nutrition: perspectives in consummatory behavior and digestion. Physiol Behav 1991;49(5):1019-24.

31. Ruiz CJ, Wray K, Delay E, Margolskee RF, Kinnamon SC. Behavioral evidence for a role of alpha-gustducin in glutamate taste. Chem Senses 2003;28(7):573-9.

32. Smriga M, Torii K. Release of hypothalamic norepinephrine during MSG intake in rats fed normal and nonprotein diet. Physiol Behav 2000;70(34):413-5. 
33. Murphy C. Flavour preference for monosodium glutamate and casein hydrolysate in young and elderly persons. Kawamura YK, M.R. , editor. New York: Marcel Dekker; 1987. 139-51 p.

34. Schiffman SS, Sattely-Miller EA, Zimmerman IA, Graham BG, Erickson RP. Taste perception of monosodium glutamate (MSG) in foods in young and elderly subjects. Physiol Behav 1994;56(2):265-75.

35. Rogers PJ, Blundell JE. Umami and appetite: effects of monosodium glutamate on hunger and food intake in human subjects. Physiol Behav 1990;48(6):801-4.

36. Niijima A. Reflex effects of oral, gastrointestinal and hepatoportal glutamate sensors on vagal nerve activity. J Nutr 2000;130(4S Suppl):971S-3S.

37. Lejeune MP, Westerterp KR, Adam TC, Luscombe-Marsh ND, WesterterpPlantenga MS. Ghrelin and glucagon-like peptide 1 concentrations, 24-h satiety, and energy and substrate metabolism during a high-protein diet and measured in a respiration chamber. Am J Clin Nutr 2006;83(1):89-94.

38. Westerterp-Plantenga MS, Rolland V, Wilson SA, Westerterp KR. Satiety related to $24 \mathrm{~h}$ diet-induced thermogenesis during high protein/carbohydrate vs high fat diets measured in a respiration chamber. Eur J Clin Nutr 1999;53(6):495-502.

39. Barkeling B, Rossner S, Bjorvell H. Effects of a high-protein meal (meat) and a high-carbohydrate meal (vegetarian) on satiety measured by automated computerized monitoring of subsequent food intake, motivation to eat and food preferences. Int J Obes 1990;14(9):743-51.

40. Crovetti R, Porrini M, Santangelo A, Testolin G. The influence of thermic effect of food on satiety. Eur J Clin Nutr 1998;52(7):482-8.

41. Hill AJ, Blundell JE. Macronutrients and satiety: the effects of high carbohydrate and high protein meals on subjective motivation to eat and preferences. Nutr Behav 1986;3:133-44.

42. Johnson J, Vickers Z. Effects of flavor and macronutrient composition of food servings on liking, hunger and subsequent intake. Appetite 1993;21(1):25-39.

43. Poppitt SD, McCormack D, Buffenstein R. Short-term effects of macronutrient preloads on appetite and energy intake in lean women. Physiol Behav 1998;64(3):279-85.

44. Porrini M, Crovetti R, Testolin G, Silva S. Evaluation of satiety sensations and food intake after different preloads. Appetite 1995;25(1):17-30.

45. Stubbs RJ, van Wyk MC, Johnstone AM, Harbron CG. Breakfasts high in protein, fat or carbohydrate: effect on within-day appetite and energy balance. Eur J Clin Nutr 1996;50(7):409-17.

46. Westerterp KR, Wilson SA, Rolland V. Diet induced thermogenesis measured over $24 \mathrm{~h}$ in a respiration chamber: effect of diet composition. Int $\mathrm{J}$ Obes Relat Metab Disord 1999;23(3):287-92.

47. Adam TC, Lejeune MP, Westerterp-Plantenga MS. Nutrient-stimulated glucagon-like peptide 1 release after body-weight loss and weight 
maintenance in human subjects. Br J Nutr 2006;95(1):160-7.

48. Adam TC, Westerterp-Plantenga MS. Nutrient-stimulated GLP-1 release in normal-weight men and women. Horm Metab Res 2005;37(2):111-7.

49. Oesch S, Degen L, Beglinger C. Effect of a protein preload on food intake and satiety feelings in response to duodenal fat perfusions in healthy male subjects. Am J Physiol Regul Integr Comp Physiol 2005;289(4):R1042-7.

50. Raben A, Agerholm-Larsen L, Flint A, Holst JJ, Astrup A. Meals with similar energy densities but rich in protein, fat, carbohydrate, or alcohol have different effects on energy expenditure and substrate metabolism but not on appetite and energy intake. Am J Clin Nutr 2003;77(1):91-100.

51. Blom WA, Lluch A, Stafleu A, Vinoy S, Holst JJ, Schaafsma G, Hendriks HF. Effect of a high-protein breakfast on the postprandial ghrelin response. Am J Clin Nutr 2006;83(2):211-20.

52. Erdmann J, Lippl F, Schusdziarra V. Differential effect of protein and fat on plasma ghrelin levels in man. Regul Pept 2003;116(1-3):101-7.

53. Marzullo P, Caumo A, Savia G, Verti B, Walker GE, Maestrini S, Tagliaferri A, Di Blasio AM, Liuzzi A. Predictors of postabsorptive ghrelin secretion after intake of different macronutrients. J Clin Endocrinol Metab 2006;91(10):4124-30.

54. Batterham RL, Heffron H, Kapoor S, Chivers JE, Chandarana K, Herzog H, Le Roux CW, Thomas EL, Bell JD, Withers DJ. Critical role for peptide YY in protein-mediated satiation and body-weight regulation. Cell Metab 2006;4(3):223-33.

55. Weigle DS, Breen PA, Matthys CC, Callahan HS, Meeuws KE, Burden VR, Purnell JQ. A high-protein diet induces sustained reductions in appetite, ad libitum caloric intake, and body weight despite compensatory changes in diurnal plasma leptin and ghrelin concentrations. Am J Clin Nutr 2005;82(1):41-8.

56. Kawada T, Sakabe S, Watanabe T, Yamamoto M, Iwai K. Some pungent principles of spices cause the adrenal medulla to secrete catecholamine in anesthetized rats. Proc Soc Exp Biol Med 1988;188(2):229-33.

57. Kawada T, Watanabe T, Takaishi T, Tanaka T, Iwai K. Capsaicin-induced beta-adrenergic action on energy metabolism in rats: influence of capsaicin on oxygen consumption, the respiratory quotient, and substrate utilization. Proc Soc Exp Biol Med 1986;183(2):250-6.

58. Chen RY, Li DS, Guth PH. Role of calcitonin gene-related peptide in capsaicin-induced gastric submucosal arteriolar dilation. Am J Physiol 1992;262(5 Pt 2):H1350-5.

59. Manzini S, Perretti F. Vascular effects of capsaicin in isolated perfused rat mesenteric bed. Eur J Pharmacol 1988;148(2):153-9.

60. Myers BM, Smith JL, Graham DY. Effect of red pepper and black pepper on the stomach. Am J Gastroenterol 1987;82(3):211-4. 
61. Solanke TF. The effect of red pepper (Capsicum frutescens) on gastric acid secretion. J Surg Res 1973;15(6):385-90.

62. Yoshioka M, St-Pierre S, Drapeau V, Dionne I, Doucet E, Suzuki M, Tremblay A. Effects of red pepper on appetite and energy intake. Br J Nutr 1999;82(2):115-23.

63. Westerterp-Plantenga MS, Smeets A, Lejeune MP. Sensory and gastrointestinal satiety effects of capsaicin on food intake. Int J Obes (Lond) 2005;29(6):682-8.

64. Lejeune MP, Kovacs EM, Westerterp-Plantenga MS. Effect of capsaicin on substrate oxidation and weight maintenance after modest body-weight loss in human subjects. Br J Nutr 2003;90(3):651-59.

65. Yoshioka M, St-Pierre S, Suzuki M, Tremblay A. Effects of red pepper added to high-fat and high-carbohydrate meals on energy metabolism and substrate utilization in Japanese women. Br J Nutr 1998;80(6):503-10.

66. Debreceni A, Abdel-Salam OM, Figler M, Juricskay I, Szolcsanyi J, Mozsik G. Capsaicin increases gastric emptying rate in healthy human subjects measured by 13C-labeled octanoic acid breath test. J Physiol Paris 1999;93(5):455-60.

67. Higgins JA. Resistant starch: metabolic effects and potential health benefits. J AOAC Int 2004;87(3):761-8.

68. Liljeberg HG, Akerberg AK, Bjorck IM. Effect of the glycemic index and content of indigestible carbohydrates of cereal-based breakfast meals on glucose tolerance at lunch in healthy subjects. Am J Clin Nutr 1999;69(4):647-55.

69. Achour L, Flourie B, Briet F, Franchisseur C, Bornet F, Champ M, Rambaud JC, Messing B. Metabolic effects of digestible and partially indigestible cornstarch: a study in the absorptive and postabsorptive periods in healthy humans. Am J Clin Nutr 1997;66(5):1151-9.

70. Raben A, Tagliabue A, Christensen NJ, Madsen J, Holst JJ, Astrup A. Resistant starch: the effect on postprandial glycemia, hormonal response, and satiety. Am J Clin Nutr 1994;60(4):544-51.

71. Heijnen ML, Deurenberg P, van Amelsvoort JM, Beynen AC. Replacement of digestible by resistant starch lowers diet-induced thermogenesis in healthy men. Br J Nutr 1995;73(3):423-32.

72. Tagliabue A, Raben A, Heijnen ML, Deurenberg P, Pasquali E, Astrup A. The effect of raw potato starch on energy expenditure and substrate oxidation. Am J Clin Nutr 1995;61(5):1070-5.

73. Topping DL, Clifton PM. Short-chain fatty acids and human colonic function: roles of resistant starch and nonstarch polysaccharides. Physiol Rev 2001;81(3):1031-64.

74. Higgins JA, Higbee DR, Donahoo WT, Brown IL, Bell ML, Bessesen DH. Resistant starch consumption promotes lipid oxidation. Nutr Metab (Lond) 2004;1(1):8.

75. Ranganathan S, Champ M, Pechard C, Blanchard P, Nguyen M, Colonna P, 
Krempf M. Comparative study of the acute effects of resistant starch and dietary fibers on metabolic indexes in men. Am J Clin Nutr 1994;59(4):87983.

76. Robertson MD, Currie JM, Morgan LM, Jewell DP, Frayn KN. Prior shortterm consumption of resistant starch enhances postprandial insulin sensitivity in healthy subjects. Diabetologia 2003;46(5):659-65.

77. Wren AM, Bloom SR. Gut hormones and appetite control. Gastroenterology 2007;132(6):2116-30.

78. Robertson MD, Bickerton AS, Dennis AL, Vidal H, Frayn KN. Insulinsensitizing effects of dietary resistant starch and effects on skeletal muscle and adipose tissue metabolism. Am J Clin Nutr 2005;82(3):559-67.

79. Sparti A, Milon H, Di Vetta V, Schneiter P, Tappy L, Jequier E, Schutz Y. Effect of diets high or low in unavailable and slowly digestible carbohydrates on the pattern of 24-h substrate oxidation and feelings of hunger in humans. Am J Clin Nutr 2000;72(6):1461-8.

80. Bazelmans J, Nestel PJ, O'Dea K, Esler MD. Blunted norepinephrine responsiveness to changing energy states in obese subjects. Metabolism 1985;34(2):154-60.

81. Grassi G, Colombo M, Seravalle G, Spaziani D, Mancia G. Dissociation between muscle and skin sympathetic nerve activity in essential hypertension, obesity, and congestive heart failure. Hypertension 1998;31(1):64-7.

82. Vaz M, Jennings G, Turner A, Cox H, Lambert G, Esler M. Regional sympathetic nervous activity and oxygen consumption in obese normotensive human subjects. Circulation 1997;96(10):3423-9.

83. Belza A, Frandsen E, Kondrup J. Body fat loss achieved by stimulation of thermogenesis by a combination of bioactive food ingredients: a placebocontrolled, double-blind 8-week intervention in obese subjects. Int J Obes (Lond) 2007;31(1):121-30.

84. Belza A, Jessen AB. Bioactive food stimulants of sympathetic activity: effect on 24-h energy expenditure and fat oxidation. Eur J Clin Nutr 2005;59(6):733-41.

85. Diepvens K, Westerterp KR, Westerterp-Plantenga MS. Obesity and thermogenesis related to the consumption of caffeine, ephedrine, capsaicin, and green tea. Am J Physiol Regul Integr Comp Physiol 2007;292(1):R7785.

86. Little TJ, Horowitz M, Feinle-Bisset C. Modulation by high-fat diets of gastrointestinal function and hormones associated with the regulation of energy intake: implications for the pathophysiology of obesity. Am J Clin Nutr 2007;86(3):531-41.

87. Woods SC. Dietary synergies in appetite control: distal gastrointestinal tract. Obesity (Silver Spring) 2006;14 Suppl 4:171S-178S.

88. Germain N, Galusca B, Le Roux CW, Bossu C, Ghatei MA, Lang F, Bloom SR, Estour B. Constitutional thinness and lean anorexia nervosa 
display opposite concentrations of peptide YY, glucagon-like peptide 1, ghrelin, and leptin. Am J Clin Nutr 2007;85(4):967-71.

89. Jarrett RJ, Baker IA, Keen H, Oakley NW. Diurnal variation in oral glucose tolerance: blood sugar and plasma insulin levels morning, afternoon, and evening. Br Med J 1972;1(5794):199-201. 

Summary 
This thesis describes studies on the plasticity of the fine-tuning mechanism of energy intake to energy requirement. Several food-related triggers for food intake regulation were investigated for their ability to affect physiological variables mediating appetite related sensations.

To gain insight into what extent mere sensory perception can influence appetite related sensations, we studied the effect of mere sensory perception, thus without ingestion of nutrients, in order to separate sensory from metabolic triggers, on appetite sensations and taste perception during the development of sensory-specific satiety. The aim of this study was to explore the role of sensory specific satiety in satiety development after oral exposure to food that was chewed but not eaten (Modified Sham Feeding). In this experiment sensory-specific satiety took place during feeding, and was then related to an increase in satiety, and a decrease in hunger and desire to eat. With sensory-specific satiety during Modified Sham Feeding however, satiety did not increase nor did hunger decrease, yet desire to eat decreased. Thus Modified Sham Feeding is sufficient for a sensory decrease in desire to eat despite of lack of satiety.

Subsequently, we studied to what extent mere sensory perception can actually influence physiological and metabolic mechanisms underlying appetite related sensations. Here also the duration of metabolic effects due to mere sensory stimulation was assessed. The aim of the studies was to provoke cephalic and metabolic responses due to oral fat stimulation with different high-fat meals that were sham fed in the postprandial state. Modified Sham Feeding with different fats increased concentrations of metabolites and stimulated satiety, with linoleic oil showing the strongest response. In the subsequent study assessing oral fat stimulation, energy expenditure appeared to be stimulated up to 1 hour after Modified Sham Feeding of a meal. Modified Sham Feeding had no effect on substrate oxidation. Taken together, Modified Sham Feeding exerts effects on sensory-specific satiety, satiety, desire to eat, metabolites, and energy expenditure up to 1 hour after the sham fed meal, taken in a postprandial state.

A different approach of studying effects of energy neutral triggers was executed with four different triggers assessing their effects on physiological variables mediating appetite related sensations. Characteristics of these specific triggers imply possible effects while these triggers do not contribute to energy intake.

Such energy neutral triggers may be certain spices that enhance sympathetic nervous system activity and have shown to affect the gastrointestinal tract, e.g. capsaicin. We studied the effects of capsaicin on energy and substrate utilization, satiety and satiety-related hormones. A single lunch containing capsaicin had no effect on satiety, EE, and plasma PYY concentrations over a period of 3 hours, but increased plasma GLP-1 concentrations and tended 
to decrease plasma ghrelin concentrations for a short period of time, i.e. 15 minutes.

An additional type of an energy neutral trigger may be a taste enhancer that increases palatability and vagal nerve activity, e.g. monosodium glutamate (MSG), and inosine 5'-monophosphate (IMP'5).

The increased palatability of a food after addition of an energy neutral trigger may be related to the taste sensitivity for the trigger. If this is the case, than taste sensitivity for that specific trigger may also predict food choice and consumption. We have studied individuals' taste threshold for MSG alone and in combination with IMP'5, and examined if this threshold was related to sensory properties (including pleasantness of taste) and/or, to ones' preference for dietary protein over carbohydrate and fat. We observed that the taste threshold of MSG in combination with IMP'5 does appear to predict ones' 'liking' of as well as 'preference' for high protein foods. Furthermore, MSG has been suggested to enhance metabolism due to sensory or gastrointestinal stimulation of vagal nerve activity. Therefore we studied if addition of MSG in combination with IMP'5 to a high protein diet has an effect on energy expenditure, substrate oxidation, appetite profile and relevant metabolites. The addition of MSG in combination with IMP-5 to a high-protein diet, either added to the food or in capsules, decreased overall desire to eat without affecting hunger and satiety. Moreover, it did not affect energy metabolism, substrate oxidation, or hormone concentrations.

The third trigger studied was indigestible starch. Spreading the amount of available energy after energy intake over a longer period of time, by using an energy neutral trigger e.g. resistant starch (RS), was studied in relation to possibly appetite related sensations through changes in metabolic rate and nutrient stimulated hormone release. Since epidemiological observations indicate that dietary fibre intake is involved in body weight control, the dietary fibre component RS was studied with respect to the effects of RS on energy and substrate utilization, satiety and satiety-related hormones. RS supplementation of a single meal had no acute effect on energy and substrate utilisation, appetite feelings and satiety-related hormones.

Finally, one macronutrient can be exchanged iso-energetically for another macronutrient, e.g. protein. High-protein foods are more satiating and have a higher thermogenic effect than normal protein foods, over the short as well as over the long-term. The acute effects on appetite related sensations of this energy neutral trigger may not only be mediated by acute effects on thermogenesis, but may also be mediated by the release of appetite related hormones. We hypothesized that acute effects of higher protein intake on satiety may be related to acute metabolic and hormonal responses. The meal, which was high in protein ( $25 \%$ of energy), increased feelings of satiety and tended to increase diet induced thermogenesis compared to the meal, which 
had a normal protein content (10\% of energy). Changes in plasma ghrelin, GLP-1 and PYY concentrations did not happen simultaneously. A single high-protein lunch, therefore, does not exert its acute effect on satiety through increased concentrations of satiety related hormones. Other factors, which may explain the high-protein effect on satiety, may be metabolites or amino acids.

The studies described in this thesis show that physiological variables mediating appetite related sensations can be influenced by energy neutral triggers (sensory exposure, MSG + IMP'5, dietary protein, capsaicin), at least over a short period of time, e.g. $15 \mathrm{~min}-24$ hours. The most effective modulators (sensory exposure, dietary protein) increased satiety through physiological variables and/or stimulating effects on energy expenditure. The sensory effects (sensory exposure, MSG+IMP'5) sustained over a short period of time, while some of the metabolic effects were sustained for a couple of hours (dietary protein). This implies that sensory and metabolic effects of food-related triggers may be useful in different elements of food intake regulation, e.g. intra-meal appetite related sensations and inter-meal appetite related sensations, respectively. The trigger tested under energy deficit conditions (sensory exposure) affected sensory and metabolic effects to a certain extent, which implies that certain triggers may temporarily overcome the effects of a negative energy balance on the fine-tuning mechanism of energy intake. The triggers that were tested under isoenergetic conditions (MSG+IMP'5, dietary protein) underscored the effects of energy intake on the fine-tuning mechanism of energy intake. Whether the observed effects of the modulators persist in different states of energy balance, and how much some effects were dependent on the level of exposure to the modulators should be subject to further studies. 
Samenvatting 
Dit proefschrift beschrijft studies naar de plasticiteit van voedselinname regulatie ten opzichte van het energiegebruik. Verschillende voedingsgerelateerde factoren die een rol spelen bij de voedselinname regulatie zijn onderzocht op hun verzadigingsgerelateerde sensorische en metabole effecten. Om een beeld te krijgen van de invloed van orale blootstelling op eetlust hebben we het effect van orale blootstelling, dus zonder daadwerkelijk te eten ten einde sensorische van metabole effecten te scheiden, op eetlust en smaakwaarneming tijdens sensorisch specifieke verzadiging onderzocht. Het doel van die studie was om de rol van sensorisch specifieke verzadiging in het ontstaan van verzadiging na enkel orale blootstelling aan voedsel te bestuderen.

In het betreffende experiment veroorzaakte eten sensorisch specifieke verzadiging die was gerelateerd aan een stijging in verzadiging en een daling in honger en "wens om te eten". Enkel orale bloostelling aan voedsel veroorzaakte ook sensorisch specifieke verzadiging die in dit geval niet gerelateerd was aan een stijging in verzadiging en een daling in honger, maar wel gerelateerd was aan een daling in "wens om te eten". Kortom, enkel orale blootstelling aan voedsel is voldoende om een sensorische daling in de "wens om te eten" te veroorzaken, die onafhankelijk is van een gebrek aan verzadiging.

Vervolgens hebben we onderzocht in hoeverre enkel orale blootstelling aan voedsel verzadigingsgerelateerde fysiologische en metabole mechanismen kan beïnvloeden. Hierbij werd ook gekeken naar de duur van de metabole effecten ten gevolge van enkel orale blootstelling aan voedsel. Het doel van de studies was om cefale en metabole reacties ten gevolge van orale blootstelling in de postprandiale fase aan verschillende vette maaltijden te weeg te brengen. Orale blootstelling aan verschillende vetten verhoogde de concentratie metabolieten in het bloed en stimuleerde het verzadigingsgevoel, waarbij orale stimulatie met linolzuur het grootste effect had. In de daaropvolgende studie bleek dat het energiegebruik verhoogd is gedurende 1 uur en dat substraatgebruik niet verandert na orale blootstelling aan een vette maaltijd. Samengevat, orale blootstelling terwijl proefpersonen in de postprandiale fase zijn heeft effecten op sensorisch specifieke verzadiging, verzadiging, metabolieten en energiegebruik gedurende een periode van 1 uur.

Een andere aanpak om de effecten van energie neutrale stimuli te onderzoeken werd uitgevoerd met vier verschillende stimuli die onderzocht werden op hun effecten op verzadigingsgerelateerde fysiologische variabelen.

Eigenschappen van deze specifieke stimuli suggereren dat ze mogelijk een effect kunnen hebben zonder bij te dragen aan energie inname.

Zulke energieneutrale stimuli zouden bepaalde kruiden kunnen zijn waarvan bekend is dat ze de activiteit van het sympathische zenuwstelsel verhogen en effecten hebben op het maag-darmstelsel, bijvoorbeeld capsaicine. 
Mogelijke effecten van capsaicine op energie- en substraatgebruik, verzadiging en verzadigingsgerelateerde hormonen werden onderzocht, bij proefpersonen die in de postprandiale fase verkeerden.

In vergelijking met een controle maaltijd had een enkele blootstelling aan de energieneutrale stimulus "capsaicine" geen effect op verzadiging en fysiologische en metabole variabelen, zoals dieet geïnduceerde thermogenese, substraat oxidatie en plasma PYY concentraties over een periode van 3 uur. Gedurende een korte periode van 15 minuten verhoogde een enkele blootstelling aan capsaicine plasma GLP-1 concentraties en neigde deze plasma ghreline concentraties te verlagen vergeleken met de controle maaltijd.

Een ander type energieneutrale stimuli zijn smaakversterkers kunnen zijn die de smaak van het voedsel en de activiteit van het zenuwstelsel bevorderen, bijvoorbeeld monosodium glutamaat (MSG) en inosine 5'-monofosfaat (IMP'5). Een verbetering van de smaak van een voedingsmiddel na toevoeging van een energieneutrale stimulus is mogelijk gerelateerd aan de smaak gevoeligheid voor die stimulus. Indien dit het geval is, zou de smaakgevoeligheid voor die specifieke stimulus mogelijk ook voedselkeuze en voedselconsumptie kunnen voorspellen.

Wij hebben de individuele smaakgevoeligheid voor enkel MSG en in combinatie met IMP'5 gemeten en onderzocht of deze gevoeligheid gerelateerd was aan sensorische eigenschappen en/of voorkeur voor eiwit boven koolhydraten en vet. De smaakgevoeligheid voor MSG na toevoeging van IMP' 5 bleek geassocieerd te zijn met de aangenaamheid van het voedsel en voorkeur voor eiwitrijke voedingsmiddelen. Daarnaast is er in de literatuur gesuggereerd dat MSG het metabolisme kan verhogen door middel van sensorische en gastro-intestinale stimulatie van het zenuwstelsel. We hebben daarom onderzocht of de toevoeging van MSG in combinatie met IMP'5 aan een eiwitrijk dieet een effect heeft op het energiegebruik, substraat oxidatie, eetlust en relevante metabolieten. De toevoeging van MSG in combinatie met IMP'5, toegevoegd aan het voedsel of in capsules, aan een eiwitrijk dieet verlaagde de wens om te eten zonder honger en verzadiging te beïnvloeden. Deze toevoeging had geen effect op energiegebruik, substraat oxidatie of concentraties van hormonen.

De derde stimulus die bestudeerd is zijn onverteerbare koolhydraten. Het spreiden van een bepaalde hoeveelheid beschikbare energie na inname over een langere periode, bijvoorbeeld door gebruik te maken van de energieneutrale stimulus onverteerbare koolhydraten, zou eetlust kunnen beïnvloeden door veranderingen in metabole snelheid en nutriënt gestimuleerde afgifte van hormonen. Epidemiologische observaties suggereren dat de inname van voedingsvezel gerelateerd is aan lichaamsgewicht. Een specifieke component van voedingsvezel die van belang zou kunnen zijn, zijn onverteerbare koolhydraten. We hebben de 
effecten van onverteerbare koolhydraten op energie- en substraatgebruik, verzadiging en verzadigingsgerelateerde hormonen onderzocht. Toevoeging van onverteerbare koolhydraten aan een enkele maaltijd had geen effect op energie- en substraatgebruik, verzadiging en verzadigingsgerelateerde hormonen.

Tenslotte kan een macronutriënt iso-energetisch worden uitgewisseld met een andere macronutriënt, bijvoorbeeld eiwit. Eiwitrijke voedingsmiddelen zijn verzadigender en hebben een groter thermogeen effect dan voedingsmiddelen die een normale hoeveelheid eiwit bevatten, zowel op korte als op lange termijn. De acute effecten op de eetlust door deze energieneutrale stimulus zijn mogelijk niet alleen het gevolg van acute effecten op thermogenese, maar zijn mogelijk ook het gevolg van de afgifte van verzadigingsgerelateerde hormonen.

Onze hypothese stelde dat acute effecten van een hogere eiwit inname op verzadiging mogelijk gerelateerd zijn aan acute metabole en hormonale reacties. Het iso-energetisch vervangen van koolhydraten door eiwitten ( $25 \%$ vs. $10 \%$ energie van eiwit) in een enkele maaltijd die genuttigd wordt terwijl de proefpersonen in de postprandiale fase verkeren, verhoogde het verzadigingsgevoel en neigde ook de DIT te verhogen. Deze effecten van een enkele eiwitrijke maaltijd in de postprandiale fase gingen niet gepaard met veranderingen in plasma ghreline, GLP-1 en PYY concentraties. Het verzadigende effect van een enkele eiwitrijke lunch is dus niet veroorzaakt door stijgingen in plasma concentraties van verzadigingsgerelateerde hormonen. Andere factoren die mogelijk bijdragen aan het verzadigende effect van eiwitrijke voeding zijn plasma concentraties van metabolieten of aminozuren.

De studies die in dit proefschrift beschreven zijn laten zien dat verzadigingsgerelateerde fysiologische variabelen kunnen worden beïnvloed door energieneutrale stimuli (orale stimulatie, MSG+IMP'5, eiwit, capsaicine), althans over een korte periode (15 minuten tot 24 uur). De meest effectieve stimuli (orale stimulatie, eiwit) verhoogde verzadiging met behulp van fysiologische variabelen en/of stimulerende effecten op energiegebruik. De sensorische effecten (orale stimulatie, MSG+IMP'5) hielden gedurende korte tijd aan, terwijl sommige metabole effecten, zoals de dieet geinduceerde thermogenese die als gevolg van een hogere eiwit inname een aantal uren aanhielden. Deze bevindingen suggereren dat sensorisch en metabole effecten van voedingsgerelateerde stimuli gebruikt kunnen worden in verschillende elementen van voedselinname regulatie, bijvoorbeeld bij respectievelijk eetlust tijdens een maaltijd en eetlust tussen maaltijden. De stimuli die in een energie-deficiënte situatie (orale stimulatie) werden getest, waren in staat om sensorische en metabole effecten te beïnvloeden tot op zekere hoogte. Dit impliceert dat bepaalde stimuli de effecten van een negatieve energiebalans op voedselinname regulatie teniet kunnen doen. 
De stimuli die in een energieneutrale situatie (MSG+IMP'5, eiwit) werden getest, onderstreepten de effecten van factoren die met de voedselinname worden ingenomen op de voedselinnameregulatie.

Nader onderzoek zal moeten uitwijzen of de in dit proefschrift beschreven effecten van de stimuli ook geobserveerd worden tijdens een negatieve of positieve energiebalans en in hoeverre mogelijke effecten afhankelijk waren van de blootstelling aan de stimuli. 



\section{Dankwoord}


Een proefschrift schrýf je niet alleen en dit is de plek om de mensen te bedanken die hieraan hebben bügedragen.

Allereerst natuurlijk mün promotor Margriet. Bü deze wil ik je bedanken voor je steun en motiverend enthousiasme. Ik heb bewondering voor de manier waarop je voor al je AIO's "zorgt" en het feit dat je altyd en overal ter wereld týd maakt voor ze. Dit proefschrift is voor een groot deel ook jow verdienste. Bedankt!

De leden van de beoordelingscommissie, Prof. dr. $k$. Westerterp, Prof. dr. R.J. Brummer, Dr. C. FeinteBisset, Prof. dr. R. Hamer en Prof. dr. A. Masclee, wil ik graag bedanken voor het lezen van mijn proefschrift en hun bujdrage aan deze büzondere dag.

Top Institute Food \& Nutrition en met name Prof. dr. R. Hamer en Prof. dr. R. J. Brummer wil ik bedanken voor de gelegenheid die zý mü geboden hebben, eerst in Programma 2 en daarna in Programma 1, om het onderzoek beschreven in dit proefschrift te doen.

I would like to thank all Diogenes RTD5 partners for our fruitful collaboration and very interesting meetings all over Europe. A special thanks goes out to Dydis for being a great RTD5 "leader" and to Andras E Timea and Øydis \& Janna for providing me with their products.

Bedankt lieve paranimfen Marcel en Stýn voor al jultie hulp, steun en vele discussie-uurtjes ats carpooler en kamergenoot. Met name jultie enthousiasme voor de wetenschap heeft me hier en daar een extra duwtje in de goede richting gegeven. 
Ik ben heel bly dat jultie mij willen byjstaan tyjdens mün promotie!

Daarnaast wil ook mujn huidige clustergenoten (Femke, Sofie, Margriet V, Freeha, Jurriaan, Anneke, Ananda, Rick, Alberto, Mieke, Guy, Arie en Klaas) en ex-chustergenoten (Kristel, Neeltje, Manuela, Tanja, Annemiek, Mirjam, Carolien, Roy, Natatie en Helene) bedanken voor de füne samenwerking. Ook alle stagiaires (het zýn er te veel om op te noemen, dus ik waag me er niet aan om een lysstje van namen te maken, stel dat ik iemand vergeet..) bedankt voor jullie hulp bü de studies!

Paul en Loek bedankt voor jullie hulp byj de Mac's, hoods en respiratiekamers. Hoewel ik officieel Ir. ben, was jultie technische bijdrage of en toe onmisbaar! Wendy, Jos, Joan en Loek bedankt voor alle analyses. Ook HB - en Diogenes-secretaresses bedankt voor alle hand-en-spandiensten.

Mamma, Pappa en Benoit, jullie zÿn mün "warme nest" in Meerssen. Bedankt voor het "BedEBreakfast" tydens respiratie-kamerstudies, jultie steun, zorg, liefde en zoveel meer...

Lieve Arjen, jy̆ bent de andere helft van het A-team. waar zow ik zonder jow zún? 



\section{Publications}


- Smeets, A.J.P.G., Soenen, S., Luscombe-Marsh, N.D., Ueland, Ø., and Westerterp-Plantenga, M.S., (2008) Energy expenditure, plasma ghrelin, glucagon-like peptide 1, PYY concentrations, and satiety following a single high protein lunch, J Nutr; 138(4), 698-702.

- Luscombe-Marsh, N.D., Smeets, A.J.P.G. and Westerterp-Plantenga, M.S., (2008) Taste sensitivity for monosodium glutamate and an increased liking of dietary protein, Br J Nutr ;99(4):904-8.

- Veldhorst, M., Smeets, A., Soenen, S., Hochstenbach-Waelen, A., Hursel, R.,Diepvens, K., Lejeune, M., Luscombe-Marsh, N., Westerterp-Plantenga, M., (2008) Protein-induced satiety: effects and mechanisms of different proteins, (review) in Physiology and Behavior, in press.

- Westerterp, K.R., Smeets, A., Lejeune, M.P., Wouters-Adriaens, M.P.E., Westerterp-Plantenga, M.S., (2008) Dietary fat oxidation as a function of body fat, Am J Clin Nutr. ;87(1):132-5

- Smeets, A.J.P.G. and Westerterp-Plantenga, M.S., (2007) Acute effects on metabolism and appetite profile of 1 meal difference in the lower range of meal frequency, Br J Nutr; 6, 1-6.

- Westerterp-Plantenga, M.S., Smeets A.J.P.G. and Nieuwenhuizen, A., (2007) Sustained protein intake for bodyweight management, Nutrition Bulletin, 32 (s1), 22-31.

- Smeets, A.J.P.G. and Westerterp-Plantenga, M.S. (2006) Oral exposure and sensory-specific satiety. Physiology and Behavior, 89 (2), 281-6.

- Smeets, A.J.P.G. and Westerterp-Plantenga, M.S. (2006) Satiety and substrate mobilization after oral fat stimulation. British Journal of Nutrition, 95 (4), 795-801.

- Westerterp-Plantenga, M.S., Smeets A.J.P.G., Lejeune M.P. (2005) Sensory and gastrointestinal satiety effects of capsaicin on food intake. International Journal of Obesity, 29 (6), 682-8.

- van der Woude H, Gliszczyńska-Swigło A, Struijs K, Smeets A, Alink GM, Rietjens IM. (2003) Biphasic modulation of cell proliferation by quercetin at concentrations physiologically relevant in humans, Cancer Lett. 8;200(1):417. 
- Smeets, A.J.P.G., Lejeune, M.P. and Westerterp-Plantenga, M.S., The second meal effect of oral fat perception compared to fat ingestion on energy expenditure, hormones and appetite profile, submitted for publication.

- Smeets, A.J.P.G., Gelencser, T., Salgo, A., and Westerterp-Plantenga, M.S., The acute effects of a lunch containing resistant starch on energy and substrate utilization, ghrelin, glucagon-like peptide-1, PYY concentrations, and satiety, submitted for publication.

- Smeets, A.J.P.G. and Westerterp-Plantenga, M.S., The acute effects of a lunch containing capsaicin on energy and substrate utilization, ghrelin, glucagon-like peptide-1, PYY concentrations, and satiety, submitted for publication.

- Smeets, A.J.P.G., Lejeune, M.P. and Westerterp-Plantenga, M.S., Effects of a high-protein diet with or without monosodium-glutamate in combination with inosine-monophosphate-5 on 24-h energy and substrate metabolism and appetite profile, submitted for publication.

- Reinbach, H.C., Smeets, A., Martinussen, T., Møller, P. and WesterterpPlantenga, M.S., Effect of Capsaicin, Green tea and CH-19 sweet pepper on appetite and food intake in humans, submitted for publication.

- den Hoed, M., Smeets, A.J.P.G., Veldhorst, M.A.B., Nieuwenhuizen, A.G., Bouwman, F., Heidema, A.G., Mariman, E.C.M., Westerterp-Plantenga, M.S. and Westerterp, K.R., SNP analyses of postprandial responses in (an)orexigenic hormones and feelings of hunger reveal long-term physiological adaptations to facilitate homeostasis, submitted for publication 
Curriculum vitae 
Astrid Jose Pierre Gertrude Smeets was born on April $8^{\text {th }} 1981$ in Geleen, Netherlands. She completed secondary school at the 'Stella Maris College' in Meerssen in 1999. In the same year, she started her study Nutrition \& Health with as main specialisation Toxicology, and as second specialisation Human Nutrition at Wageningen University, where she graduated in 2003. She started working at the department of Human Biology, Maastricht University in 2003 on a project of Top Institute Food \& Nutrition (former name Wageningen Center for Food Science), and subsequently did her PhD research 'Triggers for food intake regulation; Sensory and metabolic effects of specific food components' as part of the European project 'Diet, Obesity and Genes' (DiOGenes). The research performed during this period is described in this thesis. 